\title{
The course of mild cognitive impairment and the role of comorbidity
}

Citation for published version (APA):

Hamel, R. E. G. (2015). The course of mild cognitive impairment and the role of comorbidity. [Doctoral Thesis, Maastricht University]. Uitgeverij BOXPress. https://doi.org/10.26481/dis.20150703rh

Document status and date:

Published: 01/01/2015

DOI:

10.26481/dis.20150703rh

Document Version:

Publisher's PDF, also known as Version of record

\section{Please check the document version of this publication:}

- A submitted manuscript is the version of the article upon submission and before peer-review. There can be important differences between the submitted version and the official published version of record.

People interested in the research are advised to contact the author for the final version of the publication, or visit the DOI to the publisher's website.

- The final author version and the galley proof are versions of the publication after peer review.

- The final published version features the final layout of the paper including the volume, issue and page numbers.

Link to publication

\footnotetext{
General rights rights.

- You may freely distribute the URL identifying the publication in the public portal. please follow below link for the End User Agreement:

www.umlib.nl/taverne-license

Take down policy

If you believe that this document breaches copyright please contact us at:

repository@maastrichtuniversity.nl

providing details and we will investigate your claim.
}

Copyright and moral rights for the publications made accessible in the public portal are retained by the authors and/or other copyright owners and it is a condition of accessing publications that users recognise and abide by the legal requirements associated with these

- Users may download and print one copy of any publication from the public portal for the purpose of private study or research.

- You may not further distribute the material or use it for any profit-making activity or commercial gain

If the publication is distributed under the terms of Article $25 \mathrm{fa}$ of the Dutch Copyright Act, indicated by the "Taverne" license above, 
THE COURSE OF MILD COGNITIVE IMPAIRMENT AND THE ROLE OF COMORBIDITY 
(c) Copyright Renske E.G. Hamel, Maastricht 2015

Cover design: Ralph Blomberg

Layout: Renske Hamel

Printed by: Proefschriftmaken.nl I I Uitgeverij BOXPress

Published by: Uitgeverij BOXPress, 's-Hertogenbosch

ISBN: 978-94-6295-204-1 


\section{THE COURSE OF MILD COGNITIVE IMPAIRMENT AND THE ROLE OF COMORBIDITY}

\section{PROEFSCHRIFT}

ter verkrijging van de graad van doctor aan de Universiteit Maastricht, op gezag van de Rector Magnificus, Prof. dr. L.L.G. Soete, volgens het besluit van het College van Decanen, in het openbaar te verdedigen op vrijdag 3 juli 2015 om 12:00 uur.

door

\section{Renske Elisabeth Geertruida Hamel}

Geboren op 24 september 1987 te Prinsenbeek 


\section{Promotor}

Prof. dr. F.R.J. Verhey

\section{Co-promotores}

Dr. I.H.G.B. Ramakers

Dr. P.J. Visser

\section{Beoordelingscommissie}

Prof. dr. Rudolf Ponds (voorzitter)

Dr. Martin van Boxtel

Prof. dr. Peter Paul de Deyn (Universitair Medisch Centrum Groningen)

Dr. Albert Leentjens

Prof. dr. Ben Schmand (Universiteit van Amsterdam)

The research described in this thesis was performed at the Alzheimer Centre Limburg, Department of Psychiatry \& Neuropsychology, School for Mental Health and Neuroscience, Maastricht University, the Netherlands.

The research in this thesis was performed within the framework of the Clinical Course of Cognition and Comorbidity in MCI (4C-MCI) study and is funded by Alzheimer Nederland (grant 20083494). The 4C-MCI study was carried out in collaboration with Radboud university medical centre Nijmegen and VU university medical centre Amsterdam.

Printing of this thesis was kindly supported by Alzheimer Nederland, Internationale Stichting Alzheimer Onderzoek, Nutricia Advanced Medical Nutrition and Lundbeck.

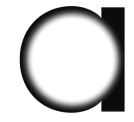


Voor opa en oma 



\section{CONTENTS}

CHAPTER 0

Prologue

9

CHAPTER 1 General introduction, aims and outline

PART A

CHAPTER 2

Domain-specific cognitive decline in the

pre-dementia phase: a systematic review

and meta-analysis

CHAPTER 3

The trajectory of cognitive decline in the

pre-dementia phase in memory clinic visitors:

findings from the 4C-MCI study

Psychological Medicine 2015

CHAPTER 4

Progression to dementia in memory clinic

patients without dementia: a latent profile

analysis

Neurology 2013

PART B

CHAPTER 5

Cohort profile: The Clinical Course of

Cognition and Comorbidity in Mild Cognitive Impairment and Dementia (the $4 \mathrm{C}$ studies):

two complementary multicenter longitudinal

clinical cohorts in the Netherlands

CHAPTER 6

The influence of severity of total comorbidity on cognitive decline and conversion to dementia in memory clinic visitors

CHAPTER 7

Determinants of Health-related Quality of Life in memory clinic visitors without dementia 
Samenvatting

Knowledge valorization

Author affiliations

193

Publications

195

Curriculum vitae

197

Dankwoord 
CHAPTER 0

PROLOGUE 
Forgetfulness is common in the elderly population, $41 \%$ of people between 55 and 65 and $52 \%$ of people over 70 report subjectively experienced memory problems (Ponds et al., 1997). Some of them are bothered by their complaints to such an extent that they seek professional help. Although these cognitive symptoms can be part of the normal ageing process, they could also be very early signs of incipient dementia. The following cases serve to illustrate common diagnostic issues in these subjects.

\section{CASE 1}

A 67-year old man, Mr. X, was referred to the memory clinic because of forgetfulness. He reported slowly progressive memory problems that had developed over the last 2 to 3 years. Mr. X complained mainly about short-term memory problems and word-finding difficulties. He had no problems in performing his daily life activities, though his wife stated that Mr. X had become less skilful in using for example his mobile phone. She confirmed his complaints and added that Mr. X had also become more insecure. The couple stated that Mr. X was not depressed, though his mood was negatively influenced by his complaints and he feared that he made mistakes. Mr. X wanted to know if he had Alzheimer's disease and what his prognosis would be.

Mr. X was a friendly, highly educated man, who appeared nervous and uncertain during the assessments. He had good insight in his complaints and mentioned his worries about possible Alzheimer's. He retired 5 years ago, but remained active through his hobbies. Mr. X reported to withdraw from social situations, because of his forgetfulness. Somatic, neurologic, psychiatric and laboratory tests revealed no abnormalities. His medical history listed no major diseases. General cognitive functioning was normal (MMSE $=28$ ), with very mild clinical dementia symptoms $(\mathrm{CDR}=0.5)$ and very mild symptoms of depression (Hamilton Depression Rating Scale $=3$ ). Additional diagnostic investigations were performed. The MRI scan showed some cortical atrophy and several white matter lesions.

Neuropsychological assessment showed impairments in mental speed and weak memory performance, though the latter was not below the age- and education adjusted cut-off. Other cognitive domains, including language, working memory, executive functioning and visuoconstruction, showed performances within the normal range. Based on all assessments, the conclusion was that $\mathrm{Mr}$. X had no dementia, though he did have some cognitive impairment. His symptoms could be early signs of dementia, but for now he received a diagnosis of Mild Cognitive Impairment (MCI). Mr. X participated in the Clinical Course of Cognition and Comorbidity in MCI (4C-MCI) study, for which he received three annual followup assessments. 


\section{1st follow-up}

Mr. X reported stable memory problems, but increasing word-finding difficulties. According to his wife, he had become more slow and clumsy. Further, Mr. X had more troubles in solving problems. Emotionally he had become more instable and Mr. X admitted that his mood was hindered by the complaints. General cognitive functioning was still only mildly impaired (MMSE $=27$ ), though performance in daily life functioning decreased. The neuropsychological assessment showed weak performances on mental speed and acquiring visual associations, but the latter problems were not severe enough to meet criteria for impairment. Scores on the other cognitive domains were within the normal range. Compared to the previous assessment there was overall stability of performance and even an improvement on an episodic memory task. The diagnosis remained MCI.

\section{$2^{\text {nd }}$ follow-up}

Mr. X experienced no cognitive decline, though he admitted he had more problems in operating electronic devices. His wife reported slow progressive decline in multiple domains. There were no obvious problems in daily life functioning, though Mrs. X did not feel save anymore when her husband drove in their car. General cognitive functioning was still hardly impaired (MMSE $=28$ ) and daily functioning was even better than previously. Test performances showed impairments in processing speed, but no problems in other cognitive domains. Compared to the previous assessment, there was general stability of performance. The diagnosis made was again MCI.

\section{$3^{\text {rd }}$ follow-up}

Mr. X reported slowly progressive decline in memory, he had more troubles remembering names and conversations. There was also mild impairment in orientation in time. His wife also reported decline, especially in performing daily life activities. Speaking had become harder, because of the word-finding difficulties. General cognitive functioning was a bit more impaired (MMSE $=24$ ) and also daily life functioning showed decline. The neuropsychological assessment showed cognitive impairments in speed, executive functioning and multiple memory tests. The diagnosis of Alzheimer type dementia was made.

\section{CASE 2}

An 80-year old man, Mr. Y, was referred to the memory clinic because of forgetfulness. He reported slowly progressive memory problems over the last several years. He said the problems tended to fluctuate over time. Mr. Y's main complaint was a general slowness, which hindered him in processing information. He noticed that his complaints increased when he was tired. His wife corroborated 
the complaints. She thought her husband was slower and less alert than before. She further described word-finding difficulties and troubles remembering names. They agreed that Mr. Y got angry more easily because of his complaints. In addition, he was a bit moody and tended to withdraw from social situations. The couple worried about the complaints, especially since they had read an article about dementia. There were no obvious impairments in daily life functioning. Mr. Y was a friendly man, who adequately described his problems, though he had the tendency to trivialize the complaints as normal for his age. Mr. Y had had two cerebrovascular accidents (15 and 8 years ago). Further, he suffered from multiple vascular problems like hypocholesterolaemia and left ventricle hypertrophy. In addition, Mr. Y had experienced multiple depressive episodes in the past, for which he never received any treatment. General cognitive functioning was normal $(\mathrm{MMSE}=28)$, with very mild clinical dementia symptoms (CDR $=0.5)$, and some depressive symptoms (HDRS $=8$ ). Additional diagnostic investigations were performed. The MRI scan showed widespread white matter lesions and endured ischemia high in the parietal lobe. There was some global atrophy, but no disproportional atrophy of the hippocampus. Laboratory tests revealed no abnormalities. Neuropsychological assessment showed impairment in mental speed, but also weak performance on memory tasks, which could possibly be attributed to the slowing in mental processing and to hearing problems.

Performance on executive functioning was variable. Other cognitive domains, including language, working memory and visuoconstruction showed performances within the normal range. Based on all assessments, the conclusion was that Mr. Y had no dementia, but he did receive a diagnosis of MCI. Mr. Y also participated in the 4C-MCI study, for which he was followed annually for 3 years.

\section{1: follow-up}

Mr. Y reported decline in short-term memory, but still stated that the complaints tended to fluctuate. He also had more problems in planning and performing dual tasks. His wife described large day-to-day fluctuations in the problems. She said Mr. Y had more trouble finding objects in their house and he had become less skilful. Besides, she reported more anxiety and irritation. General cognitive functioning showed a slight decline (MMSE = 26) and also daily life functioning declined. Test performances showed impairments in mental speed and executive functioning, but no problems in other cognitive domains. Compared to the previous assessment there was a decline in executive functioning, yet also an obvious improvement in memory performance. The diagnosis was again MCI.

\section{$2^{\text {nd }}$ follow-up}

Mr. Y reported an improvement in memory and he had become more energetic and alert. Furthermore, his mood improved. His wife corroborated his story. Yet, 
Mr. Y could still be irritated when things did not happen the way he wanted. General cognitive functioning improved 3 points (MMSE $=29$ ), and also daily life functioning improved. Test performances showed impairment in mental speed, but no problems in other cognitive domains. Compared to the previous assessment, there were (small) improvements in executive functioning and mental speed, though performances on the latter still qualified as cognitively impaired. Performance in other cognitive domains remained generally stable. The diagnosis remained MCI.

\section{$3^{\text {ra follow-up }}$}

Mr. Y reported obvious improvements in all cognitive domains, which he attributed to medication changes made by his cardiologist. He still had some minor problems in short term memory, however his mood and quality of life had improved. His wife corroborated the positive influence of the medication changes. She said there were no problems in daily life functioning, and that the complaints were now limited to mild forgetfulness. General cognitive functioning was good $(\mathrm{MMSE}=30)$, and there were no impairments in daily life functioning. Tests performances were within the normal range for all cognitive domains. Compared to the previous assessments, there was an overall improvement in cognitive functioning. Since we could not objectify any cognitive impairment, Mr. Y's diagnosis was changed from MCI to subjective cognitive complaints.

Both Mr. X and Mr. Y fulfilled the criteria for MCI when they came to the memory clinic, however their course of decline over time and thus their outcome after three years differed greatly.

Questions that arise from these cases are:

- What is the natural course of cognitive decline in people who present themselves at a memory clinic with cognitive complaints and which factors influence this course and the risk of developing dementia?

- What is the impact of these cognitive impairments on the well-being of memory clinic visitors?

In clinical practice, almost $40 \%$ of people referred to a memory clinic do not have dementia at their initial visit. Yet a part of them has a cognitive disorder (Ramakers and Verhey, 2011). These people ask similar questions as described in our cases and we see ourselves confronted with the need of patients and caregivers to receive more (accurate) information on their prognosis for the forthcoming years. These issues formed the basis for the research described in this thesis. 


\section{REFERENCES}

Ponds, R. W., Commissaris, K. J. \& Jolles, J. (1997). Prevalence and covariates of subjective forgetfulness in a normal population in The Netherlands. International Journal of Aging and Human Development, 45, 207-21.

Ramakers, I. H. \& Verhey, F. R. (2011). Development of memory clinics in the Netherlands: 1998 to 2009. Aging \& Mental Health, 15, 34-9. 
CHAPTER 1

GENERAL INTRODUCTION

AIM

OUTLINE 


\section{GENERAL INTRODUCTION}

\section{Dementia}

Dementia is a growing health problem, especially with the expected ageing of our population. The number of people with dementia worldwide was estimated to be 35.6 million in 2010 and this number is expected to increase to 65.7 million in 2030 and triple to even 115.4 million in 2050 (World Health Organization, 2012). This development poses a major challenge for society, health care systems and has great economical impact. Already in 2011, dementia was the second most expensive medical disease in the Netherlands, with disease-associated costs of almost 5 billion euros (Rijksinstituut voor Volksgezondheid en Milieu, 2011). Furthermore, dementia is thought to have the highest disease burden of all medical illnesses for the patient, but also has a tremendous impact on the caregiver (Ory et al., 1999).

Although there is currently no pharmacological treatment available to halt disease progression, it is important to early identify people at high risk of developing dementia. First, because the study of these people and their course of decline allow us to identify factors associated with faster decline and / or conversion to dementia and to increase insight into underlying pathological brain mechanisms. In addition, if pharmacological treatment becomes available in the future, diseasemodifying drugs are likely to be most effective in the early stages of the disease. Further, from a clinical point of view, it is important to be able to differentiate between individuals with cognitive complaints who are likely to develop dementia and individuals who are not, since a reliable prognosis gives us the opportunity to initiate timely care and treatment that matches the needs and expectations of patients and caregivers. Also, it allows both patients and their caregivers to make arrangements for the future.

\section{Mild Cognitive Impairment}

Currently, dementia is often regarded as the end stage at one side of a continuum, with normal cognitive functioning at the other end of the spectrum. The transitional state between normal cognitive functioning and dementia is now usually referred to as Mild Cognitive Impairment (MCI) (Petersen et al., 1999). People with MCI are characterized by having cognitive impairments in one or multiple cognitive domains, but they do not fulfill the criteria for dementia (yet). Although, people with $\mathrm{MCI}$ are at an increased risk to develop dementia, a substantial proportion of them remains stable or even reverts back to normal cognitive functioning after prolonged follow-up (Ganguli et al., 2011, Visser et al., 2006) (Figure 1). 


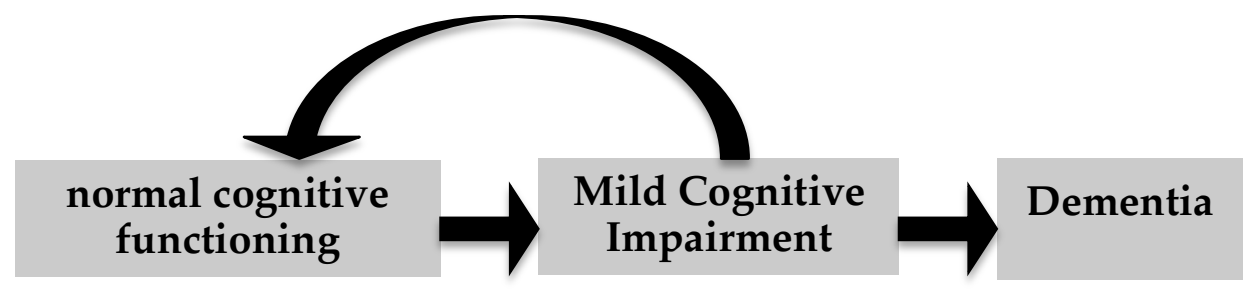

Fig 1

So, it has become clear that $\mathrm{MCI}$ denominates a heterogeneous group of people with large individual variation in the level and pattern of cognitive impairment, the course of decline over time and thus prognosis. This heterogeneity is likely due to differences in the underlying cause of the impairment, whereby stability and improvement of impairment are unlikely to be caused by dementia pathology but may result from psychological factors or medical diseases (Graham et al., 1997, Jorm et al., 2004, Olazaran et al., 2011, Sachdev et al., 2013). The observed heterogeneity increases the need for a thorough investigation of the profile of impairment and the natural course of decline in both people that progress to dementia and people that remain only mildly impaired. This may help in the identification of, and distinction between those individuals that show a pattern and rate of decline that is typical for developing underlying neurodegenerative pathology and those that do not.

\section{Multicausality}

Dementia was long thought of as a monocausal disease that resulted from a slowly progressive pathological process located in the brain. However, to date dementia is increasingly recognized as a multifactorial disease, whereby diseases and factors not necessarily located in the brain can enhance underlying neurodegenerative pathologies (Olde Rikkert et al., 2006, Olde Rikkert et al., 2005). While age remains the most important risk factor for developing dementia (Jorm and Jolley, 1998), multiple other factors have been associated with dementia development like female gender (Andersen et al., 1999, Fratiglioni et al., 1997), low education (Launer et al., 1999, Ott et al., 1995), genetic vulnerability (i.e. Apolipoprotein-E-e4 genotype) (Farrer et al., 1997), low memory performance (Albert et al., 2001, Chen et al., 2000), depression (Jorm, 2001, Palmer et al., 2007) and specific vascular factors like mid-life hypertension and diabetes (Lu et al., 2009, Mielke et al., 2007, Qiu et al., 2005). With increasing age, the combination of and interaction between multiple contributing factors may ultimately lead to dementia.

Unfortunately, an important factor in the elderly population has received little attention thus far. The presence of comorbidities has often been an exclusion criterion for both diagnostic and therapeutic studies into (early stage) dementia, thereby disregarding the increased disease burden of multimorbidity that is 
typically associated with advancing age (Uijen and van de Lisdonk, 2008, van den Akker et al., 1998).

Comorbidities are not only related to worse cognitive functioning in the general elderly (Comijs et al., 2009, Morrow et al., 2009, Patrick et al., 2002) and demented population (Doraiswamy et al., 2002), they can also effect outcomes like quality of life, daily life functioning and health service use (Fried et al., 1999, Tooth et al., 2008). These findings stress the importance of the careful study and clinical evaluation of comorbidities in a memory clinic population in order to provide a more accurate prognosis and identify additional treatment targets.

\section{Health-related Quality of life}

As so many factors are related to the development of dementia, it is hard to pinpoint which aspect should be regarded as the most important target for disease-modifying interventions. The absence of curative drug interventions at present, and likely also in the near future, signifies the importance of focusing on secondary outcomes, like Health-related Quality of Life (HRQoL) in early stage cognitive decline. Both people with dementia, their caregivers and health care professionals indeed increasingly recognize HRQoL as an important, meaningful and desirable outcome throughout the entire course of dementia (Gwyther, 1997, Logsdon et al., 2002, Ready and Ott, 2003, Walker et al., 1998, Whitehouse and Rabins, 1992). By using HRQoL as an outcome measure, the total impact of disease is comprised in a single measure that reflects its multidimensionality. In addition, while we are not able to halt or prevent disease progression, HRQoL is a potentially modifiable target that can be ameliorated using non-cognitive interventions.

HRQoL is known to be influenced by the presence of chronic medical conditions (Fortin et al., 2004), but is also effected by another essential issue in memory clinic visitors, that is: subjective cognitive complaints (Mol et al., 2009).

Therefore, HRQoL of memory clinic visitors and its determinants should be studied further in order to evaluate this important outcome and identify potential targets for interventions to improve HRQoL.

\section{AIM OF THE THESIS}

The general aim of this thesis was to determine the natural course of cognitive decline in Mild Cognitive Impairment and investigate the influence of medical comorbidity on both cognitive decline and quality of life in memory clinic visitors.

Our study addressed the following questions: 
1] What is the annual rate of domain-specific cognitive decline in the pre-dementia phase?

2] What is the natural course of cognitive decline in the pre-dementia phase in memory clinic visitors?

3] Which cognitive subtypes exist in memory clinic visitors and what is their prognostic value for conversion to dementia?

4] What is the influence of the severity of comorbidity on cognitive decline and conversion to dementia in memory clinic visitors?

5] Which factors are associated with Health-related Quality of Life (HRQoL) in memory clinic visitors?

\section{OUTLINE OF THE THESIS}

This thesis consists of two parts. In part A (chapter 2 to 4 ), we focus on the natural course and profile of cognitive decline in Mild Cognitive Impairment. In part B (chapter 5 to 7), we describe the impact of comorbidity on cognitive decline and conversion to dementia and investigate the impact of comorbidity, cognitive and emotional functioning on quality of life in memory clinic visitors.

The outline is as follows:

PART A

Chapter 2 provides a systematic review and meta-analysis of the annual rate of domain-specific cognitive decline in the pre-dementia phase.

In Chapter 3 we compare the pattern, magnitude and temporal sequence of cognitive decline between converters to $\mathrm{AD}$ dementia in their pre-dementia phase and non-converters in a memory-clinic based population.

Chapter 4 assesses the existence of multiple cognitive subtypes in subjects with cognitive complaints within a memory-clinic based setting. We determined their prognostic value for conversion to dementia.

\section{PART B}

In chapter 5 we describe the general cohort profile of the Clinical Course of Cognition and Comorbidity in MCI (4C-MCI) study and the associated Clinical Course of Cognition and Comorbidity in Dementia (4C-Dementia) study. Both 
studies are prospective, longitudinal multicentre studies into the natural course of decline, investigating either persons with MCI or persons with dementia.

Chapter 6 focuses on the influence of the severity of comorbidity on cognitive decline and conversion to dementia in memory clinic visitors from the $4 \mathrm{C}-\mathrm{MCI}$ study.

In Chapter 7 we investigate the influence of emotional functioning, cognitive functioning and comorbid disease burden on Health-related Quality of Life in memory clinic visitors with either MCI or Subjective Cognitive Impairment (SCI) from the 4C-MCI study.

Last, Chapter 8 provides a general discussion, summary of the main findings and implications for both future research and clinical practice. 


\section{REFERENCES}

Albert, M. S., Moss, M. B., Tanzi, R. \& Jones, K. (2001). Preclinical prediction of AD using neuropsychological tests. Journal of the International Neuropsychological Society, 7, 631-9.

Andersen, K., Launer, L. J., Dewey, M. E., Letenneur, L., Ott, A., Copeland, J. R., Dartigues, J. F., Kragh-Sorensen, P., Baldereschi, M., Brayne, C., Lobo, A., Martinez-Lage, J. M., Stijnen, T. \& Hofman, A. (1999). Gender differences in the incidence of AD and vascular dementia: The EURODEM Studies. EURODEM Incidence Research Group. Neurology, 53, 1992-7.

Chen, P., Ratcliff, G., Belle, S. H., Cauley, J. A., DeKosky, S. T. \& Ganguli, M. (2000). Cognitive tests that best discriminate between presymptomatic AD and those who remain nondemented. Neurology, 55, 1847-53.

Comijs, H. C., Kriegsman, D. M., Dik, M. G., Deeg, D. J., Jonker, C. \& Stalman, W. A. (2009). Somatic chronic diseases and 6-year change in cognitive functioning among older persons. Archives of Gerontology and Geriatrics, 48, 191-6.

Doraiswamy, P. M., Leon, J., Cummings, J. L., Marin, D. \& Neumann, P. J. (2002). Prevalence and impact of medical comorbidity in Alzheimer's disease. Journals of Gerontology. Series A, Biological Sciences and Medical Sciences, 57, M173-7.

Farrer, L. A., Cupples, L. A., Haines, J. L., Hyman, B., Kukull, W. A., Mayeux, R., Myers, R. H., Pericak-Vance, M. A., Risch, N. \& van Duijn, C. M. (1997). Effects of age, sex, and ethnicity on the association between apolipoprotein $\mathrm{E}$ genotype and Alzheimer disease. A meta-analysis. APOE and Alzheimer Disease Meta Analysis Consortium. Journal of the American Medical Association, 278, 1349-56.

Fortin, M., Lapointe, L., Hudon, C., Vanasse, A., Ntetu, A. L. \& Maltais, D. (2004). Multimorbidity and quality of life in primary care: a systematic review. Health and Quality of Life Outcomes, 2, 51.

Fratiglioni, L., Viitanen, M., von Strauss, E., Tontodonati, V., Herlitz, A. \& Winblad, B. (1997). Very old women at highest risk of dementia and Alzheimer's disease: incidence data from the Kungsholmen Project, Stockholm. Neurology, 48, 132-8.

Fried, L. P., Bandeen-Roche, K., Kasper, J. D. \& Guralnik, J. M. (1999). Association of comorbidity with disability in older women: the Women's Health and Aging Study. Journal of Clinical Epidemiology, 52, 27-37.

Ganguli, M., Snitz, B. E., Saxton, J. A., Chang, C. C., Lee, C. W., Vander Bilt, J., Hughes, T. F., Loewenstein, D. A., Unverzagt, F. W. \& Petersen, R. C. (2011). Outcomes of mild cognitive impairment by definition: a population study. Archives of Neurology, 68, 761-7.

Graham, J. E., Rockwood, K., Beattie, B. L., Eastwood, R., Gauthier, S., Tuokko, H. \& McDowell, I. (1997). Prevalence and severity of cognitive impairment with and without dementia in an elderly population. Lancet, 349, 1793-6.

Gwyther, L. P. (1997). The perspective of the person with Alzheimer disease: which outcomes matter in early to middle stages of dementia? Alzheimer Disease and Associated Disorders, 11 Suppl 6, 18-24.

Jorm, A. F. (2001). History of depression as a risk factor for dementia: an updated review. Australian and New Zealand Journal of Psychiatry, 35, 776-81. 
Jorm, A. F., Butterworth, P., Anstey, K. J., Christensen, H., Easteal, S., Maller, J., Mather, K. A., Turakulov, R. I., Wen, W. \& Sachdev, P. (2004). Memory complaints in a community sample aged 60-64 years: associations with cognitive functioning, psychiatric symptoms, medical conditions, APOE genotype, hippocampus and amygdala volumes, and white-matter hyperintensities. Psychological Medicine, 34, 1495-506.

Jorm, A. F. \& Jolley, D. (1998). The incidence of dementia: a meta-analysis. Neurology, 51, 728-33.

Launer, L. J., Andersen, K., Dewey, M. E., Letenneur, L., Ott, A., Amaducci, L. A., Brayne, C., Copeland, J. R., Dartigues, J. F., Kragh-Sorensen, P., Lobo, A., Martinez-Lage, J. M., Stijnen, T. \& Hofman, A. (1999). Rates and risk factors for dementia and Alzheimer's disease: results from EURODEM pooled analyses. EURODEM Incidence Research Group and Work Groups. European Studies of Dementia. Neurology, 52, 78-84.

Logsdon, R. G., Gibbons, L. E., McCurry, S. M. \& Teri, L. (2002). Assessing quality of life in older adults with cognitive impairment. Psychosomatic Medicine, 64, 510-9.

Lu, F. P., Lin, K. P. \& Kuo, H. K. (2009). Diabetes and the risk of multi-system aging phenotypes: a systematic review and meta-analysis. PLoS One, 4, e4144.

Mielke, M. M., Rosenberg, P. B., Tschanz, J., Cook, L., Corcoran, C., Hayden, K. M., Norton, M., Rabins, P. V., Green, R. C., Welsh-Bohmer, K. A., Breitner, J. C., Munger, R. \& Lyketsos, C. G. (2007). Vascular factors predict rate of progression in Alzheimer disease. Neurology, 69, 1850-8.

Mol, M. E. M., van Boxtel, M. P. J., Willems, D., Verhey, F. R. J. \& Jolles, J. (2009). Subjective forgetfulness is associated with lower quality of life in middle-aged and young-old individuals: A 9-year follow-up in older participants from the Maastricht Aging Study. Aging \& Mental Health, 13, 699-705.

Morrow, L. A., Snitz, B. E., Rodriquez, E. G., Huber, K. A. \& Saxton, J. A. (2009). High medical co-morbidity and family history of dementia is associated with lower cognitive function in older patients. Family Practice, 26, 339-43.

Olazaran, J., Torrero, P., Cruz, I., Aparicio, E., Sanz, A., Mula, N., Marzana, G., Cabezon, D. \& Begue, C. (2011). Mild cognitive impairment and dementia in primary care: the value of medical history. Family Practice, 28, 385-92.

Olde Rikkert, M. G., Teunisse, J. P. \& Vernooij-Dassen, M. (2005). One hundred years of Alzheimer's disease and the neglected second lesson of Alois Alzheimer on multicausality in dementia. American Journal of Alzheimer's Disease and Other Dementias, 20, 269-72.

Olde Rikkert, M. G., van der Flier, W. M., de Leeuw, F. E., Verbeek, M., Jansen, R. W., Verhey, F. \& Scheltens, P. (2006). Multiple diagnostic tests are needed to assess multiple causes of dementia. Archives of Neurology, 63, 144-6.

Ory, M. G., Hoffman, R. R., 3rd, Yee, J. L., Tennstedt, S. \& Schulz, R. (1999). Prevalence and impact of caregiving: a detailed comparison between dementia and nondementia caregivers. Gerontologist, 39, 177-85.

Ott, A., Breteler, M. M., van Harskamp, F., Claus, J. J., van der Cammen, T. J., Grobbee, D. E. \& Hofman, A. (1995). Prevalence of Alzheimer's disease and vascular dementia: association with education. The Rotterdam study. British Medical Journal, 310, 970-3. 
Palmer, K., Berger, A. K., Monastero, R., Winblad, B., Backman, L. \& Fratiglioni, L. (2007). Predictors of progression from mild cognitive impairment to Alzheimer disease. Neurology, 68, 1596-602.

Patrick, L., Gaskovski, P. \& Rexroth, D. (2002). Cumulative illness and neuropsychological decline in hospitalized geriatric patients. The Clinical Neuropsychologist, 16, 145-56.

Petersen, R. C., Smith, G. E., Waring, S. C., Ivnik, R. J., Tangalos, E. G. \& Kokmen, E. (1999). Mild cognitive impairment: clinical characterization and outcome. Archives of Neurology, 56, 303-8.

Qiu, C., Winblad, B. \& Fratiglioni, L. (2005). The age-dependent relation of blood pressure to cognitive function and dementia. Lancet Neurology, 4, 487-99.

Ready, R. E. \& Ott, B. R. (2003). Quality of Life measures for dementia. Health and Quality of Life Outcomes, 1, 11.

Rijksinstituut voor Volksgezondheid en Milieu (2013). Kosten van Ziekten 2011. Retrieved December 4, 2014, from http: / / www.kostenvanziekten.nl

Sachdev, P. S., Lipnicki, D. M., Crawford, J., Reppermund, S., Kochan, N. A., Trollor, J. N., Wen, W., Draper, B., Slavin, M. J., Kang, K., Lux, O., Mather, K. A. \& Brodaty, H. (2013). Factors predicting reversion from mild cognitive impairment to normal cognitive functioning: a population-based study. PLoS One, 8, e59649.

Tooth, L., Hockey, R., Byles, J. \& Dobson, A. (2008). Weighted multimorbidity indexes predicted mortality, health service use, and health-related quality of life in older women. Journal of Clinical Epidemiology, 61, 151-9.

Uijen, A. A. \& van de Lisdonk, E. H. (2008). Multimorbidity in primary care: prevalence and trend over the last 20 years. European Journal of General Practice, 14, Suppl 1, 28-32.

van den Akker, M., Buntinx, F., Metsemakers, J. F., Roos, S. \& Knottnerus, J. A. (1998). Multimorbidity in general practice: prevalence, incidence, and determinants of cooccurring chronic and recurrent diseases. Journal of Clinical Epidemiology, 51, 367-75.

Visser, P. J., Kester, A., Jolles, J. \& Verhey, F. (2006). Ten-year risk of dementia in subjects with mild cognitive impairment. Neurology, 67, 1201-7.

Walker, M. D., Salek, S. S. \& Bayer, A. J. (1998). A review of quality of life in Alzheimer's disease. Part 1: Issues in assessing disease impact. Pharmacoeconomics, 14, 499-530.

Whitehouse, P. J. \& Rabins, P. V. (1992). Quality of life and dementia. Alzheimer Disease and Associated Disorders, 6, 135-7.

World Health Organization (2012). Dementia: a public health priority. WHO: Geneva, Switzerland. 

PART A

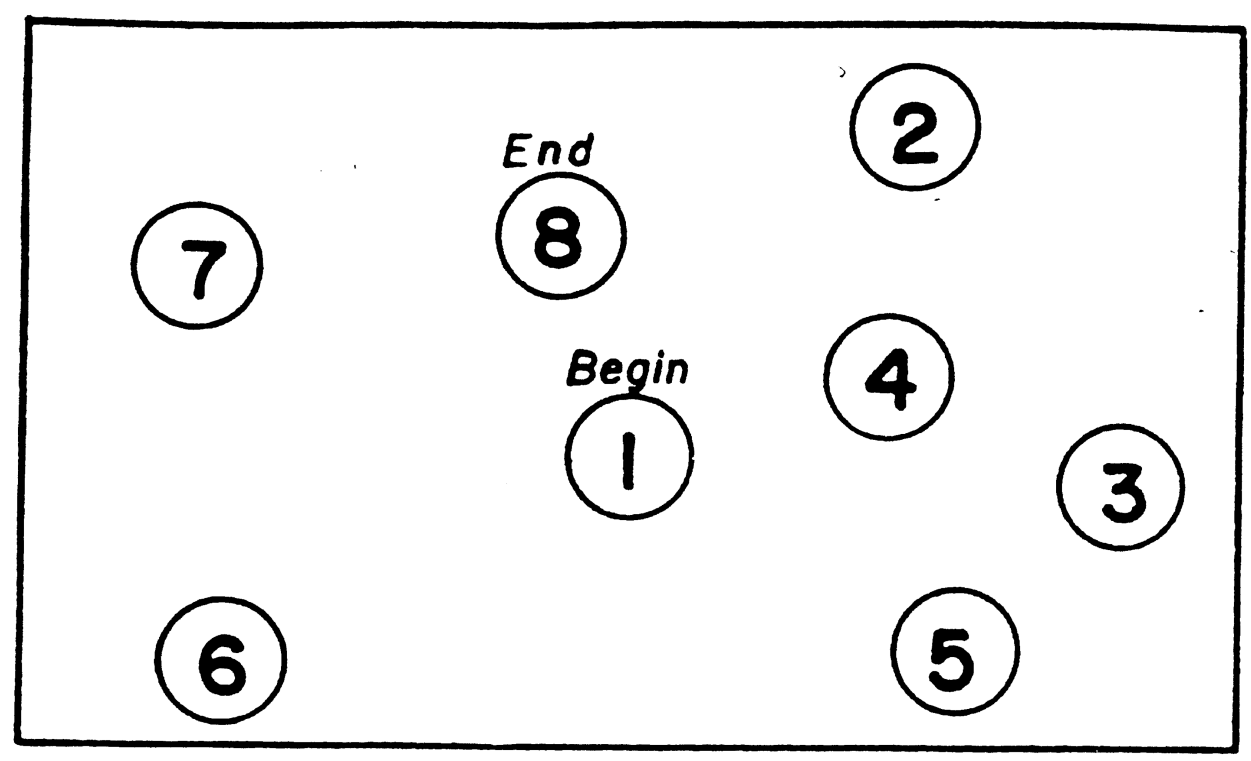





\section{CHAPTER 2}

\section{DOMAIN-SPECIFIC COGNITIVE \\ DECLINE IN THE PRE-DEMENTIA PHASE: A SYSTEMATIC REVIEW AND META-ANALYSIS}

Renske E.G. Hamel, Willemijn J. Jansen, Pieter Jelle Visser, Sebastian Koehler, Jos Kleijnen, Frans R.J. Verhey, Inez H.G.B. Ramakers 


\section{ABSTRACT}

The aim of the present study was to establish and compare the extent of annual domain-specific cognitive decline in future dementia subjects for the domains of episodic memory, executive functioning, attention/information processing speed, verbal ability, visuospatial ability and global cognitive functioning. In addition we performed domain wise comparisons to the rates of domain-specific decline in non-converters. A systematic literature search was performed into studies of cognitive decline in future dementia subjects. We included twenty-one studies, representing 2249 pre-dementia subjects and 2439 non-converting controls. The effect measure was expressed as Cohen's delta (d). In an average observation period of five years before dementia diagnosis onwards, pre-dementia decline in episodic memory $(\mathrm{d}=-0.35,95 \% \mathrm{CI}$ : $-0.43 ;-0.27)$ and global cognitive functioning ( $d=-0.44,95 \% \mathrm{CI}:-0.56 ;-0.32)$ was significantly larger than decline in the other domains, though these domains showed small but significant decline too. Rates of domain-specific decline differed significantly between converters and nonconverters for all domains, except attention/information processing speed. We can conclude that during a mean observational period of five years prior to dementia diagnosis, the strongest indicators of future dementia are accelerated decline in episodic memory and global cognitive functioning, while decline in attention/information processing speed does not discriminate between future converters to dementia and non-converters. 


\section{INTRODUCTION}

In the forthcoming decades, the prevalence of dementia is expected to dramatically rise due to the ageing population (World Health Organization, 2012). This poses a major challenge for society and health care systems, and therefore creates an urgent need for early diagnosis in order to initiate timely care and treatment. The most common cause of dementia, Alzheimer's disease (AD), affects around 60 to 70 percent of the demented population (World Health Organization, 2012). The neurodegenerative changes underlying Alzheimer's disease dementia, e.g. accumulation of amyloid plaques, neurofibrillary tangles and neuronal atrophy, start long before clinical dementia diagnosis (Jack et al., 2010, Vos et al., 2013). Other dementias are also thought to be preceded by a preclinical phase, during which subtle cognitive changes can occur (Backman et al., 2001, Ingles et al., 2002, Meyer et al., 2002).

Alterations in cognition before dementia diagnosis have been described by a number of partially overlapping terms such as "cognitive impairment no dementia" (CIND), "questionable dementia", "age-associated cognitive decline" (AACD) and others. Currently, cognitive impairment before dementia diagnosis is generally referred to as Mild Cognitive Impairment (MCI). MCI was originally conceptualized as a primarily amnestic disorder (Petersen et al., 1999), yet broader conceptualizations of MCI have been formulated, including amnestic and nonamnestic forms, and involving single or multiple cognitive domains (Petersen and Morris, 2005).

The current MCI concept corresponds to findings that show cognitive deficits in the pre-dementia phase across multiple cognitive domains, like episodic memory (Backman et al., 2001, Chen et al., 2000, Rubin et al., 1998), executive functioning (Albert et al., 2001, Rapp and Reischies, 2005), verbal fluency (Fabrigoule et al., 1998, Laukka et al., 2004), attention (Linn et al., 1995, Nielsen et al., 1999) and global cognitive functioning (Backman and Small 1998, Fabrigoule et al., 1998). These findings are also consistent with evidence from neuroimaging studies indicating that multiple brain regions are impaired in prodromal dementia (Jones et al., 2006, Burgmans et al., 2009, Jacobs et al., 2011).

Although we do know that pre-dementia cognitive deficits can occur across multiple domains, the longitudinal domain-specific course of cognitive decline remains largely undetermined. A better understanding of the magnitude of decline in different domains is important to facilitate early diagnosis and thus to increase our insight into early pathological brain mechanisms. Therefore, the aim of the present study was to systematically review and analyze the evidence on the course of cognitive decline in the pre-dementia phase. More specifically, we performed a meta-analysis to estimate and compare the annual rate of domain-specific decline in episodic memory, executive functioning, attention/information processing 
speed, verbal ability, visuospatial ability and global cognitive functioning in predementia subjects. In addition, we performed domain wise comparisons with the rates of decline in non-converters to identify the strongest indicators of incipient dementia.

\section{METHODS}

The initial selection of papers was based on the PRISMA guidelines (Moher et al., 2009)

\section{Search strategy}

We searched the Pubmed, Psychinfo, Embase and Cinahl databases for studies published from January 1990 to December 2012. The search terms used were: ('amnestic' or 'amnestic syndrome' or 'memory impairment' or 'mild cognitive decline' or 'mild cognitive impairment' or 'MCI' or 'age-associated cognitive decline' or 'AACD' or 'age-associated memory impairment' or 'AAMI' or 'cognitive impairment no dementia' or 'CIND' or 'alzheimer*' or 'memory clinic' or 'memory disorders clinic' or 'dementia clinic' or 'prodromal' or 'preclinical') and ('cognitive decline' or 'cognitive change' or 'course' or 'traject") and ('followup study' or 'longitudinal' or 'prospective'). The search resulted in 2670 hits. Titles and abstracts of the retrieved studies were screened for relevance using the criteria specified below. Subsequently we searched the references of included articles to identify additional studies.

\section{Study selection}

Studies were included in the analyses if they fulfilled the following inclusion criteria:

1) the article was published in English; 2) participants were free of dementia at baseline assessment, but over time (minimum follow-up length one year) became demented according to any of the following criteria: Diagnostic and Statistical Manual of Mental Disorders 4th edition (DSM-IV) (American Psychiatric Association, 1994), DSM 3rd Revised Edition (DSM-III-R) (American Psychiatric Association, 1987), the International Statistical Classification of Diseases and Related Health Problems 10th Revision (ICD-10) (World Health Organization, 1993), National Institute of Neurological and Communicative Disorders and Stroke and the Alzheimer's Disease and Related Disorders Association (NINCDSADRDA) (McKhann et al., 1984), or had a clinical dementia diagnosis defined as progressive cognitive decline that interfered with activities of daily living together with a Clinical Dementia Rating Scale (Morris, 1993) score of 0.5 or higher; 3 ) the article reported data on cognitive functioning at baseline and after a specified 
follow-up period or reported a slope of cognitive decline during the pre-dementia period.

We retrieved 168 full-text articles that were deemed potentially relevant for our study. Of these, 46 were excluded because subjects did not convert to dementia, 45 reported on cognitive decline but made no distinction between dementia converters and non-converters, 17 studies reported no cognitive data at follow-up, 10 did not report any cognitive data, and another 8 studies reported in a data format we could not use for the present analyses (e.g. no standardized slopes). In case multiple papers reported on the same cohort, we included the study with the largest sample size in our analyses. In case a study from the same cohort reported unique information on a specific cognitive domain that was not described by the study with the largest sample size, we included the former study for the indicated domain. The final selection included 21 studies from 18 independent cohorts (see Fig. 1).

\section{Data extraction}

Two raters (RH \& WJ) completed the data extraction for each study, any discrepancies were resolved by discussions. Studies were classified according to setting as; 1) clinical studies that included only patients presenting with cognitive complaints at a health care facility; 2) community-based studies that included a sample of the general population; 3 ) other studies that recruited participants from both clinical settings and the general population or that did not specify the source of participant recruitment. Cognitive status at baseline was classified as 1) normal (no objective cognitive impairment); 2) impaired (objectified cognitive impairment, but no dementia); 3 ) unspecified (not reported whether subjects had cognitive impairment or not differentiating between subjects with and without impairments).

When the underlying dementia aetiology at time of diagnosis was not specified or data were not differentiated according to aetiology, we included all subjects; in cases where an $\mathrm{AD}$ diagnosis was available for a specific subset of participants we included only those subjects. This decision was made since 60 to 70 percent of all dementia cases are supposed to have Alzheimer's disease (World Health Organization, 2012), so the majority of the included subjects with dementia (aetiology not further specified) will likely have AD. By broadening our inclusion criteria, we increased the sample size and thus power of our analyses, and we were able to compare rates of decline between the total dementia group and $\mathrm{AD}$ dementia group. The mean, standard deviation or standard error of the cognitive tests at baseline and follow-up (mainly time of diagnosis), or the standardized slope / rate of cognitive decline over time were recorded for the pre-dementia group and, if available, for the non-converter group. 
Figure 1 Flow diagram of study selection

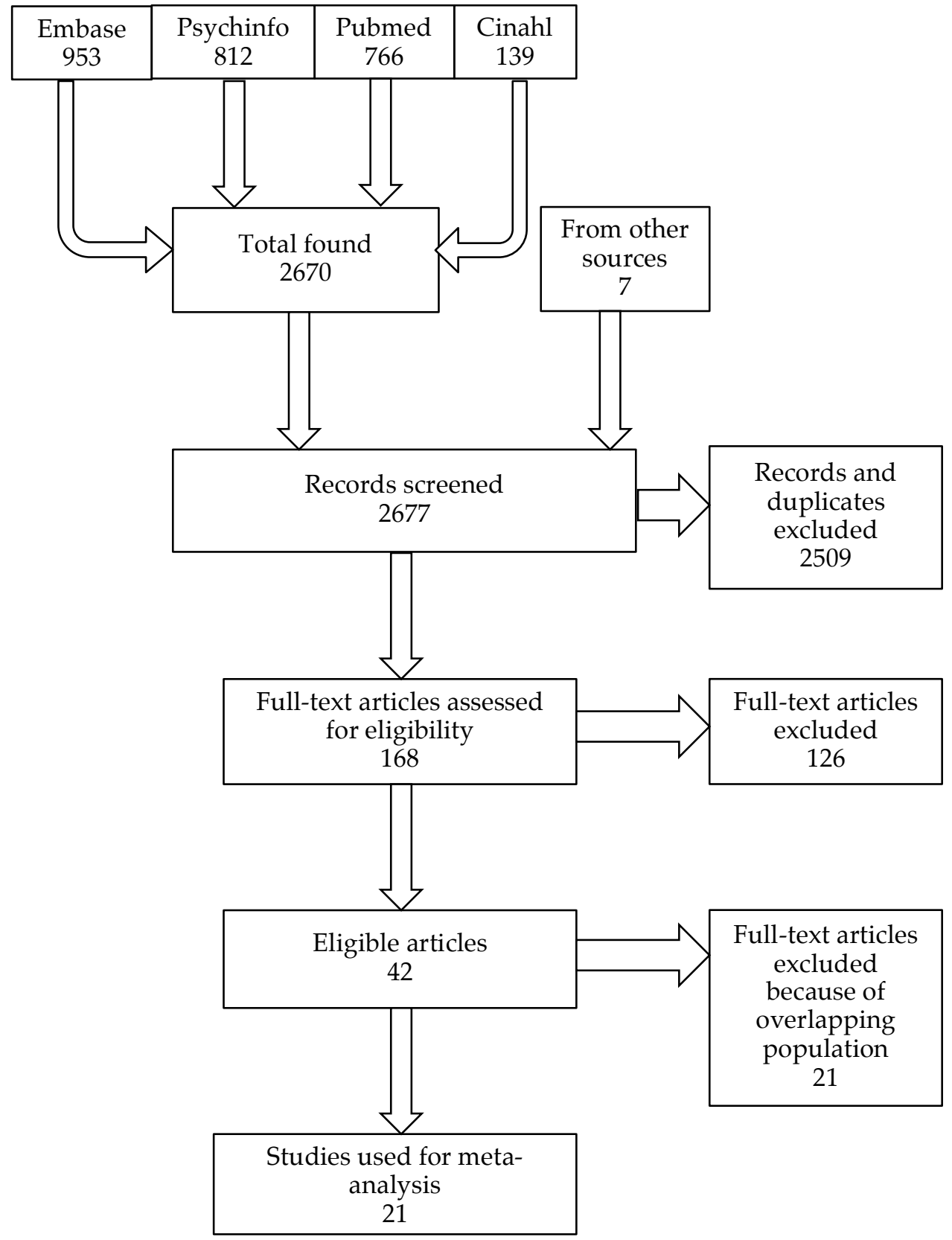




\section{Cognitive outcome measures}

The outcome measure was the average annual rate of decline in cognitive performance in the time period before dementia diagnosis. The authors organized the individual neuropsychological tests into five specific cognitive domains and one global cognitive functioning domain, based on well-known neuropsychological literature (Lezak et al., 2004). The specific domains identified were: episodic memory, executive functioning, attention/information processing speed (IPS), verbal ability and visuospatial ability. Nine studies provided cognitive domain scores themselves, which were consistent with our categories. Each domain score was a weighted/average score of all measurements used in that domain. Four of these studies provided a global cognition/global composite score too, which was based on the weighted/average scores of all neuropsychological tests in the respective study. Supplementary table 1 provides the specific domains and their associated tests as identified by the authors, please note that tests from the nine studies that provided cognitive domain scores themselves are not reported in this table.

\section{Data analysis}

Effect sizes (ES) for future dementia cases and non-converters were calculated using Cohen's delta (d), which is the difference between the mean score at baseline and follow-up divided by the pooled standard deviation (Cohen, 1988). ES were calculated such that a negative ES indicated decline in cognitive performance. If studies used more than one measure for a cognitive domain (e.g. multiple episodic memory tests) we averaged the ES of these tests, which is in accordance with the procedures used by the studies reporting cognitive domain scores.

For studies presenting only slopes as an outcome, we followed the procedure described by Peterson and Brown (Peterson and Brown, 2005) and calculated an rstatistic first, which we then transformed into a Cohen's d (Friedman, 1968). For studies that used a change-point model to model decline over time, we used only the reported decline after the change-point for calculating the ES in the predementia group, since the slope before the change-point is thought to represent age-related cognitive decline and does not differ from the slope of non-converters. For studies that reported baseline and follow-up data, we divided the ES by the mean follow-up time in years of the respective study, since slopes and their ES represent decline over a one-year time period. By this means, all ES can be considered as a measure of annual decline. Effect sizes between 0.2 and 0.5 were classified as small, between 0.5 and 0.8 as medium and 0.8 and over as large (Cohen, 1988). 


\section{Assessment of risk of bias}

Two authors (RH \& WJ) rated the risk of bias of each study using items in the categories: subject sampling, reference diagnosis, test description and longitudinal design, selected from rating scales for methodological quality of diagnostic and prognostic studies (Altman, 2001; Deeks, 2001) and based on the procedure used by Elias-Sonnenschein (Elias-Sonnenschein et al., 2011) (see supplementary table 2). Studies that did not fulfill the criteria of an item or that did not provide enough information for rating an item, received a negative assessment on that item. In case of discrepancies between the reviewers, a consensus meeting with a third reviewer was held. The total number of items to rate was fifteen. This number was divided into tertiles, and studies that scored within the highest tertile $(11-15)$ were classified as 'low risk of bias', studies that scored within the second tertile $(6-10)$ were classified as 'intermediate risk of bias' and studies that scored within the lowest tertile $(0-5)$ were classified as 'high risk of bias'. Risk of bias assessments were used in a subsequent meta-regression to identify whether studies with a high risk of bias differed in outcome from studies with an intermediate or low risk of bias.

\section{Statistical analysis}

Analyses were performed using STATA version 12 for Mac OS X (StataCorp, Texas). Significance was set at $p<0.05$ in two-sided tests.

We used random effects models to calculate the pooled Cohen's d. Basic assumption of the random effects model is that the effects being estimated in the different studies are not identical, but vary randomly around the population average. Hence, the between-study variance is estimated and included in the weighting of the effect sizes. We used t-tests to calculate differences in ES between specific domains in the converter group, and to calculate differences in domainspecific ES between groups (converters vs. non-converters).

Furthermore, we assessed heterogeneity of each outcome measure with Cochrane's $Q$, which is calculated as the weighted sum of squared differences between individual study effects and the pooled effect across studies (Gavaghan et al., 2000). A significant $Q$-value indicates heterogeneity of results, which may be due to potential moderating variables. We performed meta-regression to identify possible explanations for heterogeneity. We tested for the effect of baseline participant age, sampling method (population based, clinic based, other), initial cognitive status of participants (impaired, normal, unspecified), dementia outcome (AD vs. dementia) and risk of bias (high, intermediate, low). We tested for publication bias by visual inspection of asymmetry in funnel plots, which assess the relationship between sample size and effect size. In addition, we performed Egger's regression test (Egger et al., 1997), which statistically assesses funnel plot 
asymmetry. An asymmetrical funnel plot and a significant $p$-value on Egger's regression test indicate possible publication bias.

\section{RESULTS}

We included two clinical studies, fifteen population-based studies and four other studies (one study that was both clinical and population-based and three studies in which the source of participants was unspecified). In these studies 2249 subjects converted to dementia at follow-up. At baseline most subjects $(n=1942,86 \%)$ were classified as cognitive impairment unspecified. Of the remaining cases, $104(5 \%)$ were classified as cognitively impaired at baseline and $203(9 \%)$ subjects were cognitively normal. Twelve studies provided information on decline in subjects that did not convert to dementia and formed the non-converting control group. This group included 2439 subjects, who were classified as cognitively normal $(n=776,32 \%)$, unspecified $(n=1509,61 \%)$ or impaired $(n=154,7 \%)$ at baseline and by definition remained non-demented during follow-up. At baseline, the mean age of the pre-dementia group was 80.0 years, compared to 76.5 years in the nonconverter group. Characteristics of the included studies are provided in table 1. In the converter group data for the global cognitive functioning domain was available from 13 studies $(n=1323)$, for episodic memory from 13 studies $(n=1698)$, for executive functioning from 4 studies $(n=420)$, for attention/IPS from 7 studies $(n=873)$, for verbal ability from 12 studies $(n=1563)$ and for visuospatial ability from 10 studies $(n=1613)$. In the non-converter group data for global cognitive functioning was available from 7 studies $(n=1392)$, for episodic memory from 9 studies $(n=1182)$, for attention/IPS from 5 studies $(n=513)$, for verbal ability from 6 studies $(n=669)$ and for visuospatial ability from 6 studies $(n$ $=815$ ). The number of studies for executive functioning was considered too limited to perform meta-analysis in the non-converter group ( 3 studies, $n=302$ ) (table 2 ). The weighted mean follow-up time in the converter group ranged from 3.6 years for executive functioning to 5.9 years for attention/IPS, grand mean 5.2 years, and in the non-converter group from 3.2 years (executive functioning) to 4.7 years (visuospatial ability), grand mean 3.9 years (table 2 ).

\section{Meta-analysis}

ES were significant for all cognitive domains in the converter group (table 2; supplementary figures $1-6)$. ES for average annual decline were all small (range $\mathrm{d}=-0.16,95 \% \mathrm{CI}:-0.30 ;-0.03$ to $\mathrm{d}=-0.44,95 \% \mathrm{CI}$ : $-0.56 ;-0.32)$. The largest ES were observed for episodic memory $(\mathrm{d}=-0.35,95 \% \mathrm{CI}:-0.43 ;-0.27)$ and global cognitive functioning ( $\mathrm{d}=-0.44,95 \% \mathrm{CI}$ : $-0.56 ;-0.32)$. 


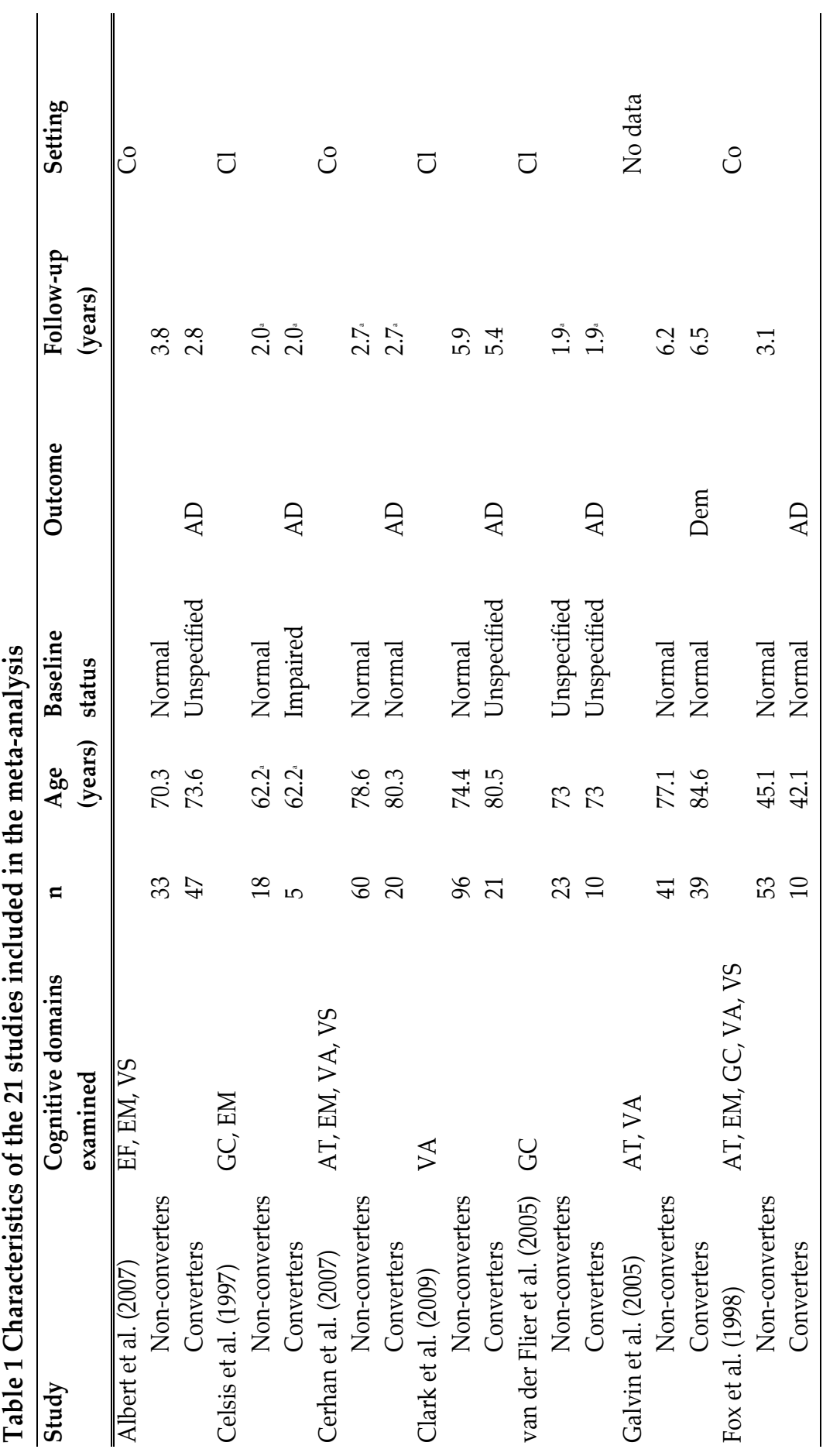




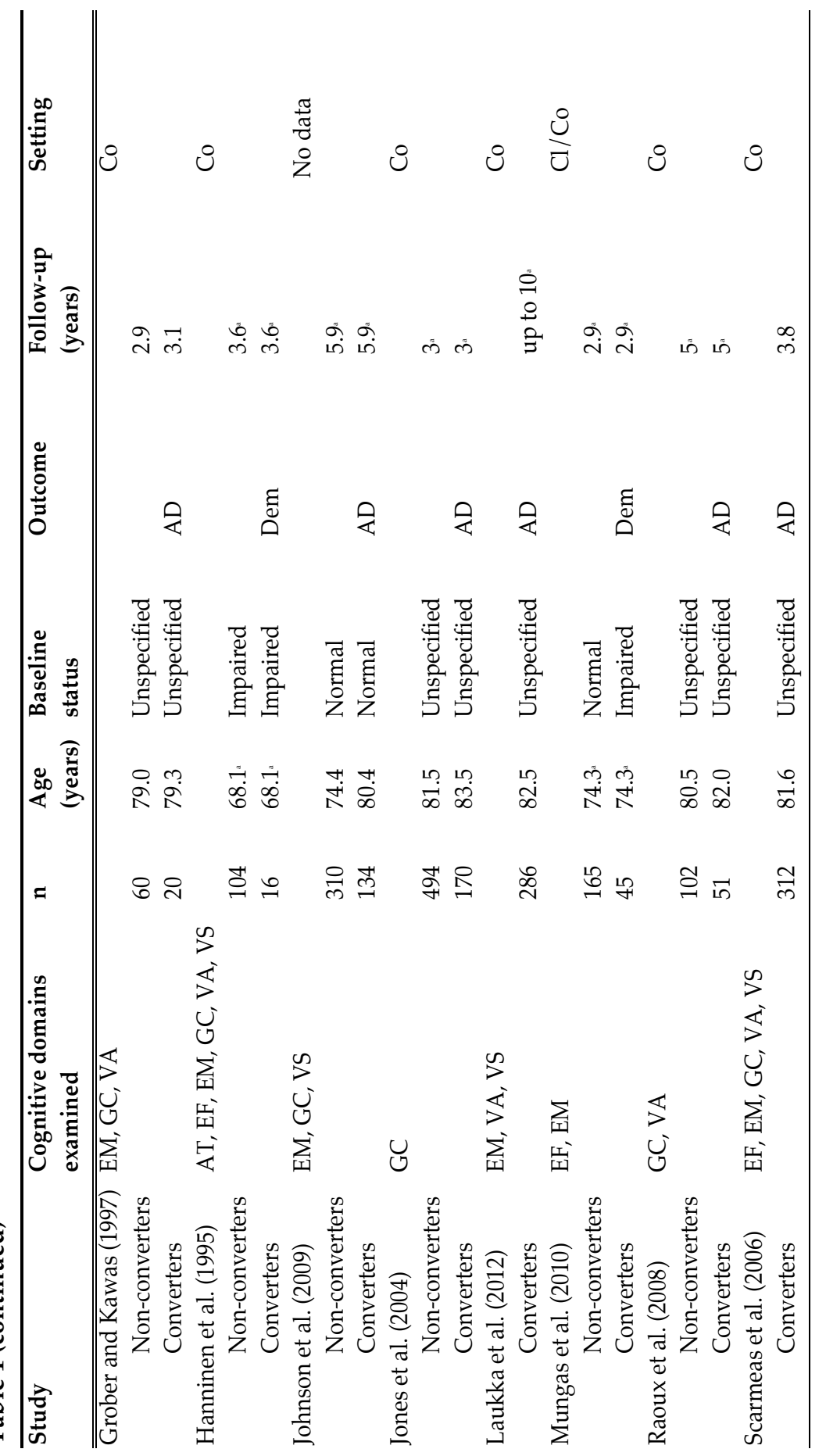




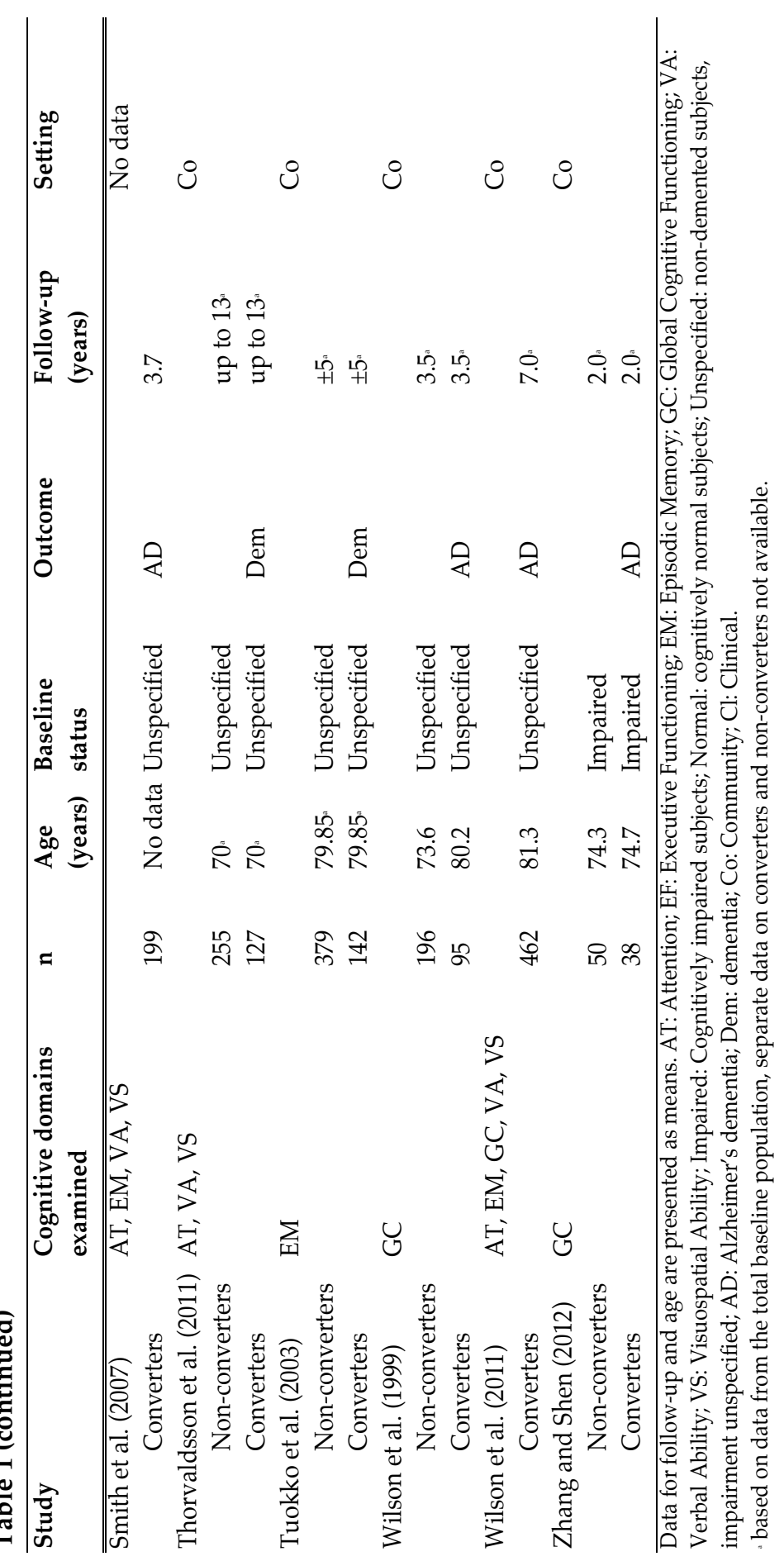




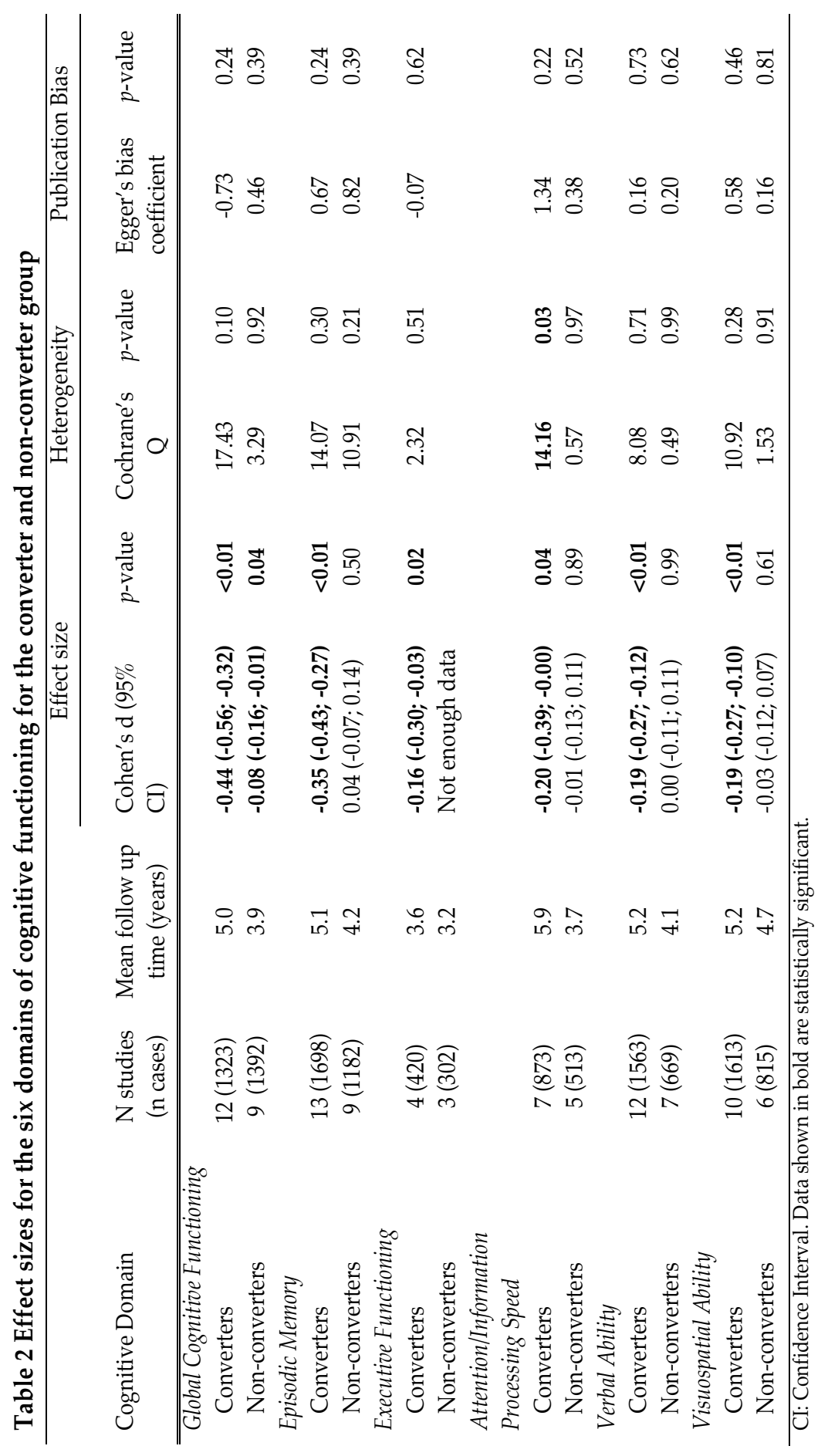


When we repeated our analysis for global cognitive functioning using only studies that reported MMSE scores (6 studies), the ES did not significantly change ( $d=-0.48,95 \%$ CI: $-0.58 ;-0.37)$. This ES corresponds to a biannual decline on MMSE of approximately 1 point. When comparing the magnitude of decline between different domains in the converter group, ES of global cognitive functioning and episodic memory were significantly larger than ES in the other cognitive domains.

When we repeated our analyses using only data of subjects who converted to AD dementia, results did not essentially change, except for the attention/IPS domain where the ES was no longer significant $(d=-0.26,95 \% \mathrm{CI}:-0.53 ; 0.01)$. Furthermore, there was not enough data available to calculate an ES for the executive functioning domain (see supplementary table 3).

ES in the non-converter group were only significant for global cognitive functioning ( $\mathrm{d}=-0.08,95 \% \mathrm{CI}$ : -0.16 ; -0.01) (table 2), and the magnitude of decline did not differ significantly between domains. When comparing the domainspecific

ES between the converter and non-converter group, the ES for attention/IPS did not differ between groups $(p=0.17)$. For all other domains, future dementia subjects showed larger decline than non-converters $(p<0.05)$.

When we excluded studies with subjects that were reported to be already cognitively impaired at baseline, results in all groups did not essentially change (results not shown).

\section{Heterogeneity and meta-regression}

The ES for attention/IPS showed a significant level of heterogeneity across studies in the converter group $(\mathrm{Q}=14.16, p=0.03)$ (table 2$)$, but meta-regression showed no significant associations between study characteristics (baseline age, initial cognitive status, sampling method and dementia outcome) and ES. In the nonconverter group there was no notable heterogeneity across studies (table 2).

\section{Publication bias}

Egger's regression test and visual inspection of the funnel plots revealed no convincing evidence for publication bias (or, more correctly, small study bias) in both groups (table 2). However, many funnel plots contained only few studies, so there might be a lack of power to detect small-study bias (supplementary figure 7 and 8).

\section{Methodological quality}

$29 \%$ of the studies were classified as 'low risk of bias' and the remaining studies as 'intermediate risk of bias'. The study with the lowest risk of bias was assessed positive on $80 \%$ of all items, most studies scored positive on 60 to $67 \%$ of all items. 
Meta-regression results showed that studies with an intermediate risk of bias did not differ in any cognitive domain outcome measure from studies with a low risk of bias. The same result was found when we repeated meta-regression using the raw risk of bias scores.

\section{DISCUSSION}

The aim of the present study was to estimate and compare the annual rate of domain-specific decline of six cognitive domains in subjects in the pre-dementia phase by means of meta-analysis. In addition, a comparison with the domainspecific rate of decline in non-converters was made. During a mean observational period of five years prior to dementia diagnosis onwards, decline in episodic memory and global cognitive functioning was significantly larger than decline in other cognitive domains, though there was modest decline in all domains. Further, attention/information processing speed was the only cognitive domain where the extent of decline did not differ between converters and non-converters.

Our established relatively large ES of episodic memory corresponds with the observation that the earliest pathological changes in $\mathrm{AD}$ usually occur in the medial temporal lobe regions, which are known to be critical for episodic memory functioning (Ridha et al., 2006, Sluimer et al., 2009). Conform expectations, global cognitive functioning and other cognitive domains showed pre-dementia decline too. This is consistent with findings of pathology spread in prodromal AD, indicating that multiple brain structures, like the cingulum (Jones et al., 2006), parietal (Jacobs et al., 2011) and frontal cortex (Burgmans et al., 2009), may be affected before dementia diagnosis. The relatively large ES of global cognitive functioning might reflect the pre-dementia decline of all other domains.

Nonetheless, it is probably the episodic memory deficit that contributes most to this large effect size, since memory tests are an important component of measures of global cognitive functioning and of the MMSE in particular.

Decline in most domains differed significantly between converters and nonconverters, except for attention/IPS. This lack of discriminative power might be due to the fact that attention/IPS is known to be affected by normal ageing processes (Finkel et al., 2007, Hoogendam et al., 2014). Interestingly, when we repeated our analyses using only data from subjects who converted to $\mathrm{AD}$ dementia, the decline in attention/information processing speed was no longer significant. This seems to indicate that decline in attention/IPS might not be a good predictor for conversion to AD dementia, which is in accordance with a previous study (Albert et al., 2001), however it could be an indicator of developing other forms of dementia. 


\section{Clinical implications}

Our findings may have implications for constructing optimal neuropsychological test batteries aimed at detecting dementia in an early phase. Since the magnitude of decline in episodic memory and global cognitive functioning was significantly larger (ES almost twofold) than decline in the other domains, measures for episodic memory and global cognitive functioning seem to be the most promising tools for early detection of dementia. In clinical practice, a decline of $0.35 \mathrm{SD}$ units per year in episodic memory and a decline of $0.44 \mathrm{SD}$ units per year in global cognitive functioning (or a biannual decline of one point on the MMSE) seems indicative of future dementia. In this way, it might be possible to detect cognitive decline at an even earlier stage

\section{Limitations}

The present study has several limitations. First, there is the potential problem of circularity in our arguments, since the clinical definition of dementia is partially based on cognitive impairment and decline. Therefore, it seems obvious that converters decline before dementia diagnosis. Nonetheless, since the aim of our study was not to demonstrate the presence of cognitive decline before dementia diagnosis, but rather to compare the magnitude of decline between domains, this has not influenced our results. Another possible limitation could be that our analyses on attention/IPS and executive functioning were based on relatively few studies. This limited power of the analyses could introduce heterogeneity by enlarging the effect of a single study on the ES. We indeed observed heterogeneity of the ES in attention/IPS in the converter group. Furthermore, we grouped the neuropsychological tests into broad cognitive domains, yet for some domains, in particular attention/IPS, there is still considerable debate about the precise definition of these functions. This might be reflected in the existence and use of a lot of different tests that intend to measure these functions. Episodic memory, for example, showed no notable heterogeneity, but there is a lot less controversy about the definition of this domain. Besides, the classification of neuropsychological tests into cognitive domains is also not straightforward. For certain tasks (e.g. word list recall learning tasks) the corresponding cognitive domain is obvious, but for others (e.g. Trail Making Test) grouping is more ambiguous (Lezak et al., 2004). Further, since different studies used different neuropsychological tests, it could be that differences in ES between studies resulted from differences in the accuracy of the used test.

Also, for the majority of subjects we did not know cognitive status at baseline. As a result we do not know the differences in rate of decline between those with normal cognition and those with mild cognitive impairment. In addition, this might have lead to an overestimation of decline in the non-converter group, since potentially impaired subjects are probably more likely to develop further cognitive decline 
and progress to dementia over time. This probably has increased the chance of type I error, and hence even stronger differences in the rate of decline between converters and "true" non-converters likely exist in nature. For both groups we included a small number of subjects with known cognitive impairment at baseline, but when repeating analyses without this group results did not essentially change (results not shown).

Next, our results may have been affected by the quality of the studies. However, the assessments of risk of bias were good to moderate, with no studies being classified as high risk of bias, although we have been lenient in our overall classifications. We may have even underestimated these assessments, because rating was only based on information that was provided in the article. In addition, our meta-regression showed that risk of bias classification had no significant effect on results. Our outcome could have been influenced also by publication bias and by the fact that not all identified studies provided standardized slopes or means and standard deviations and were therefore excluded. Despite the fact that Egger's test was not significant in both groups, many funnel plots only had a limited number of studies, meaning these assessments lacked power. However, the results of the studies not included in the present analyses because of unusable data formats do not appear to oppose our findings.

\section{Conclusions}

The present meta-analysis showed that during a mean observational period of five years prior to dementia diagnosis, the strongest indicators of future dementia were accelerated decline in episodic memory and global cognitive functioning, while decline in attention/IPS does not discriminate between future dementia converters and non-converters. 


\section{REFERENCES}

Albert, M., Blacker, D., Moss, M. B., Tanzi, R., \& McArdle, J. J. (2007). Longitudinal change in cognitive performance among individuals with mild cognitive impairment. Neuropsychology, 21, 158-169.

Albert, M. S., Moss, M. B., Tanzi, R., \& Jones, K. (2001). Preclinical prediction of AD using neuropsychological tests. Journal of the International Neuropsychological Society, 7, 631-639.

Altman, D. G. (2001). Systematic reviews of evaluations of prognostic variables. British Medical Journal, 323, 224-228.

American Psychiatric Association (1987). Diagnostic and Statistical Manual of Mental Disorders (3rd Revised Edition). Washington, DC: APA.

American Psychiatric Association (1994). Diagnostic and Statistical Manual of Mental Disorders (4th Edition) (DSM-IV). Washington DC: APA.

Backman, L., \& Small, B. J. (1998). Influences of cognitive support on episodic remembering: tracing the process of loss from normal aging to Alzheimer's disease. Psychology $\mathcal{E}$ Aging, 13, 267-276.

Backman, L., Small, B. J., \& Fratiglioni, L. (2001). Stability of the preclinical episodic memory deficit in Alzheimer's disease. Brain, 124, 96-102.

Blessed, G., Tomlinson, B. F., \& Roth, M. (1968). The association between quantative measures of dementia and senile change in the cerebral gray matter of elderly subjects. British Journal of Psychiatry, 114, 97-811.

Burgmans, S., van Boxtel, M. P., Smeets, F., Vuurman, E. F., Gronenschild, E. H., Verhey, F. R., et al. (2009). Prefrontal cortex atrophy predicts dementia over a six-year period. Neurobiology of Aging, 30, 1413-1419.

Celsis, P., Agniel, A., Cardebat, D., Demonet, J. F., Ousset, P. J., \& Puel, M. (1997). Age related cognitive decline: a clinical entity? A longitudinal study of cerebral blood flow and memory performance. Journal of Neurology, Neurosurgery \& Psychiatry, 62, 601-608.

Cerhan, J. H., Ivnik, R. J., Smith, G. E., Machulda, M. M., Boeve, B. F., Knopman, D. S., et al. (2007). Alzheimer's disease patients' cognitive status and course years prior to symptom recognition. Neuropsychology, Development, and Cognition. Section B Aging, Neuropsychology and Cognition, 14, 227-235,

Chen, P., Ratcliff, G., Belle, S. H., Cauley, J. A., DeKosky, S. T., \& Ganguli, M. (2000). Cognitive tests that best discriminate between presymptomatic $\mathrm{AD}$ and those who remain nondemented. Neurology, 55, 1847-1853.

Clark, L. J., Gatz, M., Zheng, L., Chen, Y., McCleary, C., \& Mack, W. J. (2009). Longitudinal verbal fluency in normal aging, preclinical, and prevalent Alzheimer's disease. American Journal of Alzheimer's Disease E Other Dementias, 24, 461-468.

Cohen, J. (1988). Statistical Power Analysis for the Behavioral Sciences, 2nd Edition. Hillsdale, New Jersey, USA: Lawrence Erlbaum Associates.

Deeks, J. J. (2001). Systematic reviews in health care: systematic reviews of evaluation of diagnostic and screening tests. British Medical Journal, 323, 157-162.

Egger, M., Davey Smith, G., Schneider, M., \& Minder, C. (1997). Bias in meta-analysis detected by a simple, graphical test. British Medical Journal, 315, 629-634 
Elias-Sonnenschein, L. S., Viechtbauer, W., Ramakers, I. H., Verhey, F. R., \& Visser, P. J. (2011). Predictive value of APOE-epsilon4 allele for progression from MCI to ADtype dementia: a meta-analysis. Journal of Neurology, Neurosurgery E Psychiatry, 82, 1149-1156.

Fabrigoule, C., Rouch, I., Taberly, A., Letenneur, L., Commenges, D., Mazaux, J. M., et al. (1998). Cognitive process in preclinical phase of dementia. Brain, 121, 135-141.

Finkel, D., Reynolds, C. A., McArdle, J. J., \& Pedersen, N. L. (2007). Age changes in processing speed as a leading indicator of cognitive aging. Psychology and Aging, 22, 558-568.

Folstein, M. F., Folstein, S., \& McHugh, P. R. (1975). "Mini-Mental State": A practical method for grading cognitive status of patients for the clinician. Journal of Psychiatric Research, 12, 189-198.

Fox, N. C., Warrington, E. K., Seiffer, A. L., Agnew, S. K., \& Rossor, M. N. (1998). Presymptomatic cognitive deficits in individuals at risk of familial Alzheimer's disease: A longitudinal prospective study. Brain: A Journal of Neurology, 121, 16311639 .

Friedman, H. (1968). Magnitude of experimental effect and a table for it's estimation. Psychological Bulletin, 70, 245-251.

Galvin, J. E., Powlishta, K. K., Wilkins, K., McKeel, D. W., Jr., Xiong, C., Grant, E., et al. (2005). Predictors of preclinical Alzheimer disease and dementia: a clinicopathologic study. Archives of Neurology, 62, 758-765.

Gavaghan, D. J., Moore, R. A., \& McQuay, H. J. (2000). An evaluation of homogeneity tests in meta-analyses in pain using simulations of individual patient data. Pain, 85, 415424.

Grober, E., \& Kawas, C. (1997). Learning and retention in preclinical and early Alzheimer's disease. Psychology and Aging, 12, 183-188.

Hanninen, T., Hallikainen, M., Koivisto, K., Helkala, E. L., Reinikainen, K. J., Soininen, H., et al. (1995). A follow-up study of age-associated memory impairment: neuropsychological predictors of dementia. Journal of the American Geriatrics Society, 43, 1007-1015.

Hoogendam, Y. Y., Hofman, A., van der Geest, J. N., van der Lugt, A., \& Ikram, M. A. (2014). Patterns of cognitive function in aging: the Rotterdam Study. European Journal of Epidemiology, 29, 133-140.

Ingles, J. L., Wentzel, C., Fisk, J. D., \& Rockwood, K. (2002). Neuropsychological predictors of incident dementia in patients with vascular cognitive impairment, without dementia. Stroke, 33, 1999-2002.

Jack, C. R., Jr., Knopman, D. S., Jagust, W. J., Shaw, L. M., Aisen, P. S., Weiner, M. W., et al. (2010). Hypothetical model of dynamic biomarkers of the Alzheimer's pathological cascade. Lancet Neurology, 9, 119-128.

Jacobs, H. I., Van Boxtel, M. P., Uylings, H. B., Gronenschild, E. H., Verhey, F. R., \& Jolles, J. (2011). Atrophy of the parietal lobe in preclinical dementia. Brain and Cognition, 75, 154-163.

Johnson, D. K., Storandt, M., Morris, J. C., \& Galvin, J. E. (2009). Longitudinal study of the transition from healthy aging to Alzheimer disease. Archives of Neurology, 66, 12541259 . 
Jones, B. F., Barnes, J., Uylings, H. B., Fox, N. C., Frost, C., Witter, M. P., et al. (2006). Differential regional atrophy of the cingulate gyrus in Alzheimer disease: a volumetric MRI study. Cerebral Cortex, 16, 1701-1708.

Jones, S., Laukka, E. J., Small, B. J., Fratiglioni, L., \& Backman, L. (2004). A preclinical phase in vascular dementia: cognitive impairment three years before diagnosis. Dementia and Geriatric Cognitive Disorders, 18, 233-239.

Laukka, E. J., Jones, S., Fratiglioni, L., \& Backman, L. (2004). Cognitive functioning in preclinical vascular dementia: a 6-year follow-up. Stroke, 35, 1805-1809.

Laukka, E. J., MacDonald, S. W. S., Fratiglioni, L., \& Bäckman, L. (2012). Preclinical cognitive trajectories differ for Alzheimer's disease and vascular dementia. Journal of the International Neuropsychological Society, 18, 191-199.

Linn, R. T., Wolf, P. A., Bachman, D. L., Knoefel, J. E., Cobb, J. L., Belanger, A. J., et al. (1995). The 'preclinical phase' of probable Alzheimer's disease. A 13-year prospective study of the Framingham cohort. Archives of Neurology, 52, 485-490.

McKhann, G., Drachman, D., Folstein, M., Katzman, R., Price, D., \& Stadlan, E. M. (1984). Clinical diagnosis of Alzheimer's disease: report of the NINCDS-ADRDA Work Group under the auspices of Department of Health and Human Services Task Force on Alzheimer's Disease. Neurology, 34, 939-944.

Meyer, J. S., Xu, G., Thornby, J., Chowdhury, M. H., \& Quach, M. (2002). Is mild cognitive impairment prodromal for vascular dementia like Alzheimer's disease? Stroke, 33(8), 1981-1985.

Moher, D., Liberati, A., Tetzlaff, J., \& Altman, D. G. (2009). Preferred reporting items for systematic reviews and meta-analyses: the PRISMA statement. PLoS Medicine, 6.

Morris, J. C. (1993). The Clinical Dementia Rating (CDR): current version and scoring rules. Neurology, 43, 2412-2414.

Mungas, D., Beckett, L., Harvey, D., Farias, S. T., Reed, B., Carmichael, O., et al. (2010). Heterogeneity of cognitive trajectories in diverse older persons. Psychology and Aging, 25, 606-619.

Nielsen, H., Lolk, A., Andersen, K., Andersen, J., \& Kragh-Sorensen, P. (1999).

Characteristics of elderly who develop Alzheimer's disease during the next two years-a neuropsychological study using CAMCOG. The Odense Study. International Journal of Geriatric Psychiatry, 14, 957-963.

Petersen, R. C., \& Morris, J. C. (2005). Mild cognitive impairment as a clinical entity and treatment target. Archives of Neurology, 62, 1160-1163.

Petersen, R. C., Smith, G. E., Waring, S. C., Ivnik, R. J., Tangalos, E. G., \& Kokmen, E. (1999). Mild cognitive impairment: clinical characterization and outcome. Archives of Neurology, 56, 303-308.

Peterson, R. A., \& Brown, S. P. (2005). On the use of beta coefficients in meta-analysis. Journal of Applied Psychology, 90, 175-181.

Raoux, N., Amieva, H., Le Goff, M., Auriacombe, S., Carcaillon, L., Letenneur, L., et al. (2008). Clustering and switching processes in semantic verbal fluency in the course of Alzheimer's disease subjects: results from the PAQUID longitudinal study. Cortex, 44, 1188-1196.

Rapp, M. A., \& Reischies, F. M. (2005). Attention and executive control predict Alzheimer disease in late life: results from the Berlin Aging Study (BASE). American Journal of Geriatric Psychiatry, 13, 134-141. 
Ridha, B. H., Barnes, J., Bartlett, J. W., Godbolt, A., Pepple, T., Rossor, M. N., et al. (2006). Tracking atrophy progression in familial Alzheimer's disease: a serial MRI study. Lancet Neurology, 5, 828-834.

Rubin, E. H., Storandt, M., Miller, J. P., Kinscherf, D. A., Grant, E. A., Morris, J. C., et al. (1998). A prospective study of cognitive function and onset of dementia in cognitively healthy elders. Archives of Neurology, 55, 395-401.

Scarmeas, N., Albert, S. M., Manly, J. J., \& Stern, Y. (2006). Education and rates of cognitive decline in incident Alzheimer's disease. Journal of Neurology, Neurosurgery $\mathcal{E}$ Psychiatry, 77, 308-316.

Sluimer, J. D., van der Flier, W. M., Karas, G. B., van Schijndel, R., Barnes, J., Boyes, R. G., et al. (2009). Accelerating regional atrophy rates in the progression from normal aging to Alzheimer's disease. European Radiology, 19, 2826-2833.

Smith, G. E., Pankratz, V. S., Negash, S., Machulda, M. M., Petersen, R. C., Boeve, B. F., et al . (2007). A plateau in pre-Alzheimer memory decline: evidence for compensatory mechanisms? Neurology, 69, 133-139.

Thorvaldsson, V., MacDonald, S. W. S., Fratiglioni, L., Winblad, B., Kivipelto, M., Laukka, E. J., et al. (2011). Onset and rate of cognitive change before dementia diagnosis: Findings from two Swedish population-based longitudinal studies. Journal of the International Neuropsychological Society, 17, 154-162.

Tuokko, H., Garrett, D. D., McDowell, I., Silverberg, N., \& Kristjansson, B. (2003). Cognitive decline in high-functioning older adults: reserve or ascertainment bias? Aging $\mathcal{E}$ Mental Health, 7, 259-270.

van der Flier, W. M., van der Vlies, A. E., Weverling-Rijnsburger, A. W., de Boer, N. L., Admiraal-Behloul, F., Bollen, E. L., et al. (2005). MRI measures and progression of cognitive decline in nondemented elderly attending a memory clinic. International Journal of Geriatric Psychiatry, 20, 1060-1066.

Vos, S. J., Xiong, C., Visser, P. J., Jasielec, M. S., Hassenstab, J., Grant, E. A., et al. (2013). Preclinical Alzheimer's disease and its outcome: a longitudinal cohort study. Lancet Neurology, 12, 957-65.

Wilson, R. S., Beckett, L. A., Bennett, D. A., Albert, M. S., \& Evans, D. A. (1999). Change in cognitive function in older persons from a community population: relation to age and Alzheimer disease. Archives of Neurology, 56, 1274-1279.

Wilson, R. S., Leurgans, S. E., Boyle, P. A., \& Bennett, D. A. (2011). Cognitive decline in prodromal Alzheimer disease and mild cognitive impairment. Archives of Neurology, 68, 351-356.

World Health Organization (1993). International Statistical Classification of Disease and Related Health Problems 10th revision. Geneva, Switzerland: WHO.

World Health Organization (2012). Dementia: a public health priority. Geneva, Switzerland: WHO.

Zhang, D., \& Shen, D. (2012). Predicting future clinical changes of MCI patients using longitudinal and multimodal biomarkers. PLoS One, 7. 


\section{SUPPLEMENTARY DATA}

\section{Supplementary table 1 Classification of cognitive tests into cognitive domains for studies not specifying domains}

\begin{tabular}{|c|c|}
\hline Cognitive Domain & Neuropsychological Tests \\
\hline Global Cognitive Functioning & $\begin{array}{l}\text { Mini Mental State Examination (Folstein } \text { et al., 1975); } \\
\text { Blessed Information Memory and Concentration Test } \\
\text { (Blessed et al., 1968); Alzheimer's Disease Assessment } \\
\text { Scale - Cognitive Subscale [ADAS-COG] (Rosen et al., } \\
\text { 1984); Cambridge Cognitive Examination (Derix et } \\
\text { al., 1992; Roth et al., 1986) }\end{array}$ \\
\hline Episodic Memory & $\begin{array}{l}\text { The Recognition Memory Test (Warrington, 1984); } \\
\text { Free and Cued Selective Reminding Test (Grober and } \\
\text { Buschke, 1987); Word Recall and recognition } \\
\text { (Bäckman and Forsell, 1994); Buschke Cued Recall } \\
\text { paradigm for memory assessment (Buschke, 1984); } \\
\text { Rey Auditory Verbal Learning Test (Rey, 1964); } \\
\text { Benton Visual Retention Test Multiple Choice version } \\
\text { (Benton, 1974); Benton Visual Retention Test Form C } \\
\text { (Benton, 1974); Wechsler Memory Scale Logical } \\
\text { Memory subtest (Wechsler, 1975); Wechsler Memory } \\
\text { Scale Paired Associated Learning subtest (Wechsler, } \\
\text { 1975); Buschke Selective Reminding Test (Buschke } \\
\text { and Fuld ,1974); Russell's adaptation of the Visual } \\
\text { Reproduction Test: Recall (Russell, 1975) }\end{array}$ \\
\hline Executive Functioning & $\begin{array}{l}\text { Trail Making Test AB, part B (Reitan, 1958); } \\
\text { Adaptation of the Trail Making Test: Trailmaking } \\
\text { Test ABC, part C (Koivisto et al., 1992) }\end{array}$ \\
\hline $\begin{array}{l}\text { Attention/ Information Processing } \\
\text { Speed }\end{array}$ & $\begin{array}{l}\text { Psychomotor Speed Tests (Willison and Warrington, } \\
\text { 1992); Trail Making Test part A (Reitan 1958); WAIS } \\
\text { Digit Symbol (Wechsler, 1981); Wechsler Memory } \\
\text { Scale Mental Control subtest (Wechsler, 1945); Figure } \\
\text { Identification (Dureman et al., 1971) }\end{array}$ \\
\hline Verbal Ability & $\begin{array}{l}\text { Letter Fluency Task (F, A, S, P); Category Fluency } \\
\text { Task (animals, supermarket, food); Isaacs Set Test } \\
\text { (Isaacs and Kennie, 1973); Graded Naming Test } \\
\text { (McKenna and Warrington, 1983); Boston Naming } \\
\text { Test (Mack et al., 1992); Synonym Test (Dureman et } \\
\text { al., 1971) }\end{array}$ \\
\hline Visuopatial Ability & $\begin{array}{l}\text { (modified version of ) WAIS-R Block Design } \\
\text { (Wechsler, 1981); Visual Object \& Spatial Perception } \\
\text { Test (Warrington and James, 1991); Benton Visual } \\
\text { Retention Test: Form D-Copy (Benton, 1974); } \\
\text { Russell's adaptation of the Visual Reproduction Test: } \\
\text { Copying (Russell, 1975) }\end{array}$ \\
\hline
\end{tabular}




\section{Supplementary table 2 Methodological quality rating}

\begin{tabular}{l} 
Item \\
\hline 1. Sampling of subjects \\
1.2 Random or consecutive sel \\
specified disease state \\
1.3 Selection and referral proce \\
fully described \\
1.4 Clinical and demographic \\
characteristics fully described
\end{tabular}

1.5 Complete

\subsection{Large sample size}

\section{Reference diagnosis}

2.1 Methods and tests described in detail

2.2 Positive and negative diagnoses clearly described

2.3 Available for a high proportion of subjects

2.5 Blinding procedures used to prevent knowledge of result of diagnostic test influencing the reference diagnosis (i.e. verification bias)
Criterion

Indication that consecutive subjects or randomly selected subjects were included

Indication that all subjects were included as a single cohort at a specified (usually early) point in the course of disease.

Description of sampling method and the inclusion and exclusion criteria; and (for clinical studies only), full description of referral pattern Data presented on age, gender, educational level, and score for the MMSE or equivalent cognitive screening test

This item was scored present if it was indicated that all eligible patients had undergone the diagnostic test or if it was mentioned how many of the eligible patients had not undergone the diagnostic test and that the baseline characteristics of these patients were compared with the characteristics of the patients who had undergone the diagnostic test

Baseline sample of at least 50 subjects

Description of person who made the diagnosis and of data used for diagnosis

Description of dementia criteria used

Follow-up rate of at least $85 \%$

This item was scored positive if it was explicitly mentioned that the person who made the diagnosis of dementia at follow-up was blinded for all results of the baseline diagnostic assessment (i.e. neuropsychological assessment) except for age, sex, and educational level (since these variables are not part of the diagnostic criteria).

Description of measurements used to assess cognitive functioning such that it could be reproduced

\section{Experimental test}

3.1 Description of test described in detail 
Supplementary table 2 (continued)

\begin{tabular}{ll}
\hline Item & Criterion \\
\hline 3.2 All baseline results described & Description of the baseline results of the \\
& $\begin{array}{l}\text { cognitive assessments for at least the future } \\
\text { demented subjects }\end{array}$
\end{tabular}

4. Longitudinal design

4.1 Sufficient length of follow-up

4.2 Low variability in follow-up length
This item was scored present if the length of follow-up was at least 3 years

This item was scored present if the variability in the follow-up length between subjects was 2 years or less.

Items were selected and adapted from rating scales of methodological quality of diagnostic and prognostic studies as described in Altman DG, Systematic reviews of evaluations of prognostic variables, BMJ 2001;323:224-8; and Deeks JJ, Systematic reviews in health care: Systematic reviews of evaluations of diagnostic and screening tests. BMJ 2001;323:157-62 


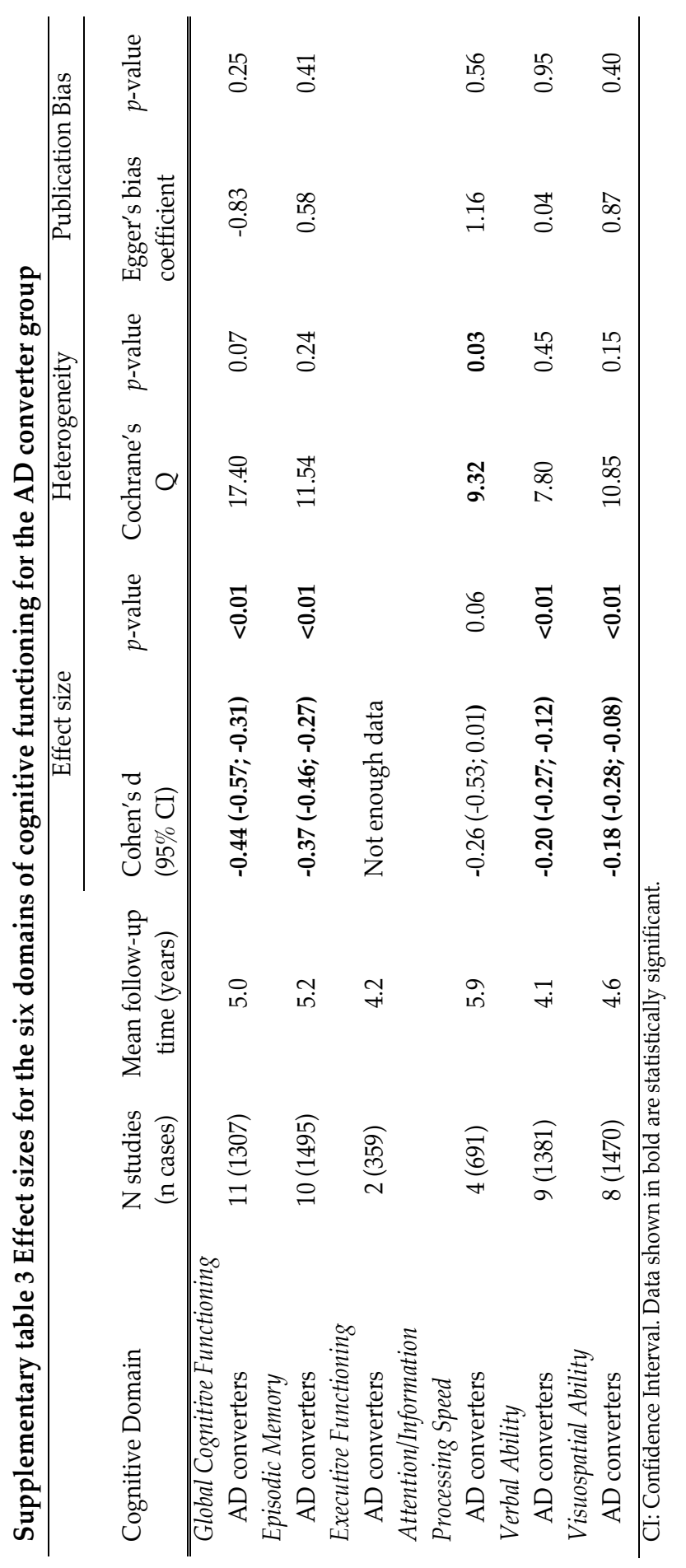




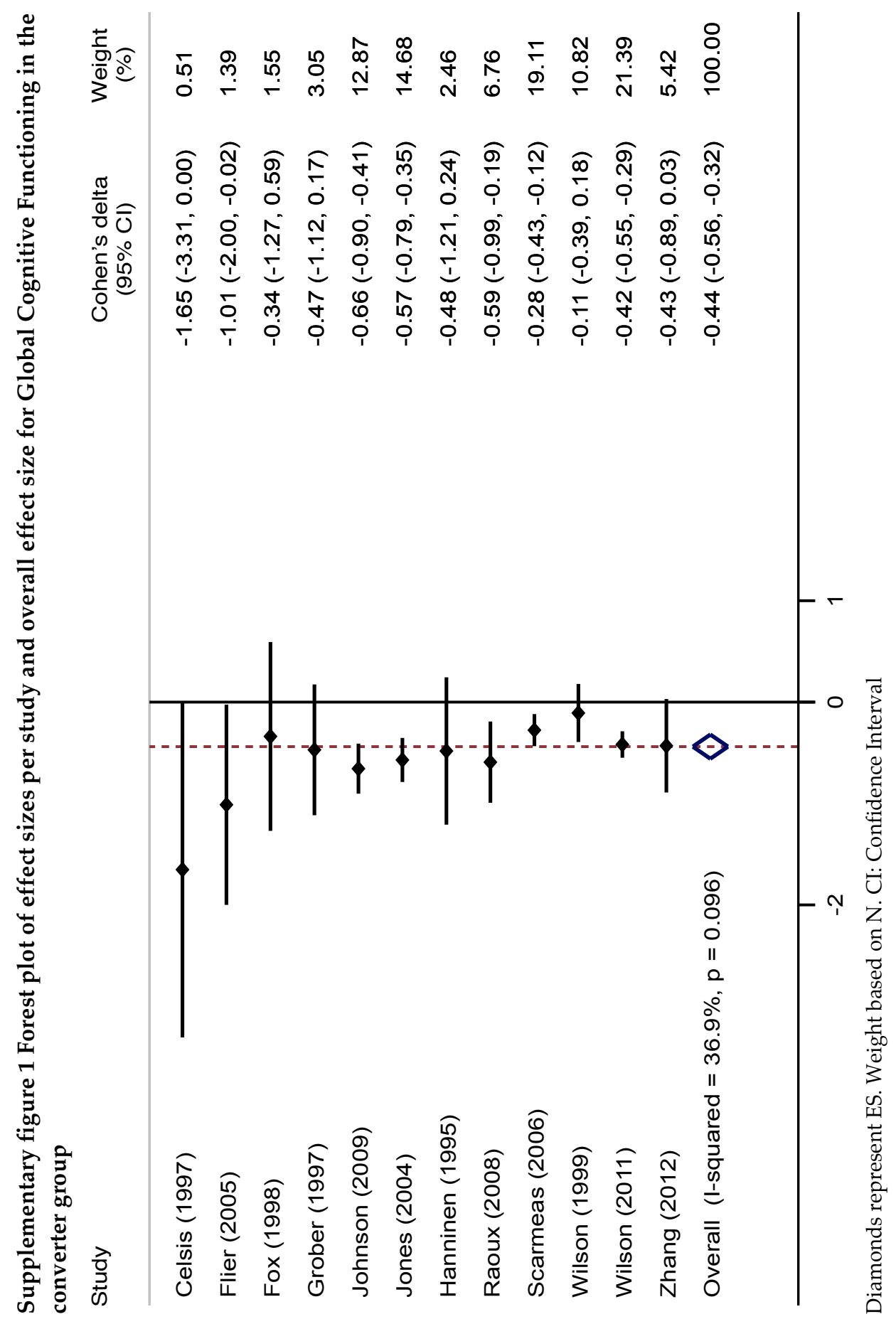




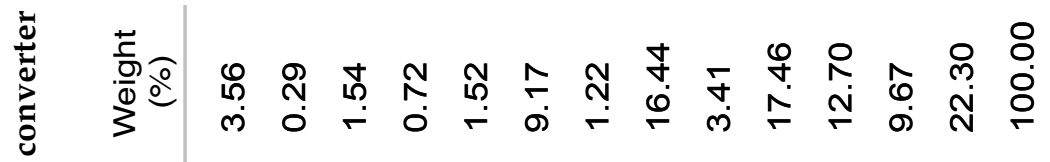

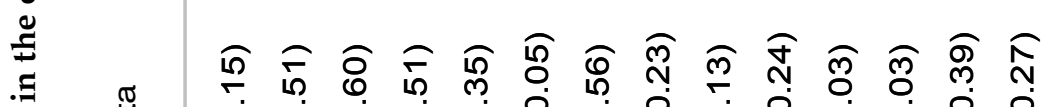

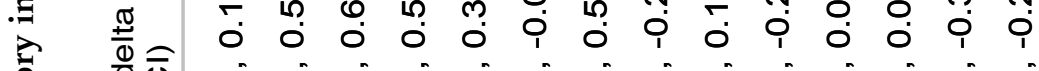

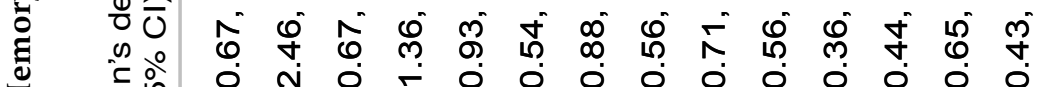

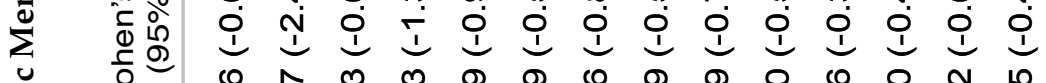

ఈ

$\frac{6}{2}$

o

西

$\frac{1}{4}$

芯

픔

్ㅠ

롤

t)

.

巡

过

范

훙

范

(1)

$\stackrel{0}{0}$

है

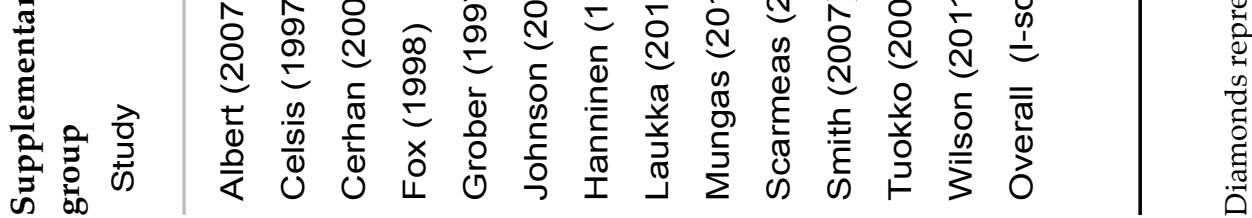

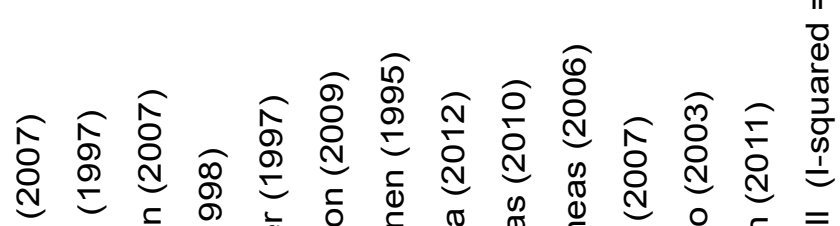




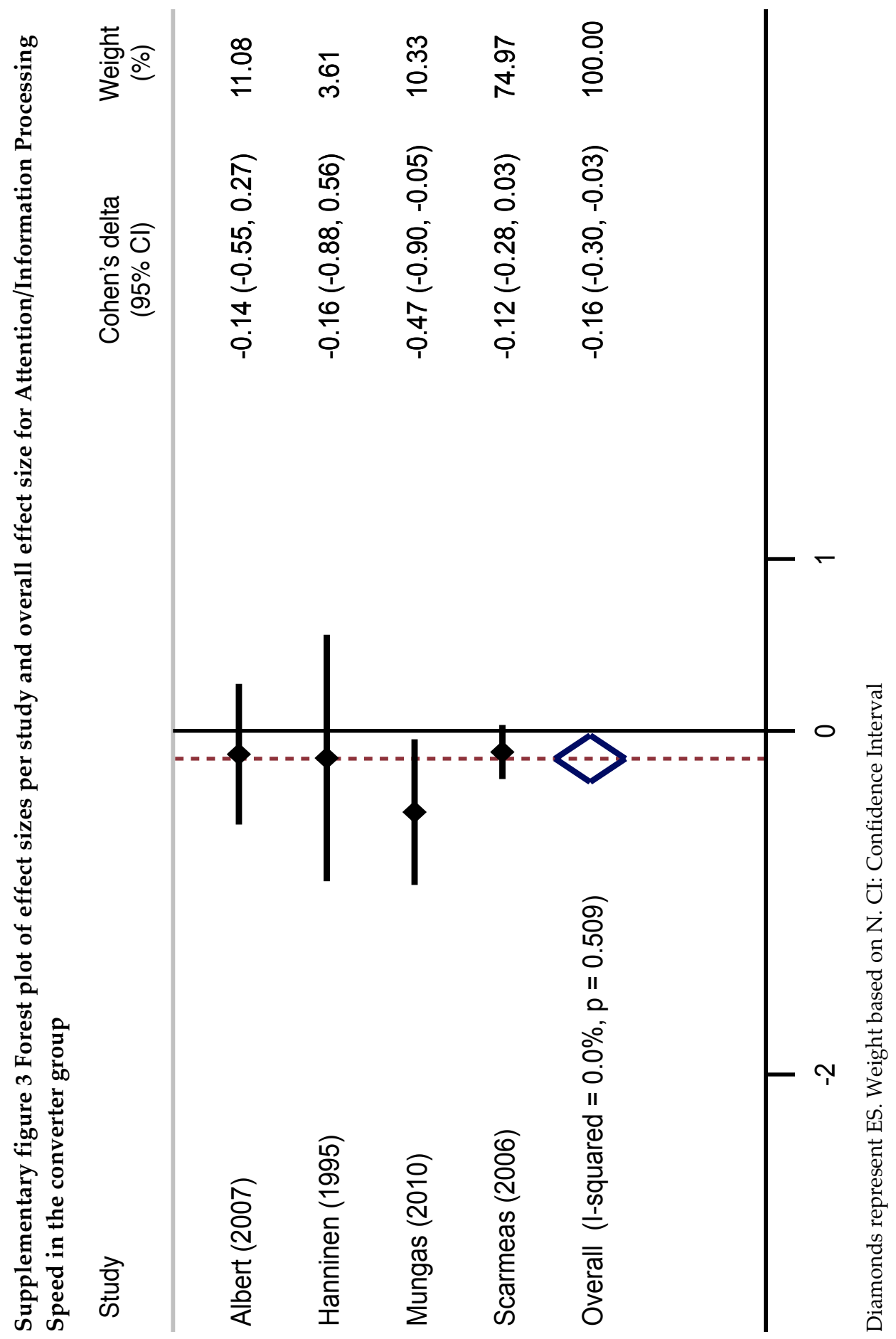




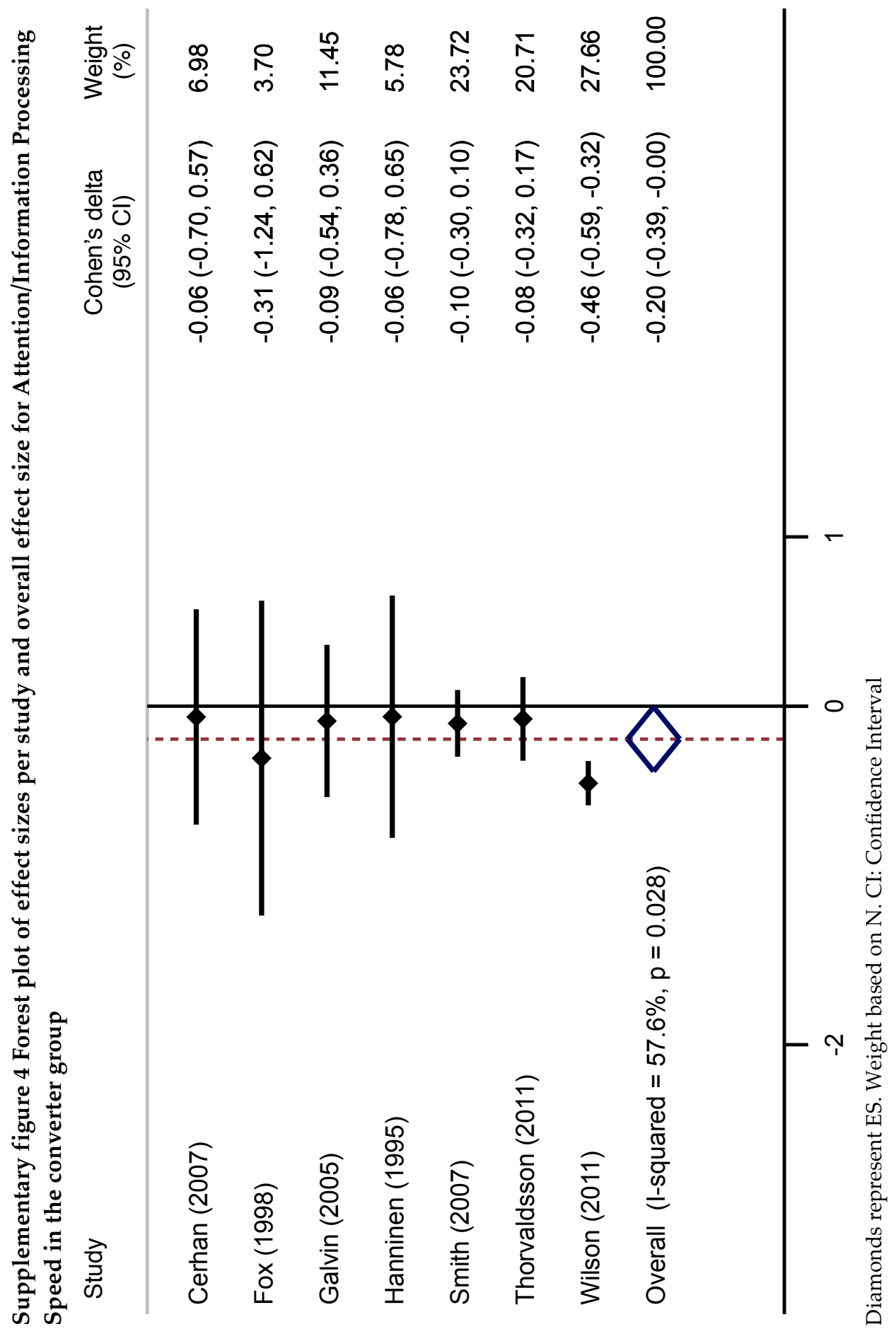




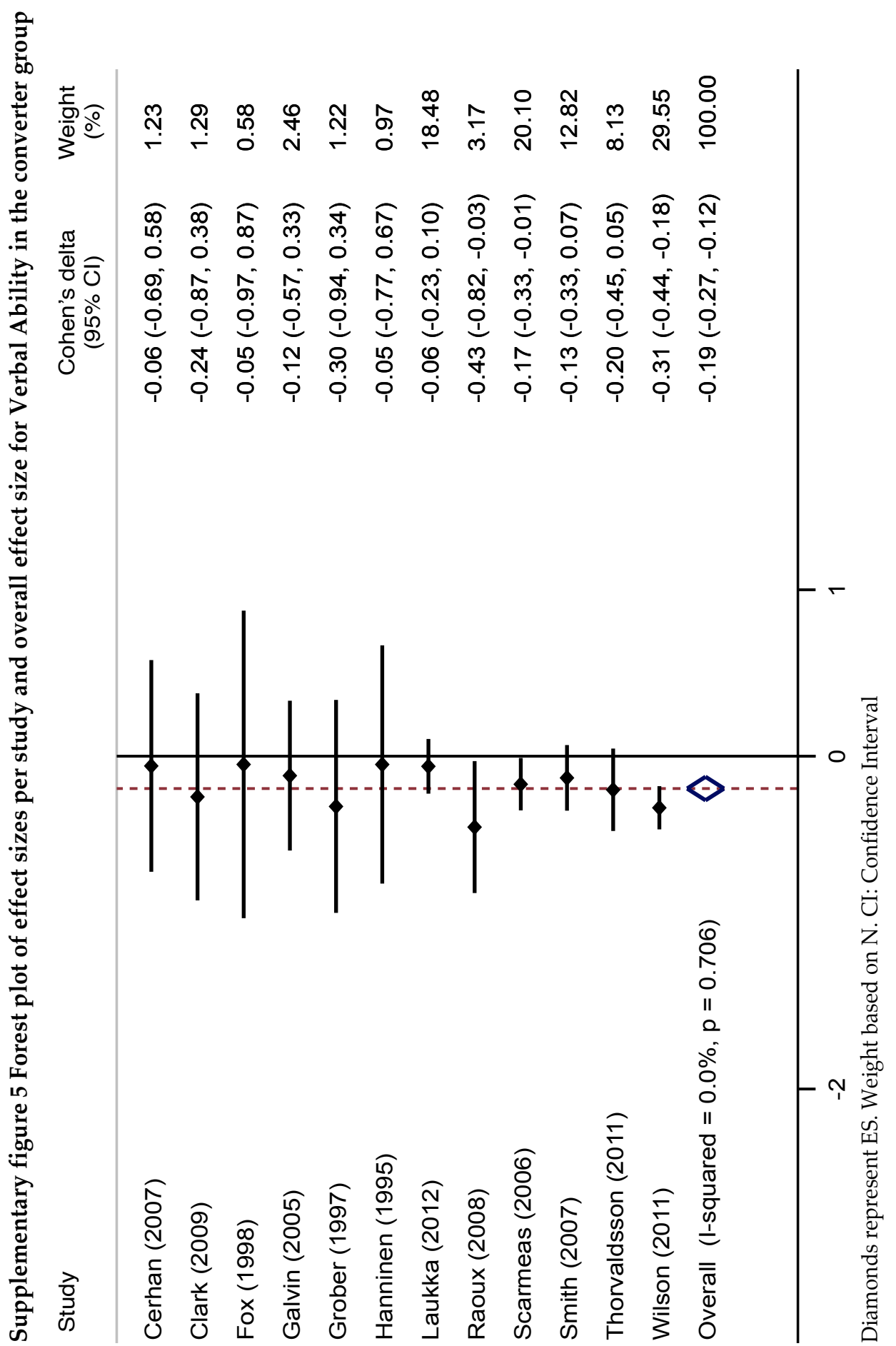




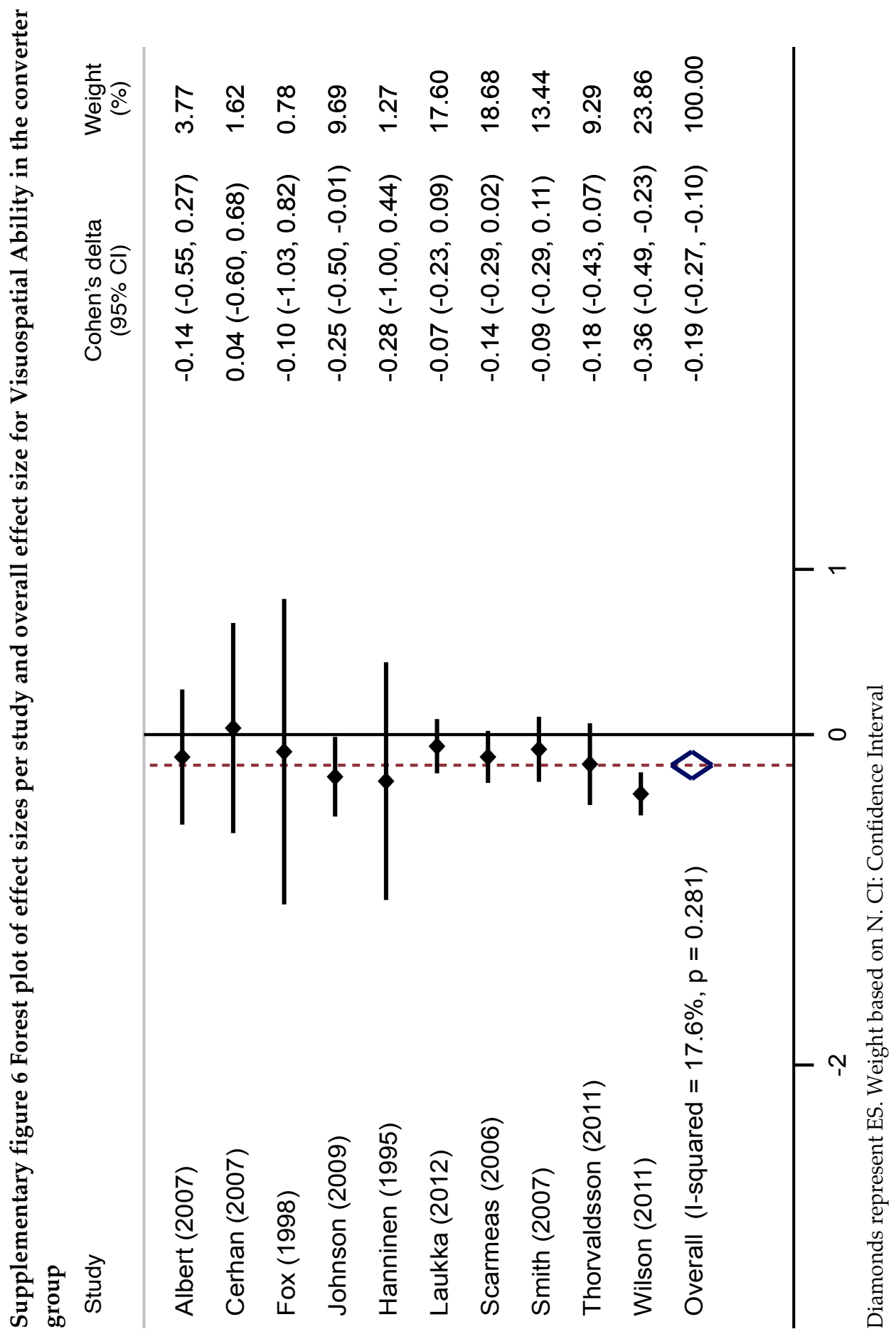




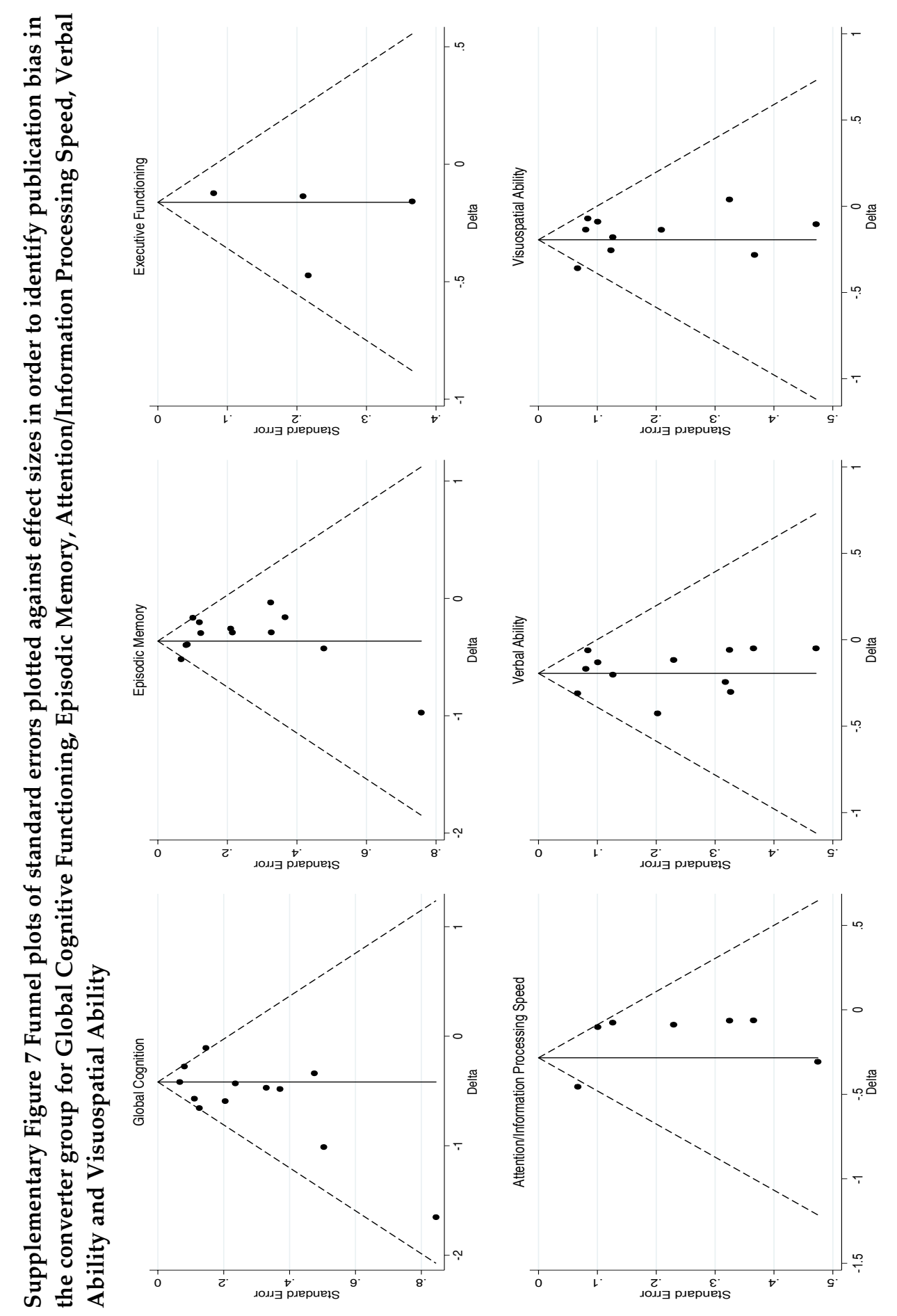




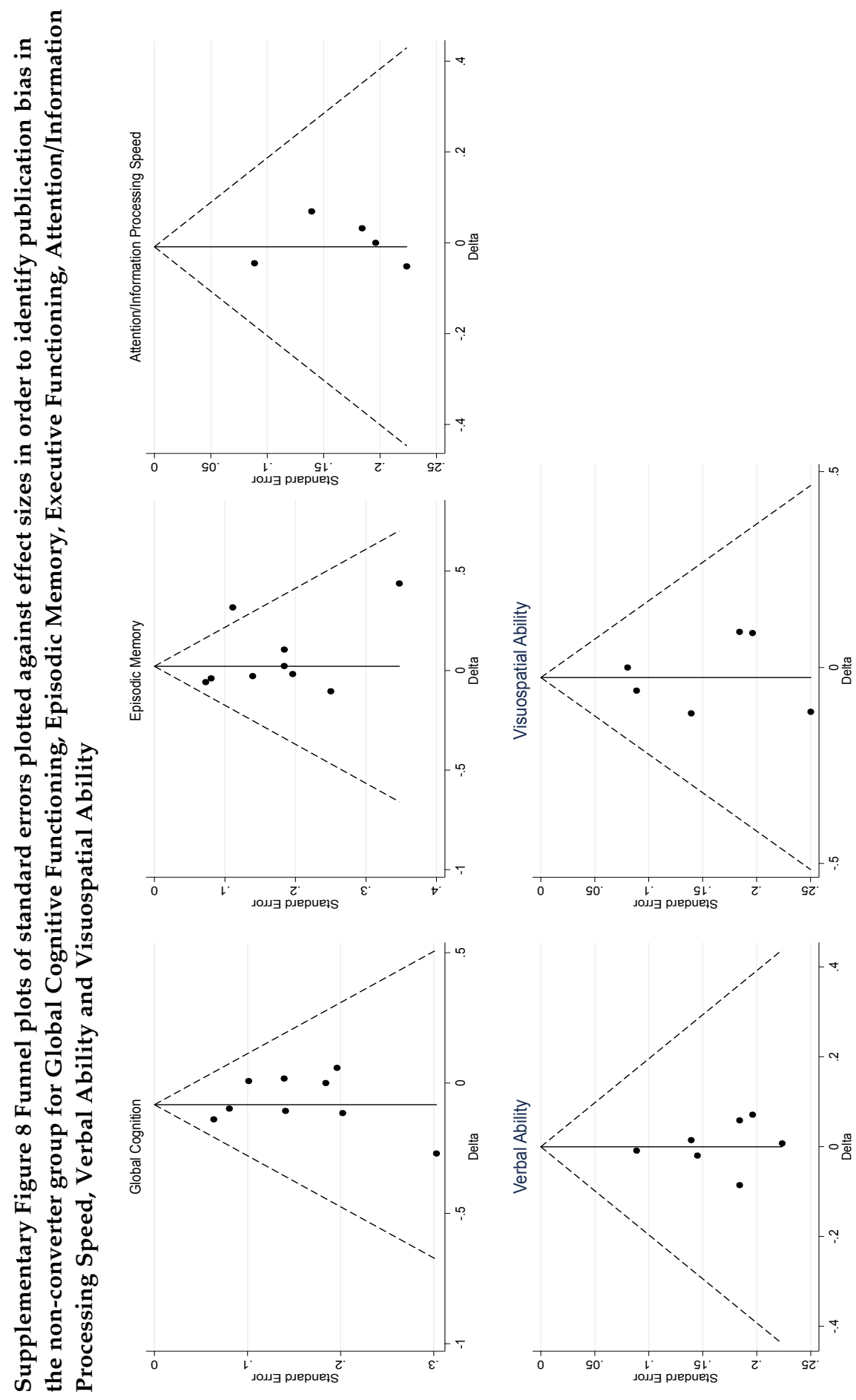




\section{SUPPLEMENTARY REFERENCES}

Bäckman, L., \& Forsell, Y. (1994). Episodic memory functioning in a community-based sample of old adults with major depression: Utilization of cognitive support. Journal of Abnormal Psychology, 103, 361-370.

Benton, A. L. (1974). Revised Visual Retention Test: clinical and experimental applications. New York: Psychological Corporation.

Buschke, H. (1984). Cued recall in amnesia. Journal of Clinical Neuropsychology, 6, 433-440.

Buschke, H., \& Fuld, P. A. (1974). Evaluating storage, retention and retrieval in disordered memory and learning. Neurology, 24, 1019-1025.

Derix, M., Hofstede, A., Teunisse, S., Hijdra, A., Wens, A. B., Walstra, G. J. M., et al. (1992). CAMDEX-N: de nederlandse versie van de cambridge examination of mental disorders of the elderly [CAMDEX-N: the Dutch version of the cambridge examination for mental disorders of the elderly]. Lisse: Zwets \& Zeitlinger.

Dureman, I., Kebbon, L., \& Österberg, E. (1971). Manual till DS-batteriet [Manual for the DSbattery]. Stockholm: Psykologiförlaget AB.

Grober, E., \& Buschke, H. (1987). Genuine memory deficits in dementia. Developmental Neuropsychology, 3, 13-36.

Isaacs, B., \& Kennie, A. T. (1973). The Set test as an aid to the detection of dementia in old people. British Journal of Psychiatry, 123, 467-470.

Koivisto, K., Helkala, E. L., Reinikainen, K. J., Hanninen, T., Mykkanen, L., Laakso, M., et al. (1992). Population-based dementia screening program in Kuopio: the effect of education, age, and sex on brief neuropsychological tests. Journal of Geriatric Psychiatry and Neurology, 5, 162-171.

Lezak, M. D., Howieson, D. B., \& Loring, D. W. (2004). Neuropsychological Assessment 4th Edition. Oxford, UK: Oxford University Press.

Mack, W. J., Freed, D. M., Williams, B. W., \& Henderson, V. W. (1992). Boston naming test: shortened versions for use in Alzheimer's disease. Journal of Gerontology, 47, 154158.

McKenna, P., \& Warrington, E. K. (1983). The Graded Naming Test. Windsor (UK): NFERNelson.

Reitan, R. (1958). Validity of the Trail Making Test as an indicator of organic brain damage. Perceptual and Motor Skills, 8, 271-276.

Rey, A. (1964). L'examen clinique en psychologie [The clinical examination in psychology]. Paris: Presses Universitaires de France.

Rosen, W. G., Mohs, R. C., \& Davis, K. L. (1984). A new rating scale for Alzheimer's disease. American Journal of Psychiatry, 141, 1356-1364.

Roth, M., Tym, E., Mountjoy, C. Q., Huppert, F. A., Hendrie, H., \& Goddard, R. (1986). CAMDEX. A standardised instrument for the diagnosis of mental disorder in the elderly with special reference to the early detection of dementia. British Journal of Psychiatry, 149, 698-709.

Russell, E. W. (1975). A mutiple scoring method for the assessment of complex memory functions. Journal of Consulting and Clinical Psychology, 43, 800-809.

Warrington, E. K. (1984). Recognition Memory Test Manual. Windsor (UK): NFER-Nelson.

Warrington, E. K., \& James, M. (1991). The Visual Object and Space Perception Battery. Bury St Edmunds (UK): Thames Valley Test Co. 
Wechsler, D. (1945). A standardized memory scale for clinical use. Journal of Psychology, 19, 87-95.

Wechsler, D. (1975). Wechsler Memory Scale. New York: Psychological Corporation.

Wechsler, D. (1981). Manual for the Wechsler Adult Intelligence Scale-Revised. New York: The Psychological Corporation.

Willison, J. R., \& Warrington, E. K. (1992). Cognitive retardation in a patient with preservation of psychomotor speed. Behavioural Neurology, 5, 113-116. 



\section{CHAPTER 3}

THE TRAJECTORY OF COGNITIVE DECLINE IN THE PRE-DEMENTIA PHASE IN MEMORY CLINIC VISITORS:

FINDINGS FROM THE 4C-MCI STUDY

Renske Hamel, Sebastian Köhler, Nicole Sistermans, Ted Koene, Yolande Pijnenburg, Wiesje van der Flier, Philip Scheltens, Pauline Aalten, Frans Verhey, Pieter Jelle Visser, Inez Ramakers 


\section{ABSTRACT}

\section{Background}

We investigated the course of decline in multiple cognitive domains in nondemented subjects from a memory clinic setting, and compared pattern, onset and magnitude of decline between subjects who progressed to AD dementia at followup and subjects who did not progress.

\section{Methods}

In this retrospective cohort study 819 consecutive non-demented patients who visited the memory clinics in Maastricht or Amsterdam between 1987 and 2010 were followed until they became demented or for a maximum of ten years (range 0.5 -10). Differences in trajectories of episodic memory, executive functioning, verbal fluency, and information processing speed/attention between converters to AD dementia and subjects remaining non-demented were compared by means of random effects modeling.

\section{Results}

The cognitive performance of converters and non-converters could be differentiated already seven (episodic memory) to three (verbal fluency and executive functioning) years prior to dementia diagnosis. Converters declined in these three domains, while non-converters remained stable on episodic memory and executive functioning and showed modest decline in verbal fluency. There was no evidence of decline in information processing speed/attention in both groups.

\section{Conclusions}

Differences in cognitive performance between converters to AD dementia and subjects remaining non-demented can be established already seven years prior to diagnosis for episodic memory, with verbal fluency and executive functioning following several years later. So, in addition to early episodic memory decline, also decline in executive functions may flag incident dementia. In contrast, change in information processing speed/attention seems less informative. 


\section{INTRODUCTION}

The neurodegenerative changes underlying Alzheimer's disease (AD) start long before the disease becomes clinically manifest (Jack et al., 2010), gradually leading to subtle cognitive changes several years before the diagnosis of AD-type dementia can be made. This transitional stage between normal cognitive functioning and dementia is often referred to as Mild Cognitive Impairment (MCI) (Petersen et al., 1999).

Consistent with the observation that neuropathological changes start in brain circuits subserving memory formation and consolidation, many studies identified memory deficits as an early predictor of conversion to AD dementia (Albert et al., 2001, Silva et al., 2013, Tabert et al., 2006). Further, population-based studies also reported subtle deficits in non-memory domains in individuals with prodromal AD, such as insufficiencies in executive functioning (Albert et al., 2001, Rapp \& Reischies, 2005), verbal fluency (Fabrigoule et al., 1998, Laukka et al., 2004), attention (Linn et al., 1995, Nielsen et al., 1999), and global cognitive functioning (Backman \& Small, 1998, Fabrigoule et al., 1998). In addition, longitudinal studies comparing the rate of cognitive decline in those who later develop AD dementia and those who do not, indicate a sudden steep decline in episodic memory in converters in the prodromal AD phase (Johnson et al., 2009, Laukka et al., 2012). These and other studies also demonstrate that multiple cognitive functions, like verbal fluency and executive functioning show a steeper decline in AD converters compared to non-converters several years prior to dementia diagnosis (Amieva et al., 2005, Grober et al., 2008, Johnson et al., 2009, Laukka et al., 2012, Mungas et al., 2010, Thorvaldsson et al., 2011). Unfortunately, current outcomes are largely based on non-clinical samples from healthy volunteer populations, which are not directly comparable to the help-seeking memory clinic visitors who already experience some cognitive problems.

A better understanding of the pattern, magnitude and temporal sequence of these cognitive deficits in clinical populations is important to facilitate early diagnosis and increase insight into early pathological brain mechanisms.

Therefore, the aim of the present study was to compare the pattern, onset and rate of cognitive decline between AD dementia converters and non-converters in a large sample of memory clinic visitors not demented at baseline. We hypothesized that a) differences in decline between groups can be established for all cognitive domains (episodic memory, information processing speed/attention, verbal fluency and executive functioning), yet converters show a pattern of most pronounced decline in memory and executive functioning, and b) that these differences become manifest many years before dementia diagnosis is made. 


\section{METHODS}

\section{Subjects}

This study is part of the Clinical Course of Cognition and Comorbidity in MCI (4CMCI) study, a longitudinal study on cognitive decline in initially non-demented memory clinic visitors. Participants for the present study were retrospectively selected from the cumulative clinical and research registration systems of the memory clinic at the Alzheimer Centre Limburg at Maastricht University Medical Centre (MUMC) and the memory clinic based Amsterdam Dementia Cohort from the Alzheimer Centre at the VU Medical Centre (VUmc) (van der Flier et al., 2014). Inclusion criteria were: age $\geq 55$ years, subjective or objective cognitive impairment, no dementia, Clinical Dementia Rating scale (CDR) score $\leq 0.5$ or Global Deterioration Scale (GDS) score $\leq 3$. Exclusion criteria were neurological diseases that could have caused cognitive impairment such as Parkinson's or Huntington's disease, acute stroke, Normal Pressure Hydrocephalus, Korsakoff's syndrome, a medical history of brain tumor or encephalitis. Participants having any other comorbidities, including cerebrovascular or psychiatric disorders were not excluded in this study. For the present study we selected patients who visited the memory clinics between 1987 and 2010 and had at least one follow-up assessment, yielding a sample size of $\mathrm{N}=819$. Both site contributed equally (Maastricht $n=393$; Amsterdam $n=426$ ). Maastricht patients tended to be younger and less educated.

\section{Assessment at baseline}

At baseline, all patients underwent a standardized clinical assessment, which included a detailed history of the patient, a psychiatric, neurologic and physical examination, appropriate laboratory tests, an extensive neuropsychological assessment (see below) and a magnetic resonance imaging (MRI) or a computerized tomography (CT) scan.

All neuropsychological test scores were converted to z-scores adjusted for age, sex and education, based on norms for the healthy population (Schmand et al., 2003, Van der Elst et al., 2005, 2006a, 2006b). Subjects with a z-score lower than -1.5 SD on any neuropsychological test were classified as having MCI, all other subjects were classified as having SCI. Participants referred with a psychiatric, neurologic or other medical disorder (not meeting exclusion criteria) that could have caused cognitive impairment were recorded as MCI or SCI with suspected underlying psychiatric comorbidity, suspected underlying neurologic comorbidity or suspected underlying other comorbidity respectively. All remaining patients were classified as MCI or SCI without relevant comorbidities. From the database we extracted data on age, gender, level of education and neuropsychological test scores. 


\section{Neuropsychological assessment}

Both centers used a standard test battery for diagnostic and research purposes. Episodic Memory was assessed by means of the Dutch adaptation of the 15-Word Verbal Learning Task (VLT) (Lezak et al., 2004, Van der Elst et al., 2005). The score at the delayed recall trial was used to measure episodic memory. Information processing speed/attention was measured using the average of the Stroop Color Word Test (SCWT) (Hammes, 1973) cards 1 and 2 (SCWT 1 - 2) and Trail Making Test (Lezak et al., 2004, Schmand et al., 2003) part A (TMT-A). An interference index from the SCWT, calculated as Card 3 - [(Card 1 + Card 2) / 2] (Van der Elst et al., 2006b), as well as TMT part B were used to measure executive functioning, more specifically two components of executive functioning: concept shifting and sensitivity to inference. For assessing verbal fluency, a one-minute animal fluency test was used (Luteijn \& Barelds, 2004).

\section{Follow-up assessment}

The follow-up assessment included a neurologic and medical examination and a neuropsychological assessment comparable to baseline. The diagnosis of dementia and $\mathrm{AD}$ dementia at follow-up was made by a neurologist or neuropsychiatrist according to the DSM-IV and NINCDS-ADRDA criteria (American Psychiatric Association, 1994, McKhann et al., 1984) after multidisciplinary consensus using all available information. Frontotemporal dementia (FTD) was diagnosed according to the Neary criteria (Neary et al., 1998). The diagnosis of vascular dementia was made according to the NINDS-AIREN criteria (Roman et al., 1993). Dementia with Lewy bodies (DLB) was diagnosed following the guideline of the international DLB consensus group (McKeith et al., 2005). Other rare forms of dementia (e.g. HIV-dementia complex, Creutzfeldt-Jakob disease etc.) were summarized under 'other dementia'. Non-demented subjects were classified as MCI or SCI conform classification procedures at baseline assessment.

For the present study we used information on dementia status at follow-up, date of dementia diagnosis and dementia type. Mean follow-up time was 2.7 years (median $=2.0$ ) with a range from 0.5 to 10.0 years. Throughout follow-up patients had on average three neuropsychological assessments ( median $=2$; range $=2-11$; total number $=2200)$. During this period $183(21.3 \%)$ incident dementia cases were established, of which $143(78.1 \%)$ subjects developed AD dementia. For the present study we excluded the 40 subjects who converted to other forms of dementia.

\section{Informed consent}

In the Netherlands, the use of anonymized routine data does not require ethical approval or written informed consent. In the Amsterdam Dementia Cohort all patients provided informed consent for the use of their routine clinical practice data for research purposes. 


\section{Statistical analyses}

Statistical analyses were performed using STATA version 12 for Mac OS X (StataCorp, Texas). Significance was set at $\mathrm{p}<0.05$ in two-sided tests. For neuropsychological test scores we used z-scores to allow comparison across domains. Baseline differences between groups were analyzed using $t$ tests for continuous variables and $\chi^{2}$ tests for categorical variables. Cognitive decline over time was assessed using random-effects (linear mixed) models, thereby accounting for the fact that repeated measurements are correlated within individuals. In addition, the use of mixed models makes the preprocessing of data by (multiple) imputation methods unnecessary, since the model handles missing data effectively by using all available_data at a given time point and by integrating missing values for cognition slopes with maximum likelihood.

Follow-up time was inverted and thus ranged from -10 years to zero, where zero (T0) is the time of diagnosis for incident dementia cases or last available assessment for non-converters. Thus, only converters' information from assessments prior to dementia diagnosis was included in order to restrict analyses to the pre-dementia phase. First, models with random intercepts were specified, where the random intercept is the difference between converters and nonconverters at T0. Random slopes were included if likelihood ratio testing (LRT) suggested that this gave better fit compared to the model with only a random intercept. To study differences in rate of decline over time between the groups $(1=$ AD dementia converters, $0=$ non-converters), a group-by-time interaction term was added. In case of statistically significant differences between groups in rate of decline (i.e. a significant group-by-time interaction), we computed model-based estimates for each one-year time-point in order to find the point of first-time deviation in cognitive performance between the two groups. The random-effects models were adjusted for age, sex, study centre and education (low, middle, high).

\section{RESULTS}

\section{Baseline differences}

Characteristics of the patients at study entry, according to dementia status at follow-up and for the total group, are listed in Table 1. Subjects who developed $\mathrm{AD}$ dementia were about 3.5 years older at their first visit to the memory clinic and had significantly lower scores on the VLT and verbal fluency compared to subjects who did not convert to AD dementia. The baseline diagnosis of the converter group was mainly MCI ( $\mathrm{n}=113 ; 79 \%)$, while baseline diagnosis in the nonconverters was more equally divided between MCI and SCI (MCI: $n=399 ; 59 \%$; SCI: $\mathrm{n}=277,41 \%$ ). 
Table 1 Characteristics of patients at first visit to the memory clinic

\begin{tabular}{|lccc|}
\hline \multicolumn{1}{c}{ Variable } & Overall & AD converters & Non-converters \\
\hline \hline$n$ & 819 & 143 & 676 \\
Age, y & $67.2(7.65)$ & $70.1(6.28)^{* *}$ & $66.6(7.77)$ \\
Education & $54.6 \%$ & $46.2 \%^{*}$ & $56.4 \%$ \\
$\%$ Low & & & \\
$\%$ Middle & $20.1 \%$ & $22.9 \%$ & $19.5 \%$ \\
$\%$ High & $43.5 \%$ & $48.6 \%$ & $42.4 \%$ \\
Baseline diagnosis, $\mathrm{n}(\%)$ & $36.4 \%$ & $28.5 \%$ & $38.1 \%$ \\
MCI & & & \\
SCI & $512(62.5)$ & $113(79.0)^{*}$ & $399(59.0)$ \\
VLT (delayed recall) & $307(37.5)$ & $30(21.0)^{*}$ & $277(41.0)$ \\
Fluency & $-1.1(1.36)$ & $-2.2(0.99)^{* *}$ & $-0.9(1.33)$ \\
TMT-A & $-0.6(0.97)$ & $-0.8(0.79)^{* *}$ & $-0.5(1.00)$ \\
TMT-B & $-0.3(1.26)$ & $-0.5(1.16)$ & $-0.2(1.28)$ \\
SCWT 1 - 2 & $0.1(1.24)$ & $-0.1(1.20)$ & $0.1(1.25)$ \\
SCWT interference & $-0.8(1.70)$ & $-0.7(1.25)$ & $-0.9(1.78)$ \\
Follow-up length, $\mathrm{y}$ & $-0.7(1.84)$ & $-0.9(1.84)$ & $-0.7(1.84)$ \\
Number of repeated & $2.7(2.16)$ & $2.2(1.53)^{* *}$ & $2.8(2.26)$ \\
measurement occasions, $\mathrm{n}(\%)$ & & & \\
2 & & & \\
3 & $482(58.9)$ & $93(65.0)$ & $389(57.5)$ \\
4 & $184(22.5)$ & $27(18.9)$ & $157(23.3)$ \\
5 or more & $113(13.8)$ & $16(11.2)$ & $97(14.4)$ \\
Da & $40(4.9)$ & $7(4.9)$ & $33(4.9)$ \\
\hline
\end{tabular}

Data are mean (SD), unless otherwise specified. All cognitive test scores are presented as z-scores. Group size is different for cognitive tests. VLT $=$ Verbal Learning Test; TMT-A = Trailmaking Test part-A; TMT-B = Trailmaking Test part-B; SCWT 1 - 2 = average of Stroop Color Word Test $1+2$; SCWT interference $=$ Stroop Color Word Test interference index.

${ }^{*} p<0.05$ compared with non-converters

${ }^{* *} p<0.01$ compared with non-converters

For the non-converters, the suspected underlying cause of the cognitive complaints was classified as follows: 91 subjects $(13.5 \%)$ were classified as "suspected underlying psychiatric comorbidity", 27 subjects $(4.0 \%)$ were classified as "suspected underlying neurological comorbidity" and 39 subjects $(5.8 \%)$ were classified as "suspected underlying other comorbidity". The remaining $519(76.8 \%)$ subjects had no relevant comorbidity. Of the subjects with suspected underlying psychiatric comorbidity only 11 patients $(10.8 \%)$ converted to AD dementia at follow-up, and of the subjects with suspected underlying neurologic comorbidity of the complaints only $2(6.9 \%)$ converted to AD dementia at follow-up. Further, for the groups with suspected underlying other comorbidity or no relevant comorbidity respectively $8(17 \%)$ and $122(19 \%)$ patients converted to AD 
dementia. More extensive information on baseline diagnosis and suspected underlying aetiology for the two groups can be found in Table 2.

Table 2 Groups at final assessment stratified by baseline diagnosis and suspected baseline aetiology

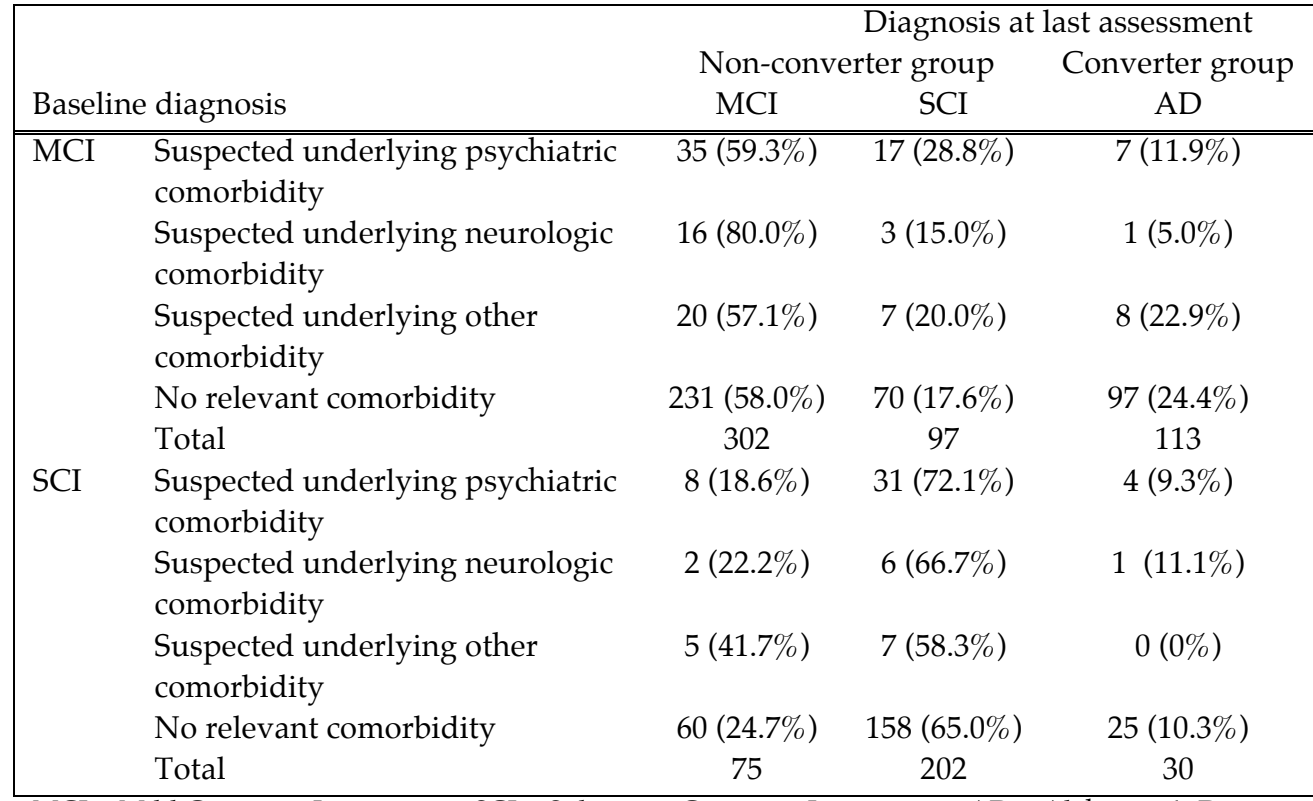

$\mathrm{MCI}=$ Mild Cognitive Impairment; SCI = Subjective Cognitive Impairment; AD = Alzheimer's Disease dementia.

Table 3 Mean annual rate of change per neuropsychological test for Alzheimer dementia (AD) converters and non-converters, and the corresponding values for a group-by-time interaction effect

\begin{tabular}{|c|c|c|c|c|c|c|}
\hline \multirow{2}{*}{$\begin{array}{c}\text { Neuropsychological } \\
\text { test }\end{array}$} & \multicolumn{2}{|c|}{ AD Converters } & \multicolumn{2}{|c|}{ Non-converters } & \multicolumn{2}{|c|}{ Interaction effect } \\
\hline & $\begin{array}{l}\text { Mean } \\
\text { change }\end{array}$ & $\mathrm{p}$-value & $\begin{array}{l}\text { Mean } \\
\text { change }\end{array}$ & p-value & $\chi^{2}$ & $\mathrm{p}$-value \\
\hline$\overline{\overline{\text { VLT }}}$ & -0.15 & $\overline{c<.01}$ & 0.01 & .56 & 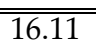 & $<<.01$ \\
\hline Fluency & -0.17 & $<.01$ & -0.10 & $<.01$ & 6.37 & .01 \\
\hline TMT-A & -0.03 & .39 & 0.02 & .08 & 1.08 & .30 \\
\hline TMT-B & -0.15 & $<.01$ & -0.01 & .59 & 17.30 & $<.01$ \\
\hline SCWT $1+2$ & -0.10 & .05 & -0.04 & $<.01$ & 2.01 & .16 \\
\hline SCWT interference & -0.25 & $<.01$ & -0.04 & .17 & 6.74 & .01 \\
\hline
\end{tabular}




\section{Rate and pattern of cognitive decline}

Random effects models compared the slope of cognitive decline between nonconverters and converters to AD dementia. A significant group-by-time interaction effect suggested that the mean annual rates of decline of the two groups differed significantly for the Verbal Learning Test, Trail Making Test-B, Stroop interference index and verbal fluency, but not for Trail Making Test-A and the averaged Stroop $1+2$ (see Table 3). AD converters declined significantly on most tests (e.g. Verbal Learning Test, Trail Making Test-B, Stroop interference index and verbal fluency), but showed no change over time on Trail Making Test-A and the averaged Stroop $1+2$ (see Table 3 ). In contrast, non-converters remained generally stable in all domains, except for a modest decline on verbal fluency and a marginal decline on the averaged Stroop $1+2$.

Next, we studied potential deviations from a linear trend over time by including the quadratic term for time in above analyses. A quadratic curvature best described the trajectory in verbal fluency (beta of time as a quadratic term $=-.01, \mathrm{p}$ $=.001$ ). For the other domains adding a quadratic term did not improve the model. The trajectories for the different cognitive domains were plotted using modelbased estimates and are shown in Figure 1.

\section{Onset of decline}

We then computed at which time point during the pre-dementia phase, significant differences in cognitive performance of AD converters and non-converters could be established for the first time looking backwards from the point of diagnosis. Segmenting follow-up time by one-year time bands and calculating model-based estimates per year, this distinction could be made already seven years prior to diagnosis for the Verbal Learning Test. For non-memory tests, the point of differentiation occurred several years later, three years before diagnosis for the Trail Making Test-B and verbal fluency and two years prior to diagnosis for the Stroop interference index. Before these time points, the cognitive performances of the two groups were not distinguishable, which is also indicated in Figure 1 by the curves (representing cognition slopes) showing overlapping 95\% confidence intervals (see fig. 1). Since the plotted curves are based on linear prediction models, for some tests (e.g. Stroop interference, Trail Making Test-B) index curves seem to start to differ between groups again, several years before the point of differentiation, but this is purely due to the linear prediction and does not represent the actual data (see fig. 1).

When we repeated our analyses using only data from patients who were followed for 3 years or more, results did not essentially change. Yet, for the TMT-B, the point of differentiation could be established even earlier in time (i.e. 6 years prior to AD dementia diagnosis). 
Figure 1 Average cognitive decline with 95\% CI for converters to Alzheimer dementia (AD, black diamonds) and non-converters (gray circles) per cognitive test. Time axis is inverted and shows years before end of study (i.e. date of dementia diagnosis for converters or last follow-up assessment for nonconverters)
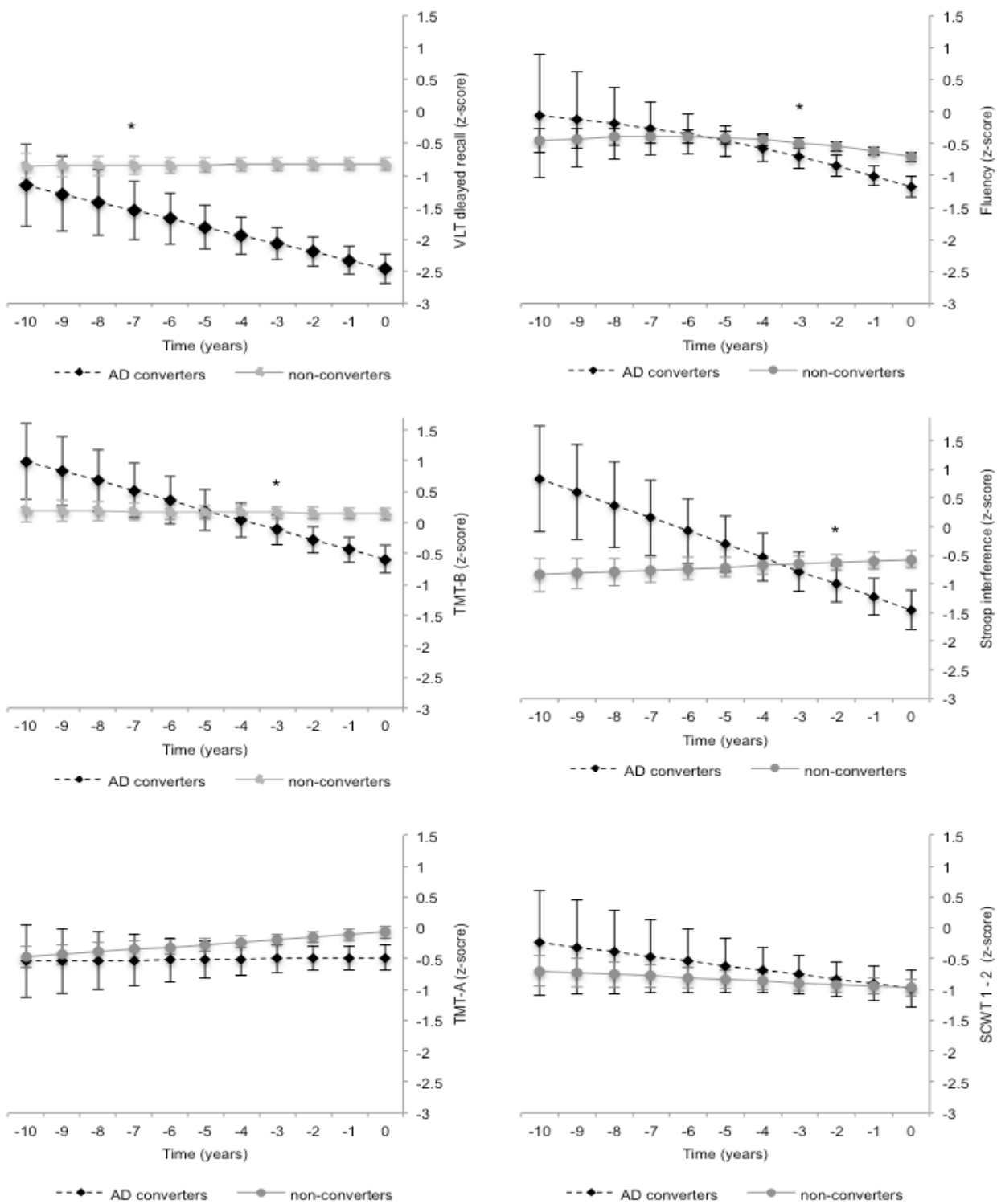

VLT = Verbal Learning Test; TMT-A = Trail Making Test part-A; TMT-B = Trail Making Test part-B; SCWT $1-2=$ average of Stroop Color Word Test $1+2$; SCWT interference $=$ Stroop Color Word Test interference index; ${ }^{*}=$ point of first differentiation between groups. 


\section{DISCUSSION}

To the best of our knowledge, the present study is the first large multicenter longitudinal study that explicitly aimed at describing the trajectories of various cognitive functions in converters to AD dementia and non-converters in a memory clinic setting. Our main finding is that differences in cognitive performance between converters to AD dementia and non-converters already exist seven (episodic memory) to three (executive functioning and verbal fluency) years prior to diagnosis. Furthermore, we found profound differences in cognitive trajectories between the two groups for these domains, with pre-demented subjects showing marked decline while non-converters remained generally stable. For information processing speed/attention both groups did not decline substantially and hence there was no difference between groups.

Our established differences in cognitive performance between converters and nonconverters several years before dementia diagnosis corroborate findings of population-based studies, although follow-up of these studies was generally shorter (1.5 to 3.6 years). As in our memory-clinic based study, the differences were found for the domains of episodic memory (Albert et al., 2001, Amieva et al., 2005, Chen et al., 2000), executive functioning (Albert et al., 2001, Chen et al., 2000, Hanninen et al., 1995) and verbal fluency (Chen et al., 2000, Clark et al., 2009, Raoux et al., 2008). Studies with longer follow-up reported differences in episodic memory, verbal fluency and abstract thinking (a part of executive functioning) already nine (Amieva et al., 2005) to five (only verbal fluency reported) (Clark et al., 2009) years prior to AD dementia diagnosis. This is roughly comparable to our established points of distinction, although differences in verbal fluency and abstract thinking in one study are reported even several years earlier than we found. Yet, when we repeated our analyses for a subgroup of our population, including only patients who were followed for three years or more, our point of differentiation for concept shifting (a part of executive functioning) proved to be six years prior to AD dementia diagnosis, which matches previous findings even better. The differences between our main results and the results of these previous studies are likely to be affected by study population, which consisted of healthy subjects from the general population, while we investigate subjects who presented with cognitive complaints at memory clinic and thus also our non-converters are likely to perform on a lower level than healthy population-based control subjects.

We observed differences between groups in the rate of decline, which was most profound for the domains of episodic memory and executive functioning, mirroring findings in non-clinical samples (Chen et al., 2001, Grober et al., 2008, Johnson et al., 2009, Mungas et al., 2010) and a clinical sample (van Harten et al., 
2013). Although one population-based study found differences only for decline in episodic memory but not in executive functioning (Albert et al., 2007), (although differences in executive functioning almost reached significance) and one negative study reported similar rates of decline for the two groups in episodic memory (Backman et al., 2001). However, it must be noted that this last study was restricted to decline from six to three years prior to diagnosis, which does not correspond to the timeframe used in most studies (i.e. immediately preceding diagnosis). Our results further correspond with the observation that the earliest pathologic changes in AD usually occur in the medial temporal lobe regions, which are known to be critical for episodic memory functioning (Ridha et al., 2006, Sluimer et al., 2009). Moreover, our established multi-domain decline in pre-demented subjects also match findings of spread pathology before AD diagnosis, indicating that multiple brains structures, like the parietal (Jacobs et al., 2011) and frontal cortex (Burgmans et al., 2009) are affected.

Our findings further indicated decline in verbal fluency for both groups, which is also reported by a population-based study (Clark et al., 2009). Moreover, significant decline on fluency measures prior to AD dementia diagnosis is reported by multiple population-based studies (Grober et al., 2008, Laukka et al., 2012, Raoux et al., 2008). Our established decline for non-converters might be due to an underlying ageing process, which is reported for verbal fluency by other studies (Auriacombe et al., 2001, Crossley et al., 1997).

For information processing speed/attention we did not find differences between groups. While our findings are supported by several previous population-based studies (Cerhan et al., 2007, Fox et al., 1998), others have reported significant differences between groups in this domain (Chen et al., 2000, Galvin et al., 2005). Differences in study design, study sample and definition of this cognitive domain might explain part of these inconsistencies. For instance the study by Galvin et al. (2005) followed subjects that converted to both AD and non-AD dementias, with the latter being more likely to exhibit attention/speed deficits early in the course of decline, e.g. due to evolving vascular cognitive impairment (O'Brien et al., 2003). Another population-based study reported significant decline for speed/attention measures in both converters and non-converters (Wilson et al., 2011). This seems to be in accordance with our (borderline) significant decline on the SCWT $1-2$ for both groups. Since the decline is found for both groups, at least part of it might be due to a common underlying ageing process. Indeed attention seems to be a poor discriminator between converters to AD dementia and non-converters (Albert et al., 2001) Interestingly, when we repeated our analyses including data that were gathered after the dementia diagnosis was made, information processing speed/attention did show significant cognitive decline for the converters (results 
not shown). This implies that decline in attention is still subtle in the pre-dementia phase and starts widening as underlying pathology progresses. More importantly, since pathological decline in information processing speed/attention is absent in the pre-dementia phase of $\mathrm{AD}$, the determined decline in executive functioning can be considered as a pure executive problem, because no underlying attention or speed problems are found.

In the present study, non-converters remained stable in general. The absence of cognitive decline in subjects remaining cognitively healthy is well established in other studies (Chen et al., 2001, Galvin et al., 2005, Rubin et al., 1998, Wilson et al., 1999). The absence of decline over time in this ageing population might be due to learning and habituation effects, which are well documented in healthy elderly populations (Ferrer et al., 2004, Machulda et al., 2013, Mitrushina \& Satz, 1991). An alternative explanation for the absence of decline in non-converters might be that subjects experiencing subjective cognitive complaints feel reassured after their visit to the memory clinic. The relieve of feelings of stress, anxiety or worrying could lead to improvement in their performance over time, since it is known that feelings of depression and anxiety are associated with poorer cognitive performance (Bunce et al., 2012).

Our findings might have implications for designing optimal neuropsychological test batteries aiming at detecting dementia at an early stage. Episodic memory and executive functioning showed the largest differences in decline between groups, and hence the trajectories on these measures might be the most indicative of future dementia. The stated decline in executive functioning, urges the need to focus not solely on episodic memory tests in the current neuropsychological assessment, but give equal importance to executive functioning measures.

The present study has its own strengths and limitations. Major strengths of this study include the large sample size and a relatively long follow-up period of up to ten years. This allowed for the inclusion of a considerable number of dementia converters with several assessment points, leading to stable estimates in wellpowered random-effect analyses. Furthermore, we tried to maximize generalizability by a) using data that were not locally restricted to a single center, and b) applying broad inclusion criteria in which most comorbidities were included. In addition, the statistical analyses made maximal use of all available data from the repeated measures design. However, the use of routine clinical data might have impact on data quality and lead to missing observations on several relevant neuropsychological tests. Though, a considerable number of patients also participate in ongoing research, in which the standard assessment protocol contains all cognitive tests specified here. Hence, most patients had full 
information on these measures. Also, some neuropsychological domains were not routinely assessed, like visuospatial functions. However, these functions are often regarded as less discriminative between future $\mathrm{AD}$ converters and non-converters (Albert et al., 2001, Rubin et al., 1998). Next, some non-converters might have been misclassified at their latest follow-up assessment because they will convert to dementia in the future, thereby diluting the effect. However, when we compare our conversion rate ( $21.3 \%$ over a mean period of 2.7 years) with the established conversion estimates in a systematic review (6.5\% / year) (Mitchell and ShiriFeshki, 2009) our ratio corresponds to the established estimates. In addition, it should be noted that conversion rates are known to diminish over time, with cumulative numbers averaging $22.9 \%$ in studies with long-term follow-up. Further, some non-converters did not return for further follow-up assessment, leading to selection bias. Unfortunately, we do not have information about specific reasons of attrition due to the naturalistic setting of this cohort. However, again, this selection bias most likely would have led to an underestimation of the differences between groups, as non-converters with intact cognition might be inclined to get lost to follow-up in this clinical setting.

In conclusion, the present study shows that differences in cognitive performance between converters to $\mathrm{AD}$ dementia and non-converters can be established already seven years prior to diagnosis for episodic memory, with verbal fluency and executive functioning following several years later. Additionally, we found profound differences between the two groups in the cognitive trajectories of these domains, however not for information processing speed/attention. Next to accelerated decline in episodic memory, decline in executive functions may flag future dementia converters and should be given equal weight as memory decline in the diagnostic process. 


\section{REFERENCES}

Albert, M., Blacker, D., Moss, M.B., Tanzi, R., \& McArdle, J.J. (2007). Longitudinal change in cognitive performance among individuals with mild cognitive impairment. Neuropsychology, 21, 158-169.

Albert, M.S., Moss, M.B., Tanzi, R., \& Jones, K. (2001). Preclinical prediction of AD using neuropsychological tests. Journal of the International Neuropsychological Society, 7, 631-639.

Amieva, H., Jacqmin-Gadda, H., Orgogozo, J.M., Le Carret, N., Helmer, C., Letenneur, L., Barberger-Gateau, P., Fabrigoule, C., \& Dartigues, J.F. (2005). The 9 year cognitive decline before dementia of the Alzheimer type: a prospective population-based study. Brain, 128, 1093-1101.

American Psychiatric Association (1994). Diagnostic and Statistical Manual of Mental Disorders, fourth edition. Washington DC: American Psychiatric Association.

Auriacombe, S., Fabrigoule, C., Lafont, S., Jacqmin-Gadda, H., \& Dartigues, J.F. (2001). Letter and Cateogry Fluency in Normal Elderly Participants: a Population-Based Study. Aging, Neuropsychology and Cognition, 8, 98-108.

Backman, L., \& Small, B.J. (1998). Influences of cognitive support on episodic remembering: tracing the process of loss from normal aging to Alzheimer's disease. Psychology and Aging, 13, 267-276.

Blessed, G., Tomlinson, B.E., \& Roth, M. (1968). The association between quantitative measures of dementia and of senile change in the cerebral grey matter of elderly subjects. British Journal of Psychiatry, 114, 797-811.

Bruscoli, M., \& Lovestone, S. (2004). Is MCI really just early dementia? A systematic review of conversion studies. International Psychogeriatrics, 16, 129-140.

Bunce, D., Batterham, P.J., Mackinnon, A.J., \& Christensen, H. (2012). Depression, anxiety and cognition in community-dwelling adults aged 70 years and over. Journal of Psychiatric Research, 46, 1662-1666.

Burgmans, S., van Boxtel, M.P., Smeets, F., Vuurman, E.F., Gronenschild, E.H., Verhey, F.R., Uylings, H.B., \& Jolles, J. (2009). Prefrontal cortex atrophy predicts dementia over a six-year period. Neurobiology of Aging, 30, 1413-1419.

Cerhan, J.H., Ivnik, R.J., Smith, G.E., Machulda, M.M., Boeve, B.F., Knopman, D.S., Petersen, R.C., \& Tangalos, E.G. (2007). Alzheimer's disease patients' cognitive status and course years prior to symptom recognition. Aging, Neuropsychology, and Cognition: A Journal on Normal and Dysfunctional Development, 14, 227-235.

Chen, P., Ratcliff, G., Belle, S.H., Cauley, J.A., DeKosky, S.T., \& Ganguli, M. (2000). Cognitive tests that best discriminate between presymptomatic $\mathrm{AD}$ and those who remain nondemented. Neurology, 55, 1847-1853.

Chen, P., Ratcliff, G., Belle, S.H., Cauley, J.A., DeKosky, S.T., \& Ganguli, M. (2001). Patterns of cognitive decline in presymptomatic Alzheimer disease: a prospective community study. Archives of General Psychiatry, 58, 853-858.

Clark, L.J., Gatz, M., Zheng, L., Chen, Y.L., McCleary, C., \& Mack, W.J. (2009). Longitudinal verbal fluency in normal aging, preclinical, and prevalent Alzheimer's disease. American Journal of Alzheimer's Disease and Other Dementias, 24, 461-468. 
Crossley, M., D'Arcy, C., \& Rawson, N.S. (1997). Letter and category fluency in communitydwelling Canadian seniors: a comparison of normal participants to those with dementia of the Alzheimer or vascular type. Journal of Clinical and Experimental Neuropsychology, 19, 52-62.

Fabrigoule, C., Rouch, I., Taberly, A., Letenneur, L., Commenges, D., Mazaux, J.M., Orgogozo, J.M., \& Dartigues, J.F. (1998). Cognitive process in preclinical phase of dementia. Brain, 121, 135-141.

Ferrer, E., Salthouse, T.A., Stewart, W.F., \& Schwartz, B.S. (2004). Modeling age and retest processes in longitudinal studies of cognitive abilities. Psychology and Aging, 19, 243-259.

Fox, N.C., Warrington, E.K., Seiffer, A.L., Agnew, S.K., \& Rossor, M.N. (1998). Presymptomatic cognitive deficits in individuals at risk of familial Alzheimer's disease. A longitudinal prospective study. Brain, 121, 1631-1639.

Galvin, J.E., Powlishta, K.K., Wilkins, K., McKeel, D.W., Jr., Xiong, C., Grant, E., Storandt, M., \& Morris, J.C. (2005). Predictors of preclinical Alzheimer disease and dementia: a clinicopathologic study. Archives of Neurology, 62, 758-765.

Gelinas, I., Gauthier, L., McIntyre, M., \& Gauthier, S. (1999). Development of a functional measure for persons with Alzheimer's disease: the disability assessment for dementia. American Journal of Occupational Therapy, 53, 471-481.

Grober, E., Hall, C.B., Lipton, R.B., Zonderman, A.B., Resnick, S.M., \& Kawas, C. (2008). Memory impairment, executive dysfunction, and intellectual decline in preclinical Alzheimer's disease. Journal of the International Neuropsychological Society, 14, 266278.

Hammes, J. (1973). De Stroop Kleur-Woord Test: Handleiding [The Stroop Color-Word Test: Manual]. Amsterdam: Swets \& Zeitlinger.

Hanninen, T., Hallikainen, M., Koivisto, K., Helkala, E.L., Reinikainen, K.J., Soininen, H., Mykkanen, L., Laakso, M., Pyorala, K., \& Riekkinen, P.J., Sr. (1995). A follow-up study of age-associated memory impairment: neuropsychological predictors of dementia. Journal of the American Geriatrics Society, 43, 1007-1015.

Jack, C.R., Jr., Knopman, D.S., Jagust, W.J., Shaw, L.M., Aisen, P.S., Weiner, M.W., Petersen, R.C., \& Trojanowski, J.Q. (2010). Hypothetical model of dynamic biomarkers of the Alzheimer's pathological cascade. Lancet Neurology, 9, 119-128.

Jacobs, H.I., Van Boxtel, M.P., Uylings, H.B., Gronenschild, E.H., Verhey, F.R., \& Jolles, J. (2011). Atrophy of the parietal lobe in preclinical dementia. Brain and Cognition, 75, 154-163.

Johnson, D.K., Storandt, M., Morris, J.C., \& Galvin, J.E. (2009). Longitudinal study of the transition from healthy aging to Alzheimer disease. Archives of Neurology, 66, 12541259.

Laukka, E.J., Jones, S., Small, B.J., Fratiglioni, L., \& Backman, L. (2004). Similar patterns of cognitive deficits in the preclinical phases of vascular dementia and Alzheimer's disease. Journal of the International Neuropsychological Society, 10, 382-391.

Laukka, E.J., Macdonald, S.W., Fratiglioni, L., \& Backman, L. (2012). Preclinical cognitive trajectories differ for Alzheimer's disease and vascular dementia. Journal of the International Neuropsychological Society, 18, 191-199.

Lezak, M.D., Howieson, D.B., \& Loring, D.W. (2004). Neuropsychological Assessment, 4th Edition (4th Edition ed.). Oxford, UK: Oxford University Press. 
Linn, R.T., Wolf, P.A., Bachman, D.L., Knoefel, J.E., Cobb, J.L., Belanger, A.J., Kaplan, E.F., \& D'Agostino, R.B. (1995). The 'preclinical phase' of probable Alzheimer's disease. A 13-year prospective study of the Framingham cohort. Archives of Neurology, 52, 485490.

Luteijn, F., \& Barelds, D.P.H. (2004). Groninger Intelligentie Test 2 Handleiding [Groninger Intelligence Test 2 Manual]. Amsterdam: Harcourt Assessment BV.

Machulda, M.M., Pankratz, V.S., Christianson, T.J., Ivnik, R.J., Mielke, M.M., Roberts, R.O., Knopman, D.S., Boeve, B.F., \& Petersen, R.C. (2013). Practice effects and longitudinal cognitive change in normal aging vs. incident mild cognitive impairment and dementia in the Mayo Clinic Study of Aging. The Clinical Neuropsychologist, 27, 1247-1264.

McKeith, I.G., Dickson, D.W., Lowe, J., Emre, M., O'Brien, J.T., Feldman, H., Cummings, J., Duda, J.E., Lippa, C., Perry, E.K., Aarsland, D., Arai, H., Ballard, C.G., Boeve, B., Burn, D.J., Costa, D., Del Ser, T., Dubois, B., Galasko, D., Gauthier, S., Goetz, C.G., Gomez-Tortosa, E., Halliday, G., Hansen, L.A., Hardy, J., Iwatsubo, T., Kalaria, R.N., Kaufer, D., Kenny, R.A., Korczyn, A., Kosaka, K., Lee, V.M., Lees, A., Litvan, I., Londos, E., Lopez, O.L., Minoshima, S., Mizuno, Y., Molina, J.A., MukaetovaLadinska, E.B., Pasquier, F., Perry, R.H., Schulz, J.B., Trojanowski, J.Q., \& Yamada, M. (2005). Diagnosis and management of dementia with Lewy bodies: third report of the DLB Consortium. Neurology, 65, 1863-1872.

McKhann, G., Drachman, D., Folstein, M., Katzman, R., Price, D., \& Stadlan, E.M. (1984). Clinical diagnosis of Alzheimer's disease: report of the NINCDS-ADRDA Work Group under the auspices of Department of Health and Human Services Task Force on Alzheimer's Disease. Neurology, 34, 939-944.

Mitchell, A. J. \& Shiri-Feshki, M. (2009). Rate of progression of mild cognitive impairment to dementia--meta-analysis of 41 robust inception cohort studies. Acta Psychiatrica Scandinavica, 119, 252-65.

Mitrushina, M., \& Satz, P. (1991). Effect of repeated administration of a neuropsychological battery in the elderly. Journal of Clinical Psychology, 47, 790-801.

Mungas, D., Beckett, L., Harvey, D., Farias, S.T., Reed, B., Carmichael, O., Olichney, J., Miller, J., \& DeCarli, C. (2010). Heterogeneity of cognitive trajectories in diverse older persons. Psychology and Aging, 25, 606-619.

Neary, D., Snowden, J.S., Gustafson, L., Passant, U., Stuss, D., Black, S., Freedman, M., Kertesz, A., Robert, P.H., Albert, M., Boone, K., Miller, B.L., Cummings, J., \& Benson, D.F. (1998). Frontotemporal lobar degeneration: a consensus on clinical diagnostic criteria. Neurology, 51, 1546-1554.

Nielsen, H., Lolk, A., Andersen, K., Andersen, J., \& Kragh-Sorensen, P. (1999). Characteristics of elderly who develop Alzheimer's disease during the next two years-a neuropsychological study using CAMCOG. The Odense Study. International Journal of Geriatric Psychiatry, 14, 957-963.

O'Brien, J.T., Erkinjuntti, T., Reisberg, B., Roman, G., Sawada, T., Pantoni, L., Bowler, J.V., Ballard, C., DeCarli, C., Gorelick, P.B., Rockwood, K., Burns, A., Gauthier, S., \& DeKosky, S.T. (2003). Vascular cognitive impairment. Lancet Neurology, 2, 89-98.

Petersen, R.C. (2004). Mild cognitive impairment as a diagnostic entity. Journal of Internal Medicine, 256, 183-194. 
Petersen, R.C., Smith, G.E., Waring, S.C., Ivnik, R.J., Tangalos, E.G., \& Kokmen, E. (1999). Mild cognitive impairment: clinical characterization and outcome. Archives of Neurology, 56, 303-308.

Raoux, N., Amieva, H., Le Goff, M., Auriacombe, S., Carcaillon, L., Letenneur, L., \& Dartigues, J.F. (2008). Clustering and switching processes in semantic verbal fluency in the course of Alzheimer's disease subjects: results from the PAQUID longitudinal study. Cortex, 44, 1188-1196.

Rapp, M.A., \& Reischies, F.M. (2005). Attention and executive control predict Alzheimer disease in late life: results from the Berlin Aging Study (BASE). American Journal of Geriatric Psychiatry, 13, 134-141.

Ridha, B.H., Barnes, J., Bartlett, J.W., Godbolt, A., Pepple, T., Rossor, M.N., \& Fox, N.C. (2006). Tracking atrophy progression in familial Alzheimer's disease: a serial MRI study. Lancet Neurology, 5, 828-834.

Roman, G.C., Tatemichi, T.K., Erkinjuntti, T., Cummings, J.L., Masdeu, J.C., Garcia, J.H., Amaducci, L., Orgogozo, J.M., Brun, A., Hofman, A., \& et al. (1993). Vascular dementia: diagnostic criteria for research studies. Report of the NINDS-AIREN International Workshop. Neurology, 43, 250-260.

Rubin, E.H., Storandt, M., Miller, J.P., Kinscherf, D.A., Grant, E.A., Morris, J.C., \& Berg, L. (1998). A prospective study of cognitive function and onset of dementia in cognitively healthy elders. Archives of Neurology, 55, 395-401.

Schmand, B., Houx, P., \& de Koning, I. (2003). Normen voor Stroop kleur-woord tests, Trail Making test en Story Recall van de Rivermead Behavioural Memory Test. [Norms for Stroop color-word tests, Trail Making Test and Story Recall of the Rivermead Behavioural Memory Test]. Amsterdam: Nederlands Instituut van Psychologen, Sectie Neuropsychologie.

Silva, D., Guerreiro, M., Santana, I., Rodrigues, A., Cardoso, S., Maroco, J., \& de Mendonca, A. (2013). Prediction of long-term (5 years) conversion to dementia using neuropsychological tests in a memory clinic setting. Journal of Alzheimer's Disease, 34, 681-689.

Sluimer, J.D., van der Flier, W.M., Karas, G.B., van Schijndel, R., Barnes, J., Boyes, R.G., Cover, K.S., Olabarriaga, S.D., Fox, N.C., Scheltens, P., Vrenken, H., \& Barkhof, F. (2009). Accelerating regional atrophy rates in the progression from normal aging to Alzheimer's disease. European Radiology, 19, 2826-2833.

Tabert, M.H., Manly, J.J., Liu, X., Pelton, G.H., Rosenblum, S., Jacobs, M., Zamora, D., Goodkind, M., Bell, K., Stern, Y., \& Devanand, D.P. (2006). Neuropsychological prediction of conversion to Alzheimer disease in patients with mild cognitive impairment. Archives of General Psychiatry, 63, 916-924.

Thorvaldsson, V., Macdonald, S.W., Fratiglioni, L., Winblad, B., Kivipelto, M., Laukka, E.J., Skoog, I., Sacuiu, S., Guo, X., Ostling, S., Borjesson-Hanson, A., Gustafson, D., Johansson, B., \& Backman, L. (2011). Onset and rate of cognitive change before dementia diagnosis: findings from two Swedish population-based longitudinal studies. Journal of the International Neuropsychological Society, 17, 154-162.

Van der Elst, W., van Boxtel, M.P., van Breukelen, G.J., \& Jolles, J. (2005). Rey's verbal learning test: normative data for 1855 healthy participants aged 24-81 years and the influence of age, sex, education, and mode of presentation. Journal of the International Neuropsychological Society, 11, 290-302. 
Van der Elst, W., Van Boxtel, M.P., Van Breukelen, G.J., \& Jolles, J. (2006a). Normative data for the Animal, Profession and Letter M Naming verbal fluency tests for Dutch speaking participants and the effects of age, education, and sex. Journal of the International Neuropsychological Society, 12, 80-89.

Van der Elst, W., Van Boxtel, M.P., Van Breukelen, G.J., \& Jolles, J. (2006b). The Stroop colorword test: influence of age, sex, and education; and normative data for a large sample across the adult age range. Assessment, 13, 62-79.

van der Flier, W.M., Pijnenburg, Y.A., Prins, N., Lemstra, A.W., Bouwman, F.H., Teunissen, C.E., van Berckel, B.N., Stam, C.J., Barkhof, F., Visser, P.J., van Egmond, E., \& Scheltens, P. (2014). Optimizing patient care and research: the amsterdam dementia cohort. Journal of Alzheimer's Disease, 41, 313-327.

van Harten, A.C., Smits, L.L., Teunissen, C.E., Visser, P.J., Koene, T., Blankenstein, M.A., Scheltens, P., \& van der Flier, W.M. (2013). Preclinical AD predicts decline in memory and executive functions in subjective complaints. Neurology, 81, 1409-1416.

Wilson, R.S., Beckett, L.A., Bennett, D.A., Albert, M.S., \& Evans, D.A. (1999). Change in cognitive function in older persons from a community population: relation to age and Alzheimer disease. Archives of Neurology, 56, 1274-1279.

Wilson, R.S., Leurgans, S.E., Boyle, P.A., \& Bennett, D.A. (2011). Cognitive decline in prodromal Alzheimer disease and mild cognitive impairment. Archives of Neurology, 68, 351-356. 



\section{CHAPTER 4}

\section{PROGRESSION TO DEMENTIA IN MEMORY CLINIC PATIENTS WITHOUT DEMENTIA: A LATENT PROFILE ANALYSIS}

Sebastian Köhler, Renske Hamel, Nicole Sistermans, Ted Koene, Yolande A.L. Pijnenburg, Wiesje M. van der Flier, Philip Scheltens, Pieter Jelle Visser, Pauline Aalten, Frans R.J. Verhey, Inez Ramakers

Neurology 2013; 81(15), 1342-1349 


\section{ABSTRACT}

\section{Objective}

To identify the existence of discrete cognitive subtypes among memory clinic patients without dementia and test their prognostic values.

\section{Methods}

In a retrospective cohort study of 635 patients without dementia visiting the Alzheimer centers in Maastricht or Amsterdam, latent profile analysis identified cognitive subtypes based on immediate and delayed memory recall, delayed recognition, information-processing speed, attention, verbal fluency, and executive functions. Time to dementia was tested in weighted Cox proportional hazard models adjusted for confounders.

\section{Results}

Five latent classes represented participants with high-normal cognition (15\%), lownormal cognition (37\%), primary memory impairment in recall (MI) (36\%), memory impairment in recall and recognition (MI+) $(5 \%)$, and primary nonmemory impairment (NMI) (6\%). Compared with low-normal cognition, participants with NMI had the highest risk of dementia (hazard ratio [HR] 5 5.94, 95\% confidence interval [CI] 5 3.46-10.18) followed by MI (HR 5 3.05, 95\% CI 5 2.09-4.46) and MI+ (HR 5 3.26, 95\% CI 5 1.72-6.17), while participants with highnormal cognition had the lowest risk (HR 5 0.24, 95\% CI 5 0.07-0.80). Subtypes further showed differential relationships with dementia types, with MI and MI+ most often converting to Alzheimer-type dementia and NMI to other forms of dementia.

\section{Conclusions}

Cognitive subtypes can be empirically identified in otherwise heterogeneous samples of memory clinic patients and largely confirm current strategies to distinguish between amnestic and nonamnestic impairment. Studying more homogeneous cognitive subtypes may improve understanding of disease mechanisms and outcomes. 


\section{INTRODUCTION}

A major pursuit in current dementia research is finding early diagnostic markers flagging individuals at risk of dementia. Several cognitive high-risk groups have been defined by imposing different cut-offs on neuropsychological tests such as in age-associated cognitive decline (AACD), cognitive impairment no dementia (CIND) or mild cognitive impairment (MCI) (Gauthier et al., 2006). These high-risk groups have higher conversion rates to dementia than cognitively healthy individuals (Visser et al., 2006). For MCI, several subtypes have been proposed to account for differences in clinical presentation, with the most common distinction being made on two axes: single-domain versus multi-domain impairment, and amnestic versus non-amnestic impairment (Petersen and Morris, 2005).

While the definition of MCI and related concepts has been guided by theoretical and clinical insight, an alternative approach to understand cognitive heterogeneity is to statistically test the existence of distinct but in themselves homogeneous subpopulations. A few studies have used cluster analysis (Delano-Wood et al., 2009, Libon et al., 2010, McKinlay et al., 2009, Ylikoski et al., 1999) or latent profile analysis (LPA) (Hanfelt et al., 2011) in non-demented memory clinic patients, and found three (Delano-Wood et al., 2009, Libon et al., 2010, McKinlay et al., 2009), five (Ylikoski et al., 1999), or seven different patient subgroups (Hanfelt et al., 2011). Most of these studies had a small sample size ( $\leq 120$ patients), with the exception of one study (Hanfelt et al., 2011). In addition, the predictive validity of these subtypes for the dementia outcome remains opaque.

Therefore, the aim of the present study was to 1) explore the existence of one or more cognitive subtypes in a large sample of non-demented memory-clinic patients, and 2) to study their prognostic value for predicting dementia.

\section{METHODS}

\section{Study population}

The Clinical Course of Cognition and Comorbidity in MCI (4C-MCI) study examines the prognosis of memory clinic patients. For the retrospective study arm, data were pooled from the clinical and research record systems of the Alzheimer Centre Limburg at Maastricht University Medical Centre and the Amsterdam Dementia Cohort from the Alzheimer Centre at the VU University Medical Centre in the Netherlands. Inclusion criteria were: age $\geq 55$ years, subjective or objective cognitive impairment based on neuropsychological assessment, no dementia, Clinical Dementia Rating scale score $\leq 0.5$ or Global Deterioration Scale score $\leq 3$. Exclusion criteria were: current diagnosis of normal pressure hydrocephalus, Huntington's disease, Parkinson's disease, Korsakoff's syndrome, brain tumor, encephalitis or recent cerebrovascular accident. Participants were allowed to take 
any medication. For the present study we excluded 325 participants with incomplete neuropsychological information on relevant tests (see below), yielding a sample size of $\mathrm{N}=635$. Those included tended to be younger, male, better educated, to have a baseline diagnosis of SCI instead of MCI, and better neuropsychological test performance than those excluded. Both sites contributed equally (Maastricht: $n=321$, Amsterdam: $n=314$ ). Maastricht participants tended to be younger and less educated.

\section{Clinical assessment at baseline}

At baseline, all participants underwent a standardized assessment: detailed history of the subject; psychiatric, neurological, and physical examination; appropriate laboratory tests; neuropsychological assessment; computerized tomography or magnetic resonance imaging (for differential diagnosis). A clinical consensus diagnosis of MCI was made according to standard criteria, i.e. presence of significant cognitive impairment on neuropsychological tests, and absence of interference with instrumental activities of daily living (using the Blessed Dementia Rating Scale (Blessed et al., 1968) Disability Assessment for Dementia (Gelinas et al., 1999)) and dementia (Petersen, 2004). Participants referred with a psychiatric or neurological disorder (not meeting exclusion criteria) for suspicion of primary cognitive deficits were recorded as "psychiatric disorder" or "neurological disorder". In the absence of cognitive impairment and major psychiatric or neurological disorders, a diagnosis of subjective cognitive impairment (SCI) was made. From the databases, we extracted information on age, gender, level of education, baseline diagnosis, and neuropsychological test scores.

\section{Neuropsychological assessment}

Both centers use a standard test battery for diagnostic and research purposes (appendix). Episodic memory was assessed with the Rey Verbal Learning Task (Lezak et al., 2004, van der Elst et al., 2005). The scores for immediate recall, delayed recall (after 20 minutes) and delayed recognition were recorded. Information processing speed and executive functions were measured with the Trail Making Test (TMT) (Lezak et al., 2004, Schmand et al., 2003) and the Stroop Color Word Test (SCWT) (Hammes, 1973). For the latter, an interference index was calculated as Card 3 - [(Card 1 + Card 2) / 2] (van der Elst et al., 2006b). The TMTA and the average of SCWT cards 1 and 2 were used as measures of informationprocessing speed. The difference between TMT-B and TMT-A as well as the SCWT interference index were used as a measure of executive functions / inhibitory control. For verbal fluency, participants had to name as many animals as possible within 60 seconds (Lezak et al., 2004, van Der Elst et al., 2006a). 


\section{Dementia outcome at follow-up}

The follow-up assessment included a neurological and medical examination and a neuropsychological assessment. A diagnosis of dementia and Alzheimer's disease (AD) was made after multidisciplinary consensus using all available information by a neurologist or neuropsychiatrist according to the DSM-IV and NINCDSADRDA criteria (APA, 1994; McKhann, Drachman et al. 1984). Frontotemporal dementia (FTD) was diagnosed according to the Neary criteria, without further distinction between FTD variants (Neary et al., 1998). A diagnosis of vascular dementia (VaD) was made according to the NINDS-AIREN criteria (Roman et al., 1993). A diagnosis of dementia with Lewy-bodies (DLB) followed the guidelines of the international DLB consensus group (McKeith et al., 2005). Other, rare forms of dementia (e.g. HIV-dementia complex, Creutzfeldt-Jakob disease) were summarized under "other dementia". For the present study, we used information on dementia status at last follow-up, date of dementia diagnosis, dementia type, and date of death (if available). The mean follow-up time was 3.4 years (median $=$ 2.4 years), with a range from 0.2 to 14.6 years. During a total of 2187.18 personyears, 155 incident dementia cases were recorded (annual incidence rate $=7.1 \%$ ).

\section{Statistical analyses}

LPA (Garrett et al., 2002) was run in Mplus 7 (Múthen \& Múthen, Los Angeles). For easy comparisons, neuropsychological test scores were centered using the sample's grand mean. Models with increasing numbers of classes were run. Model fit and parsimony were compared by adjusted Bayesian Information Criterion (Nylund et al., 2007) (BIC; lower is better) and comparing the model with k classes to the model with k-1 classes using the Lo-Mendell-Rubin likelihood ratio test (Nylund et al., 2007) (LMR LRT). Amount of ambiguity in class allocation was assessed by standardized entropy score (scores $\geq .80$ are acceptable) (Ramaswamy et al., 1993). Cox proportional hazard regression were then run in Stata 12.1 (StataCorp, Texas) to test differences in hazard ratios (HR) and their 95\% confidence intervals (CI) between cognitive classes, adjusted for current age, gender, level of education (binned into low, middle high), and study site. Survival time was entered as years since birth (in order to adjust for current age (Thiébaut and Bénichou, 2004)), and entry into the study (start of risk period) as date of first neuropsychological assessment. Observations were censored at date of dementia diagnosis, date of last record of neuropsychological assessment or date of death, whatever came first. Cox regressions were weighted using the inverse of an individual's posterior class probability. Similarly, comparisons of means and proportions across classes were inverse-probability weighted, yielding a design-based F statistic. All tests were two-sided with an alpha-level of $\mathrm{p}<.05$. For more details see the appendix. 


\section{Standard protocol approvals, registrations, and patient consents}

In the Netherlands, the use of anonymized routine data does not require ethical approval or written informed consent.

\section{RESULTS}

The sample characteristics of the 635 participants are shown in Table 1.

Table 1 Baseline characteristics of the sample

\begin{tabular}{lll}
\hline & $N$ & $\%$ \\
\cline { 2 - 3 } Total & 635 & 100 \\
Females & 266 & 41.9 \\
Education & & \\
$\quad$ Low & 91 & 14.8 \\
$\quad$ Middle & 287 & 46.6 \\
High & 238 & 38.6 \\
& & \\
Age, y & Mean & SD \\
\cline { 2 - 2 } Immediate recall, no of words & 67.1 & 7.2 \\
Delayed recall, no of words & 35.1 & 9.9 \\
Recognition memory, no of words & 6.0 & 3.6 \\
Trail Making A, sec & 13.2 & 2.3 \\
SCWT average cards 1+2, sec & 49.5 & 19.7 \\
Verbal fluency, no of words & 58.7 & 12.9 \\
Trail Making B - A, sec & 20.1 & 6.0 \\
SCWT interference, sec & 62.0 & 57.1 \\
\hline SCWT = Stroop Color-Word Test. & 68.9 & 38.5
\end{tabular}

SCWT $=$ Stroop Color-Word Test.

\section{Cognitive profiles}

Model fit and substantive interpretation suggested that five classes represented the most parsimonious solution (appendix). Figure 1 and Table 2 show their cognitive profiles. Quantitative (i.e. differences in severity of impairment) and qualitative differences (i.e. differences in affected domains) between participants became apparent. We then compared the mean scores of each class to Dutch norm scores (for the mean age and education of that class), and used this and the standardized scores (Figure 1) to identify the cognitive domains that differentiated subtypes most saliently. Classes $1(\mathrm{~N}=99,15 \%$ of the sample) and $2(\mathrm{~N}=238,38 \%)$ consisted of participants with normal cognitive functioning, with the former performing superior in terms of immediate and delayed memory recall. In contrast, classes $3(\mathrm{~N}=232,36 \%), 4(\mathrm{~N}=30,4 \%)$ and $5(\mathrm{~N}=38,5 \%)$ presented with 
cognitive impairments, albeit with differences in their underlying profile. Classes 3 and 4 were characterized by prominent impairment in memory recall, but only class 4 showed additional deficits in delayed recognition. Participants in class 5 showed marked deficits in non-memory functions, while memory functioning was in between the other classes.

Based on these profiles, we labeled classes as follows: class $1=$ high normal cognition (HNC), class 2 = low normal cognition (LNC), class 3 = primary memory impairment in recall (MI), class $4=$ memory impairment in recall + impairment in delayed recognition ( $\mathrm{MI}+$ ), and class $5=$ primary non-memory impairment (NMI). Table 2 gives the raw cognitive test scores for the latent classes and their distribution of baseline diagnoses. HNC mostly consisted of participants diagnosed with subjective cognitive impairment. MI and MI+ included relatively more participants with MCI, while the LNC class was in-between. In NMI, half had a diagnosis of MCI, while the remainders were scattered over the other diagnostic groups.

\section{Dementia risk}

Of the 155 incident dementia cases, only 3 were in HNC (weighted cumulative incidence $=2.7 \%), 37$ in LNC (15.1\%), 86 in $\mathrm{MI}(38.8 \%), 12$ in $\mathrm{MI}+(39.6 \%)$, and 17 in NMI $(44.9 \%)$. We then tested differences in dementia risk using weighted Cox proportional hazard regression adjusted for age, gender, level of education and study site. Compared to LNC (being the largest class), HNC had a lower risk for dementia $(\mathrm{HR}=0.24,95 \% \mathrm{CI}=0.07$ to $0.80, \mathrm{p}=.020)$. In contrast, increased risks were observed for $\mathrm{MI}(\mathrm{HR}=3.05,95 \% \mathrm{CI}=2.09$ to $4.46, \mathrm{p}<.001), \mathrm{MI}+(\mathrm{HR}=3.26$, $95 \% \mathrm{CI}=1.72$ to $6.17, \mathrm{p}<.001)$ and $\mathrm{NMI}(\mathrm{HR}=5.94,95 \% \mathrm{CI}=3.46$ to $10.18, \mathrm{p}<$ .001). The cumulative hazard function is plotted in Figure 2 and shows largely similar curves for MI and MI+.

\section{Type of dementia}

The distribution of dementia subtypes among classes (Figure 3) further suggested aetiological heterogeneity (design-based $\mathrm{F}=3.25$, d.f. $=17.82,2744.57, \mathrm{p}<.001$ ). While all three cases in HNC developed AD dementia, LNC showed a more diverse outcome pattern, including a relatively high risk of FTD (proportion weighted for participants' class probability $=26 \%$ of cases). MI and MI+ most often developed AD dementia ( $82 \%$ versus $73 \%$, respectively), whereas most cases in NMI $(53 \%)$ were diagnosed with non-AD dementia. 


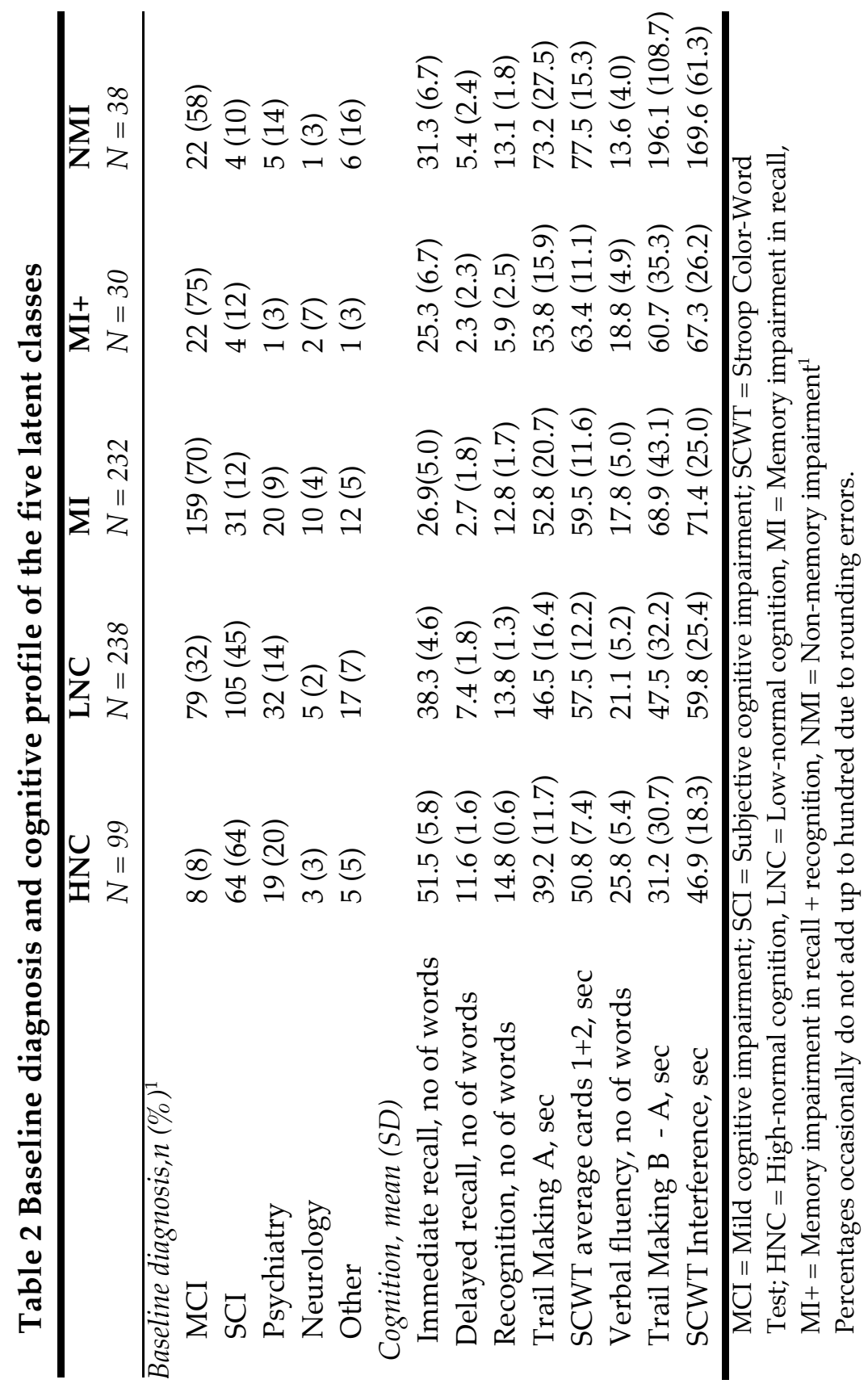


Figure 1 Neuropsychological profiles of the five latent classes. For easy comparisons, raw scores were standardized using the total sample's grand mean $(=$ score of ' 0 ')

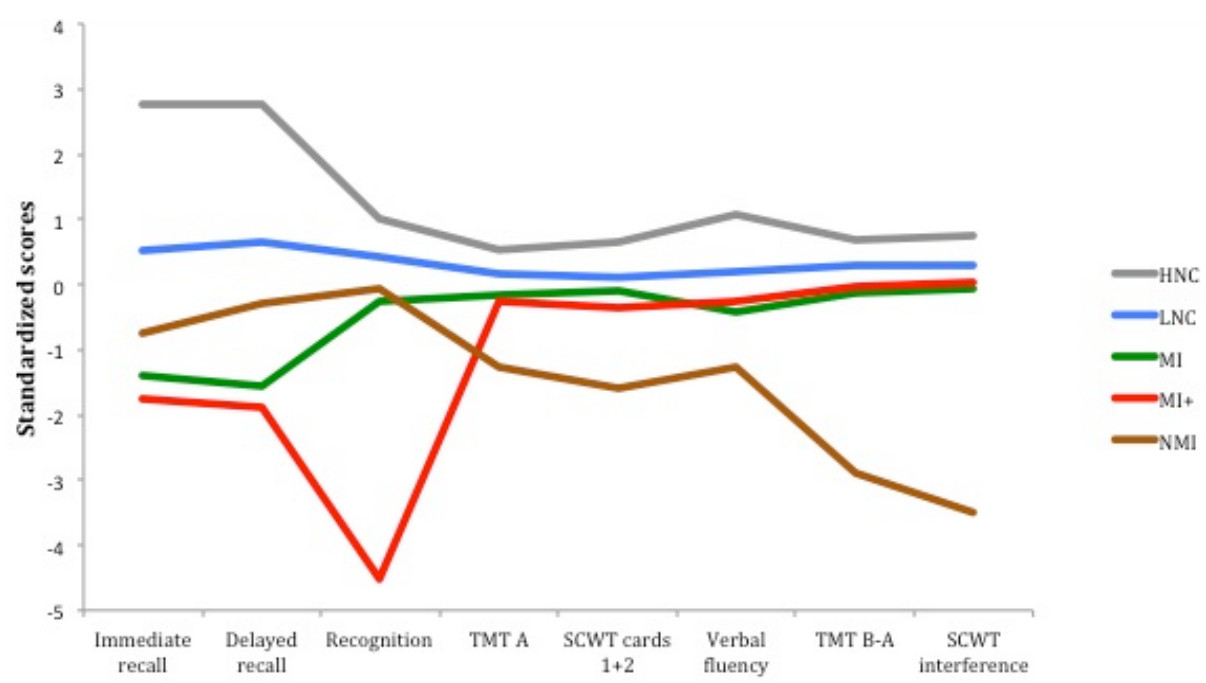

HNC = High-normal cognition, LNC = Low-normal cognition, $\mathrm{MI}=$ Memory impairment in recall, $\mathrm{MI}+=$ Memory impairment in recall + recognition, $\mathrm{NMI}=$ Non-memory impairment.

Figure 2 Cumulative hazard plot of differential associations with dementia risk across cognitive subtypes (note that curves for MI and MI+ largely overlap)

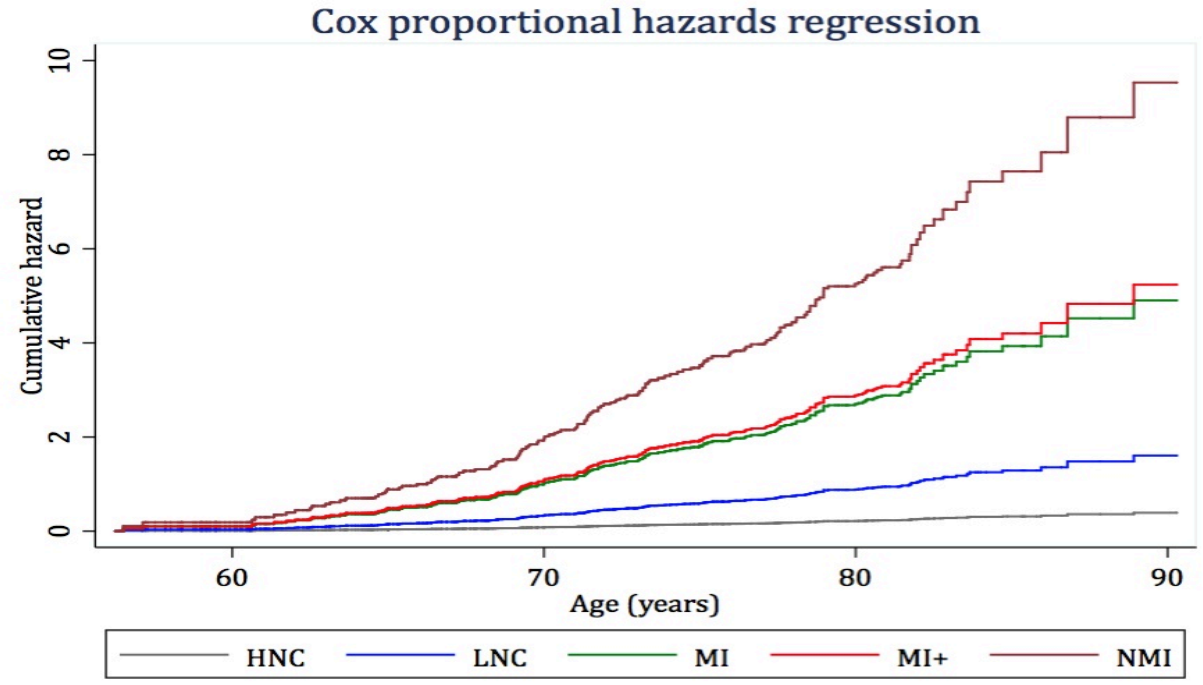

HNC = High-normal cognition, LNC = Low-normal cognition, MI = Memory impairment in recall, MI+ $=$ Memory impairment in recall + recognition, $\mathrm{NMI}=$ Non-memory impairment. 
Figure 3 Distribution of dementia types within cognitive subgroups. Individual bars sum up to the number of total cases within a group, and numbers within bars show absolute numbers of cases per dementia type

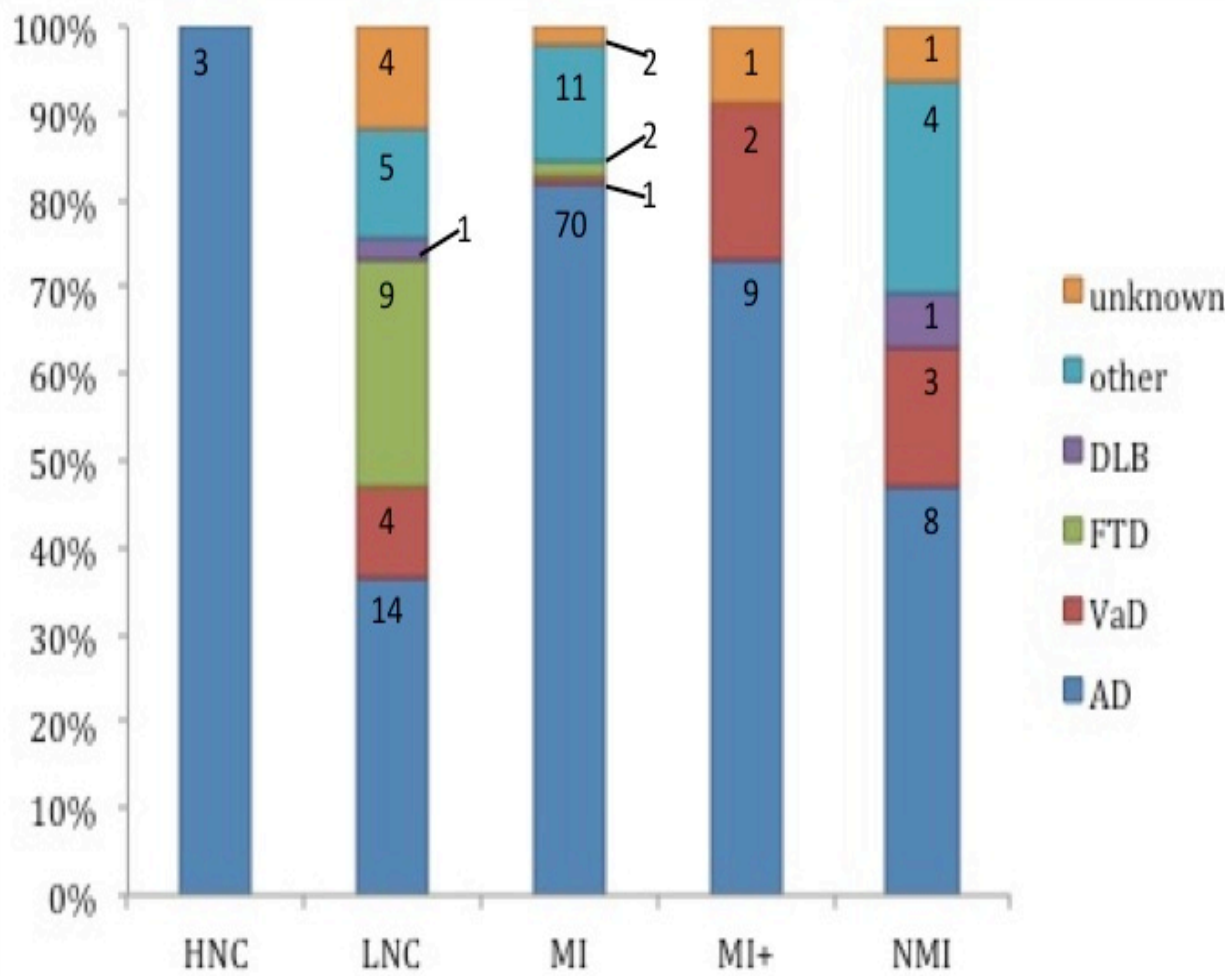

$\mathrm{AD}=$ Alzheimer's disease, $\mathrm{VaD}=$ Vascular dementia, FTD = Frontotemporal dementia, $\mathrm{DLB}=$ Dementia with Lewy bodies; HNC = High-normal cognition, LNC = Low-normal cognition, $\mathrm{MI}=$ Memory impairment in recall, MI+ = Memory impairment in recall + recognition, NMI = Non-memory impairment.

\section{DISCUSSION}

This study found five cognitive subtypes among a naturalistic sample of consecutive memory clinic patients. Subtypes represented participants with low and high normal cognition, participants with primary amnestic deficits with or without impairment in long-term memory consolidation, and participants with primary non-amnestic impairment. Subtypes displayed differential associations with overall dementia risk and types of dementia. Findings show that it is inefficient to treat patients' data as if coming from a single population (e.g. MCI), and that failure to take variability into account may dilute associations that exist between subpopulations. 
The cognitive subtypes are largely congruent with an earlier study in a similar population (Hanfelt et al., 2011). This study found seven classes among 1,655 MCI patients, representing minimal impairment, functional and neuropsychiatric features, amnestic impairment with or without functional and neuropsychiatric features, amnestic multi-domain with or without functional and neuropsychiatric features, and executive dysfunctions with language disorder. The study was restricted to participants with $\mathrm{MCI}$, and hence did not include subjective cognitive impairment. Another study found four cognitive subtypes among patients with AD dementia: mild global impairment, severe global impairment, impairment in memory and orientation, and non-memory impairment (Davidson et al., 2010). Empirical evidence thus lends support for differentiating between subjective, amnestic and non-amnestic impairment.

The assessed neuropsychological domains that differentiated patient groups with low / high dementia risk were memory recall (immediate and delayed), attention and executive functions, which is consistent with previous studies (Gauthier et al., 2006, Tabert et al., 2006). The Alzheimer Disease Neuroimaging Initiative showed that the predictive power for dementia conversion increased after adding memory recall and TMT B scores to a model that already included measures of structural brain changes (Ewers et al., 2012). Another study from that group compared cognitive, brain volumetric and cerebrospinal biomarkers, and concluded that delayed recall, TMT A and a construction test were strong predictors of dementia risk, with scores in delayed recall explaining more variance in the dementia outcome than any biomarker (Gomar et al., 2011).

We observed the highest risk in participants with prominent non-amnestic impairment, though this subtype made up a relatively small proportion of all participants $(6 \%)$. It seems unlikely that this group merely represents a more advanced disease stage, because memory functions were relatively spared. It instead suggests aetiological differences with other subtypes. Indeed, fewer participants in the NMI group had a baseline diagnosis of MCI compared to MI and MI+. More importantly, more than half of cases were diagnosed with non-AD dementia at follow-up, supporting the idea that non-amnestic impairment more often evolves into non-AD dementia (Petersen and Morris, 2005). The higher risk in NMI compared to MI and MI+ is consistent with the finding that non-memory functions predict short-term dementia conversion, whereas memory functions predict dementia only in the long run (Sacuiu et al., 2009). Executive dysfunctions have been related to small vessel disease and $\mathrm{VaD}$ (O'Brien et al., 2003). In patients with subcortical $\mathrm{VaD}$, deficits in executive functions are predictive of the severity of white matter abnormalities (Price et al., 2005). Hence, one might speculate that NMI may display more severe cerebrovascular abnormalities that make them convert to non-AD dementia more rapidly than people with memory deficits develop AD dementia. 
In contrast, impairment in recognition memory did not impress as a major taxon for differentiating between participants with varying dementia risk, as indicated by very similar conversion rates for MI and MI+. Impaired delayed recognition is often considered to arise from damage to the hippocampus and entorhinal cortex, which in turn predicts MCI-to-dementia conversion (deToledo-Morrell et al., 2004, Visser et al., 2002). Yet, delayed recall might relate as strongly to hippocampal changes as delayed recognition scores, or even more so (Dos Santos et al., 2011, Kerchner et al., 2012). It seems unlikely that the MI and MI+ subtypes represent different disease stages as their time-to-dementia would be expected differ. As shown in Figure 2, their risk is identical at all time points during the follow-up, with neither group consuming their risk more rapidly. Yet, small class sizes led to relatively wide confidence intervals, and larger samples would be needed to get more precise estimates.

Another interesting aspect was that differentiation between high and low normal cognition, and the higher dementia risk in the latter. We explored potential differences post-hoc. There were no differences in education $(p=.275)$, but the LNC group was 4.7 years older on average $(\mathrm{P}<.001)$ and more often male $(\mathrm{p}=$ .003 , but these aspects did not explain the differences in dementia risk. The LNC group performed worse on all cognitive tests compared to the HNC group (all $\mathrm{p}<.001)$. Since they did not differ on educational level, the groups could represent different disease stages with similar premorbid functioning. Alternatively, the LNC might represent pathological decline while HNC represents the 'worried well' without a neuropathological substrate. Intriguingly, the LNC subtype comprised a relatively high proportion of FTD cases. This fits with the observation that non-cognitive symptoms are more prominent in prodromal FTD than cognitive impairment, especially in the behavioral FTD variant (Seelaar et al., 2011). We explored whether a diagnosis of FTD in LNC was predicted by baseline diagnosis, but there was no case with a referral diagnosis of psychiatric or neurological disorder in this subtype. Of the 9 FTD cases, $1(11 \%)$ had a diagnosis of SCI, $2(22 \%)$ a diagnosis of MCI, while $6(67 \%)$ had a postponed diagnosis. The latter category reflects diagnostic uncertainty. No other major patterns were identified by cross-tabulation of referral diagnosis at baseline against dementia type at follow-up for each of the remaining latent classes.

Our findings have implications for designing neuropsychological batteries for differentiating cognitive subtypes (e.g. within the MCI construct), and maximizing predictive power for dementia conversion. Measures of immediate and delayed recall, processing speed and executive functions (TMT B-A, SCWT interference index) appear most informative. LPA and related multivariate statistics might help finding cognitive endophenotypes for studying disease mechanisms, relations with structural and functional brain changes and dementia disease loci and risk alleles in genetic association studies. This approach may reveal more informative patterns of associations than studying isolated cognitive domains. 
This study has its own strengths and weaknesses. We used a relatively large sample size that allowed for stable solutions in a multivariate framework. We included a naturalistic sample of consecutive memory clinic admissions with minimal selection criteria. The sample was not restricted to $\mathrm{MCI}$, but included subjective impairment and psychiatric/neurological patients with a (suspected) primary cognitive impairment. This follows recent recommendations to include these patients in clinical research of cognitive disorders in order to maximize generalizability (Steffens et al., 2006). Yet, the reliance on routine data might have impacted on data quality. Some neuropsychological domains were not routinely assessed including visuospatial functions and language. Whether their inclusion would have led to additional subtypes with prognostic value is unclear. We also excluded participants with incomplete neuropsychological data. The remaining sample showed a relatively high proportion of cognitively normal individuals, and therefore they might not mirror the true population prevalence of these subtypes. This might have affect precision (95\% CIs) of the estimates for a given class. A larger sample size would have increased the power of statistical tests. In addition, the routine data did not include neuropathological confirmation or collection of potential diagnostic biomarkers for dementia diagnosis.

Finally, fit criteria for the LPA solution were not entirely consistent. The decision for five classes was based on the LMR LRT, although the adjusted BIC suggested six or even seven classes. The LMR LRT serves as an upper limit in latent class / profile analysis as it is more likely to overestimate rather than to underestimate the number of classes (Nylund et al., 2007). Solutions with more than five classes further tended to result in less meaningful/interpretable solutions, and the five-class model was considered to be more parsimonious. 


\section{REFERENCES}

Blessed, G., Tomlinson, B. E. \& Roth, M. (1968). The association between quantitative measures of dementia and of senile change in the cerebral grey matter of elderly subjects. The British Journal of Psychiatry, 114, 797-811.

Davidson, J. E., Irizarry, M. C., Bray, B. C., Wetten, S., Galwey, N., Gibson, R., Borrie, M., Delisle, R., Feldman, H. H., Hsiung, G.-Y., Fornazzari, L., Gauthier, S., Guzman, D., Loy-English, I., Keren, R. O. N., Kertesz, A., George-Hyslop, P. S., Wherrett, J. \& Monsch, A. U. (2010). An exploration of cognitive subgroups in Alzheimer's disease. Journal of the International Neuropsychological Society, 16, 233-243.

Delano-Wood, L., Bondi, M. W., Sacco, J., Abeles, N., Jak, A. J., Libon, D. J. \& Bozoki, A. (2009). Heterogeneity in mild cognitive impairment: Differences in neuropsychological profile and associated white matter lesion pathology. Journal of the International Neuropsychological Society, 15, 906-914.

deToledo-Morrell, L., Stoub, T. R., Bulgakova, M., Wilson, R. S., Bennett, D. A., Leurgans, S., Wuu, J. \& Turner, D. A. (2004). MRI-derived entorhinal volume is a good predictor of conversion from MCI to AD. Neurobiology of Aging, 25, 1197-1203.

Dos Santos, V., Thomann, P. A., Wüstenberg, T., Seidl, U., Essig, M. \& Schröder, J. (2011). Morphological cerebral correlates of CERAD test performance in mild cognitive impairment and Alzheimer's disease. Journal of Alzheimer's Disease, 23, 411-420.

Ewers, M., Walsh, C., Trojanowski, J. Q., Shaw, L. M., Petersen, R. C., Jack Jr, C. R., Feldman, H. H., Bokde, A. L. W., Alexander, G. E., Scheltens, P., Vellas, B., Dubois, B., Weiner, M. \& Hampel, H. (2012). Prediction of conversion from mild cognitive impairment to Alzheimer's disease dementia based upon biomarkers and neuropsychological test performance. Neurobiology of Aging, 33, 1203-1214.

Garrett, E. S., Eaton, W. W. \& Zeger, S. (2002). Methods for evaluating the performance of diagnostic tests in the absence of a gold standard: a latent class model approach. Statistics in Medicine, 21, 1289-1307.

Gauthier, S., Reisberg, B., Zaudig, M., Petersen, R. C., Ritchie, K., Broich, K., Belleville, S., Brodaty, H., Bennett, D., Chertkow, H., Cummings, J. L., de Leon, M., Feldman, H., Ganguli, M., Hampel, H., Scheltens, P., Tierney, M. C., Whitehouse, P. \& Winblad, B. (2006). Mild cognitive impairment. The Lancet, 367, 1262-1270.

Gelinas, I., Gauthier, L., McIntyre, M. \& Gauthier, S. (1999). Development of a functional measure for persons with Alzheimer's disease: the Disability Assessment for Dementia. American Journal of Occupational Therapy, 53, 471-81.

Gomar, J. J., Bobes-Bascaran, M. T., Conejero-Goldberg, C., Davies, P., Goldberg, T. E. \& for the Alzheimer's Disease Neuroimaging Initiative (2011). Utility of combinations of biomarkers, cognitive markers, and risk factors to predict conversion from mild cognitive impairment to Alzheimer disease in patients in the Alzheimer's Disease Neuroimaging Initiative. Archives of General Psychiatry, 68, 961-969.

Hammes, J. (1973). De Stroop Kleur-Woord Test: Handleiding [The Stroop Color-Word Test: Manual]. Swets \& Zeitlinger: Amsterdam. 
Hanfelt, J. J., Wuu, J., Sollinger, A. B., Greenaway, M. C., Lah, J. J., Levey, A. I. \& Goldstein, F. C. (2011). An exploration of subgroups of mild cognitive impairment based on cognitive, neuropsychiatric and functional features: analysis of data from the National Alzheimer's Coordinating Center. American Journal of Geriatric Psychiatry, 19, 940-50.

Kerchner, G. A., Deutsch, G. K., Zeineh, M., Dougherty, R. F., Saranathan, M. \& Rutt, B. K. (2012). Hippocampal CA1 apical neuropil atrophy and memory performance in Alzheimer's disease. NeuroImage, 63, 194-202.

Lezak, M. D., Howieson, D. B. \& Loring, D. W. (2004). Neuropsychological Assessment. Oxford University Press: Oxford, UK.

Libon, D. J., Xie, S. X., Eppig, J., Wicas, G., Lamar, M., Lippa, C., Bettcher, B. M., Price, C. C., Giovannetti, T., Swenson, R. O. D. \& Wambach, D. M. (2010). The heterogeneity of mild cognitive impairment: A neuropsychological analysis. Journal of the International Neuropsychological Society, 16, 84-93.

McKeith, I., Dickson DW, Lowe J, Emre M, O'Brien JT, Feldman H, Cummings J, Duda JE, Lippa C, Perry EK, Aarsland D, Arai H, Ballard CG, Boeve B, Burn DJ, Costa D, Del Ser T, Dubois B, Galasko D, Gauthier S, Goetz CG, Gomez-Tortosa E, Halliday G, Hansen LA, Hardy J, Iwatsubo T, Kalaria RN, Kaufer D, Kenny RA, Korczyn A, Kosaka K, Lee VM, Lees A, Litvan I, Londos E, Lopez OL, Minoshima S, Mizuno Y, Molina JA, Mukaetova-Ladinska EB, Pasquier F, Perry RH, Schulz JB, Trojanowski JQ, Yamada M \& DLB, C. o. (2005). Diagnosis and management of dementia with Lewy bodies: third report of the DLB Consortium. Neurology, 65, 1863-72.

McKinlay, A., Grace, R. C., Dalrymple-Alford, J. C. \& Roger, D. (2009). Cognitive characteristics associated with mild cognitive impairment in Parkinson's disease. Dementia and Geriatric Cognitive Disorders, 28, 121-9.

Neary, D., Snowden, J. S., Gustafson, L., Passant, U., Stuss, D., Black, S., Freedman, M., Kertesz, A., Robert, P. H., Albert, M., Boone, K., Miller, B. L., Cummings, J. \& Benson, D. F. (1998). Frontotemporal lobar degeneration: a consensus on clinical diagnostic criteria. Neurology, 51, 1546-54.

Nylund, K. L., Asparouhov, T. \& Muthén, B. O. (2007). Deciding on the number of classes in latent class analysis and growth mixture modeling: A Monte Carlo simulation study. Structural Equation Modeling, 14, 535-569.

O'Brien, J. T., Erkinjuntti, T., Reisberg, B., Roman, G., Sawada, T., Pantoni, L., Bowler, J. V., Ballard, C., DeCarli, C., Gorelick, P. B., Rockwood, K., Burns, A., Gauthier, S. \& DeKosky, S. T. (2003). Vascular cognitive impairment. The Lancet Neurology, 2, 8998.

Petersen, R. C. (2004). Mild cognitive impairment as a diagnostic entity. Journal of Internal Medicine, 256, 183-194.

Petersen, R. C. \& Morris, J. C. (2005). Mild cognitive impairment as a clinical entity and treatment target. Archives of Neurology, 62, 1160-1163.

Price, C. C., Jefferson, A. L., Merino, J. G., Heilman, K. M. \& Libon, D. J. (2005). Subcortical vascular dementia: Integrating neuropsychological and neuroradiologic data. Neurology, 65, 376-382.

Ramaswamy, V., DeSarbo, W., Reibstein, D. \& Robinson, W. (1993). An empirical pooling approach for estimating marketing mix elasticities with PIMS data. Marketing Science, 12, 103-124. 
Roman, G. C., Tatemichi, T. K., Erkinjuntti, T., Cummings, J. L., Masdeu, J. C., Garcia, J. H., Amaducci, L., Orgogozo, J. M., Brun, A., Hofman, A. \& et al. (1993). Vascular dementia: diagnostic criteria for research studies. Report of the NINDS-AIREN International Workshop. Neurology, 43, 250-60.

Sacuiu, S., Gustafson, D., Johansson, B., Thorvaldsson, V., Berg, S., Sjogren, M., Guo, X., Ostling, S. \& Skoog, I. (2009). The pattern of cognitive symptoms predicts time to dementia onset. Alzheimers \& Dementia, 5, 199-206.

Schmand, B., Houx, P. \& de Koning, I. (2003). Normen voor Stroop kleur-woord tests, Trail Making test en Story Recall van de Rivermead Behavioural Memory Test. Nederlands Instituut van Psychologen, Sectie Neuropsychologie: Amsterdam.

Seelaar, H., Rohrer, J. D., Pijnenburg, Y. A. L., Fox, N. C. \& van Swieten, J. C. (2011). Clinical, genetic and pathological heterogeneity of frontotemporal dementia: a review. Journal of Neurology, Neurosurgery \& Psychiatry, 82, 476-486.

Steffens, D. C., Otey, E., Alexopoulos, G. S., Butters, M. A., Cuthbert, B., Ganguli, M., Geda, Y. E., Hendrie, H. C., Krishnan, R. R., Kumar, A., Lopez, O. L., Lyketsos, C. G., Mast, B. T., Morris, J. C., Norton, M. C., Peavy, G. M., Petersen, R. C., Reynolds, C. F., Salloway, S., Welsh-Bohmer, K. A. \& Yesavage, J. (2006). Perspectives on depression, mild cognitive impairment, and cognitive decline. Archives of General Psychiatry, 63, 130-138.

Tabert, M. H., Manly, J. J., Liu, X., Pelton, G. H., Rosenblum, S., Jacobs, M., Zamora, D., Goodkind, M., Bell, K., Stern, Y. \& Devanand, D. P. (2006). Neuropsychological prediction of conversion to Alzheimer disease in patients with mild cognitive impairment. Archives of General Psychiatry, 63, 916-924.

Thiébaut, A. C. M. \& Bénichou, J. (2004). Choice of time-scale in Cox's model analysis of epidemiologic cohort data: a simulation study. Statistics in Medicine, 23, 3803-3820.

van der Elst, W., van Boxtel, M. P., van Breukelen, G. J. \& Jolles, J. (2005). Rey's verbal learning test: normative data for 1855 healthy participants aged 24-81 years and the influence of age, sex, education, and mode of presentation. Journal of the International Neuropsychological Society, 11, 290-302.

van Der Elst, W., van Boxtel, M. P. J., van Breukelen, G. J. P. \& Jolles, J. (2006a). Normative data for the Animal, Profession and Letter M Naming verbal fluency tests for Dutch speaking participants and the effects of age, education, and sex. Journal of the International Neuropsychological Society, 12, 80-89.

van der Elst, W., van Boxtel, M. P. J., van Breukelen, G. J. P. \& Jolles, J. (2006b). The Stroop Color-Word Test: influence of age, sex, and education; and normative data for a large sample across the adult age range. Assessment, 13, 62-79.

Visser, P. J., Kester, A., Jolles, J. \& Verhey, F. (2006). Ten-year risk of dementia in subjects with mild cognitive impairment. Neurology, 67, 1201-1207.

Visser, P. J., Verhey, F. R., Hofman, P. A., Scheltens, P. \& Jolles, J. (2002). Medial temporal lobe atrophy predicts Alzheimer's disease in patients with minor cognitive impairment. Journal of Neurology, Neurosurgery and Psychiatry, 72, 491-7.

Ylikoski, R., Ylikoski, A., Keskivaara, P., Tilvis, R., Sulkava, R. \& Erkinjuntti, T. (1999). Heterogeneity of congnitive profiles in aging: successful aging, normal aging, and individuals at risks for cognitive decline. European Journal of Neurology, 6, 645-652. 


\section{SUPPLEMENTARY DATA}

\section{Details on neuropsychological assessment}

Both centers use a standard test battery for diagnostic and research purposes. Episodic memory was assessed with the Rey Verbal Learning Task (Lezak et al., 2004, van der Elst et al., 2005). In the Dutch version of this test, participants have to reproduce a list of 15 non-related monosyllabic words in five subsequent trials (immediate recall). Delayed recall after 20 minutes measures active memory retrieval, while delayed recognition measures long-term memory retention. Information processing speed and executive functions were measured with the Trail Making Test (TMT) and the Stroop Color Word Test (SCWT). The TMT consists of two parts. Part A requires participants to connect circles numbered 1 to 25 in ascending order. In part B, participants have to connect circles by alternating between numbers (1 to 13 ) and letters (A to L), i.e. they go from 1 to A, to 2 , to B etc. (Lezak et al., 2004, Schmand et al., 2003). The SCWT (Hammes, 1973) had a 10 rows by 10 columns format with four colors (red, blue, green, yellow) and consisted of three conditions: card 1 requires participants to read as fast as possible a series of 100 color-names; card 2 requires them to name the colors of the ink in which a series of 100 colored bars is printed; card 3 requires them to name the colors in which a series of 100 color-names is printed, with there being an incongruence between the color and the color-name (e.g. the word "red" printed in green color). An interference index was calculated as Card 3 - [(Card 1 + Card 2) / 2] (van der Elst et al., 2006b). The TMT-A and the average of SCWT cards 1 and 2 were used as measures of information-processing speed. The difference between TMT-B and TMT-A as well as the SCWT interference index were used as a measure of executive functions / inhibitory control. For verbal fluency, participants had to name as many animals as possible within 60 seconds (Lezak et al., 2004, van der Elst et al., 2006a).

\section{Details on statistical analysis}

LPA tests whether the observed distribution of parameters can be described more parsimoniously as a mixture of two or more unobserved (i.e. latent) subpopulations (Garrett et al., 2002). In contrast to cluster analysis, informative model fit indices assist in judging model parsimony, number of classes, and uncertainty in class allocation. Different models with increasing numbers of classes were run, and model fit and parsimony were compared using the sample size adjusted Bayesian Information Criterion (BIC; lower is better) (Nylund et al., 2007). In addition, we compared the model with $\mathrm{k}$ classes to the model with $\mathrm{k}-1$ classes using the Lo-Mendell-Rubin likelihood ratio test (LMR LRT) (Nylund et al., 2007). After deciding on the number of latent classes, individuals were allocated to the class for which they had the highest posterior probability of belonging. The 
ambiguity in class allocation is captured by the standardized entropy score, which ranges from 0 to 1 , with scores $\geq .80$ being acceptable (Ramaswamy et al., 1993). Data were then exported to Stata 12.1 (StataCorp, Texas). Cox proportional hazard regression was used to study differences in hazard ratios (HR) and their $95 \%$ confidence intervals (CI) across cognitive classes, adjusted for current age, gender, level of education (binned into low, middle high), and study site. Survival time was entered as years since birth (in order to adjust for current age as opposed to baseline age), and entry into the study (start of risk period) as date of first neuropsychological assessment (Thiébaut and Bénichou, 2004). All observations were censored at date of diagnosis, date of last record of neuropsychological assessment or date of death. The proportional hazard assumption was assessed by Schoenfeld residuals and inspection of Nelson-Aalen plot. To adequately reflect the probabilistic nature of the cognitive subtypes, Cox regressions were weighted using the inverse of an individual's posterior class probability, thereby giving relatively more weight to participants with higher certainty of class allocation when estimating hazards. For the same reason, comparisons of means and proportions across classes were inverse-probability weighted using procedures for complex surveys (i.e. Rao-Scott second-order corrections of $\chi^{2}$, yielding a designbased F statistic and adjusted degrees of freedom). All tests were two-sided with an alpha-level of $\mathrm{p}<.05$.

\section{Results from latent profile analysis}

Model fit for the LPA, suggested that five classes fit the data better than four classes when judged by the LMR LRT (see supplementary table 1). The adjusted BIC suggested further improvement by adding more classes to the model, but comparing the 5- and the 6-class solution suggested that the latter model essentially broke one of the smaller classes down into two even smaller classes ( $<3 \%$ of the sample). We hence decided to accept the more parsimonious 5-class solution. The entropy score of 0.86 suggested good certainty in class allocation for individual participants. 
Supplementary table1 Fit indices for models with different numbers of latent classes

\begin{tabular}{cccc}
\hline No. of classes & adj. BIC & LMR LRT & Entropy \\
\hline 1 & 39399 & - & - \\
2 & 38464 & $<0.0001$ & 0.803 \\
3 & 38011 & 0.0112 & 0.873 \\
4 & 37799 & 0.0290 & 0.884 \\
5 & 37629 & 0.0013 & 0.857 \\
6 & 37496 & $\mathbf{0 . 8 0 7 5}$ & 0.863 \\
7 & 37368 & $\mathbf{0 . 1 0 2 5}$ & 0.876 \\
\hline
\end{tabular}

LMR LRT = Lo-Mendell-Rubin likelihood ratio test for comparing non-nested models; adj. BIC = sample-size adjusted Bayesian Information Criterion. 


\section{SUPPLEMENTARY REFERENCES}

Garrett, E. S., Eaton, W. W. \& Zeger, S. (2002). Methods for evaluating the performance of diagnostic tests in the absence of a gold standard: a latent class model approach. Statistics in Medicine, 21, 1289-1307.

Hammes, J. (1973). De Stroop Kleur-Woord Test: Handleiding [The Stroop Color-Word Test: Manual]. Swets \& Zeitlinger: Amsterdam.

Lezak, M. D., Howieson, D. B. \& Loring, D. W. (2004). Neuropsychological Assessment. Oxford University Press: Oxford, UK.

Nylund, K. L., Asparouhov, T. \& Muthén, B. O. (2007). Deciding on the number of classes in latent class analysis and growth mixture modeling: A Monte Carlo simulation study. Structural Equation Modeling, 14, 535-569.

Ramaswamy, V., DeSarbo, W., Reibstein, D. \& Robinson, W. (1993). An empirical pooling approach for estimating marketing mix elasticities with PIMS data. Marketing Science, 12, 103-124.

Schmand, B., Houx, P. \& de Koning, I. (2003). Normen voor Stroop kleur-woord tests, Trail Making test en Story Recall van de Rivermead Behavioural Memory Test. Nederlands Instituut van Psychologen, Sectie Neuropsychologie: Amsterdam.

Thiébaut, A. C. M. \& Bénichou, J. (2004). Choice of time-scale in Cox's model analysis of epidemiologic cohort data: a simulation study. Statistics in Medicine, 23, 3803-3820.

van der Elst, W., van Boxtel, M. P., van Breukelen, G. J. \& Jolles, J. (2005). Rey's verbal learning test: normative data for 1855 healthy participants aged 24-81 years and the influence of age, sex, education, and mode of presentation. Journal of the International Neuropsychological Society, 11, 290-302.

van Der Elst, W., van Boxtel, M. P. J., van Breukelen, G. J. P. \& Jolles, J. (2006a). Normative data for the Animal, Profession and Letter M Naming verbal fluency tests for Dutch speaking participants and the effects of age, education, and sex. Journal of the International Neuropsychological Society, 12, 80-89.

van der Elst, W., van Boxtel, M. P. J., van Breukelen, G. J. P. \& Jolles, J. (2006b). The Stroop Color-Word Test: influence of age, sex, and education; and normative data for a large sample across the adult age range. Assessment, 13, 62-79. 
PART B

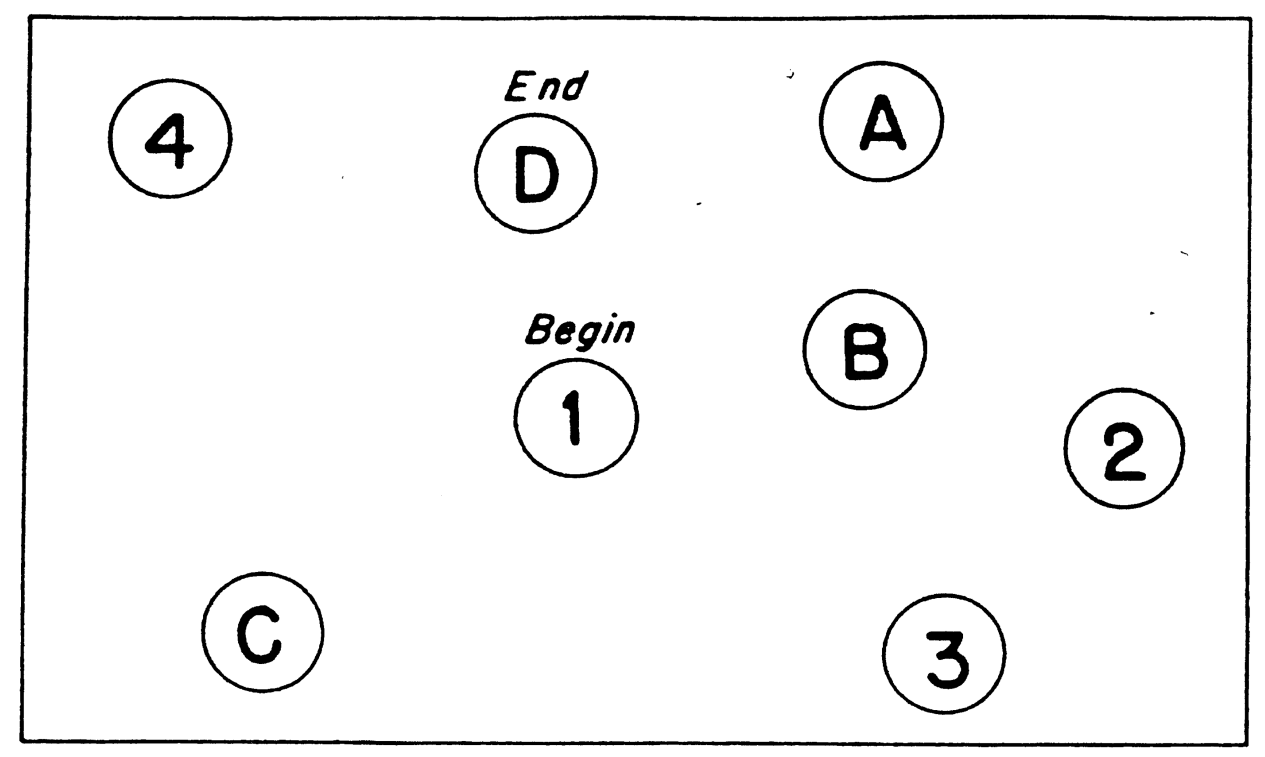





\title{
CHAPTER 5
}

\author{
COHORT PROFILE: THE CLINICAL COURSE OF \\ COGNITION AND COMORBIDITY IN MILD COGNITIVE \\ IMPAIRMENT AND DEMENTIA (THE 4C STUDIES): TWO \\ COMPLEMENTARY MULTICENTER LONGITUDINAL \\ CLINICAL COHORTS IN THE NETHERLANDS
}

Weiqi Liao, Renske E.G. Hamel, Marcel G.M. Olde Rikkert, Saskia M. Oosterveld, Pauline Aalten, Frans R.J. Verhey, Wiesje M. van der Flier, Nicole Sistermans, Philip Scheltens, Yolande A.L. Pijnenburg, Inez H.G.B. Ramakers, René J.F. Melis 


\section{ABSTRACT}

Heterogeneous disease trajectories of mild cognitive impairment (MCI) and dementia are frequently encountered in clinical practice but there is still insufficient knowledge to understand the reasons and mechanisms causing this heterogeneity. In addition to correlates of the disorder (e.g. dementia subtype), patient characteristics such as their health status, comorbidities and frailty may contribute to heterogeneous trajectories over time. Therefore, two complementary longitudinal cohort studies called the Clinical Course of Cognition and Comorbidity in Mild Cognitive Impairment (4C-MCI study, $n=315$ ) and Dementia (4C-Dementia study, $n=327$ ) began enrolment in 2009. Participants were prospectively recruited from three collaborating Dutch Alzheimer Centers, with three annual follow-up assessments after baseline. Extensive neuropsychological assessments, reliable diagnoses of the cognitive disorder present and detailed profiling of comorbidities, health and frailty at each follow up are the key features of the $4 \mathrm{C}$ studies. As such, the $4 \mathrm{C}$ studies studied the hypothesis that patients' comorbidities and frailty are associated with the course of MCI and dementia measured with a comprehensive and multidimensional set of outcomes including cognition, daily functioning, quality of life, behavioral disturbances, caregiver burden, institutionalization and death. 


\section{WHY WERE THE COHORTS SET UP?}

Dementia is a syndrome of impaired cognitive functioning that interferes with living independently. It is a global public health issue with numbers of people suffering from dementia estimated to increase from 35.6 million in 2010 to 65.7 million in 2030, and to 115.4 million in 2050 worldwide (World Health Organization, 2012). Mild cognitive impairment (MCI) is a state of impaired cognitive performance, which does not significantly interfere with living independently. Yet, MCI is a risk factor for developing dementia. Both in MCI and dementia, progression over time varies tremendously among patients. Some patients with MCI progress precipitately after the diagnosis, whereas a substantial proportion of patients do not develop dementia even after a prolonged period of up to 10 years (Visser et al. 2006). In the stage of a clinically manifest dementia syndrome, studies have shown huge differences in speed of decline over time, even within a well-characterized cohort of persons with dementia of the Alzheimer type (Leoutsakos et al., 2014). Understanding the causes leading to heterogeneous trajectories is essential for healthcare professionals to deliver personalized care and to maximally delay the progression of the condition. However, current knowledge cannot fully explain the phenotypical heterogeneity present in patients. Part of the heterogeneity can be attributed to different aetiological diagnoses, such as Alzheimer's Disease (AD), Vascular Dementia (VaD), Dementia with Lewy Bodies (DLB) and Frontotemporal Dementia (FTD). To further increase our understanding of the observed heterogeneity, it was hypothesized that dementia may be a multicausal, complex and dynamic disorder with involvement of many body systems/organs at different levels, rather than a disease with a single pathology (Fotuhi et al., 2009). Therefore, the phenotypes may be highly influenced by patient profile factors such as the health status of an individual patient (Boyle et al., 2009, Buchman et al., 2008, Melis et al., 2013, Leoutsakos et al. 2012), in addition to disease characteristics such as the nosological subtype. The majority of patients with MCI and dementia are aged, experience different levels of frailty and suffer from a considerable number of comorbidities (Marengoni et al., 2009). Unfortunately, how these patient characteristics influence the development and prognosis of the disorder is largely unknown. Two complementary multicenter longitudinal cohorts were launched in the Netherlands in 2009, named the Clinical Course of Cognition and Comorbidity in Mild Cognitive Impairment and Dementia, the ' $4 \mathrm{C}-\mathrm{MCI}^{\prime}$ and '4C-Dementia' for short, with the following research objectives:

1. explore heterogeneity in trajectories of progression in multiple outcomes, survival and institutionalization in persons with newly diagnosed MCI and dementia, for MCI this includes conversion to dementia;

2. investigate whether comorbidity (number and severity of chronic comorbidities and presence of certain comorbidities) and physical frailty influence the course and outcome of MCI and dementia; 
3. develop prediction rules for individual decline in cognition, behavior, and daily functioning, institutionalization and death.

\section{WHO IS IN THE COHORT?}

Included were patients with subjective and/or objective cognitive complaints referred to three memory clinics: Alzheimer Center, VU University Medical Center Amsterdam (West of the Netherlands), Alzheimer Centre Limburg, Maastricht University Medical Center (South of the Netherlands) and Radboud Alzheimer Centre, Radboud university medical center (East of the Netherlands). The three local ethical committees of the respective centers approved the studies. Patients had to be fluent in Dutch, and otherwise meet the inclusion and exclusion criteria of the 4C-MCI or 4C-Dementia study to be included. Written informed consent was obtained from all the participants and their informal caregivers.

In essence, the 4C-MCI and the 4C-Dementia studies were similar in study design and implementation, but were conducted in different disease stages. People with a new diagnosis of dementia were included in the 4C-Dementia cohort. Patients who had subjective cognitive complaints or objective cognitive impairments based on neuropsychological test results but did not fulfill the diagnostic criteria for dementia were included in the MCI cohort. As such the inclusion was broader than in previous studies on $\mathrm{MCI}$ and dementia since comorbidities were allowed, thus resulting in a patient sample that was more representative for regular patient groups. The eligibility criteria for the $4 \mathrm{C}-\mathrm{MCI}$ and the $4 \mathrm{C}-$ Dementia cohorts are shown in table 1.

\section{Table 1 Inclusion criteria for the 4C-MCI and 4C-Dementia studies}

\begin{tabular}{lll}
\hline & The 4C-MCI cohort & The 4C-Dementia cohort \\
\hline Cognitive performance & $\begin{array}{l}\text { subjective and/or objective } \\
\text { cognitive impairments } \\
\text { No }\end{array}$ & $\begin{array}{l}\text { objective cognitive } \\
\text { impairments } \\
\text { Yes }\end{array}$ \\
$\begin{array}{l}\text { Fulfil the DSM-IV diagnostic } \\
\text { criteria for dementia (American }\end{array}$ & $\begin{array}{l}\text { Psychiatric Association, 1994) } \\
\begin{array}{l}\text { Clinical Dementia Rating (CDR) } \\
\text { Scale (Morris, 1993) }\end{array}\end{array}$ & $0-0.5$ \\
$\begin{array}{l}\text { Mini Mental State Examination } \\
\text { (MMSE) score (Folstein, Folstein } \\
\begin{array}{l}\text { \& McHugh, 1975) } \\
\text { Age }\end{array}\end{array}$ & Not specified & $\geq 10$ \\
\hline
\end{tabular}


The exclusion criteria for both cohorts were similar:

1) The absence of a reliable informant (defined as someone who had contact with the participant for at least once a week);

2) If the participant was expected to be unable to have at least one follow-up assessment;

3) The presence of other neurological disorders that could cause cognitive impairment or affect cognitive performance, such as, Parkinson's Disease, Huntington's Disease, Normal Pressure Hydrocephalus (NPH), Korsakov's syndrome, and a medical history of brain tumour, encephalitis or epilepsy.

\section{How often have the subjects been followed up?}

The 4C-MCI and 4C-Dementia cohort studies were carried out simultaneously. Both cohorts aimed to enrol over 300 participants at baseline, equally from three centres. This goal was accomplished in May 2011 for both studies. The participants were scheduled to have three annual follow-ups (12, 24, 36 months) after the baseline measurement. The flowcharts for both cohorts are shown in Figures 1 and 2 .

What has been measured and how has this changed?

A multidisciplinary team, consisting of physicians, neuropsychologists and research assistants collaborated in the standardized collection of the baseline and follow-up data. Data were collected on demographics, syndromal and aetiological diagnosis, cognitive functioning, health conditions, functional abilities, neuropsychiatric symptoms, quality of life, and care resource use. An overview of the collected data per measurement is presented in table 2.

\section{Syndromal diagnosis of MCI and dementia}

Syndromal diagnoses were made at baseline and reviewed and updated at every follow-up visit. The diagnosis of MCI was based on Petersen criteria (Petersen et al., 1999) and was operationalized as a z-score lower than -1.5 SD (compared to Dutch norms) on any of the cognitive tests (see below). Subjects with cognitive complaints without verified impairment on cognitive tests were categorized as subjective cognitive decline (SCD). The diagnosis of dementia was based on DSMIV criteria (American Psychiatric Association, 1994). Aetiological dementia diagnoses were made according to standardized clinical criteria for AD (NINCDSADRDA criteria,(McKhann et al., 1984)), vascular dementia (NINDS-AIREN criteria, (Roman et al., 1993)), frontotemporal dementia (Neary et al., 1998), and Lewy body dementia (McKeith et al., 1996). 
Figure 1 Flowchart of the 4C-MCI cohort

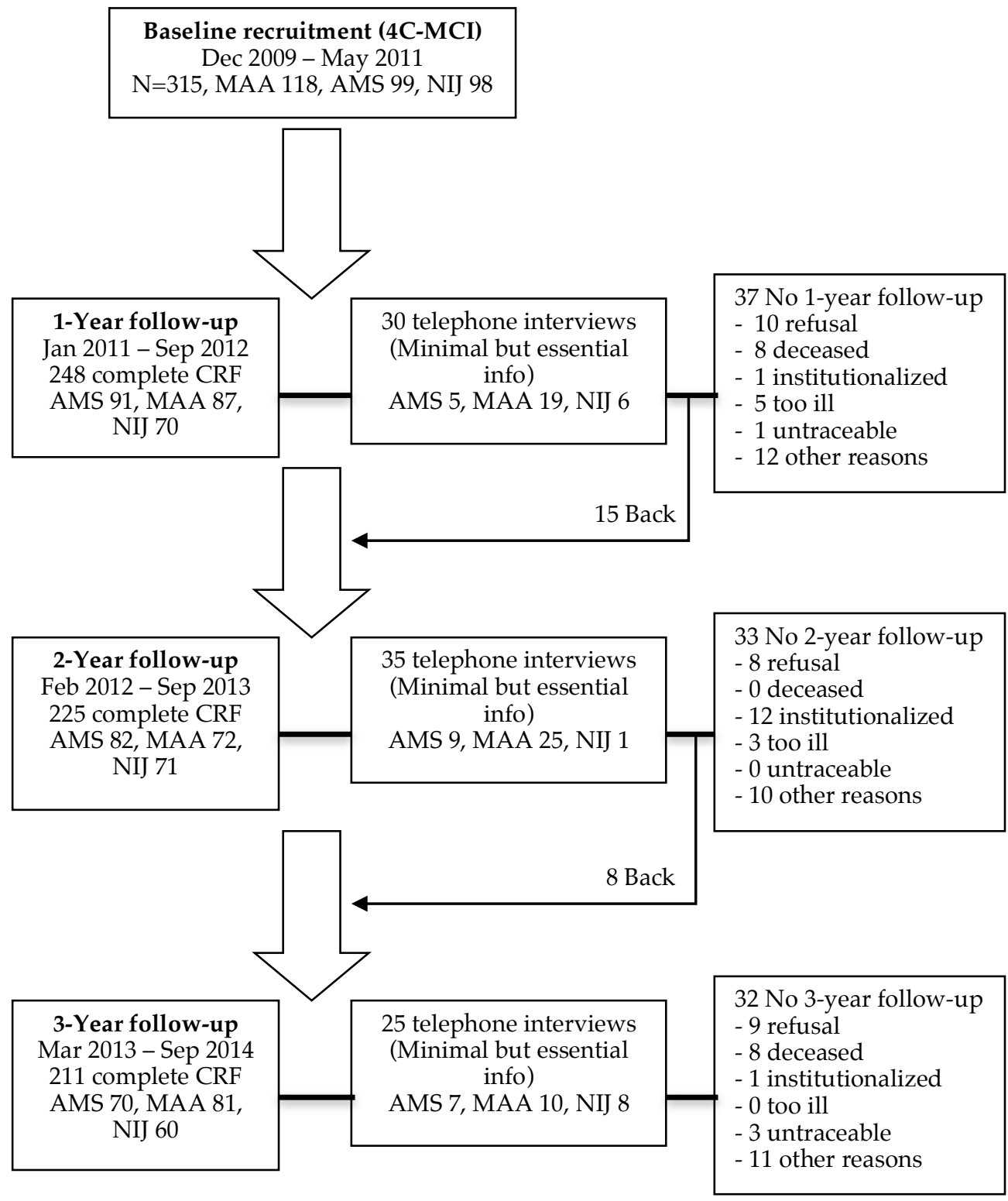

AMS $=$ Amsterdam $;$ MAA $=$ Maastricht $; \mathrm{Nij}=$ Nijmegen $; \mathrm{CRF}=$ case record form. 
Figure 2 Flowchart of the 4C-Dementia cohort

Baseline recruitment (4C-Dementia)

Feb 2010 - May 2011

$\mathrm{N}=327$, AMS 112, MAA 112, NIJ 103

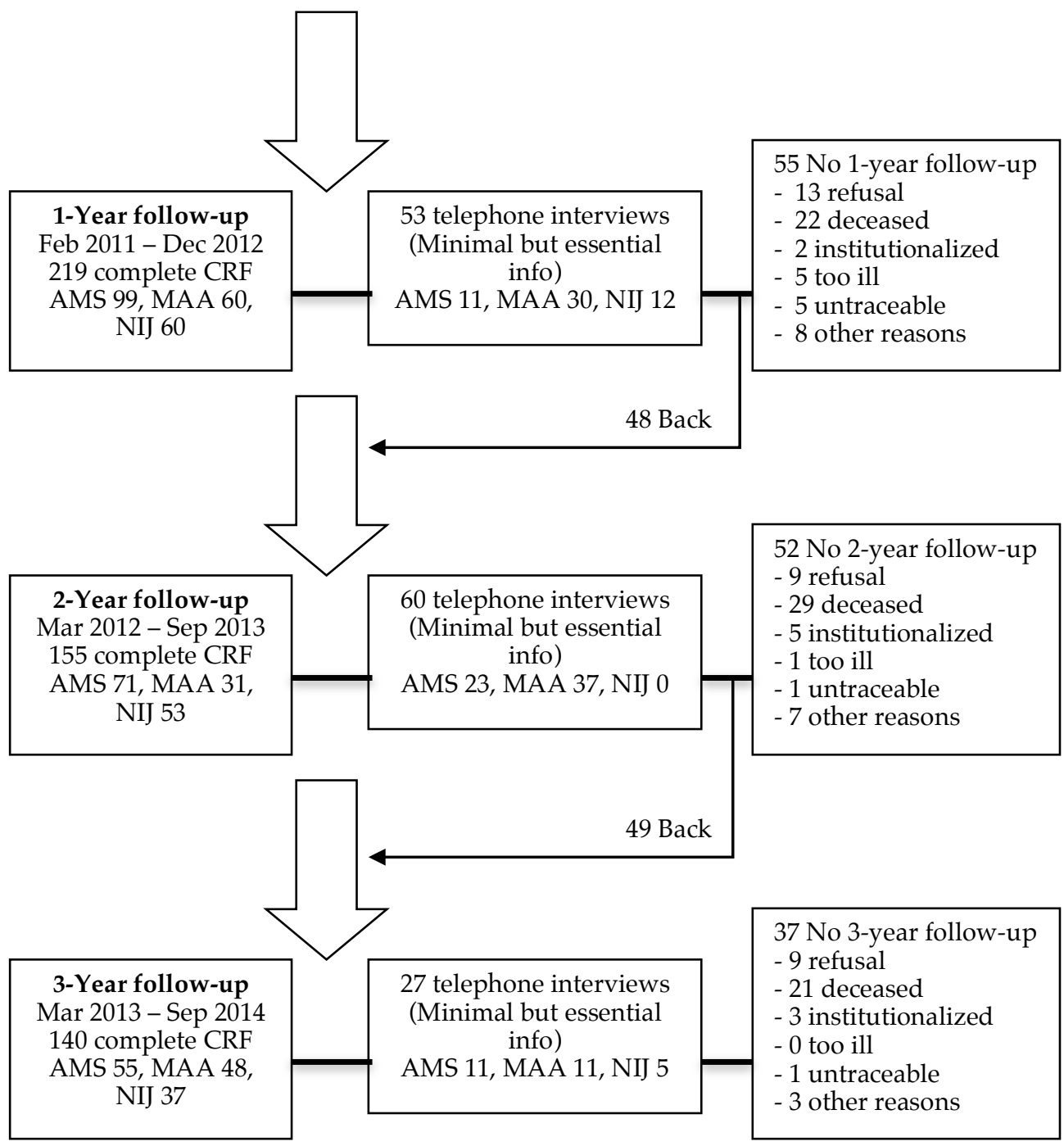

AMS $=$ Amsterdam; MAA = Maastricht Nij = Nijmegen, $\mathrm{CRF}=$ case record form. 
Table 2 Contents of data collection in the $4 \mathrm{C}$ studies

\begin{tabular}{|c|c|c|c|c|}
\hline & Baseline & $\begin{array}{c}12 \\
\text { months }\end{array}$ & $\begin{array}{c}24 \\
\text { months }\end{array}$ & $\begin{array}{c}36 \\
\text { months }\end{array}$ \\
\hline Informed consent & $\sqrt{ }$ & & & \\
\hline Demographics & $\sqrt{ }$ & $\sqrt{ }$ & $\sqrt{ }$ & $\sqrt{ }$ \\
\hline Subjective cognitive functions & $\sqrt{ }$ & $\sqrt{ }$ & $\sqrt{ }$ & $\sqrt{ }$ \\
\hline MMSE & $\sqrt{ }$ & $\sqrt{ }$ & $\sqrt{ }$ & $\sqrt{ }$ \\
\hline CDR & $\sqrt{ }$ & $\sqrt{ }$ & $\sqrt{ }$ & $\sqrt{ }$ \\
\hline Subjective cognitive functioning & $\sqrt{ }$ & $\sqrt{ }$ & $\sqrt{ }$ & $\sqrt{ }$ \\
\hline Neuropsychological assessment & $\sqrt{ }$ & $\sqrt{ }$ & $\sqrt{ }$ & $\sqrt{ }$ \\
\hline $\begin{array}{l}\text { Physical examination \& structural } \\
\text { medical review }\end{array}$ & $\sqrt{ }$ & $\sqrt{ }$ & $\sqrt{ }$ & $\sqrt{ }$ \\
\hline Medications (prescribed \& taken) & $\sqrt{ }$ & $\sqrt{ }$ & $\sqrt{ }$ & $\sqrt{ }$ \\
\hline Hospitalization (if any) & & $\sqrt{ }$ & $\sqrt{ }$ & $\sqrt{ }$ \\
\hline Syndromal diagnoses & $\sqrt{ }$ & $\sqrt{ }$ & $\sqrt{ }$ & $\sqrt{ }$ \\
\hline Comorbidities (CIRS-G) & $\sqrt{ }$ & $\sqrt{ }$ & $\sqrt{ }$ & $\sqrt{ }$ \\
\hline Frailty (Fried criteria + Frailty index) & $\sqrt{ }$ & $\sqrt{ }$ & $\sqrt{ }$ & $\sqrt{ }$ \\
\hline DAD (disability assessment) & $\sqrt{ }$ & $\sqrt{ }$ & $\sqrt{ }$ & $\sqrt{ }$ \\
\hline GDS-15 (depression, self-reported) & $\sqrt{ }$ & $\sqrt{ }$ & $\sqrt{ }$ & $\sqrt{ }$ \\
\hline NPI (neuropsychiatric symptoms) & $\sqrt{ }$ & $\sqrt{ }$ & $\sqrt{ }$ & $\sqrt{ }$ \\
\hline Euroqol 5D & $\sqrt{ }$ & $\sqrt{ }$ & $\sqrt{ }$ & $\sqrt{ }$ \\
\hline Care resource use & $\sqrt{ }$ & $\sqrt{ }$ & $\sqrt{ }$ & $\sqrt{ }$ \\
\hline Refusal or withdrawal data & & $\sqrt{ }$ & $\sqrt{ }$ & $\sqrt{ }$ \\
\hline Institutionalization (outcome \& date) & & $\sqrt{ }$ & $\sqrt{ }$ & $\sqrt{ }$ \\
\hline Death (outcome \& date) & & $\sqrt{ }$ & $\sqrt{ }$ & $\sqrt{ }$ \\
\hline
\end{tabular}

\section{Cognitive performance and neuropsychological assessment}

Cognitive performance in the $4 \mathrm{C}$ studies was evaluated by subjective rating and an extensive neuropsychological assessment.

\subsection{Subjective cognitive symptoms}

Data about the self-reported start (gradual or sudden), course (stable, fluctuated or progressively deteriorated) and duration of the cognitive complaints were collected. In addition, patients were asked whether they had noticed a change in four cognitive functions (memory, concentration, mental capacity, and vitality) during the last year (Aalten et al., 2014). Change in each function was scored on a 7-point Likert scale ranging from -3 (very strong decline) to +3 (very strong improvement). If the participant was unable to answer by himself, the caregiver rated the changes based on daily contact and observation. 


\subsection{Objective cognitive assessment}

The neuropsychological assessment consisted of the same standardized battery of cognitive tests as used in the Dutch Parelsnoer Institute study (www.string-ofpearls.org), covering the following domains: global cognition, episodic memory, implicit visual learning, working memory, word fluency, information processing speed, attention, executive functioning and visual perception (table 3 ).

\section{Table 3 Standardized cognitive tests and the corresponding domains}

\begin{tabular}{|c|c|}
\hline Neuropsychological tests & Cognitive domain(s) \\
\hline $\begin{array}{l}\text { Mini Mental State Examination (MMSE) } \\
\text { (Folstein et al., 1975, Kok and Verhey, 2002) }\end{array}$ & Global cognition \\
\hline $\begin{array}{l}\text { 15-Word Verbal Learning Test (VLT) } \\
\text { (Brand and Jolles, 1985, Van der Elst et al., } \\
\text { 2005) immediate recall ( } 5 \text { trails), delayed } \\
\text { recall and delayed recognition }\end{array}$ & Episodic memory \\
\hline $\begin{array}{l}\text { Visual Association Test (VAT), short } \\
\text { version (Lindeboom et al., 2002) }\end{array}$ & Implicit associative visual learning \\
\hline $\begin{array}{l}\text { Digit Span subtest (forwards and } \\
\text { backwards) of the Wechsler Adult } \\
\text { Intelligence Test (3rd Edition) (Wechsler, } \\
\text { 1997) }\end{array}$ & Working memory \\
\hline 60 seconds animal fluency (Lezak, 2004) & Verbal word fluency / semantic memory \\
\hline $\begin{array}{l}\text { Letter Digit Substitution Test (LDST) (van } \\
\text { der Elst et al., 2006a) }\end{array}$ & Information processing speed \\
\hline $\begin{array}{l}\text { Stroop Color Word Test (SCWT, } 3 \text { subtasks) } \\
\text { (Hammes, 1973, Stroop, 1992, Van der Elst } \\
\text { et al., 2006b) }\end{array}$ & $\begin{array}{l}\text { Information processing speed, attention } \\
\text { and executive functioning / response } \\
\text { inhibition }\end{array}$ \\
\hline $\begin{array}{l}\text { Trail Making Test (TMT) parts A \& B } \\
\text { (Reitan, 1958, Tombaugh, 2004) }\end{array}$ & $\begin{array}{l}\text { Information processing speed, attention } \\
\text { and executive functioning / concept } \\
\text { shifting }\end{array}$ \\
\hline $\begin{array}{l}\text { Visual Object and Space Perception battery } \\
\text { (VOSP, Optional) (Warrington and James, } \\
\text { 1991) Dot counting and incomplete letters } \\
\text { subtests }\end{array}$ & Visual perception \\
\hline
\end{tabular}




\section{Health conditions \& functional abilities}

\subsection{Physical examination and structural medical review}

Height, weight, waist circumference, averaged systolic and diastolic blood pressure of the participants were recorded. Smoking and drinking status, the type, quantity and frequency of tobacco and alcohol consumption were asked. The physician structurally reviewed the patient's personal medical history at baseline, and particularly queried extrapyramidal symptoms, gait disturbances, and family history of dementia and Parkinson's disease. Newly diagnosed diseases were updated at every follow-up visit, also recording any taken medication and each hospitalization (supplementary table 1).

\subsection{Comorbidity}

The presence of the chronic conditions hypertension, heart failure, obesity, delirium, COPD, and renal failure was checked and, if present, the disease duration and the stages of heart failure (NYHA) (Dolgin, 1994) COPD (GOLD) (Global Initiative for Chronic Obstructive Lung Disease, 2014) and renal failure (K/DOQI) (National Kidney Foundation, 2002) were recorded.

The Cumulative Illness Rating Scale for Geriatrics (CIRS-G) (Miller et al., 1992) was used to quantitatively measure the disease burden and reflects the number and severity of the diseases. Using the CIRS-G, all diseases were classified into 14 organ systems: cardiac (heart only), vascular, hematologic, respiratory, ophthalmologic and otorhinolaryngologic, upper gastrointestinal, lower gastrointestinal, hepatic and pancreatic, renal, genitourinary, musculoskeletal and tegumental, neurologic, endocrine/metabolic and breast, and psychiatric. If a patient had multiple diseases in a single category, the most severe one was appraised. The severity of impairment was rated with a $0-4$ grading scale from no problem to extremely severe problems (e.g. organ failure) resulting in a total score ranging from $0-56$. The CIRS-G can be adapted as a measure of pure physical functioning in the $4 \mathrm{C}$ studies by excluding the psychiatric category, since this category includes cognition related comorbidities. The total score than runs from 0 to 52 .

\subsection{Frailty}

Frailty was operationalized using the widely accepted five physical criteria developed by Fried et al. (2001): A frailty index based on accumulated deficits can be operationalized from the $4 \mathrm{C}$ data (Searle et al., 2008).

\section{Functional abilities}

The Disability Assessment for Dementia (DAD) scale (Gelinas et al., 1999), measuring both basic and instrumental activities of daily living (ADL, IADL), was used to evaluate the severity of impairment in everyday functioning through a 
structured interview with the caregiver. The participant's abilities to perform ten different (I)ADL activities in the 2 weeks prior to the visit were rated. The final DAD score was converted to a percentage from 0 to 100, in which a higher percentage indicates a higher level of daily functioning.

\section{Neuropsychiatric symptoms}

Neuropsychiatric symptoms are common in MCI and dementia and may cause emotional burden and distress to the caregiver. Further, they are one of the principal determinants of institutionalization. The $4 \mathrm{C}$ studies used the Geriatric Depression Scale (GDS-15) (Sheikh and Yesavage, 1986) to assess the presence and severity of depressive symptom in older patients. The Neuropsychiatric Inventory (NPI) (Cummings, 1997) was used to characterize the psychopathology of the patient through a structured interview with the caregiver, assessing 12 common neuropsychiatric symptoms. A screening question for each neuropsychiatric symptom was asked to confirm the presence of the symptom before rating the frequency (1-4, rarely-very often) and severity (1-3, mild-severe) and caregiver burden (0-5, not at all-very severely / extremely). The total NPI score ranged from 1 to 144 .

\section{Quality of life}

The EQ-5D (EuroQol-group, 1990), was used to measure health-related quality of life and results in a score from $0-100$, where higher scores indicate better functioning. The EQ-5D was rated by the patient and by the caregiver: for the situation of the patient and for the caregiver him-/herself.

\section{Care resource use}

Besides patient and disease related data, also data about the patient's care resource use was investigated by assessing the number of visits to the general practitioner, home care, day care, institutionalized care, hospital in- and outpatient, emergency care, other professionals, informal care, medical goods, and out-of-pocket expenditures.

\section{Refusal or withdrawal, minimum but essential data collected for research} The reasons for dropout were collected and categorized. The attrition is shown in the flowchart of Figures 1-2. With their consent, the study investigators made efforts to collect minimal but essential data for research through a telephone interview with the participant (or caregiver) who wanted to discontinue their full participation. Researchers asked about the course of cognitive symptoms, functional abilities in (i)ADLs (any help or assistance needed in certain activities), and global severity of dementia (CDR). If the participant had received a diagnosis of MCI or dementia from another physician, the syndromal diagnosis was documented. Despite refusal to participate in a particular follow-up, some patients 
agreed to be approached at the next follow-up and did return to fully participate in the studies, as shown in Figures 1-2.

\section{Changes of study protocol and implementation}

Some changes to the original research protocol were made for better implementation and completion of the studies. Based on the experiences during the baseline interview, an evaluation of the reliability of information provided by the participant and the caregiver was added to the follow-up assessments.

By default, the assessments were carried out in the memory clinics. However, for some participants, it was inconvenient to visit the memory clinic due to immobility or other physical conditions. Where possible, home visits (to the patient's house or nursing home) were implemented in the follow-ups, carried out by a well-trained researcher, to limit attrition.

\section{WHAT HAS BEEN FOUND? KEY FINDINGS AND PUBLICATIONS}

\section{Sample characteristics and differences}

In the MCI and dementia cohort, 315 and 327 participants were included respectively. Noticeably, more men than women were recruited in the MCI cohort, consistently across the three centers, whereas more women were recruited in the Dementia cohort, except in Amsterdam (table 4). Participants in the MCI cohort were on average 5.2 years younger, had better cognitive performance, functional abilities, physical condition and quality of life. However, they also had higher depression scores than those in the Dementia cohort at baseline (Table 5). Due to different geographical locations and the different medical specialty (neurology, psychiatry and geriatrics) of the departments hosting the three memory clinics, there may be a center effect within each cohort, which will be accommodated in the analyses.

\section{Cognition}

The majority of the participants experienced a progressive cognitive decline in the phase before the baseline diagnosis, namely $67.6 \%$ in the MCI cohort, and $85.9 \%$ in the Dementia cohort, starting at about 3-3.5 years on average before entering in either cohort. Episodic memory was the most severely impaired cognitive domain among MCI patients, whereas among dementia patients, multiple cognitive functions were severely impaired (with a $4 \mathrm{C}$ dementia cohort average of less than -1.5 SD worse than the Dutch norm), especially executive functioning, attention and information processing speed. 
Table 4 Baseline demographic characteristics of the participants in the $4 \mathrm{C}-\mathrm{MCI}$ and 4C-Dementia cohorts

\begin{tabular}{lll}
\hline & 4 C-MCI cohort & $\begin{array}{l}4 \text { C-Dementia } \\
\text { cohort }\end{array}$ \\
\hline $\mathrm{N}$ & 315 & 327 \\
Age at baseline (years, mean \pm SD) & $69.8 \pm 8.7$ & $75.0 \pm 10.1$ \\
Female sex & $111(35.2)$ & $179(54.7)$ \\
Caucasian & $311(98.7)$ & $323(98.8)$ \\
Education & & $9(2.8)$ unreported \\
Low (lower than middle school) & $126(40.0)$ & $140(42.8)$ \\
Middle (high school / vocational education) & $78(24.8)$ & $88(26.9)$ \\
High (university) & $111(35.2)$ & $90(27.5)$ \\
BMI (mean \pm SD) & $26.2 \pm 3.9$ & $25.9 \pm 4.2$ \\
Marital Status & & \\
Married/ registered partnership, cohabiting & $244(77.5)$ & $199(60.9)$ \\
Widow/ widower & $42(13.3)$ & $92(28.1)$ \\
Single, divorced & $29(9.2)$ & $31(9.5)$ \\
Others & 0 & $5(1.5)$ \\
Living situation & & $1(0.3)$ unreported \\
Alone, independently & $59(18.7)$ & $87(26.6)$ \\
With partner and/or children & $242(76.8)$ & $202(61.8)$ \\
In nursing home (institutionalized) & $9(2.9)$ & $21(6.4)$ \\
Others & $5(1.6)$ & $16(4.9)$ \\
Caregiver's relation with the participant & $1(0.3)$ unreported & $2(0.6)$ unreported \\
Partner & $224(71.1)$ & $168(51.4)$ \\
Son/ daughter & $60(19.5)$ & $110(33.6)$ \\
Brother/sister & $7(2.2)$ & $10(3.1)$ \\
$\quad$ Other relatives or acquaintance & $23(7.3)$ & $37(10.3)$ \\
\hline All & &
\end{tabular}

All the data represent $\mathrm{N}(\%)$, unless otherwise specified. BMI = Body Mass Index.

\section{Comorbidities and physical conditions}

Hypertension was highly prevalent in dementia patients $(50.5 \%)$ at baseline. The prevalences of other comorbidities were similar in both cohorts: diabetes mellitus $(17 \%)$, COPD (8\%), and kidney problems (8\%). By quantitative measures of disease burden (CIRS-G), vascular diseases were the most frequently and severely affected comorbid category in both cohorts. For the AD patients in the dementia cohort, it was found that comorbidities were associated with cognitive performance; frailty was associated with functional abilities at baseline (Oosterveld et al., 2014).

\section{Neuropsychiatric symptoms}

The most prevalent neuropsychiatric symptoms reported by the caregivers in the MCI cohort were irritability (50.5\%, average score 5.4 out of 12 in NPI), 
apathy / indifference $(42.5 \%, 5.3)$ and depression/dysphoria $(40.6 \%, 4.7)$. These neuropsychiatric symptoms were also the most common in the dementia cohort, with different rankings: apathy / indifference $(50.5 \%, 6.5)$, depression/dysphoria $(37.6 \%, 5.3)$, irritability $(35.5 \%, 5.3)$.

Table 5 Baseline cognitive, physical and functional characteristics and quality of life of the participants in the $4 \mathrm{C}$ studies

\begin{tabular}{|c|c|c|}
\hline & $\begin{array}{l}\text { The 4C-MCI } \\
\text { cohort }\end{array}$ & $\begin{array}{l}\text { The 4C-Dementia } \\
\text { cohort }\end{array}$ \\
\hline Duration of cognitive problems (range) & $3.3 \pm 3.8(0 \sim 32)$ & $3.1 \pm 2.6(0 \sim 18)$ \\
\hline \multicolumn{3}{|l|}{ Course of cognitive problems, $\mathrm{N}(\%)$} \\
\hline Unreported & $29(9.2)$ & $18(5.5)$ \\
\hline Progressive & $213(67.6)$ & $281(85.9)$ \\
\hline Stable & $40(12.7)$ & $14(4.3)$ \\
\hline Fluctuated & $33(10.5)$ & $14(4.3)$ \\
\hline MMSE & $26.9 \pm 2.6$ & $21.9 \pm 3.7$ \\
\hline \multicolumn{3}{|l|}{ Cognitive tests (Z-score) ${ }^{*}$} \\
\hline VLT immediate & $-1.1 \pm 1.2$ & $-2.3 \pm 1.1$ \\
\hline VLT delayed & $-1.2 \pm 1.3$ & $-2.4 \pm 0.9$ \\
\hline Animal fluency & $-0.7 \pm 0.8$ & $-1.7 \pm 0.9$ \\
\hline TMT-A & $-0.3 \pm 1.4$ & $-1.7 \pm 1.9$ \\
\hline TMT-B & $-0.4 \pm 1.3$ & $-1.5 \pm 1.7$ \\
\hline Stroop card $1+2$ (mean) & $-1.2 \pm 1.7$ & $-2.8 \pm 2.5$ \\
\hline Stroop card 3 & $-1.2 \pm 2.4$ & $-3.8 \pm 3.8$ \\
\hline GDS-15 & $3.6 \pm 2.8$ & $3.2 \pm 2.7$ \\
\hline NPI total score & $14.5 \pm 15.0$ & $16.4 \pm 16.4$ \\
\hline CIRS-G total score (range) & $7.09 \pm 4.87(0 \sim 23)$ & $9.07 \pm 4.68(1 \sim 25)$ \\
\hline CIRS-G severity index & $0.55 \pm 0.37$ & $0.58 \pm 0.38$ \\
\hline CIRS-G comorbidity index (range) & $2.25 \pm 1.93(0 \sim 8)$ & $3.08 \pm 1.84(0 \sim 9)$ \\
\hline DAD & $86.74 \pm 15.70$ & $70.36 \pm 24.65$ \\
\hline \multicolumn{3}{|l|}{ Frailty, N (\%) } \\
\hline insufficient information & $22(7.0)$ & $17(5.2)$ \\
\hline Not frail $(\leq 1)$ & $219(69.5)$ & $215(65.7)$ \\
\hline Pre-frail (2) & $44(14.0)$ & $49(15.0)$ \\
\hline Frail $(\geq 3)$ & $30(9.5)$ & $46(14.1)$ \\
\hline EQ-5D VAS & $69.35 \pm 15.63$ & $67.26 \pm 17.79$ \\
\hline
\end{tabular}

All the data are presented as mean (SD) unless otherwise specified. MMSE $=$ Mini Mental State Examination; VLT $=$ Verbal Learning Test; TMT-A $=$ Trailmaking Test part A; TMT-B = Trailmaking Test part B; SCWT $=$ Stroop Colour Word Test; GDS-15 = Geriatric Depression Scale; NPI = Neuropsychiatric Inventory; CIRS-G = Cumulative Illness Rating Scale for Geriatrics; DAD = Disability Assessment for Dementia; EQ-5D = Euroqol 5D;

* Despite the application of the Petersen criteria for definition of $\mathrm{MCI}$, mean cognitive scores on the different domains may be above -1.5 sd of the Dutch norm scores, because people with SCD were included in the $4 \mathrm{C}$ MCI cohort, but do not satisfy the MCI criteria, also MCI patients were not required to score below $-1.5 \mathrm{sd}$ on all domains assessed. 


\section{Disease trajectories and progression}

In the MCI cohort, 225 subjects ( $71 \%$ ) were classified as MCI at baseline and 90 subjects $(29 \%)$ as SCI, based on the cognitive test results. After 3 follow-ups, 23 subjects $(23 / 90,26 \%)$ classified as SCI at baseline were reclassified as MCI, 23 subjects $(23 / 225,10 \%)$ with MCI reverted to SCI, and 74 subjects (10 subjects with $\mathrm{SCI}$ at baseline and 64 subjects with $\mathrm{MCI}$ at baseline) progressed to different types of dementia (supplementary table 2). The annual incidence of MCI subjects progressing to dementia was $11 \%(32 / 278)$ in the first year, $7 \%(18 / 260)$ in the second year and $10 \%(24 / 236)$ in the third year of follow up. In the dementia cohort, 58 patients (18\%) received a different nosological diagnosis of dementia during follow-up. 16 patients (5\%) in the MCI cohort and $72(22 \%)$ in the Dementia cohort died during follow-up.

\section{What are the main strengths and weaknesses?}

One of the main research questions for the $4 \mathrm{C}$ studies was whether the interaction with health status would influence the natural disease course of $\mathrm{MCI}$ and dementia and would contribute to the heterogeneity of clinical outcomes. Thus, including participants with comorbidity in the study - rather than excluding them, which is regularly done in $\mathrm{MCI}$ and dementia research - while assessing the disease burden was the essential strength of our studies.

Prospectively sampling diverse participants with natural disease courses from various routine clinical settings (neurology, geriatrics and psychiatry departments) who were representative for the MCI and dementia patients regularly seen in memory clinics was another strength. Finally, cognitive functioning is a central feature of MCI and dementia. In the $4 \mathrm{C}$ studies, in addition to global measures of cognition, standardized and validated neuropsychological tests were available to detail how different cognitive domains changed and to explore the effect of comorbidities on cognitive functioning in different domains over time.

Although separated into two cohorts by disease phases, the 4C-MCI and 4CDementia cohorts were the same in essence, with comparable research objectives. Discerning typical disease trajectories based on long-term observation and developing prediction models for disease progression would be beneficial for patient care. However, for FTD, DLB or other rarer types of dementia, due to limited cases, more efforts should be made to include more patients in future studies to increase the power or combining the current samples with other studies.

Attrition was the biggest challenge for the $4 \mathrm{C}$ studies, although it is inevitable due to the nature of the disease and the aged population. In the MCI cohort, 227 of 315 (72\%) participants completed either the entire follow up $(211 ; 67 \%)$ or reached the endpoint of death (16; 5\%). In the Dementia cohort, 212 of $327(65 \%)$ participants completed either the follow up $(140 ; 43 \%)$ or reached the endpoint of death $(72$; 
$22 \%$ ). In order to minimize the dropout rate and collect as much research data as possible, whenever possible home visits by a well-trained researcher to the participant's residence or nursing home were implemented, for those participants who were willing to continue participation in the study but unable to visit the memory clinics.

\section{Can I get hold of the data? Where can I find out more?}

The $4 \mathrm{C}$ research group actively encourages and welcomes external collaborations. Data is available for researchers with a specific research question. Interested and potential collaborators are invited to contact the study coordinators (Dr. René Melis: Rene.Melis@radboudumc.nl or Dr. Inez Ramakers:

i.ramakers@maastrichtuniversity.nl). 


\section{REFERENCES}

Aalten, P., Ramakers, I., Biessels, G., de Deyn, P., Koek, H.L., OldeRikkert, M., et al. (2014). The Dutch Parelsnoer Institue - Neurodegenerative diseases; methods, design and baseline results. BioMedCentral Neurology, 14, 1060.

American Psychiatric Association (1994). Diagnostic and Statistical Manual of Mental Disorders, Fourth Edition (DSM-IV). American Psychiatric Association: Washington, DC.

Alzheimer's Disease International (2010). World Alzheimer Report 2010: The Global Economic Impact of Dementia.

Boyle, P.A., Buchman, A.S., Wilson, R.S., Leurgans, S.E., Bennett, D.A. (2009). Association of muscle strength with the risk of Alzheimer disease and the rate of cognitive decline in community-dwelling older persons. Archives of Neurology, 66, 1339-44.

Brand, N. \& Jolles, J. (1985). Learning and retrieval rate of words presented auditorily and visually. Journal of General Psychology, 112, 201-10.

Buchman, A.S., Schneider, J.A., Leurgans, S., Bennett, D.A. (2008). Physical frailty in older persons is associated with Alzheimer disease pathology. Neurology, 71, 499-504.

Cummings, J. L. (1997). The Neuropsychiatric Inventory: assessing psychopathology in dementia patients. Neurology, 48, S10-6.

Dolgin M. (1994). Nomenclature and criteria for diagnosis of diseases of the heart and great vessels. 9th edition. Boston; London: Little Brown \& company.

Folstein, M. F., Folstein, S. E. \& McHugh, P. R. (1975). "Mini-mental state". A practical method for grading the cognitive state of patients for the clinician. Journal of Psychiatric Research, 12, 189-98.

Fotuhi, M., Hachinski, V. \& Whitehouse, P. J. (2009). Changing perspectives regarding late-life dementia. Nature Reviews Neurology, 5, 649-658.

Fried, L. P., Tangen, C. M., Walston, J., Newman, A. B., Hirsch, C., Gottdiener, J., Seeman, T., Tracy, R., Kop, W. J., Burke, G., McBurnie, M. A. \& Cardiovascular Health Study Collaborative Research, G. (2001). Frailty in older adults: evidence for a phenotype. Journals of Gerontololgy Series A: Biological Sciences and Medical Sciences, 56, M146-56.

Gelinas, I., Gauthier, L., McIntyre, M. \& Gauthier, S. (1999). Development of a functional measure for persons with Alzheimer's disease: the disability assessment for dementia. American Journal of Occupational Therapy, 53, 471-81.

Global Initiative for Chronic Obstructive Lung Disease (2014). Global strategy for the diagnosis, management and prevention of COPD.

Hammes, J. (1973). De Stroop Kleur-Woord Test: Handleiding [The Stroop ColorWord Test: Manual]. Swets \& Zeitlinger: Amsterdam.

Hudon, C., Fortin, M. \& Soubhi, H. (2007). Abbreviated guidelines for scoring the Cumulative Illness Rating Scale (CIRS) in family practice. Journal of Clinical Epidemiology, 60, 212.

Kok, R. M. \& Verhey, F. R. J. (2002). Dutch Translation of the Mini Mental State Examination (Folstein et al. 1975).

Leoutsakos J.M., Forrester S.N., Corcoran C.D., Norton M.C., Rabins P.V., Steinberg M.I., et al. (2014). Latent classes of course in Alzheimer's disease and predictors: the Cache County Dementia Progression Study. International Journal of Geriatric Psychiatry. 
Leoutsakos, J.M., Han, D. Mielke, M.M., Forrester, S.N., Tschanz, J.T., Corcoran, C.D., et al (2012). Effects of general medical health on Alzheimer's progression: the Cache County Dementia Progression Study. International Psychogeriatrics, 24, 1561-70.

Lezak, M. (2004). Neuropsychological Assessment. 4th edition. Oxford University Press: New York.

Lindeboom, J., Schmand, B., Tulner, L., Walstra, G. \& Jonker, C. (2002). Visual association test to detect early dementia of the Alzheimer type. Journal of Neurology Neurosurgery and Psychiatry, 73, 126-33.

Marengoni, A., Rizzuto, D., Wang, H. X., Winblad, B. \& Fratiglioni, L. (2009). Patterns of chronic multimorbidity in the elderly population. Journal of the American Geriatrics Society, 57, 225-30.

Melis, R.J., Marengoni, A., Rizzuto, D., Teerenstra, S., Kivipelto, M., Angleman, S.B., et al. (2013). The influence of multimorbidity on clinical progression of dementia in a population-based cohort. PLoS one, 8, e84014.

Miller, M. D., Paradis, C. F., Houck, P. R., Mazumdar, S., Stack, J. A., Rifai, A. H., Mulsant, B. \& Reynolds, C. F., 3rd (1992). Rating chronic medical illness burden in geropsychiatric practice and research: application of the Cumulative Illness Rating Scale. Psychiatry Research, 41, 237-48.

Morris, J. C. (1993). The Clinical Dementia Rating (CDR): Current vision and scoring rules. Neurology, 43, 2412-4.

National Kidney Foundation (2002). K/ DOQI clinical practice guidelines for chronic kidney disease: evaluation, classification, and stratification. American journal of kidney diseases: the official journal of the National Kidney Foundation, 39 (2 Suppl 1), S1-266.

Oosterveld, S. M., Kessels, R. P., Hamel, R., Ramakers, I. H., Aalten, P., Verhey, F. R., Sistermans, N., Smits, L. L., Pijnenburg, Y. A., van der Flier, W. M., Olde Rikkert, M. G. \& Melis, R. J. (2014). The Influence of Co-Morbidity and Frailty on the Clinical Manifestation of Patients with Alzheimer's Disease. Journal of Alzheimer's Disease.

Petersen, R. C., Smith, G. E., Waring, S. C., Ivnik, R. J., Tangalos, E. G. \& Kokmen, E. (1999). Mild cognitive impairment: clinical characterization and outcome. Archives of Neurology, 56, 303-8.

Reitan, R. M. (1958). Validity of the Trail Making Test as an indicator of organic brain damange. Perceptual and Motor Skills, 8, 271-76.

Searle, S.D., Mitnitski, A., Gahbauer, E.A., Gill, T.M., Rockwood, K. (2008). A standard procedure for creating a frailty index. BioMedCentral Geriatrics, 8, 24.

Sheikh, J. I. \& Yesavage, J. A. (1986). Geriatric Depression Scale (GDS): recent evidence and development of a shorter version. Clinical Gerontology : A Guide to Assessment and Intervention, 5, 165-173.

Stroop, J. R. (1992). Studies of Interference in Serial Verbal Reactions (Reprinted from Journal Experimental-Psychology, Vol 18, Pg 643-662, 1935). Journal of Experimental Psychology-General, 121, 15-23.

The EuroQol Group (1990). Euroqol - a New Facility for the Measurement of HealthRelated Quality-of-Life. Health Policy, 16, 199-208.

Tombaugh, T. N. (2004). Trail Making Test A and B: normative data stratified by age and education. Archives of Clinical Neuropsychology, 19, 203-14. 
Van der Elst, W., van Boxtel, M. P., van Breukelen, G. J. \& Jolles, J. (2005). Rey's verbal learning test: normative data for 1855 healthy participants aged $24-81$ years and the influence of age, sex, education, and mode of presentation. Journal of the International Neuropsychological Society, 11, 290-302.

van der Elst, W., van Boxtel, M. P., van Breukelen, G. J. \& Jolles, J. (2006a). The Letter Digit Substitution Test: normative data for 1,858 healthy participants aged 24-81 from the Maastricht Aging Study (MAAS): influence of age, education, and sex. Journal of Clinical and Experimental Neuropsychology, 28, 998-1009.

Van der Elst, W., Van Boxtel, M. P., Van Breukelen, G. J. \& Jolles, J. (2006b). The Stroop color-word test: influence of age, sex, and education; and normative data for a large sample across the adult age range. Assessment, 13, 62-79.

Visser, P. J., Kester, A., Jolles, J. \& Verhey, F. (2006). Ten-year risk of dementia in subjects with mild cognitive impairment. Neurology, 67, 1201-7.

Warrington, E. K. \& James, M. (1991). The Visual Object and Space Perception Battery. Thames Valley Test Company: Bury St Edmunds, England, UK.

Wechsler, D. (1997). Wechsler Memory Scale - 3rd edition: Administration and Scoring Manual. The Psychological Corporation: San Antonio.

World Health Organization (2012). Dementia: a public health priority. WHO: Geneva, Switzerland. 


\section{SUPPLEMENTARY DATA}

\section{Supplementary Table 1 Structural medical review of participant's health} conditions

\begin{tabular}{ll}
\hline Body systems & Concerned diseases \\
\hline Cardiovascular & $\begin{array}{l}\text { angina, myocardial infarction, angioplasty/stent, coronary bypass } \\
\text { surgery, carotid stenosis, hypertension, heart failure, others } \\
\text { transient ischemic attack (TIA), cerebrovascular accidents (infarction, } \\
\text { bleeding), reversible ischemic neurologic deficit (RIND), others } \\
\text { diabetes mellitus, hypothyroidism, hyperthyroidism, obesity, others }\end{array}$ \\
Endocrinal & $\begin{array}{l}\text { depression, psychosis, delirium, others } \\
\text { chronic obstructive pulmonary disease (COPD), kidney problems, } \\
\text { Somatic }\end{array}$ \\
& liver problems, others \\
\hline
\end{tabular}

\section{Supplementary Table 2 Incidence of MCI subjects progressing to dementia} within the study duration

\begin{tabular}{lccc}
\hline \multirow{2}{*}{ Study time line } & \multicolumn{2}{c}{ Number of subjects } & \multirow{2}{*}{$\%$} \\
\cline { 2 - 3 } 1 year follow-up & MCI - dementia & In the cohort & 11.5 \\
2 year follow-up & 32 & 278 & 6.9 \\
3 year follow-up & 18 & 260 & 10.1 \\
Total & 24 & 236 & 23.4 \\
\hline
\end{tabular}




\section{CHAPTER 6}

\section{THE INFLUENCE OF SEVERITY OF TOTAL COMORBIDITY ON COGNITIVE DECLINE AND CONVERSION TO DEMENTIA IN MEMORY CLINIC VISITORS}

Renske E.G. Hamel, Inez H.G.B. Ramakers, Saskia M. Oosterveld, Rene J.F. Melis, Marcel G.M. Olde Rikkert, Roy P.C. Kessels, Nicole Sistermans, Yolande A.L. Pijnenburg, Ted Koene, Wiesje M. van der Flier, Philip Scheltens, Pauline Aalten, Pieter Jelle Visser, Frans R.J. Verhey 


\section{ABSTRACT}

\section{Background}

Specific medical diseases are known to influence cognitive functioning and decline. However, most studies focus on a single risk factor and do not take multimorbidity into account. Therefore, the aim of this study was to investigate the effect of severity of total comorbidity on cognitive decline and conversion to dementia in memory clinic visitors.

\section{Methods}

This prospective cohort study is part of the Dutch Clinical Course of Cognition and Comorbidity in MCI (4C-MCI) Study and consists of 315 consecutive nondemented patients who visited the Alzheimer centers of Maastricht, Nijmegen and VUmc Amsterdam. Patients were followed annually for three years. Severity of comorbidity was rated using the Cumulative Illness Rating Scale for Geriatrics (CIRS-G). Random-effects mixed models were performed to investigate the influence of comorbidity on cognitive decline for the domains of episodic memory, executive functioning, verbal fluency and information processing speed. Time to dementia was assessed using Cox proportional hazard models.

\section{Results}

Patients were on average 69.6 years old, $34.8 \%$ was male. More severe comorbidity was associated with lower performance on information processing speed and executive functioning at baseline. Further, patients with moderate/ severe comorbidity showed a significant decline on information processing speed and verbal fluency, while patients with less comorbidity remained generally stable. However, severity of comorbidity was not associated with a higher risk of conversion to dementia after three years.

\section{Conclusion}

The severity of total comorbidity is associated with lower performance and faster decline on mental speed dependent tests, and should thus be taken into account when evaluating cognitive performance in clinical practice. However, severity of comorbidity is not associated with a higher risk of conversion to dementia. 


\section{INTRODUCTION}

The increasing prevalence of dementia poses a major challenge for society and health care systems, and therefore creates an urgent need for early diagnosis to initiate timely care and treatment. People with Mild Cognitive Impairment (MCI), which is known as the transitional state between normal cognitive functioning and dementia, are at increased risk for developing dementia. However, due to differences in the underlying cause of the impairment, MCI is a heterogeneous concept, with large individual differences in course and prognosis.

This variation in the natural course of decline in MCI might be affected by medical illnesses, which are known to influence cognitive functioning and decline.

Multiple medical diseases, but especially (cardio)vascular factors have been related to cognitive impairment and / or (more rapid) cognitive decline in the cognitively healthy population (Aleman et al., 2005, Arntzen et al., 2011, Lipnicki et al., 2013, Spauwen et al., 2013, van Boxtel et al., 1997). These (cardio)vascular factors have also been related to worse cognitive performance and cognitive decline in people with MCI (Ettorre et al., 2012, Siuda et al., 2007, Villeneuve et al., 2009) and were associated with an increased risk of developing dementia (Akomolafe et al., 2006, Mielke et al., 2007, Solfrizzi et al., 2004).

Unfortunately, most studies tend to focus on one specific disease or a specific cluster of diseases (e.g. cardiovascular factors), thereby ignoring the increased burden of multimorbidity that is typically associated with advancing age (Uijen and van de Lisdonk, 2008). Few studies have examined the impact of multiple comorbid diseases on cognitive functioning. These studies showed that cumulative medical illness is related to worse cognitive performance (Morrow et al., 2009) and cognitive decline in the elderly population (Patrick et al., 2002). Further, total comorbidity burden has also been related to worse cognitive performance and cognitive decline in people with dementia (Doraiswamy et al., 2002, Oosterveld et al., 2014, Solomon et al., 2011).

Summarizing, there is evidence that certain medical diseases are associated with cognitive decline and conversion to dementia. However, most studies remain inconclusive in identifying all medical risk factors and do not take multimorbidity into account. Therefore, the aim of this study was to evaluate the effect of the severity of total medical comorbidity on cognitive decline and conversion to dementia within 3-years in memory clinic visitors.

\section{METHODS}

Data from the Clinical Course of Cognition and Comorbidity in MCI (4C-MCI) study was used. The prospective 4C-MCI study is a longitudinal multicenter study into the course of cognitive decline in non-demented memory clinic visitors. 
Participants for the present study were included from the memory clinics of Maastricht University Medical Centre, Radboud university medical centre and VU Medical Centre Amsterdam between January 2010 and May 2011. Participants were followed annually for three years. The local Medical Ethical Committee of each centre approved the study. All participants provided written informed consent.

\section{Participants}

The study included 315 patients at baseline who were classified as having either objectified cognitive impairment (MCI) or no objectified cognitive impairment (SCI), based on neuropsychological test results. Inclusion criteria were: 1 ) age $\geq 55$ years, 2) the presence of subjective cognitive complaints and/or objective impairments, in absence of dementia, and 3) a Clinical Dementia Rating (CDR) (Morris, 1993) score of $\leq 0.5$. Exclusion criteria were: 1 ) the absence of a primary caregiver (who has contact with the participant at least once a week), 2) the expectation that the participant would not be able to have at least one follow-up, and 3) presence of specific neurological disorders that could have caused cognitive impairment: Parkinson's or Huntington's disease, Normal Pressure Hydrocephalus, Korsakoff's syndrome, and a medical history of brain tumor or encephalitis. Participants having any other comorbidities, including cerebrovascular or psychiatric disorders were not excluded in this study.

\section{Baseline assessment}

At baseline, all patients underwent a standardized clinical assessment, which included a detailed (medical) history of the patient, a psychiatric, neurologic and physical examination, assessments of daily functioning, appropriate laboratory tests, an extensive neuropsychological assessment (see below) and a magnetic resonance imaging (MRI) scan. These assessments were part of the regular patient diagnostic procedures of the memory clinics. Baseline diagnosis of MCI was defined as a z-score lower than -1.5 SD on any neuropsychological test. All other subjects were classified as having SCI. For the current study we extracted data on age, gender, level of education, study centre, medical comorbidity, neuropsychological test scores at baseline and follow-up, dementia status at follow-up and date of dementia diagnosis.

\section{Assessment of medical comorbidity}

All available information on comorbidity from the medical history, data on medication use, smoking habits and alcohol usage and information from the 
physical examination was summarized and scored using the Cumulative Illness Rating Scale for geriatrics (CIRS-G) (Miller et al., 1992). Scores between zero (no problems) and four (extremely severe problems) were given to 14 categories of organ systems (i.e. heart; vascular; hematopoietic; respiratory; eyes, ears, nose, throat and larynx; upper gastrointestinal tract; lower gastrointestinal tract; liver; renal; genito-urinary; musculoskeletal; neurological, endocrine/metabolic and breast; psychiatric). For this study an adapted version of the CIRS-G was used, excluding the psychiatric illness category since this category includes psychiatric and cognition related comorbidities. By excluding the psychiatric category the CIRS-G was used as a measure of pure physical comorbidity, thus avoiding overlap with cognitive functioning. The possible total score of this adapted version varies from 0 to 52 . In addition to the total score, the CIRS-G severity index was calculated by dividing the CIRS-G total score by the number of categories endorsed. This severity index reflects a more precise estimate of the general severity of comorbidity than the CIRS total score, since it allows us to see whether the CIRS total score reflects a few serious problems or multiple problems of mild severity. The severity index can range between 0 and 4 .

\section{Neuropsychological assessment}

The neuropsychological assessment investigated the following cognitive domains: episodic memory, information processing speed, executive functioning and verbal fluency. Episodic memory was assessed by means of the Dutch adaptation of the Verbal Learning Task (VLT) (Lezak et al., 2004, Van der Elst et al., 2005). The score at the delayed recall trial was chosen as measure of episodic memory. Information processing speed and executive functioning were measured with the Stroop Colour Word Test (SCWT) (Hammes, 1973) and Trail Making Test (TMT) (Lezak et al., 2004, Schmand et al., 2003). The average of SCWT cards 1 and 2 (SCWT $1-2$ ) was used as a measure of information processing speed, as was TMT part A. An interference index from the SCWT, calculated as Card $3-$ [(Card $1+$ Card 2) / 2] (Van der Elst et al., 2006c), as well as TMT part B were used to measure executive functioning. For assessing verbal fluency, a one-minute animal fluency test was used (Van der Elst et al., 2006b). All neuropsychological test scores were converted to z-scores adjusted for age, sex and education, based on norms for the Dutch healthy population (Schmand et al., 2003, Van der Elst et al., 2005, 2006a, b, c).

\section{Follow-up assessment}

Follow-up assessments were conducted annually, for a total of three years. Assessments at follow-up were comparable to baseline, except for medical history. At follow-up participants and caregivers were asked if there had been any medical 
changes since baseline (e.g. a new medical diagnosis), if the participant had been admitted to the hospital during that year, and if there had been made any medication changes. Diagnosis of dementia at follow-up was made according to the DSM-IV criteria (American Psychiatric Association, 2000). Alzheimer's disease was diagnosed according to NINCDS-ADRDA criteria (McKhann et al., 1984), vascular dementia according to NINCDS-AIREN criteria (Roman et al., 1993), Lewy Body dementia according to the McKeith criteria (McKeith et al., 2005) and frontotemporal dementia according to the Neary criteria (Neary et al., 1998).

\section{Statistical analyses}

Analyses were performed using STATA version 12 for Mac OS X. Significance was set at $p<0.05$ in two-sided tests. Baseline differences between diagnostic groups were compared using t-tests for continuous variables and chi-square tests for categorical variables.

For medical comorbidity, the CIRS total score and severity index were trichotomized $(0=$ no problems; 1 = mild problems; 2 = moderate to severe problems) based on tertiles in the distribution of the respective scores, because of the right-skewedness in the distribution of the scores. For the same reason the scores of the subcategories of the CIRS-G were also trichotomized (using the same coding).

The influence of severity of total comorbidity (measured by CIRS total score and CIRS severity index) on cognitive decline was assessed using random-effects (linear mixed) models, thereby accounting for the fact that repeated measurements are correlated within individuals. First models with random intercepts were specified. Random slopes were included if likelihood ratio testing (LRT) suggested that this gave better fit compared to the model with only a random incept. To study differences in rate of decline over time between different comorbidity groups $(0=$ no comorbidity, $1=$ mild comorbidity, $2=$ moderate $/$ severe comorbidity), a group-by-time interaction term was added. In addition, we tested whether rate of decline over time differed between baseline diagnostics groups $(0$ $=\mathrm{SCI}, 1=\mathrm{MCI}$ ) per comorbidity severity group by adding a diagnosis-by-groupby-time interaction. For explorative purposes, analyses were repeated using the CIRS subcategory scores, to see whether results could be attributed to specific comorbidity clusters. The influence of severity of comorbidity on conversion to dementia was assessed using cox proportional hazards regression to assess differences in hazard ratios (HRs) between comorbidity groups. Observations were censored at date of dementia diagnosis or date of last neuropsychological assessment. All analyses were corrected for current age, sex, study centre and education. 


\section{RESULTS}

Characteristics of the participants at study entry, according to baseline diagnosis (MCI/SCI) and for the total group, are presented in table 1. Compared to patients with SCI, patients with MCI were older at baseline and scored significantly lower on all neuropsychological tests. Further, MCI patients had more severe total comorbidity, as indicated by a higher score on both the CIRS total score and the CIRS severity index.

\section{Baseline associations}

At baseline, the presence of moderate/severe comorbidity as measured by the CIRS total score was associated with significantly lower performance on TMT-A, TMT-B and SCWT $1-2$. The presence of moderate/severe comorbidity as measured with the CIRS severity index was also associated with lower performance on the TMT-A, SCWT $1-2$ and SCWT interference (table 2; figure 1).

Table 1 Baseline characteristics

\begin{tabular}{|lccc|}
\hline \multicolumn{1}{|c}{ Variable } & Overall & SCI & MCI \\
\hline \hline$n$ Age, y & 315 & 90 & 225 \\
Sex (\% female) & $69.8(8.7)$ & $66.9(8.3)$ & $70.7(8.3)^{* *}$ \\
Education & $34.8 \%$ & $33.3 \%$ & $35.5 \%$ \\
$\%$ Low & & & \\
$\%$ Middle & $39.0 \%$ & $36.7 \%$ & $40.0 \%$ \\
$\%$ High & $25.2 \%$ & $26.6 \%$ & $24.5 \%$ \\
MMSE & $35.8 \%$ & $36.7 \%$ & $35.5 \%$ \\
VLT delayed recall & $-1.9(2.9)$ & $-0.7(2.0)$ & $-2.4(3.1)^{* *}$ \\
Fluency & $-1.2(1.3)$ & $-0.1(1.0)$ & $-1.6(1.2)^{* *}$ \\
TMT-A & $-0.7(0.8)$ & $-0.2(0.7)$ & $-0.9(0.8)^{* *}$ \\
TMT-B & $-0.3(1.4)$ & $0.4(0.9)$ & $-0.6(1.5)^{* *}$ \\
SCWT 1 - 2 & $-0.4(1.3)$ & $0.4(1.0)$ & $-0.8(1.3)^{* *}$ \\
SCWT interference & $-1.2(1.7)$ & $-0.1(0.7)$ & $-1.6(1.7)^{* *}$ \\
CIRS-G total score & $-0.9(2.4)$ & $0.3(0.8)$ & $-1.4(2.7)^{* *}$ \\
CIRS Severity Index & $7.0(4.9)$ & $5.9(4.6)$ & $7.5(4.9)^{* *}$ \\
Follow-up length, y & $1.6(0.5)$ & $1.4(0.5)$ & $1.6(0.5)^{* *}$ \\
\hline
\end{tabular}

Data are presented as mean (SD) unless otherwise specified. Cognitive test scores are presented as zscores. MMSE = Mini Mental State Examination; VLT = Verbal Learning Test; TMT-A = Trail Making Test part A; TMT-B $=$ Trail Making Test part B; SCWT $1-2=$ Stroop Colour Word Test average of cards 1 and 2; SCWT interference $=$ Stroop Colour Word Test interference index; CIRS-G $=$ Cumulative Ilness Rating Scale for Geriatrics.

$$
\begin{array}{ll}
* & p<0.05 \\
* * & p<0.01
\end{array}
$$


Table 2 Baseline associations between severity of comorbidity and cognitive performance

\begin{tabular}{|c|c|c|c|c|c|c|}
\hline \multirow{2}{*}{\multicolumn{2}{|c|}{$\begin{array}{l}\text { Comorbidity } \\
\text { category }\end{array}$}} & \multirow{2}{*}{$\begin{array}{c}\text { Neuropsychological } \\
\text { test }\end{array}$} & \multirow{2}{*}{$\begin{array}{l}\text { Baseline } \\
\text { score }\end{array}$} & \multirow[t]{2}{*}{ p-value } & \multicolumn{2}{|c|}{ Interaction effect } \\
\hline & & & & & $\chi^{2}$ & p-value \\
\hline CIRS & None & TMT-B & $-0.20(0.15)$ & 0.17 & & \\
\hline total & Mild & & $-0.43(0.13)$ & $<0.01$ & 1.40 & 0.24 \\
\hline \multirow[t]{16}{*}{ score } & Moderate & & $-0.63(0.16)$ & $<0.01$ & 4.12 & 0.04 \\
\hline & None & TMT-A & $-0.06(0.14)$ & 0.66 & & \\
\hline & Mild & & $-0.28(0.12)$ & 0.03 & 1.32 & 0.25 \\
\hline & Moderate & & $-0.62(0.14)$ & $<0.01$ & 7.09 & $<0.01$ \\
\hline & None & SCWT 1 - 2 & $-0.90(0.18)$ & $<0.01$ & & \\
\hline & Mild & & $-1.07(0.16)$ & $<0.01$ & 0.50 & 0.48 \\
\hline & Moderate & & $-1.59(0.19)$ & $<0.01$ & 7.32 & $<0.01$ \\
\hline & None & SCWT interference & $-1.00(0.22)$ & $<0.01$ & & \\
\hline & Mild & & $-0.79(0.19)$ & $<0.01$ & 0.50 & 0.48 \\
\hline & Moderate & & $-0.97(0.23)$ & $<0.01$ & 0.01 & 0.92 \\
\hline & None & Fluency & $-0.62(0.09)$ & $<0.01$ & & \\
\hline & Mild & & $-0.65(0.08)$ & $<0.01$ & 0.09 & 0.76 \\
\hline & Moderate & & $-0.83(0.08)$ & $<0.01$ & 2.43 & 0.12 \\
\hline & None & VLT delayed & $-1.33(0.14)$ & $<0.01$ & & \\
\hline & Mild & & $-1.01(0.12)$ & $<0.01$ & 2.86 & 0.09 \\
\hline & Moderate & & $-1.07(0.13)$ & $<0.01$ & 1.72 & 0.19 \\
\hline CIRS & None & TMT-B & $-0.32(0.13)$ & 0.01 & & \\
\hline Severity & Mild & & $-0.38(0.13)$ & $<0.01$ & 0.04 & 0.84 \\
\hline \multirow[t]{19}{*}{ Index } & Moderate & & $-0.66(0.15)$ & $<0.01$ & 2.49 & 0.11 \\
\hline & None & TMT-A & $-0.16(0.13)$ & 0.20 & & \\
\hline & Mild & & $-0.34(0.13)$ & $<0.01$ & 1.08 & 0.30 \\
\hline & Moderate & & $-0.55(0.14)$ & $<0.01$ & 4.20 & 0.04 \\
\hline & None & SCWT 1 - 2 & $-1.00(0.16)$ & $<0.01$ & & \\
\hline & Mild & & $-1.11(0.16)$ & $<0.01$ & 0.35 & 0.56 \\
\hline & Moderate & & $-1.53(0.19)$ & $<0.01$ & 4.82 & 0.03 \\
\hline & None & SCWT interference & $-0.67(0.19)$ & $<0.01$ & & \\
\hline & Mild & & $-0.91(0.20)$ & $<0.01$ & 0.66 & 0.42 \\
\hline & Moderate & & $-1.29(0.24)$ & $<0.01$ & 3.89 & 0.04 \\
\hline & None & SCWT interference & $-0.67(0.19)$ & $<0.01$ & & \\
\hline & Mild & & $-0.91(0.20)$ & $<0.01$ & 0.66 & 0.42 \\
\hline & Moderate & & $-1.29(0.24)$ & $<0.01$ & 3.89 & 0.04 \\
\hline & None & Fluency & $-0.70(0.08)$ & $<0.01$ & & \\
\hline & Mild & & $-0.75(0.08)$ & $<0.01$ & 0.14 & 0.70 \\
\hline & Moderate & & $-0.67(0.09)$ & $<0.01$ & 0.07 & 0.79 \\
\hline & None & VLT delayed recall & $-1.10(0.12)$ & $<0.01$ & & \\
\hline & Mild & & $-1.10(0.12)$ & $<0.01$ & 0.00 & 0.98 \\
\hline & Moderate & & $-1.19(0.14)$ & $<0.01$ & 0.19 & 0.66 \\
\hline
\end{tabular}

Data are presented as z-cores. VLT delayed $=$ Verbal Learning Test delayed recall; TMT-A $=$ Trail Making Test part A; TMT-B = Trail Making Test part B; SCWT $1-2=$ Stroop Colour Word Test average of cards 1 and 2; SCWT interference $=$ Stroop Colour Word Test interference index. 
Figure 1 Baseline cognitive performance per comorbidity category for CIRS total score (upper graph) and CIRS severity index (lower graph)
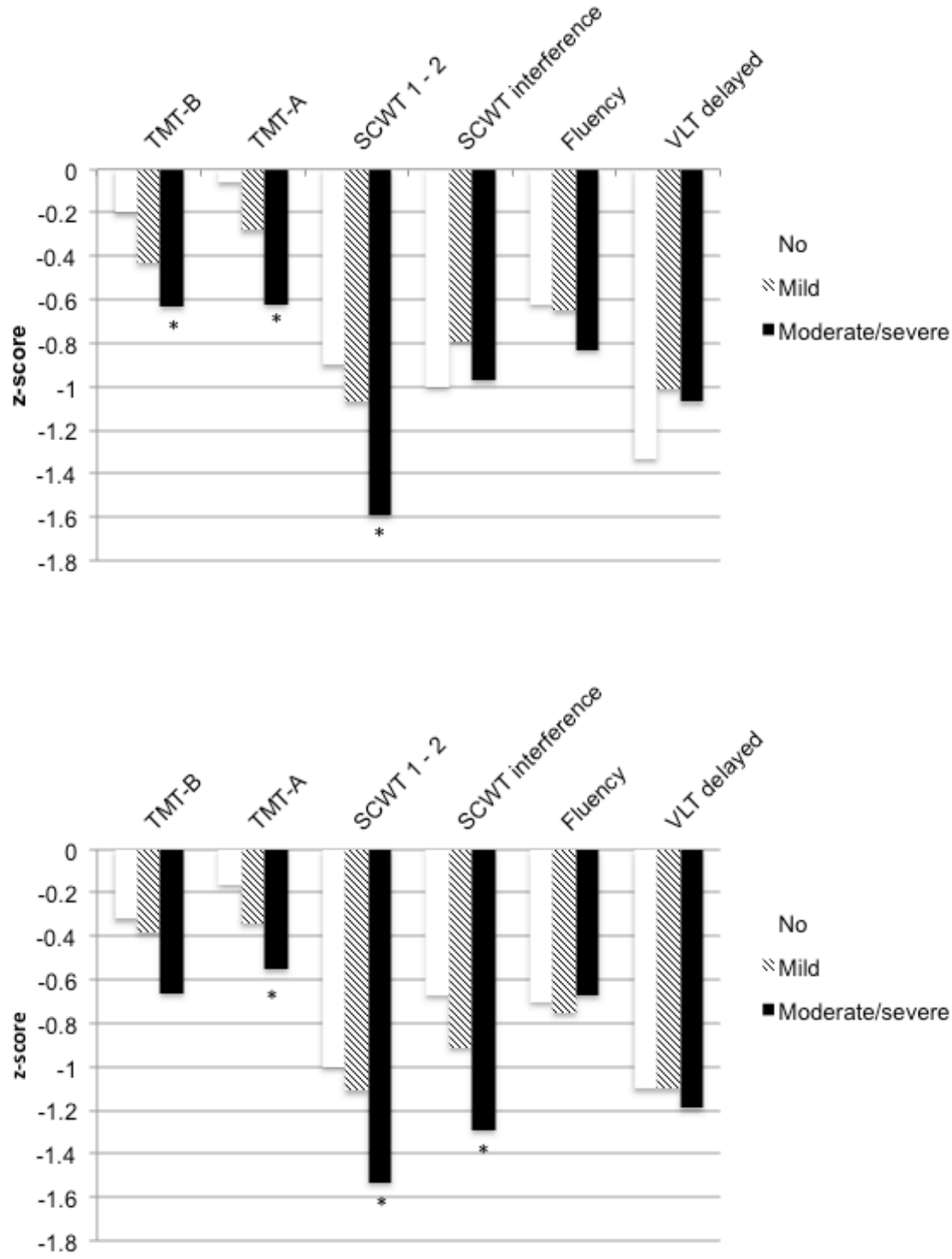

- $\quad$ significantly different from no comorbidity group

VLT delayed $=$ Verbal Learning Test delayed recall; TMT-A $=$ Trail Making Test part A; TMT-B = Trail Making Test part B; SCWT $1-2$ = Stroop Colour Word Test average of cards 1 and 2; SCWT interference $=$ Stroop Colour Word Test interference index. 


\section{Cognitive decline}

Random effects models comparing the slope of cognitive decline between subjects with no, mild and moderate/severe comorbidity showed a significant group-bytime interaction effect. Stratified analyses showed that subjects with moderate/severe comorbidity as measured by the CIRS severity index declined significantly on verbal fluency and TMT-A, while subjects without comorbidity and with mild comorbidity remained generally stable (table 3; figure 2). On the other cognitive tests, there was no significant decline over time in any of the comorbidity groups (table 3).

Next, we studied the effect of baseline diagnostic group (SCI vs. MCI) on decline over time per comorbidity group by including a three-way interaction term in the analyses. A significant diagnosis-by-group-by-time interaction suggested that rates of decline per comorbidity group differed between patients with MCI or SCI only for VLT delayed recall, but not for other tests. Stratified analyses specified that SCI subjects with moderate/severe comorbidity showed significant decline on the VLT delayed recall (beta $=-0.43, p$-value $<0.01$ ) while all other subjects (regardless their baseline diagnosis or severity of comorbidity) remained generally stable on the VLT delayed recall.

\section{Association with specific comorbidities}

We repeated our analyses using CIRS subcategory scores instead of total comorbidity scores to see whether specific clusters of disease were mainly associated with lower performance and/or faster decline. Results showed that significant associations between severity of comorbidity and cognitive performance existed predominantly in the cardiac, respiratory, neurological and endocrine domain. Significant results were again only found for TMT-A, TMT-B SCWT $1-2$, and verbal fluency (see supplementary table 1). Further, more severe comorbidity in the heart and respiratory domain was associated with faster decline on TMT-A (beta $=-0.26, p<0.01$ and beta $=-0.17 p=0.04$ respectively). In the other disease clusters there was generally no association between severity of comorbidity and cognitive performance or decline (results not shown).

\section{Conversion to dementia}

At three years follow-up, 37 people had dropped out of the study. Drop-outs were older at baseline and scored significantly lower on the MMSE, TMT-A, TMT-B and SCWT 1 - 2. Further, drop-outs were more often classified as MCI baseline and 
Table 3 Influence of comorbidities on cognitive decline

\begin{tabular}{|c|c|c|c|c|c|c|}
\hline \multirow{2}{*}{\multicolumn{2}{|c|}{$\begin{array}{l}\text { Comorbidity } \\
\text { category }\end{array}$}} & \multirow{2}{*}{$\begin{array}{c}\text { Neuropsychological } \\
\text { test }\end{array}$} & \multirow[t]{2}{*}{ B (SE) } & \multirow[t]{2}{*}{ p-value } & \multicolumn{2}{|c|}{ Interaction effect } \\
\hline & & & & & $\chi^{2}$ & p-value \\
\hline \multirow{18}{*}{$\begin{array}{l}\text { CIRS } \\
\text { total } \\
\text { score }\end{array}$} & No & TMT-B & $-0.05(0.06)$ & 0.37 & & \\
\hline & Mild & & $0.08(0.05)$ & 0.10 & 3.16 & 0.08 \\
\hline & Moderate & & $-0.01(0.06)$ & 0.84 & 0.24 & 0.63 \\
\hline & No & TMT-A & $0.03(0.08)$ & 0.72 & & \\
\hline & Mild & & $0.09(0.07)$ & 0.16 & 0.42 & 0.52 \\
\hline & Moderate & & $-0.17(0.08)$ & 0.02 & 3.51 & 0.06 \\
\hline & No & SCWT $1-2$ & $-0.18(0.10)$ & 0.08 & & \\
\hline & Mild & & $-0.14(0.09)$ & 0.13 & 0.12 & 0.73 \\
\hline & Moderate & & $-0.10(0.11)$ & 0.35 & 0.31 & 0.58 \\
\hline & No & SCWT interference & $-0.05(0.16)$ & & & \\
\hline & Mild & & $0.05(0.14)$ & 0.72 & 0.22 & 0.64 \\
\hline & Moderate & & $-0.18(0.16)$ & 0.27 & 0.32 & 0.57 \\
\hline & No & Fluency & $-0.06(0.05)$ & 0.18 & & \\
\hline & Mild & & $-0.05(0.04)$ & 0.17 & 0.02 & 0.89 \\
\hline & Moderate & & $-0.01(0.04)$ & 0.75 & 0.63 & 0.43 \\
\hline & No & VLT delayed & $0.01(0.06)$ & 0.82 & & \\
\hline & Mild & & $0.01(0.05)$ & 0.79 & 0.00 & 0.99 \\
\hline & Moderate & & $0.10(0.05)$ & 0.08 & 1.15 & 0.28 \\
\hline \multirow{18}{*}{$\begin{array}{l}\text { Severity } \\
\text { index }\end{array}$} & No & TMT-B & $0.06(0.05)$ & 0.22 & & \\
\hline & Mild & & $0.01(0.05)$ & 0.84 & 0.53 & 0.47 \\
\hline & Moderate & & $-0.06(0.07)$ & 0.40 & 1.95 & 0.16 \\
\hline & No & TMT-A & $0.05(0.07)$ & 0.50 & & \\
\hline & Mild & & $0.06(0.07)$ & 0.39 & 0.02 & 0.88 \\
\hline & Moderate & & $-0.17(0.08)$ & 0.04 & 4.05 & 0.04 \\
\hline & No & SCWT $1-2$ & $-0.18(0.09)$ & 0.05 & & \\
\hline & Mild & & $-0.06(0.09)$ & 0.53 & 0.88 & 0.35 \\
\hline & Moderate & & $-0.17(0.12)$ & 0.14 & 0.00 & 0.97 \\
\hline & No & SCTW interference & $0.0(0.14)$ & 0.99 & & \\
\hline & Mild & & $-0.09(0.15)$ & 0.56 & 0.18 & 0.67 \\
\hline & Moderate & & $-0.10(0.18)$ & 0.57 & 0.17 & 0.68 \\
\hline & No & Fluency & $-0.03(0.04)$ & 0.60 & & \\
\hline & Mild & & $0.02(0.04)$ & 0.60 & 0.52 & 0.47 \\
\hline & Moderate & & $-0.16(0.05)$ & $<0.01$ & 4.71 & 0.03 \\
\hline & No & VLT delayed & $0.01 \quad(0.05)$ & & & \\
\hline & Mild & & $0.11(0.05)$ & 0.03 & 1.45 & 0.23 \\
\hline & Moderate & & $-0.06(0.06)$ & 0.34 & 1.00 & 0.32 \\
\hline
\end{tabular}

Data are presented as z-scores. VLT delayed $=$ Verbal Learning Test delayed recall; TMT-A $=$ Trail Making Test part A; TMT-B $=$ Trail Making Test part B; SCWT $1-2=$ Stroop Colour Word Test average of cards 1 and 2; SCWT interference $=$ Stroop Colour Word Test interference index. 
had more severe comorbidity as measured by both the CIRS total score and severity index.

Of the remaining 278 subjects at third follow-up, $74(26.6 \%)$ had converted to dementia within the three years. Converters were older at baseline and scored lower on all neuropsychological tests, except TMT-A and SCWT 1 - 2, compared to non-converters. Total severity of comorbidity at baseline did not differ between groups. Total severity of comorbidity was not associated with a higher risk of conversion to dementia after 3 years, both measured with the severity index $(\mathrm{HR}=$ 1.3; 95\% CI: $0.72 ; 1.78, p=0.60)$ and the CIRS total score ( $\mathrm{HR}=0.90 ; 95 \% \mathrm{CI}: 0.54$; $1.49, p=0.67)$.

\section{DISCUSSION}

To the best of our knowledge, this study is the first longitudinal multicenter study that aimed to evaluate the association between the severity of total medical comorbidity and cognitive performance, decline and conversion to dementia in memory clinic visitors. We found that the severity of total comorbidity was related to worse cognitive performance in executive functioning and information processing speed, and that it was also related to faster cognitive decline on verbal fluency and information processing speed. On the contrary, severity of total comorbidity was not associated with an increased risk of conversion to dementia within three years.

Our results indicate that in particular the cognitive domains of information processing speed, executive functioning and verbal fluency are influenced by the severity of comorbidity. All tests used to assess these functions (i.e. TMT AB, SCWT and verbal fluency) are (partially) based on mental speed. So, our findings suggest that participants with more severe comorbidity mainly have problems with their speed of processing and executive functioning.

Our established association between severity of total comorbidity and worse baseline cognitive performance corroborates findings of previous cross-sectional studies in cognitively healthy elderly (Morrow et al., 2009, Uchiyama et al., 1996), people with mild cognitive impairment (Lyketsos et al., 2005) and dementia (Doraiswamy et al., 2002, Lyketsos et al., 2005, Oosterveld et al., 2014). Yet, most of these studies focused on the effects of comorbidity on global cognitive functioning and did not report on domain-specific performances.

Our results further show that subjects with moderate/severe total comorbidity demonstrate faster cognitive decline, again only on mental speed dependent tests (i.e. TMT-A and verbal fluency), though severity of comorbidity is not associated with a higher risk of conversion to dementia within 3 years. To the best of our 
Figure 2 Differences in rate of cognitive decline by severity of comorbidity (significant results for the CIRS severity index)
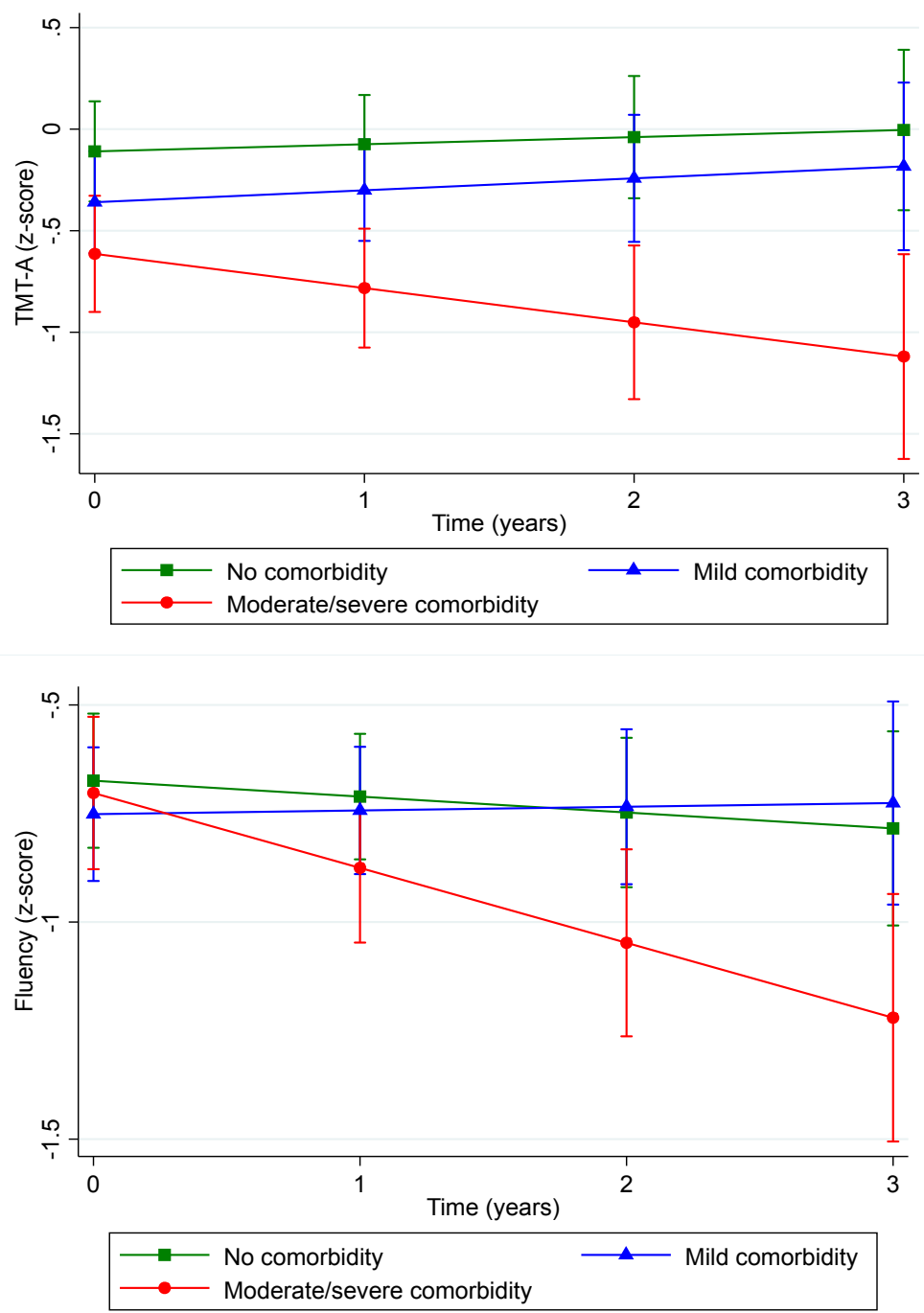

TMT-A = Trail Making Test part A.

knowledge, previous studies did not investigate the relationship between severity of total comorbidity and conversion to dementia, though multiple single risk factors have been associated with an increased risk of dementia (Barnes and Yaffe, 2011). The association between total severity of comorbidity and cognitive decline has been reported before in cognitively healthy elderly (Patrick et al., 2002) and people with dementia (Solomon et al., 2011). Though, the latter study focused only 
on global cognitive functioning. Interestingly, we did not find a significant association between severity of total comorbidity and decline on the SCWT $1-2$ (another mental speed based test), while baseline associations with severity of comorbidity for this test were quite robust. This could be due to a so-called floor effect in performance, since performance of all comorbidity groups on the SCWT 1 -2 was already quite low at baseline (1 to $1.5 \mathrm{SD}$ below the population mean). Furthermore, we observed an overall stability of performance on most cognitive tests for all comorbidity groups. The overall absence of decline over time in this ageing population might be due to the heterogeneity associated with an MCI sample that includes both converters to dementia and people whose performance improves over time. An alternative explanation could be the presence of practice and habituation effects, which are well documented for a variety of tests in elderly populations (Ferrer et al., 2004, Rabbitt et al., 2001).

When we explored whether we could identify specific clusters of disease that were related to cognitive performance or decline, severity of comorbidity in the cardiac and respiratory domain showed significant associations with cognitive performance and decline, again on speed-dependent tests. Factors like atrial fibrillation and chronic heart failure are known to influence performance in global cognitive functioning (Bellomo et al., 2012) and other cognitive domains (Vogels et al., 2007) in the elderly. Besides, these diseases are also related to global cognitive decline (Almeida et al., 2012, Thacker et al., 2013) and decline on speed measures (Thacker et al., 2013). Likewise, the association between pulmonary diseases and worse performance in information processing speed has been reported before in both clinic-based (Dal Negro et al., 2014, Klein et al., 2010) and general populations (Cleutjens et al., 2014), and this effect on cognitive performance seems to increase with increasing severity of the disease (Dal Negro et al., 2014, Klein et al., 2010). Further, severity of comorbidity in the neurological and endocrine domain was related to lower performance on speed dependent tests, though not to cognitive decline. Neurological diseases, like stroke and transient ischemic attacks have been associated with lower speed-related performance before in clinical populations (Middleton et al., 2014, van Rooij et al., 2014). The effect of the endocrine domain could likely be attributed to diabetes, which is known to influence cognitive performance in speed measures (Ganguli et al., 2013, Spauwen et al., 2013). So, although most disease clusters on their own show no significant association with cognitive performance or decline, the magnitude of total disease burden is related to worse cognitive performance and faster decline. Up till now, studies investigating cognitive decline in elderly patients typically address only single risk factors, with less attention being paid to multimorbidity and the total severity of comorbid disorders. Our study might indicate that a restricted disease-specific focus is insufficient in explaining associations between comorbidities and cognitive decline and demonstrates the importance of a broad assessment of multiple comorbid medical disorders. Furthermore, it provides a basis for shifting from a 
single disease risk factor approach to a more integrative approach, which also better matches the typical increasing disease burden of the elderly population.

\section{Strengths and limitations}

The present study is among the first to evaluate the influence of the severity of total comorbidity on cognitive functioning and decline in multiple domains in memory clinic visitors. Strengths of the study include the prospective design and the enrollment of a relatively large, well-characterized sample. Furthermore, by using data that were not restricted to a single center and applying broad inclusion criteria in which most comorbidities were not excluded, as is often done in other studies, generalizability to the general memory clinic population was maximized. Further, we used an extensive neuropsychological assessment to assess cognitive performance, which covers the most important cognitive domains. However, this study also has some limitations. First, not all patients had information on all cognitive tests, for example due to patients getting exhausted during the assessment or patients being no longer able to perform specific tests. However, by applying random-effects mixed models we are to handle missing data effectively by using all available data at a given time point and by integrating missing values for slopes of decline with maximum likelihood. Secondly, several participants dropped out during follow-up and their characteristics at baseline were significantly different from the participants that had follow-up data, which might have biased the results for the conversion analyses. Dropouts were older, had more health problems and lower cognitive scores at baseline (data not shown), which might explain their dropout, as visiting the memory clinic for follow-up is likely to be a greater burden in those with more health problems and a higher age. More cognitive decline and higher risk of dementia is seen among patients with a higher age and more recent diseases (Backman et al., 2003, Kivipelto et al., 2006), so dropout of these participants most likely resulted in an underestimation of our results. In addition, our follow-up was currently limited to three years, which is a relatively short period to investigate effects on cognitive decline. Further, this could have led to the relatively small number of people that converted to dementia, which might have resulted in (too) limited power for the analyses. In addition, some non-converters might have been misclassified at their latest followup assessment, as they will convert to dementia in the future, thereby diluting the effect of comorbidity on conversion to dementia. Still, our conversion rate $(23.5 \% \%$ over a mean period of 2.4 years) corresponds to the established conversion estimates in a systematic review (6.5\% / year) (Mitchell and Shiri-Feshki, 2009). Furthermore, although we extensively assessed comorbidity and used a structured method for scoring the severity, we had to remove the psychiatry category from the CIRS-G because of the inclusion of cognitive problems in this category and thus avoid circularity in our reasoning. However, by excluding this category we 
also lost data on other psychiatric comorbidities, like depression or anxiety, that are known to be related to cognitive performance (Bunce et al., 2012).

\section{Clinical implications}

Our findings might have implications for current practice in memory clinics. Our results show that multimorbidity is important to take into account and also underscore the significance of a broad assessment of medical disorders in clinical practice, since worse performance on speed dependent tests seems to be influenced by the severity of total comorbidity. Furthermore, it is important to realize that although patients with more severe total comorbidity show faster cognitive decline on several speed dependent tests, they are not at an increased risk to develop dementia in a time period of three years.

\section{Conclusions}

The severity of total comorbidity is associated with lower performance and faster decline on speed dependent tests, and should thus be taken into account when evaluating cognitive performance in clinical practice. However, severity of comorbidity is not associated with a higher risk of conversion to dementia within three years. 


\section{REFERENCES}

Akomolafe, A., Beiser, A., Meigs, J. B., Au, R., Green, R. C., Farrer, L. A., Wolf, P. A. \& Seshadri, S. (2006). Diabetes mellitus and risk of developing Alzheimer disease: results from the Framingham Study. Archives of Neurology, 63, 1551-5.

Aleman, A., Muller, M., de Haan, E. H. \& van der Schouw, Y. T. (2005). Vascular risk factors and cognitive function in a sample of independently living men. Neurobiology of Aging, 26, 485-90.

Almeida, O. P., Beer, C., Lautenschlager, N. T., Arnolda, L., Alfonso, H. \& Flicker, L. (2012). Two-year course of cognitive function and mood in adults with congestive heart failure and coronary artery disease: the Heart-Mind Study. International Psychogeriatrics, 24, 38-47.

American Psychiatric Association (2000). Diagnostic and Statistical Manual of Mental Disorders, fourth edition. Washington, DC: American Psychiatric Association

Arntzen, K. A., Schirmer, H., Wilsgaard, T. \& Mathiesen, E. B. (2011). Impact of cardiovascular risk factors on cognitive function: the Tromso study. European Journal of Neurology, 18, 737-43.

Backman, L., Jones, S., Small, B. J., Aguero-Torres, H. \& Fratiglioni, L. (2003). Rate of cognitive decline in preclinical Alzheimer's disease: the role of comorbidity. Journals of Gerontology Series B: Psychological Sciences and Social Sciences, 58, P228-36.

Barnes, D. E. \& Yaffe, K. (2011). The projected effect of risk factor reduction on Alzheimer's disease prevalence. Lancet Neurology, 10, 819-28.

Bellomo, A., De Benedetto, G., Fossati, C., D'Ottavio, E., Formosa, V., Gianturco, V., Iori, A., Marigliano, B., Lo Iacono, C., Troisi, G. \& Marigliano, V. (2012). Atrial fibrillation (AF) and cognitive impairment in the elderly: a case-control study. Archives of Gerontology and Geriatrics, 55, 247-50.

Bunce, D., Batterham, P. J., Mackinnon, A. J. \& Christensen, H. (2012). Depression, anxiety and cognition in community-dwelling adults aged 70 years and over. Journal of Psychiatric Research, 46, 1662-6.

Cleutjens, F. A., Spruit, M. A., Ponds, R. W., Dijkstra, J. B., Franssen, F. M., Wouters, E. F. \& Janssen, D. J. (2014). Cognitive functioning in obstructive lung disease: results from the United Kingdom biobank. Journal of the American Medical Directors Association, 15, 214-9.

Dal Negro, R. W., Bonadiman, L., Tognella, S., Bricolo, F. P. \& Turco, P. (2014). Extent and prevalence of cognitive dysfunction in chronic obstructive pulmonary disease, chronic non-obstructive bronchitis, and in asymptomatic smokers, compared to normal reference values. International Journal of Chronic Obstructive Pulmonary Disease, 9, 675-83.

Doraiswamy, P. M., Leon, J., Cummings, J. L., Marin, D. \& Neumann, P. J. (2002). Prevalence and impact of medical comorbidity in Alzheimer's disease. Journals of Gerontology Series A, Biological Sciences and Medical Sciences, 57, M173-7.

Ettorre, E., Cerra, E., Marigliano, B., Vigliotta, M., Vulcano, A., Fossati, C., De Benedetto, G., Servello, A., Andreozzi, P. \& Marigliano, V. (2012). Role of cardiovascular risk factors (CRF) in the patients with mild cognitive impairment (MCI). Archives of Gerontology and Geriatrics, 54, 330-2. 
Ferrer, E., Salthouse, T. A., Stewart, W. F. \& Schwartz, B. S. (2004). Modeling age and retest processes in longitudinal studies of cognitive abilities. Psychology and Aging, 19, 243-59.

Ganguli, M., Fu, B., Snitz, B. E., Hughes, T. F. \& Chang, C. C. (2013). Mild cognitive impairment: incidence and vascular risk factors in a population-based cohort. Neurology, 80, 2112-20.

Hammes, J. (1973). De Stroop Kleur-Woord Test: Handleiding [The Stroop Color-Word Test: Manual]. Swets \& Zeitlinger: Amsterdam.

Kivipelto, M., Ngandu, T., Laatikainen, T., Winblad, B., Soininen, H. \& Tuomilehto, J. (2006). Risk score for the prediction of dementia risk in 20 years among middle aged people: a longitudinal, population-based study. Lancet Neurology, 5, 735-41.

Klein, M., Gauggel, S., Sachs, G. \& Pohl, W. (2010). Impact of chronic obstructive pulmonary disease (COPD) on attention functions. Respiratory Medicine, 104, 52-60.

Lezak, M. D., Howieson, D. B. \& Loring, D. W. (2004). Neuropsychological Assessment, 4th Edition. Oxford University Press: Oxford, UK.

Lipnicki, D. M., Sachdev, P. S., Crawford, J., Reppermund, S., Kochan, N. A., Trollor, J. N., Draper, B., Slavin, M. J., Kang, K., Lux, O., Mather, K. A. \& Brodaty, H. (2013). Risk factors for late-life cognitive decline and variation with age and sex in the Sydney Memory and Ageing Study. PLoS One, 8, e65841.

Lyketsos, C. G., Toone, L., Tschanz, J., Rabins, P. V., Steinberg, M., Onyike, C. U., Corcoran, C., Norton, M., Zandi, P., Breitner, J. C., Welsh-Bohmer, K., Anthony, J., Ostbye, T., Bigler, E., Pieper, C., Burke, J., Plassman, B., Green, R. C., Steffens, D. C., Klein, L., Leslie, C., Townsend, J. J., Wyse, B. W., Munger, R. \& Williams, M. (2005).

Population-based study of medical comorbidity in early dementia and "cognitive impairment, no dementia (CIND)": association with functional and cognitive impairment: The Cache County Study. American Journal of Geriatric Psychiatry, 13, 656-64.

McKeith, I. G., Dickson, D. W., Lowe, J., Emre, M., O'Brien, J. T., Feldman, H., Cummings, J., Duda, J. E., Lippa, C., Perry, E. K., Aarsland, D., Arai, H., Ballard, C. G., Boeve, B., Burn, D. J., Costa, D., Del Ser, T., Dubois, B., Galasko, D., Gauthier, S., Goetz, C. G., Gomez-Tortosa, E., Halliday, G., Hansen, L. A., Hardy, J., Iwatsubo, T., Kalaria, R. N., Kaufer, D., Kenny, R. A., Korczyn, A., Kosaka, K., Lee, V. M., Lees, A., Litvan, I., Londos, E., Lopez, O. L., Minoshima, S., Mizuno, Y., Molina, J. A., MukaetovaLadinska, E. B., Pasquier, F., Perry, R. H., Schulz, J. B., Trojanowski, J. Q. \& Yamada, M. (2005). Diagnosis and management of dementia with Lewy bodies: third report of the DLB Consortium. Neurology, 65, 1863-72.

McKhann, G., Drachman, D., Folstein, M., Katzman, R., Price, D. \& Stadlan, E. M. (1984). Clinical diagnosis of Alzheimer's disease: report of the NINCDS-ADRDA Work Group under the auspices of Department of Health and Human Services Task Force on Alzheimer's Disease. Neurology, 34, 939-44.

Middleton, L. E., Lam, B., Fahmi, H., Black, S. E., Mcllroy, W. E., Stuss, D. T., Danells, C., Ween, J. \& Turner, G. R. (2014). Frequency of domain-specific cognitive impairment in sub-acute and chronic stroke. NeuroRehabilitation, 34, 305-12.

Mielke, M. M., Rosenberg, P. B., Tschanz, J., Cook, L., Corcoran, C., Hayden, K. M., Norton, M., Rabins, P. V., Green, R. C., Welsh-Bohmer, K. A., Breitner, J. C., Munger, R. \& Lyketsos, C. G. (2007). Vascular factors predict rate of progression in Alzheimer disease. Neurology, 69, 1850-8. 
Miller, M. D., Paradis, C. F., Houck, P. R., Mazumdar, S., Stack, J. A., Rifai, A. H., Mulsant, B. \& Reynolds, C. F., 3rd (1992). Rating chronic medical illness burden in geropsychiatric practice and research: application of the Cumulative Illness Rating Scale. Psychiatry Research, 41, 237-48.

Mitchell, A. J. \& Shiri-Feshki, M. (2009). Rate of progression of mild cognitive impairment to dementia--meta-analysis of 41 robust inception cohort studies. Acta Psychiatrica Scandinavica, 119, 252-65.

Morris, J. C. (1993). The Clinical Dementia Rating (CDR): current version and scoring rules. Neurology, 43, 2412-4.

Morrow, L. A., Snitz, B. E., Rodriquez, E. G., Huber, K. A. \& Saxton, J. A. (2009). High medical co-morbidity and family history of dementia is associated with lower cognitive function in older patients. Family Practice, 26, 339-43.

Neary, D., Snowden, J. S., Gustafson, L., Passant, U., Stuss, D., Black, S., Freedman, M., Kertesz, A., Robert, P. H., Albert, M., Boone, K., Miller, B. L., Cummings, J. \& Benson, D. F. (1998). Frontotemporal lobar degeneration: a consensus on clinical diagnostic criteria. Neurology, 51, 1546-54.

Oosterveld, S. M., Kessels, R. P., Hamel, R., Ramakers, I. H., Aalten, P., Verhey, F. R., Sistermans, N., Smits, L. L., Pijnenburg, Y. A., van der Flier, W. M., Olde Rikkert, M. G. \& Melis, R. J. (2014). The Influence of Co-Morbidity and Frailty on the Clinical Manifestation of Patients with Alzheimer's Disease. Journal of Alzheimer's Disease.

Patrick, L., Gaskovski, P. \& Rexroth, D. (2002). Cumulative illness and neuropsychological decline in hospitalized geriatric patients. The Clinical Neuropsychologist, 16, 145-56.

Rabbitt, P., Diggle, P., Smith, D., Holland, F. \& Mc Innes, L. (2001). Identifying and separating the effects of practice and of cognitive ageing during a large longitudinal study of elderly community residents. Neuropsychologia, 39, 532-43.

Roman, G. C., Tatemichi, T. K., Erkinjuntti, T., Cummings, J. L., Masdeu, J. C., Garcia, J. H., Amaducci, L., Orgogozo, J. M., Brun, A., Hofman, A. \& et al. (1993). Vascular dementia: diagnostic criteria for research studies. Report of the NINDS-AIREN International Workshop. Neurology, 43, 250-60.

Schmand, B., Houx, P. \& de Koning, I. (2003). Normen voor Stroop kleur-woord tests, Trail Making test en Story Recall van de Rivermead Behavioural Memory Test. [Norms for Stroop color-word tests, Trail Making Test and Story Recall of the Rivermead Behavioural Memory Test]. Nederlands Instituut van Psychologen, Sectie Neuropsychologie: Amsterdam.

Siuda, J., Gorzkowska, A., Opala, G. \& Ochudlo, S. (2007). Vascular risk factors and intensity of cognitive dysfunction in MCI. Journal of the Neurological Sciences, 257, 202-5.

Solfrizzi, V., Panza, F., Colacicco, A. M., D'Introno, A., Capurso, C., Torres, F., Grigoletto, F., Maggi, S., Del Parigi, A., Reiman, E. M., Caselli, R. J., Scafato, E., Farchi, G. \& Capurso, A. (2004). Vascular risk factors, incidence of MCI, and rates of progression to dementia. Neurology, 63, 1882-91.

Solomon, A., Dobranici, L., Kareholt, I., Tudose, C. \& Lazarescu, M. (2011). Comorbidity and the rate of cognitive decline in patients with Alzheimer dementia. International Journal of Geriatric Psychiatry, 26, 1244-51. 
Spauwen, P. J., Kohler, S., Verhey, F. R., Stehouwer, C. D. \& van Boxtel, M. P. (2013). Effects of type 2 diabetes on 12-year cognitive change: results from the Maastricht Aging Study. Diabetes Care, 36, 1554-61.

Thacker, E. L., McKnight, B., Psaty, B. M., Longstreth, W. T., Jr., Sitlani, C. M., Dublin, S., Arnold, A. M., Fitzpatrick, A. L., Gottesman, R. F. \& Heckbert, S. R. (2013). Atrial fibrillation and cognitive decline: a longitudinal cohort study. Neurology, 81, 119-25.

Uchiyama, C. L., Mitrushina, M., Satz, P. \& Schall, M. (1996). Direct and indirect effects of demographic, medical, and psychological variables on neuropsychological performance in normal geriatric persons: a structural equation model. Journal of the International Neuropsychological Society, 2, 299-305.

Uijen, A. A. \& van de Lisdonk, E. H. (2008). Multimorbidity in primary care: prevalence and trend over the last 20 years. European Journal of General Practice, 14 Suppl 1, 28-32.

van Boxtel, M. P., Gaillard, C., Houx, P. J., Buntinx, F., de Leeuw, P. W. \& Jolles, J. (1997). Can the blood pressure predict cognitive task performance in a healthy population sample? Journal of Hypertension, 15, 1069-76.

Van der Elst, W., van Boxtel, M. P., van Breukelen, G. J. \& Jolles, J. (2005). Rey's verbal learning test: normative data for 1855 healthy participants aged 24-81 years and the influence of age, sex, education, and mode of presentation. Journal of the International Neuropsychological Society, 11, 290-302.

van der Elst, W., van Boxtel, M. P., van Breukelen, G. J. \& Jolles, J. (2006a). The Letter Digit Substitution Test: normative data for 1,858 healthy participants aged 24-81 from the Maastricht Aging Study (MAAS): influence of age, education, and sex. Journal of Clinical and Experimental Neuropsychology, 28, 998-1009.

Van der Elst, W., Van Boxtel, M. P., Van Breukelen, G. J. \& Jolles, J. (2006b). Normative data for the Animal, Profession and Letter M Naming verbal fluency tests for Dutch speaking participants and the effects of age, education, and sex. Journal of the International Neuropsychological Society, 12, 80-9.

Van der Elst, W., Van Boxtel, M. P., Van Breukelen, G. J. \& Jolles, J. (2006c). The Stroop color-word test: influence of age, sex, and education; and normative data for a large sample across the adult age range. Assessment, 13, 62-79.

van Rooij, F. G., Schaapsmeerders, P., Maaijwee, N. A., van Duijnhoven, D. A., de Leeuw, F. E., Kessels, R. P. \& van Dijk, E. J. (2014). Persistent cognitive impairment after transient ischemic attack. Stroke, 45, 2270-4.

Villeneuve, S., Belleville, S., Massoud, F., Bocti, C. \& Gauthier, S. (2009). Impact of vascular risk factors and diseases on cognition in persons with mild cognitive impairment. Dementia and Geriatric Cognitive Disorders, 27, 375-81.

Vogels, R. L., Oosterman, J. M., van Harten, B., Scheltens, P., van der Flier, W. M., Schroeder-Tanka, J. M. \& Weinstein, H. C. (2007). Profile of cognitive impairment in chronic heart failure. Journal of the American Geriatrics Society, 55, 1764-70. 


\section{SUPPLEMENTARY DATA}

Supplementary table 1 Significant baseline associations between severity of comorbidity within specific disease clusters and cognitive performance

\begin{tabular}{|c|c|c|c|c|c|c|}
\hline \multirow[t]{2}{*}{$\begin{array}{l}\text { Comorbidity } \\
\text { category }\end{array}$} & & \multirow[t]{2}{*}{$\begin{array}{c}\text { Neuropsychological } \\
\text { test }\end{array}$} & \multirow[t]{2}{*}{ B (SE) } & \multirow[t]{2}{*}{ p-value } & \multicolumn{2}{|c|}{$\begin{array}{c}\text { Interaction } \\
\text { effect }\end{array}$} \\
\hline & & & & & $\chi^{2}$ & $\mathrm{p}$-value \\
\hline \multirow[t]{6}{*}{ Heart } & No & TMT-A & $-0.20(0.05)$ & 0.04 & & \\
\hline & Mild & & $-0.58(0.26)$ & 0.02 & 1.90 & 0.17 \\
\hline & Moderate & & $-0.58(0.15)$ & $<0.01$ & 4.04 & 0.04 \\
\hline & No & SCWT 1 - 2 & $-1.00(0.12)$ & $<0.01$ & & \\
\hline & Mild & & $-1.60(0.33)$ & $<0.01$ & 2.48 & 0.12 \\
\hline & Moderate & & $-1.54(0.21)$ & $<0.01$ & 4.48 & 0.03 \\
\hline \multirow[t]{3}{*}{ Respiratory } & No & TMT-B & $-0.33(0.10)$ & $<0.01$ & & \\
\hline & Mild & & $-0.25(0.19)$ & 0.18 & 0.19 & 0.66 \\
\hline & Moderate & & $-0.84(0.17)$ & $<0.01$ & 6.05 & 0.01 \\
\hline \multirow[t]{6}{*}{ Neurological } & No & TMT-A & $-0.20(0.10)$ & 0.05 & & \\
\hline & Mild & & $-0.37(0.17)$ & 0.03 & 0.83 & 0.36 \\
\hline & Moderate & & $-0.64(0.16)$ & $<0.01$ & 5.37 & 0.02 \\
\hline & No & SCWT $1-2$ & $-0.97(0.13)$ & $<0.01$ & & \\
\hline & Mild & & $-1.03(0.22)$ & $<0.01$ & 0.05 & 0.83 \\
\hline & Moderate & & $-1.86(0.20)$ & $<0.01$ & 12.96 & $<0.01$ \\
\hline \multirow[t]{15}{*}{ Endocrine } & No & TMT-B & $-0.31(0.09)$ & $<0.01$ & & \\
\hline & Mild & & $-0.63(0.19)$ & $<0.01$ & 2.27 & 0.13 \\
\hline & Moderate & & $-0.77(0.21)$ & $<0.01$ & 4.15 & 0.04 \\
\hline & No & TMT-A & $-0.20(0.09)$ & 0.03 & & \\
\hline & Mild & & $-0.55(0.19)$ & $<0.01$ & 2.87 & 0.09 \\
\hline & Moderate & & $-0.72(0.20)$ & $<0.01$ & 5.82 & 0.02 \\
\hline & No & SCWT $1-2$ & $-0.98(0.12)$ & 0.03 & & \\
\hline & Mild & & $-1.64(0.23)$ & $<0.01$ & 6.78 & 0.01 \\
\hline & Moderate & & $-1.61(0.26)$ & $<0.01$ & 4.84 & 0.03 \\
\hline & No & SCWT $1-2$ & $-0.98(0.12)$ & 0.03 & & \\
\hline & Mild & & $-1.64(0.23)$ & $<0.01$ & 6.78 & 0.01 \\
\hline & Moderate & & $-1.61(0.26)$ & $<0.01$ & 4.84 & 0.03 \\
\hline & No & Fluency & $-0.64(0.06)$ & $<0.01$ & & \\
\hline & Mild & & $-0.73(0.11)$ & $<0.01$ & 0.41 & 0.52 \\
\hline & Moderate & & $-0.99(0.12)$ & $<0.01$ & 7.04 & 0.01 \\
\hline
\end{tabular}

Data are presented as z-scores. TMT-A = Trail Making Test part A; TMT-B = Trail Making Test part B; SCWT $1-2=$ Stroop Colour Word Test average of cards 1 and 2. 

CHAPTER 7

\author{
DETERMINANTS OF HEALTH-RELATED QUALITY OF LIFE IN \\ MEMORY CLINIC VISITORS WITHOUT DEMENTIA
}

Renske E.G. Hamel, Inez H.G.B. Ramakers, Saskia M. Oosterveld, Rene J.F. Melis, Marcel G.M. Olde Rikkert, Roy P.C. Kessels, Nicole Sistermans, Yolande A.L. Pijnenburg, Ted Koene, Wiesje M. van der Flier, Philip Scheltens, Pauline Aalten, Pieter Jelle Visser, Frans R.J. Verhey 


\section{ABSTRACT}

\section{Objective}

As diagnostic assessment and treatment options increasingly focus on early stages of cognitive decline, more information on Health-related Quality of Life (HRQoL) in people searching medical help for cognitive complaints is needed. Therefore, this study aimed to investigate the association between HRQoL and comorbid disease burden, emotional and cognitive functioning in memory clinic visitors.

\section{Methods}

This study consists of 301 non-demented patients with memory complaints who visited one of three Dutch Alzheimer centres. Multiple linear regression analyses, corrected for age, gender, study center and education, were used to investigate the relation between HRQoL and comorbid disease burden, emotional functioning and cognitive functioning. Analyses were performed for the total group and for the group with Mild Cognitive Impairment (MCI) and subjective cognitive complaints (SCI) separately

\section{Results}

Participant's mean age was 69.7 years and $64.8 \%$ of them were men. The majority of the group was classified as having MCI (70\%). All three domains were significantly associated with HRQoL in the total cohort and the MCI group $\left(\mathrm{R}^{2}=31 \%\right)$. In the SCI group only emotional functioning was significantly associated with HRQoL $\left(\mathrm{R}^{2}=46 \%\right)$. Depressive symptoms were most strongly related to HRQoL in all groups.

\section{Conclusions}

The HRQoL of memory clinic visitors is largely influenced by their emotional functioning, especially by depressive symptoms. Furthermore, HRQoL in MCI is also influenced by cognitive functioning and comorbid disease burden, while HRQoL in SCI is not. These factors should be taken into account in clinical practice and might be promising targets for non-cognitive interventions to improve HRQoL. 


\section{INTRODUCTION}

Health-related Quality of Life (HRQoL) is a complex, multidimensional construct that refers to the functional effect a medical condition and/or its consequent therapy has upon a patient. Most definitions of HRQoL incorporate the domains of general health, mental health, physical and social functioning, with important concepts such as cognition integrated in these broader categories (Bowling, 2001, Ware, 1987). HRQoL has become a topic of interest within dementia research, as it has been increasingly acknowledged as a significant outcome.

Multiple studies have demonstrated decreased HRQoL in people with dementia relative to cognitively unimpaired elderly (Missotten, et al. 2008; Ready, et al. 2004). However, we know little about HRQoL in the earlier stages of cognitive decline, though diagnostic and therapeutic efforts are increasingly focusing on this group. Results concerning HRQoL in people with Mild Cognitive Impairment (MCI) are inconsistent: some studies showed no reduced HRQoL (Missotten et al., 2008, Ready et al., 2004), while others demonstrated decreased HRQoL compared to people with unimpaired cognitive functioning (Muangpaisan et al., 2008, Teng et al., 2012, Weiss et al., 2012). Further, diminished HRQoL has also been reported in people with subjective cognitive complaints (SCI) (Mol et al., 2009).

According to the above-mentioned definition, emotional well-being, medical disease burden and cognitive functioning seem important determinants of HRQoL. Indeed, reduced HRQoL in individuals with MCI has been related to the presence of neuropsychiatric symptoms and especially depressive symptoms (Teng et al., 2012, Weiss et al., 2012). However, no associations with cognitive functioning have been found (Muangpaisan et al., 2008, Teng et al., 2012), while the relation with general health has not been thoroughly investigated in the $\mathrm{MCI}$ population. In all, current research on HRQoL in people with MCI is limited and shows conflicting results, while research on HRQOL in SCI is almost entirely lacking. In addition, the contribution of factors influencing HRQoL relative to one another and differences in these factors between diagnostic groups have not been investigated yet. A better understanding of factors that influence HRQoL in memory clinic visitors is important to identify potential targets to ameliorate HRQoL, and thus further enhance care for these persons.

Therefore, the aim of the present study was to investigate which factors are associated with HRQoL in memory clinic visitors, both in people with MCI and in those with SCI. More specifically, we aimed to investigate the association between HRQoL and comorbid disease burden, cognitive and emotional functioning. We hypothesized that emotional functioning and comorbid disease burden are 
associated with HRQoL in all groups, while cognitive functioning is associated with HRQoL only in the MCI group.

\section{METHODS}

Baseline data from the Clinical Course of Cognition and Comorbidity in MCI (4C$\mathrm{MCI})$ study were used. The $4 \mathrm{C}-\mathrm{MCI}$ study is a longitudinal multicenter study into the course of cognitive decline in non-demented memory clinic visitors. Participants were included from the memory clinics of Maastricht University Medical Centre, Radboud university medical center and VUmc Medical Centre between January 2010 and May 2011. Participants were followed annually for three years. The local Medical Ethical Committee of each centre approved the study. All participants provided written informed consent. The authors assert that all procedures contributing to this work comply with the ethical standards of the relevant national and institutional committees on human experimentation and with the Helsinki Declaration of 1975, as revised in 1983.

\section{Participants}

The study included 315 participants at baseline, who were classified as having either objectified cognitive impairment (MCI) or no objectified cognitive impairment (SCI), based on neuropsychological test results. Inclusion criteria were: 1) age $\geq 55$ years, 2 ) having subjective cognitive complaints and / or cognitive impairments, in absence of dementia, and 3) Clinical Dementia Rating (CDR) (Morris, 1993) score $\leq$ 0.5. Exclusion criteria were: 1 ) absence of a primary caregiver, 2) expectation that the participant will not be able to have at least one follow-up, based on clinical judgment, and 3) presence of specific neurological disorders that could have caused cognitive impairment: Parkinson's or Huntington's disease, Normal Pressure Hydrocephalus, Korsakoff's syndrome, a medical history of brain tumor or encephalitis. Contrary to common practice in MCI studies, participants having any other comorbidities, including cerebrovascular and psychiatric disorders were not excluded.

\section{Baseline assessment}

At baseline, all participants underwent a standardized clinical assessment, which included a detailed history of the patient, a psychiatric, neurologic and physical examination, assessments of daily functioning, appropriate laboratory tests, an extensive neuropsychological assessment and a magnetic resonance imaging (MRI) 
scan. These assessments were part of the regular patient diagnostic procedures of the memory clinics. For the current study we extracted data on age, gender, education, quality of life, comorbid disease burden, cognitive and emotional functioning.

\section{Health-related Quality of Life}

The EuroQol-5D (EQ-5D) (The EuroQol Group, 1990) including a Visual Analogue Scale (VAS) was used to measure (self-rated) HRQoL. Participants rated their current health state on a three-point scale in five dimensions (i.e. mobility, selfcare, daily activities, pain/discomfort and anxiety/depression). Scores in each dimension ranged from zero (no impairments/complaints) to two (severe impairments / complaints), with higher scores indicating worse HRQoL. This scoring yields 243 potential combinations of health states across the dimensions. Each health state can be allocated a utility score through an algorithm (Dolan, 1997), indicating its attractiveness based on valuations of the general population. Utility scores can vary between -0.59 (worst health) and 1.00 (perfect health). The EQ-5D also includes the rating of a VAS score, with values from zero (worst possible health state) to 100 (best possible health state).

\section{Comorbid disease burden}

The Cumulative Illness Rating Scale for geriatrics (CIRS-G) (Miller et al., 1992) was used to score all available data on medical comorbidities, medication use, smoking and drinking habits and information from the physical examination. Scores between zero (no problems) and four (extremely severe problems) were given to 14 categories of organ systems (i.e. cardiac; vascular; hematopoietic; respiratory; eyes / ears/nose/throat/larynx; upper gastrointestinal tract; lower gastrointestinal tract; liver; renal; genitourinary; musculoskeletal; neurological; endocrine/metabolic and breast; psychiatric). For the current analyses, we excluded the psychiatric category from the CIRS-G since it contains psychiatric and cognition related comorbidities. By excluding this category, the CIRS-G was used as a measure of pure medical comorbid disease burden, thus minimizing overlap with the cognitive and emotional functioning domain.

\section{Cognitive functioning}

The neuropsychological assessment consisted of the following tests: the Mini Mental State Examination (MMSE) (Folstein et al., 1975), the Dutch adaptation of the 15-Word Verbal Learning Task (VLT) (Lezak et al., 2004, Van der Elst et al., 2005), the Stroop Color Word Test (SCWT) (Hammes, 1973), the Letter Digit 
Substitution Test (LDST) (van der Elst et al., 2006a), the Trail Making Test (TMT) (Lezak et al., 2004, Schmand et al., 2003) and the category fluency test (animal naming) (Van der Elst et al., 2006b).

\section{Emotional functioning and depressive symptoms}

The Neuropsychiatric Inventory (NPI) (Cummings et al., 1994) was used to assess the frequency and severity of 12 neuropsychiatric symptoms (i.e. delusions, hallucinations, agitation, depression, anxiety, apathy, irritability, euphoria, disinhibition, aberrant motor behavior, nighttime behavior disturbances, and appetite/ eating disturbances) through a structured interview with the participants' caregiver. For each symptom, severity and frequency scores are multiplied to acquire a total symptom score, with higher scores indicating more severe problems.

The Geriatric Depression Scale-15 (GDS-15) (Sheikh and Yesavage, 1986) was used to determine the presence and severity of depression by self-rating. The GDS-15 is a screening tool in which 15 questions about mood are answered. A score of six or more is indicative for possible depression.

\section{Diagnostic procedures}

All neuropsychological test scores were converted to z-scores adjusted for age, sex and education, based on norm scores from the Dutch healthy population

(Schmand et al., 2003, Van der Elst et al., 2005, 2006a, b, c). Adopting a psychometric approach, individuals with a z-score lower than -1.5 SD on any neuropsychological test were classified as having MCI. All others were classified as SCI.

\section{Statistical analyses}

Analyses were performed using SSPS version 20 (Chicago, IL., USA) for Mac OS X. Baseline differences between groups (i.e. SCI and MCI group) were analyzed using $t$ tests for continuous and $\chi^{2}$ tests for categorical variables.

For cognitive functioning, extreme z-score values were handled by winsorising them, i.e. they were fixed at the lower $(-5)$ or upper $(+5)$ boundary. Extreme values were found only for the SCWT (i.e. $1.6 \%$ of all scores on Stroop card 2 and $4.7 \%$ of all scores on the SCWT interference index). For the emotional functioning and comorbid disease burden domain, the scores of the subcategories of the CIRS-G and of the symptoms of the NPI were dichotomized ( $0=$ absence of comorbidity or neuropsychiatric symptom; 1 = presence of comorbidity or neuropsychiatric symptom). 
To test for multicollinearity a Spearman's rank-order correlation was conducted between all variables within a predictive domain (i.e. comorbid disease burden, cognitive and emotional functioning). Using a cut-off of 0.7 , the VLT delayed recall score was removed from the analyses, since it correlated high with the VLT immediate recall score $(\mathrm{r}=0.744, \mathrm{p}<0.01)$ and the latter had a larger range of scores, which makes it more applicable for multiple linear regression analyses.

For HRQoL, the VAS score was used as outcome measure, since the utility weight scores are predominantly based on the rating of a person's physical abilities (e.g. mobility, pain/discomfort). By using the VAS score, HRQoL was based on the pure subjective experience of general health, thus minimizing overlap with the comorbid disease burden domain.

To examine the relationship between each of the above-mentioned domains and HRQoL, separate multiple linear regression analyses were performed within each predictive domain. Models were built using backward selection $\left(p_{\text {intusion }}<0.10 ; p_{\text {excusian }} \geq\right.$ $0.10)$. Significantly associated variables were subsequently included into a final multiple regression model (enter method), combining the results of the three domains (significance set at $p<0.05$ ). To give an indication of the predictive power of the model, the percentage of explained variance (Nagelkerke's $\mathrm{R}^{2}$ ) was presented. All regression analyses were corrected for age, gender, study centre and education (low, middle, high), and were performed for the total cohort and in the MCI and SCI group separately.

\section{RESULTS}

For the present study, we selected 301 individuals with available EuroQoL-VAS scores. Their characteristics at study entry, according to baseline diagnosis and the characteristics of the total group, are presented in table 1. Participants were on average almost 70 years old and more than half of them were men. 210 participants were classified as MCI at baseline, while only 84 participants were classified as SCI, 7 participants remained unclassified due to missing data. The mean HRQoL score of the entire group was $69.4(\mathrm{SD}=15.63)$. Further, almost $40 \%$ had a HRQoL score higher than 70. HRQoL scores did not differ between participants with MCI and SCI. Yet, people with MCI were older, performed worse on all neuropsychological tests, and had more often comorbidity in the cardiac and eyes / ears / nose domain than those with SCI. However, the levels of neuropsychiatric and depressive symptoms were similar in both groups. 
Table 1 Baseline characteristics of the total group and subgroups

\begin{tabular}{|c|c|c|c|}
\hline Variable & Overall & SCI & MCI \\
\hline $\bar{n}$ & 301\# & 84 & 210 \\
\hline Age, y & $69.7(8.55)$ & $66.4(8.00)$ & $70.8(8.41)^{* *}$ \\
\hline Sex (\% male $)$ & $64.8 \%$ & $67.9 \%$ & $64.3 \%$ \\
\hline \multicolumn{4}{|l|}{ Education } \\
\hline$\%$ Low & $38.4 \%$ & $34.5 \%$ & $39.5 \%$ \\
\hline$\%$ Middle & $24.8 \%$ & $27.4 \%$ & $25.7 \%$ \\
\hline$\%$ High & $35.2 \%$ & $38.1 \%$ & $34.8 \%$ \\
\hline \multicolumn{4}{|l|}{ Cognitive tests } \\
\hline VLT (immediate recall) & $-1.1(1.22)$ & $-0.0(0.99)$ & $-1.5(1.03)^{* *}$ \\
\hline Fluency & $-0.7(0.85)$ & $-0.2(0.69)$ & $-0.9(0.82)^{* *}$ \\
\hline TMT-A & $-0.3(1.31)$ & $0.4(0.93)$ & $-0.6(1.37)^{* *}$ \\
\hline TMT-B & $-0.4(1.34)$ & $0.4(1.00)$ & $-0.8(1.34)^{* *}$ \\
\hline SCWT $1-2$ & $-1.1(1.42)$ & $-0.1(0.69)$ & $-1.4(1.41)^{* *}$ \\
\hline SCWT interference & $-0.6(1.72)$ & $0.4(0.87)$ & $-1.1(1.80)^{* *}$ \\
\hline LDST & $-0.5(1.12)$ & $0.2(0.83)$ & $-0.8(1.08)^{\star *}$ \\
\hline MMSE & $26.9(2.50)$ & $28.0(1.64)$ & $26.5(2.66)^{* *}$ \\
\hline NPI total score & $14.2(14.5)$ & $13.4(14.2)$ & $14.2(14.6)$ \\
\hline \multicolumn{4}{|l|}{ NPI items (\% with symptoms) } \\
\hline Delusions & $6.3 \%$ & $8.3 \%$ & $5.7 \%$ \\
\hline Hallucinations & $3.7 \%$ & $2.4 \%$ & $4.3 \%$ \\
\hline Agitation & $19.3 \%$ & $17.9 \%$ & $20.0 \%$ \\
\hline Depression & $39.5 \%$ & $40.5 \%$ & $39.0 \%$ \\
\hline Anxiety & $26.2 \%$ & $23.8 \%$ & $27.1 \%$ \\
\hline Euphoria & $9.0 \%$ & $13.1 \%$ & $7.6 \%$ \\
\hline Apathy & $43.5 \%$ & $41.7 \%$ & $43.8 \%$ \\
\hline Irritability & $50.2 \%$ & $54.8 \%$ & $48.1 \%$ \\
\hline Disinhibition & $17.6 \%$ & $16.7 \%$ & $18.1 \%$ \\
\hline Aberrant motor behavior & $10.3 \%$ & $11.9 \%$ & $9.5 \%$ \\
\hline Nighttime behavior disturbances & $26.6 \%$ & $21.4 \%$ & $28.6 \%$ \\
\hline Appetite and eating abnormalities & $20.6 \%$ & $11.9 \%$ & $23.3 \%$ \\
\hline Self reported depression & $19.6 \%$ & $15.5 \%$ & $19.7 \%$ \\
\hline CIRS total score & $8.0(4.96)$ & $6.5(4.46)$ & $8.5(5.02)^{\star *}$ \\
\hline \multicolumn{4}{|l|}{ CIRS categories ( $\%$ with comorbidity) } \\
\hline Cardiac & $36.5 \%$ & $25 \%$ & $40 \% *$ \\
\hline Vascular & $61.5 \%$ & $60.7 \%$ & $61.0 \%$ \\
\hline Hematopoietic & $16.6 \%$ & $10.7 \%$ & $19.0 \%$ \\
\hline Respiratory & $38.9 \%$ & $35.7 \%$ & $39.5 \%$ \\
\hline Eyes, ears, nose & $42.9 \%$ & $29.8 \%$ & $47.1 \%^{*}$ \\
\hline Upper digestive tract & $22.3 \%$ & $16.7 \%$ & $23.3 \%$ \\
\hline Lower digestive tract & $23.3 \%$ & $22.6 \%$ & $22.4 \%$ \\
\hline Liver & $14.0 \%$ & $9.5 \%$ & $15.7 \%$ \\
\hline Kidneys & $12.6 \%$ & $11.9 \%$ & $12.9 \%$ \\
\hline Urogenital & $35.9 \%$ & $36.9 \%$ & $33.8 \%$ \\
\hline
\end{tabular}


Table 1 (continued)

\begin{tabular}{|lccc|}
\hline \multicolumn{1}{c}{ Variable } & Overall & SCI & MCI \\
\hline \hline Neuromuscular & $37.5 \%$ & $36.9 \%$ & $38.1 \%$ \\
Neurological & $41.9 \%$ & $34.5 \%$ & $46.2 \%$ \\
Endocrine & $31.6 \%$ & $27.4 \%$ & $33.3 \%$ \\
EuroQol & & & \\
VAS score categories & & & \\
$0-50$ & $15.0 \%$ & $8.3 \%$ & $16.7 \%$ \\
$51-70$ & $44.5 \%$ & $50.0 \%$ & $43.8 \%$ \\
$71-100$ & $39.5 \%$ & $41.7 \%$ & $39.5 \%$ \\
VAS total score & $69.4(15.6)$ & $70.8(12.7)$ & $69.2(16.3)$ \\
\hline
\end{tabular}

VLT = Verbal Learning Test; TMT-A: TrailMaking Test part A; TMT-B: TrailMaking Test part B; SCWT 1-2, average of Stroop Color Word Test card 1 + 2; SCWT interference index = Stroop Color Word Test card 3 divided by the average of Stroop Color Word Test card 1 + 2; MMSE: Mini Mental State Examination; NPI: NeuroPsychiatric Inventory; CIRS: Cumulative Illness Rating Scale; VAS: Visual Analogue Scale;

Data are presented as mean (SD) unless otherwise specified. Neuropsychological test scores are presented as z-scores.

\# 7 patients of the overall group did not have sufficient neuropsychological data to receive a MCI of SCI classification.

${ }^{*} \mathrm{p}<0.05$

${ }^{* *} \mathrm{p}<0.01$

\section{HRQoL in the total group}

Within the cognitive functioning domain, only a slow mental speed (i.e. lower score on the LDST) was significantly associated with lower HRQoL. Within the comorbid disease burden domain, the presence of comorbidity in the eyes/ ears/nose, lower gastrointestinal tract and kidney domain was significantly associated with lower HRQoL. Regarding emotional functioning, informant and self-reported depressive symptoms, nighttime behavior and appetite/eating disturbances were significantly associated with lower HRQoL.

In the final model, that combined the significant predictors from the analyses within each domain, all domains remained significantly associated with HRQoL. More specifically, lower scores on the LDST (beta $=0.16, p<0.01$ ) and the presence of self-reported depressive symptoms (beta $=-0.36, p<0.01$ ), appetite/ eating disturbances (beta $=-0.13, p=0.03$ ), nighttime behavior disturbances (beta $=-0.14$, $p=0.02$ ) and eyes / ears / nose comorbidities (beta $=-0.12, p=0.04$ ) were associated with lower HRQoL (table 2). This final model accounted for $31 \%$ of the total variance. The largest proportion of the variance was explained by emotional functioning $\left(\mathrm{R}^{2}=23 \%\right)$. Cognitive functioning and comorbid disease burden both explained $3 \%$ of the total variance. 
When we repeated our analyses using the EuroQoL utility weight as outcome measure, results did not essentially change. Only the association between comorbid disease burden and HRQoL was now found for comorbidities in the respiratory and lower gastrointestinal tract domain instead of the eyes/ears/nose domain.

Table 2 Final predictive model for HRQoL in the total group, based on all significant predictors within each predictive domain (analyses corrected for age, education, gender and study centre)

\begin{tabular}{|lcc|}
\hline Predictor & Beta & p-value \\
\hline Nighttime behaviour disturbances & -0.14 & 0.02 \\
Appetite/Eating disturbances & -0.13 & 0.03 \\
Self-reported depression & -0.36 & $<0.01$ \\
Eyes / ears / nose & -0.12 & 0.04 \\
Lower digestive tract & -0.10 & 0.07 \\
Kidney & -0.10 & 0.07 \\
LDST & 0.16 & $<0.01$ \\
$\mathrm{R}^{2}=0.31$ & &
\end{tabular}

\section{HRQoL in the MCI and SCI group}

We repeated the analyses in the MCI and SCI subgroups separately. In the SCI group, cognitive functioning and comorbid disease burden were not related to HRQoL. Within the emotional functioning domain, the presence of nighttime behavior disturbances (beta $=-0.28, p<0.01$ ) and informant and self-reported depression (beta $=-0.24, p<0.01$ and beta $=-0.31, p<0.01$ respectively) were related to lower HRQoL. The presence of agitation, however, was related to higher HRQoL (beta $=0.20, p=0.03$ ) (table 3). The total variance explained by the model was $46 \%$.

In the MCI group, comorbid disease burden, emotional and cognitive functioning remained significantly related to HRQoL (table 3). Again, a lower score on the LDST (beta $=0.22, \mathrm{p}<0.01$ ) and the presence of appetite/ eating disturbances (beta $=-0.14, p=0.04$ ), self-reported depression (beta $=-0.41, p<0.01$ ) and eyes / ears / nose comorbidities (beta $=-0.15, \mathrm{p}=0.03$ ) were associated with lower HRQoL. Also, the presence of lower gastrointestinal tract comorbidities was associated with lower HRQoL (beta $=-0.17, p=0.01$ ), while this association was not significant in the total group. The total variance explained by the model was $31 \%$, with emotional functioning explaining most of the variance (19\%). Cognitive functioning and comorbid disease burden both explained $5 \%$ of the variance. 
Table 3 Final predictive model for HRQoL based on all significant predictors within each predictive domain, reported for the SCI and MCI group separately (analyses corrected for age, education, gender and study centre)

\begin{tabular}{|llcc|}
\hline Group & Predictor & Beta & p-value \\
\hline SC̈I & Agitation & 0.20 & 0.03 \\
& Peer reported depression (NPI) & -0.24 & $<0.01$ \\
& Nighttime behavior disturbances & -0.28 & $<0.01$ \\
& Self-reported depression & -0.31 & $<0.01$ \\
\hline MCI & Appetite/ Eating disturbances & -0.14 & 0.04 \\
& Self-reported depression & -0.41 & $<0.01$ \\
& Eyes / ears/nose & -0.15 & 0.03 \\
& Lower digestive tract & -0.17 & 0.01 \\
& Kidney & -0.08 & 0.27 \\
& LDST & 0.22 & $<0.01$ \\
\hline
\end{tabular}

$\mathrm{R}^{2} \mathrm{SCI}=0.47$

$\mathrm{R}^{2} \mathrm{MCI}=0.31$

\section{DISCUSSION}

This study aimed to investigate the effect of comorbid disease burden, cognitive and emotional functioning on HRQoL in memory clinic visitors with SCI and MCI. We found that all three domains were significantly related to HRQoL in patients with $\mathrm{MCI}$, though most of the variance was explained by emotional functioning and especially depressive symptoms. In the SCI group only emotional functioning was related to HRQoL.

HRQoL was affected strongest by the presence of neuropsychiatric symptoms, in particular depressive symptoms, in all groups. The association between depressive symptoms, and reduced HRQoL in individuals with MCI has been reported in other studies (Muangpaisan et al., 2008, Teng et al., 2012, Weiss et al., 2012), and has also been found in people with subjective cognitive complaints (Maki et al., 2014). This seems to suggest that worries are an important determinant of HRQoL in all persons who present themselves at a memory clinic, irrespective of whether or not actual cognitive impairment can be demonstrated. In this regard, it is important to consider that the clinical diagnosis of SCI or MCI was not yet made at the time of assessment of HRQoL and the predictive factors. As a result, persons did not know whether their cognitive complaints were verified .

Further, lower HRQoL was also associated with agitation and nighttime behavior disturbances (SCI group) and appetite/eating disturbances (MCI group) in our study. The association between lower HRQoL and total NPI scores has been investigated previously, however the association with specific neuropsychiatric 
symptoms has not (Mhaolain et al., 2012, Naglie et al., 2011, Teng et al., 2012). Our finding that the presence of agitation was related to increased HRQoL was not in line with previous research in patients with dementia (Mjorud et al., 2014, Wetzels et al., 2010). A possible explanation for this could be that the level of agitation is low in our population (mean score $=1.2$ ), while the severity and thus influence of agitation is likely to increase with increasing severity of dementia. Possibly, the current low level of agitation may not be experienced as disturbing by the person himself and is thus not negatively related to HRQoL. In addition, the NPI is based on caregiver reports, which could introduce bias in the ratings of emotional functioning of the patient. That is, it may be that predominantly symptoms causing more distress for the caregiver, like agitation (Fauth and Gibbons, 2014) are recalled. Indeed the NPI items which refer more to concrete behavior (e.g. eating and nighttime behavior disturbances) and are less likely to be influenced by the caregivers' perception show the expected association with HRQoL.

In the present study, cognitive functioning also significantly influenced the HRQoL of people with MCI and of the total cohort. This finding is in contrast with that of other studies (Mhaolain et al., 2012, Naglie et al., 2011) that found no association between cognitive functioning and HRQoL in both MCI and dementia samples. However, instead of using only a cognitive screening instrument, our study examined the effect of cognitive functioning using a variety of cognitive measures which assesses cognition in much more detail. Yet, the study of Teng et al., 2012 also failed to find a significant association between cognitive functioning and HRQoL in an MCI sample using a more extensive neuropsychological test battery. This might be due to the use of cognitive domain scores that combined the results of multiple tests, while we used all test scores separately.

Comorbid disease burden had a significant influence on HRQoL in the MCI group and the total group, with eyes/ears/nose comorbidities being associated with lower HRQoL in both groups and lower gastrointestinal tract comorbidities being associated with lower HRQoL in the MCI group only. Indeed, gastrointestinal problems have been related to lower HRQOL in the general population (Halder et al., 2004, Irvine et al., 2002). The same association has been found for hearing and vision problems in the general elderly (Carabellese et al., 1993, Fischer et al., 2009) and nursing home population (Dev et al., 2014). However, the effect of specific comorbidities on HRQoL in MCI patients has not been investigated before. It should be noted that the severity of comorbidities was mild in our cohort, representing a relatively physically healthy sample. Associations might be even stronger when people suffer from more severe comorbidities 
When looking at differences between groups, we found that HRQoL did not differ between SCI and MCI patients, as was also reported in previous studies (Missotten et al., 2008, Muangpaisan et al., 2008, Ready et al., 2004). However, Barrios et al.

(2013) did find a lower HRQoL in patients with MCI compared to healthy controls. This might be due to differences in study population, since we compared groups that both searched medical attention because of worry about cognitive complaints.

\section{Strengths and Limitations}

To the best of our knowledge, the present study was the first that included comorbid disease burden, cognitive and emotional functioning simultaneously as predictors of HRQoL in memory clinic visitors. This enables comparison of the relative importance of these domains for predicting HRQoL. Further, cognitive functioning was assessed by an extensive neuropsychological assessment covering various domains rather than a short dementia screen, which allows a broader and more reliable investigation of the influence of cognition. Another strength of the study is the relatively large, well-characterized sample. Furthermore, by using data that were not restricted to a single center and applying broad inclusion criteria, generalizability to other memory clinic samples was maximized. A limitation of the current study might be the use of a non-disease specific HRQoL questionnaire. Although this measure is well-established and widely used, one could argue that HRQoL questionnaires that have been adapted for use in individuals with cognitive impairment, should have been implemented. However, the EuroQoL-5D has been reported before as a valid and reliable measure in patients with cognitive impairments (Wolfs et al., 2007). An additional limitation could be that the measurement of emotional functioning was largely based on informant reports (NPI), which might be less reliable than self reports in persons with only limited cognitive impairments. This could have diluted the established effects.

Furthermore, since all measurements in this study were performed at the start of the diagnostic trajectory, all individuals had not received a clinical diagnosis yet. Possibly, uncertainty about the eventual diagnosis may have been the main reason for the large impact of depressive symptoms. However, regardless of whether uncertainty is the underlying cause, reduced HRQoL remains important to target in these persons.

\section{Clinical Implications}

Our findings might have implications for current practice in memory clinics. It is important to realize that the HRQoL of memory clinic visitors, whether they have cognitive impairment or not, is influenced mainly by various emotional factors and 
especially depressive symptoms, but also by sensory impairments. The recognition and detection of these factors and possible underlying causes by the clinician should be given more importance in current practice. Furthermore, these factors might be promising targets for non-cognitive interventions to improve HRQoL in these patients.

\section{Conclusions}

In conclusion, the present study shows that the HRQoL of memory clinic visitors is mainly influenced by their emotional functioning, and especially by depressive symptoms. Furthermore, the HRQoL of MCI subjects is also influenced by cognitive functioning and comorbid disease burden. These factors should be taken into account in clinical practice and might be promising targets for interventions to improve HRQoL. 


\section{REFERENCES}

Barrios, H., Narciso, S., Guerreiro, M., Maroco, J., Logsdon, R. \& de Mendonca, A. (2013). Quality of life in patients with mild cognitive impairment. Aging and Mental Health, 17, 287-92.

Bowling, A. (2001). Measuring disease: a review of disease-specific quality of life measurement scales. Open University Press: Buckingham, Philadelphia (USA).

Carabellese, C., Appollonio, I., Rozzini, R., Bianchetti, A., Frisoni, G. B., Frattola, L. \& Trabucchi, M. (1993). Sensory impairment and quality of life in a community elderly population. Journal of the American Geriatrics Society, 41, 401-7.

Cummings, J. L., Mega, M., Gray, K., Rosenberg-Thompson, S., Carusi, D. A. \& Gornbein, J. (1994). The Neuropsychiatric Inventory: comprehensive assessment of psychopathology in dementia. Neurology, 44, 2308-14.

Dev, M. K., Paudel, N., Joshi, N. D., Shah, D. N. \& Subba, S. (2014). Psycho-social impact of visual impairment on health-related quality of life among nursing home residents. BMC Health Services Research, 14, 345.

Dolan, P. (1997). Modeling valuations for EuroQol health states. Medical Care, 35, 1095-108.

Fauth, E. B. \& Gibbons, A. (2014). Which behavioral and psychological symptoms of dementia are the most problematic? Variability by prevalence, intensity, distress ratings, and associations with caregiver depressive symptoms. International Journal of Geriatric Psychiatry, 29, 263-71.

Fischer, M. E., Cruickshanks, K. J., Klein, B. E., Klein, R., Schubert, C. R. \& Wiley, T.

L. (2009). Multiple sensory impairment and quality of life. Ophthalmic Epidemiology 16, 346-53.

Folstein, M. F., Folstein, S. E. \& McHugh, P. R. (1975). "Mini-mental state". A practical method for grading the cognitive state of patients for the clinician. Journal of Psychiatric Research, 12, 189-98.

Halder, S. L., Locke, G. R., 3rd, Talley, N. J., Fett, S. L., Zinsmeister, A. R. \& Melton, L. J., 3rd (2004). Impact of functional gastrointestinal disorders on health-related quality of life: a population-based case-control study. Alimentary Pharmacology and Therapeutics, 19, 233-42.

Hammes, J. (1973). De Stroop Kleur-Woord Test: Handleiding [The Stroop ColorWord Test: Manual]. Swets \& Zeitlinger: Amsterdam.

Irvine, E. J., Ferrazzi, S., Pare, P., Thompson, W. G. \& Rance, L. (2002). Healthrelated quality of life in functional GI disorders: focus on constipation and resource utilization. American Journal of Gastroenterology, 97, 1986-93.

Lezak, M. D., Howieson, D. B. \& Loring, D. W. (2004). Neuropsychological Assessment, 4th Edition. Oxford University Press: Oxford, UK.

Maki, Y., Yamaguchi, T., Yamagami, T., Murai, T., Hachisuka, K., Miyamae, F., Ito, K., Awata, S., Ura, C., Takahashi, R. \& Yamaguchi, H. (2014). The impact of subjective memory complaints on quality of life in community-dwelling older adults. Psychogeriatrics, 14, 175-81. 
Mhaolain, A. M., Gallagher, D., Crosby, L., Ryan, D., Lacey, L., Coen, R. F., Coakley, D., Walsh, J. B., Cunningham, C. \& Lawlor, B. (2012). Frailty and quality of life for people with Alzheimer's dementia and mild cognitive impairment. American Journal of Alzheimer's Disease and Other Dementias, 27, 48-54.

Miller, M. D., Paradis, C. F., Houck, P. R., Mazumdar, S., Stack, J. A., Rifai, A. H., Mulsant, B. \& Reynolds, C. F., 3rd (1992). Rating chronic medical illness burden in geropsychiatric practice and research: application of the Cumulative Illness Rating Scale. Psychiatry Research, 41, 237-48.

Missotten, P., Squelard, G., Ylieff, M., Di Notte, D., Paquay, L., De Lepeleire, J. \& Fontaine, O. (2008). Quality of life in older Belgian people: comparison between people with dementia, mild cognitive impairment, and controls. International Journal of Geriatric Psychiatry, 23, 1103-9.

Mjorud, M., Kirkevold, M., Rosvik, J., Selbaek, G. \& Engedal, K. (2014). Variables associated to quality of life among nursing home patients with dementia. Aging and Mental Health, 1-9.

Mol, M. E. M., van Boxtel, M. P. J., Willems, D., Verhey, F. R. J. \& Jolles, J. (2009). Subjective forgetfulness is associated with lower quality of life in middle-aged and young-old individuals: A 9-year follow-up in older participants from the Maastricht Aging Study. Aging and Mental Health, 13, 699-705.

Morris, J. C. (1993). The Clinical Dementia Rating (CDR): current version and scoring rules. Neurology, 43, 2412-4.

Muangpaisan, W., Assantachai, P., Intalapaporn, S. \& Pisansalakij, D. (2008). Quality of life of the community-based patients with mild cognitive impairment. Geriatrics $\mathcal{E}$ Gerontology International, 8, 80-5.

Naglie, G., Hogan, D. B., Krahn, M., Beattie, B. L., Black, S. E., Macknight, C., Freedman, M., Patterson, C., Borrie, M., Bergman, H., Byszewski, A., Streiner, D., Irvine, J., Ritvo, P., Comrie, J., Kowgier, M. \& Tomlinson, G. (2011). Predictors of patient self-ratings of quality of life in Alzheimer disease: cross-sectional results from the Canadian Alzheimer's Disease Quality of Life Study. American Journal of Geriatric Psychiatry, 19, 881-90.

Ready, R. E., Ott, B. R. \& Grace, J. (2004). Patient versus informant perspectives of Quality of Life in Mild Cognitive Impairment and Alzheimer's disease. International Journal of Geriatric Psychiatry, 19, 256-65.

Schmand, B., Houx, P. \& de Koning, I. (2003). Normen voor Stroop kleur-woord tests, Trail Making test en Story Recall van de Rivermead Behavioural Memory Test. [Norms for Stroop color-word tests, Trail Making Test and Story Recall of the Rivermead Behavioural Memory Test]. Nederlands Instituut van Psychologen, Sectie Neuropsychologie: Amsterdam.

Sheikh, J. I. \& Yesavage, J. A. (1986). Geriatric Depression Scale (GDS): recent evidence and development of a shorter version. Clinical Gerontology, 5, 165-173.

Teng, E., Tassniyom, K. \& Lu, P. H. (2012). Reduced quality-of-life ratings in mild cognitive impairment: analyses of subject and informant responses. American Journal of Geriatric Psychiatry, 20, 1016-25.

The EuroQol Group (1990). EuroQol--a new facility for the measurement of health-related quality of life. Health Policy, 16, 199-208. 
Van der Elst, W., van Boxtel, M. P., van Breukelen, G. J. \& Jolles, J. (2005). Rey's verbal learning test: normative data for 1855 healthy participants aged $24-81$ years and the influence of age, sex, education, and mode of presentation. Journal of the International Neuropsychological Society, 11, 290-302.

van der Elst, W., van Boxtel, M. P., van Breukelen, G. J. \& Jolles, J. (2006a). The Letter Digit Substitution Test: normative data for 1,858 healthy participants aged 24-81 from the Maastricht Aging Study (MAAS): influence of age, education, and sex. Journal of Clinical and Experimental Neuropsychology, 28, 998-1009.

Van der Elst, W., Van Boxtel, M. P., Van Breukelen, G. J. \& Jolles, J. (2006b). Normative data for the Animal, Profession and Letter M Naming verbal fluency tests for Dutch speaking participants and the effects of age, education, and sex. Journal of the International Neuropsychological Society, 12, 80-9.

Van der Elst, W., Van Boxtel, M. P., Van Breukelen, G. J. \& Jolles, J. (2006c). The Stroop color-word test: influence of age, sex, and education; and normative data for a large sample across the adult age range. Assessment, 13, 62-79.

Ware, J. E., Jr. (1987). Standards for validating health measures: definition and content. Journal of Chronic Diseases, 40, 473-80.

Weiss, E. M., Papousek, I., Fink, A., Matt, T., Marksteiner, J. \& Deisenhammer, E. A. (2012). [Quality of life in mild cognitive impairment, patients with different stages of Alzheimer disease and healthy control subjects]. Neuropsychiatrie, 26, 72-7.

Wetzels, R. B., Zuidema, S. U., de Jonghe, J. F., Verhey, F. R. \& Koopmans, R. T. (2010). Determinants of quality of life in nursing home residents with dementia. Dementia and Geriatric Cognitive Disorders, 29, 189-97.

Wolfs, C. A., Dirksen, C. D., Kessels, A., Willems, D. C., Verhey, F. R. \& Severens, J. L. (2007). Performance of the EQ-5D and the EQ-5D+C in elderly patients with cognitive impairments. Health and Quality of Life Outcomes, 5, 33. 

CHAPTER 8

GENERAL DISCUSSION 


\section{GENERAL DISCUSSION}

The transitional state between normal cognitive functioning and dementia is usually referred to as Mild Cognitive Impairment (MCI) (Petersen et al., 1999). People with MCI are characterized by having cognitive impairments in one or multiple cognitive domains, but do not fulfil criteria for dementia. Although they have an increased risk to develop dementia, a substantial number of them remains cognitively stable or even reverts back to normal cognitive functioning after prolonged follow-up (Ganguli et al., 2011, Visser et al., 2006). So, MCI denominates a heterogeneous group of people with large individual variation in the level and pattern of cognitive impairment, course of decline over time and thus prognosis. This heterogeneity is likely due to differences in the underlying causes of the impairment, whereby stability or improvement in cognition is unlikely to be caused by neurodegenerative pathology.

Although dementia was long regarded as a monocausal disease, currently it has become clear that, especially at older age, a pure form of dementia does not exist and multiple factors contribute together to the development of dementia. Yet, multimorbidity, which is typically associated with advancing age (Uijen and van de Lisdonk, 2008, van den Akker et al., 1998), has received little attention in research into early stage cognitive decline thus far.

Therefore, it is important to investigate the natural course of decline in MCI and detect factors that can influence this course. This may help in the identification of and distinction between those individuals that show a pattern and rate of decline that is typical for emerging underlying neurodegenerative pathology and those that do not, which in turns lead to a more accurate prognosis and better care and treatment for these patients.

The aim of the first part of this thesis was to investigate the profile and course of cognitive decline in Mild Cognitive Impairment. In chapter 2, we examined the rates of domain-specific cognitive decline in the pre-dementia phase by means of a systematic literature review and meta-analysis. In chapter 3 , we studied the temporal sequence, pattern and rate of cognitive decline before dementia diagnosis in people selected from a memory clinic setting. Further, we described the existence of different subtypes of cognitive impairment in a memory clinic-based population and their predictive value for conversion to dementia (chapter 4). The aim of the second part of this thesis was to investigate the influence of the often-overlooked issue of comorbidity on the course of cognitive decline, and also on Health-related Quality of Life (HRQoL) in a memory clinic setting. We described the study outline of the prospective Clinical Course of Cognition and Comorbidity in MCI (4C-MCI) study (chapter 5). This study was set up to investigate the abovementioned aims. Further, we assessed the influence of total severity of comorbidity on cognitive decline and conversion to dementia in a 
memory clinic-based population (chapter 6). In addition, we studied the association between emotional functioning, cognitive functioning and comorbid disease burden and HRQoL in memory clinic visitors (chapter 7).

In this last chapter, we will summarize and discuss the general findings, elaborate on methodological considerations and report on the scientific and clinical implications of our findings.

\section{Pattern and rate of cognitive decline in MCI}

The current MCI concept includes amnestic and non-amnestic forms, which can involve single or multiple cognitive domains (Petersen and Morris, 2005). This concept corresponds to findings that show impairments in the pre-dementia phase across multiple cognitive domains, like episodic memory (Backman et al., 2001, Chen et al., 2000, Rubin et al., 1998), executive functioning (Albert et al., 2001, Rapp and Reischies, 2005), verbal fluency (Fabrigoule et al., 1998, Laukka et al., 2004), attention (Linn et al., 1995, Nielsen et al., 1999) and global cognitive functioning (Backman and Small, 1998, Fabrigoule et al., 1998). Impairments in some of these domains, e.g. episodic memory, have been identified as a strong predictor for conversion to dementia (Albert et al., 2001, Twamley et al., 2006), especially dementia of the Alzheimer-type. However, the longitudinal course of decline in specific domains remains largely undetermined, while a better understanding of the pattern, magnitude and temporal sequence of these cognitive deficits is important to facilitate early diagnosis, better prognosis and increase insight into early pathological brain mechanisms, since changes in the rate of decline might be more indicative of incipient dementia than impaired cognitive performance on an isolated assessment at baseline.

By means of meta-analysis, we compared the rate of domain-specific decline in six distinct cognitive domains before dementia diagnosis, over a relatively long period of about 5 years. In addition, we tested whether rates of decline differed between future converters $(n=2249)$ and non-converters $(n=2439)$ (chapter 2$)$. During the period before dementia diagnosis, decline in episodic memory and global cognitive functioning was almost two times larger than decline in other cognitive domains. In addition, the rate of decline in attention/ information processing speed (IPS) was relatively small and, more importantly, did not differ between converters to dementia and non-converters. Interestingly, our results did not essentially change when we included only people who converted to Alzheimer's Disease (AD) dementia compared to the inclusion of people who converted to dementia (AD or underlying aetiology not specified). This finding appears legitimate, because the majority of this second (aetiology not specified) group probably has underlying AD pathology, as AD is the most common cause of dementia. The finding that pre-dementia decline is most salient in global cognitive functioning and episodic memory is consistent with observations that the earliest 
pathologic changes in (AD) dementia occur in the medial temporal lobe regions (Ridha et al., 2006, Sluimer et al., 2009), which are known to be crucial for episodic memory functioning. The lack of discriminative power of attention/IPS might be attributed to the effects of normal ageing on attention/IPS performance (Finkel et al., 2007, Hoogendam et al., 2014) and matches findings of previous studies into the limited predictive value of attention deficits for AD dementia (Albert et al., 2001).

The results found in chapter 2 were mainly based on studies performed in the general population. However, these populations of cognitively healthy volunteers are not directly comparable to people who present themselves at a memory clinic because of cognitive complaints. Yet, the latter group includes subjects that seeks help and asks for their prognosis and possible treatment options.

Therefore, in chapter 3 we studied decline before dementia diagnosis in a memory clinic-based population. We examined the pattern, magnitude and temporal sequence of decline in various cognitive domains in people who converted to AD dementia and compared this to decline in those who did not convert. We found that the performance of converters and non-converters differed already seven (episodic memory) to three (executive functioning and verbal fluency) years prior to AD dementia diagnosis. Again, large differences in decline between groups were found for episodic memory, but also for executive functioning, which is in line with findings from population-based studies (Chen et al., 2001, Grober et al., 2008, Johnson et al., 2009). Again, there was no difference in decline in attention/(IPS) between groups, which corroborates our findings in chapter 2. Yet, when we included data on decline after dementia diagnosis, the trajectories for attention/IPS of converters and non-converters did differ. This implies that decline in attention is still subtle in the pre-dementia phase and starts widening as underlying pathology progresses. Further the absence of decline in attention/IPS indicated that the observed decline in executive functioning was merely due to a higher order cognitive processing problem instead of being due to an underlying mental speed problem.

Our findings from these two chapters might have implications for early detection of dementia and indicate that cognitive assessments should not focus solely on episodic memory, but should also take measures of executive functioning and global cognitive functioning into account. In addition, decline in attention/IPS might be regarded as less important since it appears to be not indicative of underlying dementia pathology in the early stages of cognitive decline.

In chapter 4, we studied the existence of cognitive subtypes in a memory clinic population in order to assess the heterogeneity in clinical presentation (i.e. singlevs. multi-domain impairment and amnestic vs. non-amnestic impairment) that is often found in people with MCI. Instead of using a theoretical or clinical 
framework we used a data-driven approach with sophisticated statistics (i.e. latent profile analysis) to identify different cognitive subtypes. Our study detected five cognitive subtypes: people with low- and high-normal cognition, people with primary memory impairments with impairments in long-term consolidation (recognition), people with primary memory impairments but without impairments in long-term consolidation and people with primary non-memory impairments. These different subtypes parallel the current MCI concept. Subtypes displayed unique associations with overall dementia risk and dementia aetiology. Lowest dementia risk was found in the high-normal cognition subtype, which likely represents the "worried-well" patient whose performance is not indicative of any underlying neurodegenerative pathology. The highest dementia risk was found in people with primarily non-amnestic impairment and they developed most often non-AD dementia, which matches previous findings (Petersen and Morris, 2005). People with primary amnestic impairment most often developed AD-type dementia, regardless of whether they had impaired recognition memory or not. Although impaired recognition has been reported before as a predictor of AD-type dementia (Didic et al., 2013), our findings state that impaired recognition does not discriminate between people with varying dementia risk.

These findings indicate that it is important to take cognitive variability within a memory clinic population into account, because treating people as a single population disregards the diverse extent and patterns of cognitive impairment that exist within the MCI population and their different associations with dementia risk and aetiology. Our results support the use of a three-group classification system: normal cognitive functioning, amnestic cognitive impairment and non-amnestic cognitive impairment

\section{Multimorbidity}

Advancing age is typically associated with multimorbidity (Uijen and van de Lisdonk, 2008, van den Akker et al., 1998), however little is known on whether multimorbidity affects cognitive decline. There is some evidence that the cumulative medical disease burden is related to worse cognitive functioning in the general elderly population (Morrow et al., 2009, Patrick et al., 2002) and in demented subjects (Doraiswamy et al., 2002, Oosterveld et al., 2014), hence we expected an effect of severity of total comorbidity on cognitive performance over time and progression to dementia in our non-demented memory clinic-based population.

Findings of our study indicated that the severity of total comorbidity was related to worse cognitive performance on speed related tests already at the time patients entered the memory clinic. This corroborates findings of studies in people with MCI (Lyketsos et al., 2005) and dementia (Doraiswamy et al., 2002, Oosterveld et al., 2014), though these studies reported on global cognition instead of specific cognitive domains. In addition, severity of comorbidity was also related to 
cognitive decline over three years, again only on speed dependent tests, which corroborates findings in cognitively healthy elderly (Patrick et al., 2002). When looking at the influence of specific disease clusters on cognitive decline, mainly severity of comorbidity in the cardiac and respiratory domain was associated with worse cognitive performance and steeper decline over time. Factors like atrial fibrillation and chronic heart failure have been related previously to worse cognitive performance and cognitive decline (Almeida et al., 2012, Bellomo et al., 2012, Thacker et al., 2013), and the same associations have been found for (the severity of) pulmonary diseases (Dal Negro et al., 2014, Klein et al., 2010).

However, severity of total comorbidity was not related to an increased risk of conversion to dementia after three years, though multiple single medical diseases have been associated with an increased risk of dementia before (Barnes and Yaffe, 2011). Our finding might be a result of the relatively short follow-up period, which limited the number of converters to dementia and thus power of our analyses. In addition, it is possible that some non-converters might have been misclassified at their latest follow-up assessment because they will convert to dementia in the future, thereby diluting the effect. Further, severity of comorbidity mainly affects speed and it has been shown before that speed impairments are not an important predictor of conversion to dementia.

Our study showed that multimorbidity has a strong impact on cognitive performance and may rather be a cause of cognitive decline than a consequence of an underlying neurodegenerative process. Furthermore, our results provide a basis for shifting from a single pathology approach to a more integrative approach, which also is more representative for the typical increasing disease burden in our ageing population.

\section{Health-related Quality of Life}

In absence of curative drug interventions at present, and likely also in the near future, the importance of focusing on secondary outcomes, i.e. HRQoL, throughout the entire course of dementia is increasingly recognized (Gwyther, 1997, Logsdon et al., 2002, Ready and Ott, 2003, Walker et al., 1998, Whitehouse and Rabins, 1992). HRQoL has been reported to be diminished in dementia (Lapid et al., 2011, Missotten et al., 2008, Ready et al., 2004), but has not been extensively investigated in MCI and results thus far are inconsistent. It is known that the uncertain MCI label may evoke negative reactions like anxiety and loss of selfconfidence, feelings of irritation and anger towards others or abandoning leisure activities (Joosten-Weyn Banningh et al., 2008). As a result, MCI could also be related to lower HRQoL, which would be an important target for interventions. We investigated the association between comorbid disease burden, emotional and cognitive functioning and HRQoL to see whether these factors, that are associated with HRQoL in dementia (Banerjee et al., 2006, Mhaolain et al., 2012, Sloane et al., 2005), are also related to HRQoL in memory clinic visitors with MCI and in those 
with subjective cognitive complaints (SCI).

Our study showed that most of the variance in HRQoL in memory clinic visitors is explained by emotional functioning and especially by depressive symptoms. This corresponds to findings of a systematic review into HRQoL in people with dementia (Banerjee et al., 2009). In addition, lower HRQoL in people with MCI was also related to the presence of comorbidities in the eyes/ears/nose and gastrointestinal tract domain. The relation between HRQoL and cognition was limited to performance on a processing speed test in MCI. Our study indicated that HRQoL in memory clinic visitors is influenced by several potentially modifiable factors that are known to be prevalent in this elderly population. These factors should be taken into account in this population with cognitive complaints and they might be promising targets for non-cognitive interventions to improve HRQoL.

\section{Methodological considerations}

The present thesis reports findings from multiple study designs, including a systematic review and meta-analysis, a retrospective cohort study, a prospective cohort study and cross-sectional data.

\section{Strengths}

One of the main strengths of our studies was the use of large sample sizes, which increased the power of our studies and allowed us to perform sophisticated multivariate and random-effects analyses. In addition, our samples were not restricted to a single centre and we included both people with $\mathrm{MCI}$ and people with subjective cognitive complaints. Essentially, and in contrast to what is often done in MCI studies, we applied broad inclusion criteria in which most comorbid disorders were not excluded, thus avoiding elimination of these potentially important contributing factors in advance and maximizing generalization to the general elderly population.

The longitudinal study designs with follow-ups from 3 (chapter 6) up to 10 (chapter 3) and 14 years (chapter 4) gave us the opportunity to investigate shortterm as well as long-term outcomes of subjects. Further, the relatively long followup period (chapters 3 and 4) allowed us to investigate dementia outcome by including a considerable number of converters to dementia with several assessment points. In addition, we used an extensive neuropsychological assessment in all studies, which covered the most relevant cognitive domains. By means of meta-analysis we could increase insight into the annual rate of domainspecific cognitive decline in the pre-dementia phase by pooling data from previous studies and taking into account the sample size of all studies (chapter 2). 


\section{Limitations}

Our studies also had several limitations. First, people who present themselves at highly specialized memory clinics in academic medical centres are likely not representative of the general population with cognitive complaints. Further, there is the issue of missing data, since not all participants had information on all measures through the entire follow-up period, because of which valuable information could have been missing. Yet, this is a common and unavoidable problem that is intrinsic to clinical research with an elderly population. In addition, there is the matter of loss to follow-up that could lead to selection bias. In the prospective 4C-MCI study (chapters $5-7$ ) participants that dropped out were significantly different from the participants that had follow-up data, while in the retrospective 4C-MCI study (chapters 3 and 4) we partially relied on routine clinical data, which led to absence of information regarding dropouts. However, by employing statistical procedures like random-effects linear mixed models we made maximum use of all available data for each participant. Yet, given that attrition was not completely at random, effects might have been diluted as either non-converters with intact cognition in the routine clinical setting (chapters 3 and 4 ) or the older, more fragile and more cognitively impaired individuals in a research setting (chapter 6) are inclined to get lost to follow-up.

Furthermore, although our follow-up time was relatively long (especially in chapters 3 and 4) it is still possible that some non-converters might have been misclassified at their latest follow-up assessment because they will convert to dementia in the future, thereby attenuating the effect. This is especially salient in the prospective part of the 4C-MCI study which currently only has three years of follow-up. A follow-up time of five to ten years seems most appropriate for studies into early stage cognitive decline, as this time frame encompasses both the earliest decline in cognitive functioning and covers a period that is relevant for questions regarding prognosis in the general elderly population (e.g. for how will I remain non-demented?). Another important factor to take into account in these longitudinal studies is the existence of test-retest or practice effects. When neuropsychological tests are applied longitudinally practice effects are unavoidable, as the test procedures become more familiar to the participants. We indeed observed absence of decline in a part of our ageing study population (chapters 3 and 6), which could possibly be attributed to test-retest effects. In chapter 3, changes in neuropsychological test performances were compared for individuals who did or did not convert to dementia. Given the fact that only nonconverters showed a practice effect, the absence of such an effect might possibly also be regarded as an indication of underlying dementia pathology. In chapter 6, we compared changes in neuropsychological test performances for people who did or did not have a certain risk factor (i.e. severity of comorbidity). Given the assumption that practice effects are not dependent on the risk factor of interest, test-retest effects most likely did not affect our results substantially. Further, our 
data did not include neuropathologic confirmation of dementia diagnosis or collection of potential diagnostic biomarkers. However, this is presumably an adequate reflection of current clinical practice, where biomarkers are complementary and only recommended in case of substantial clinical uncertainty (Hort et al., 2010). In addition, use and availability of biomarkers is still limited in countries outside Europe or the United States.

\section{Recommendations}

\section{Scientific implications}

The results of the research in this thesis have several implications for future studies in subjects with MCI. We showed that episodic memory, but also executive functioning and global cognitive functioning display early and large decline before dementia diagnosis. Future research should investigate the predictive value of cognitive decline in these domains over time for conversion to dementia rather than focussing on the predictive value of an isolated assessment of cognitive performance.

Another important recommendation for future research is the inclusion of subjects with multimorbidity at baseline in studies into prodromal dementia.

Multimorbidity is common in the elderly population and was related to cognitive performance and decline (chapter 6) and HRQoL (chapter 7). By excluding this important aspect in diagnostic and therapeutic studies in advance, generalizability to the MCI population will be limited, a factor contributing to cognitive decline will be overlooked and a substantial number of people at risk for dementia will not be detected. Further, as multimorbidity was not related to an increased risk of conversion to dementia it does not seem to be a confounder for conversion studies, mainly because it affects speed performance, which is not a good predictor of conversion to dementia.

We further recommend that studies into early stage cognitive decline aim to follow subjects for five years or more, since AD related decline in episodic memory can precede dementia diagnosis by seven years (chapter 3 ), with other domains following several years later. By applying limited follow-up lengths important information on cognitive decline in the earliest stages might not be detected. Further, the influence of comorbidity on conversion to dementia is likely to be more evident after a longer follow-up period, since after three years follow-up severity of comorbidity influences only speed related decline but not conversion to dementia (chapter 6). In addition, we advocate the use of latent profile analyses and multivariate statistics in dementia research, since these statistic techniques may reveal more informative patterns of associations than the study of isolated cognitive domains. These cognitive patterns can then be used for studying disease mechanisms and relations with biomarkers. 


\section{Clinical implications}

The clinical implications of our findings lie in the establishment of the natural course of decline in MCI in memory clinic visitors, the contribution of multimorbidity in this population and the determinants of HRQoL we identified. We found that episodic memory and global cognitive functioning declined almost two times faster than other cognitive domains before dementia diagnosis. The findings for episodic memory were corroborated in a memory clinic-based population, where decline in episodic memory was the earliest and strongest indicator of incipient AD dementia, while also executive functioning showed an accelerated rate of decline compared to people that remained non-demented. These findings have implications for the use of optimal neuropsychological test batteries that aim to detect dementia at an early stage. Although our results confirm the importance of episodic memory impairment early in the disease process, also decline in executive functioning and global cognitive functioning seem early and sensitive indicators of future dementia. Therefore, cognitive assessment should not primarily focus on episodic memory, but give equal importance to executive functioning and global cognitive functioning using sensitive and reliable measures. These domains are also important in the identification of different cognitive subtypes within the MCI population. These subtypes can be used for establishing specific dementia risks and the suspected underlying aetiology.

Another important consequence of our results is that for detecting early stage cognitive decline the main emphasis in a cognitive assessment should not be on the attention / IPS domain, since we showed that decline in attention/IPS does not differ between converters to dementia and non-converters. It is likely that the established decline in attention/IPS in both groups can be attributed to an ageing effect in this elderly population (Finkel et al., 2007, Hoogendam et al., 2014) and to the presence of comorbidity, which might obscure the effect of eventual developing underlying neurodegenerative pathology.

We further found that performance and decline on speed dependent tests is influenced by severity of comorbidity. This implies that medical disorders should be intensively assessed in clinical practice in order to assure broad recognition and detection of factors that are associated with worse cognitive performance and decline. Since (part of) these factors are potentially modifiable, they may be an important target for interventions to ameliorate cognitive performance and in the long-term prevent cognitive decline and conversion to dementia. This multifactorial approach might be a more fruitful and realistic treatment strategy than a single molecule approach to, for instance, beta-amyloid removal. Treatment of comorbidities may be an explanation for the recently observed decline in incidence of dementia (Barnes and Yaffe, 2011, Qiu et al., 2013, Rocca et al., 2011, Schrijvers et al., 2012), although this declining incidence might also be due to the improved educational level of the population. 
Our finding that HRQoL in memory clinic visitors is associated with comorbid disease burden, but also with worse performance on a speed-related test and depressive symptoms, also emphasize the importance of the broad assessment of additional non-cognitive factors in clinical practice and underscore the importance of a multidisciplinary approach in the diagnostic and treatment possibilities for people with MCI. Special attention should be paid to the detection of depressive symptoms, since they turned out to be the most important determinant of HRQoL, but have also been related previously to worse cognitive performance (Ganguli et al., 2006, Steffens et al., 2006). As depressive symptoms can be ameliorated by a diversity of treatments, they appear to be an important target for interventions to improve HRQoL.

\section{Conclusions}

In conclusion, this thesis expands our knowledge about the natural course of cognitive decline in people with MCI that convert to dementia and those that do not. It is important to differentiate at an early stage between progressive and stable $\mathrm{MCI}$, as both groups likely benefit from other sorts of advice and interventions. A first step in this direction is that we showed that differentiation in cognitive performance between stable and progressive MCI is possible already seven years prior to dementia diagnosis for episodic memory. Further, besides episodic memory also executive functioning and global cognitive functioning show early and large decline before dementia diagnosis and are thus important targets for early stage dementia detection. In addition, we demonstrated that decline in attention/IPS seems less indicative of future dementia. Yet, performance and decline in this domain is influenced by severity of comorbidity. However, severity of comorbidity seems not related to conversion to dementia in the short-term. In absence of curative treatments for dementia, we found that HRQoL of memory clinic visitors is affected by several potentially modifiable factors of which depressive symptoms appear to be the most important.

It seems likely that the use of a multifactorial disease model, including cognitive, medical, emotional and biological predictors will optimize early recognition of dementia and identify new targets for interventions aimed at both preventing future cognitive decline and improving current HRQoL. 


\section{REFERENCES}

Albert, M. S., Moss, M. B., Tanzi, R. \& Jones, K. (2001). Preclinical prediction of AD using neuropsychological tests. Journal of the International Neuropsychological Society, 7, 631-9.

Almeida, O. P., Beer, C., Lautenschlager, N. T., Arnolda, L., Alfonso, H. \& Flicker, L. (2012). Two-year course of cognitive function and mood in adults with congestive heart failure and coronary artery disease: the Heart-Mind Study. International Psychogeriatrics, 24, 38-47.

Backman, L. \& Small, B. J. (1998). Influences of cognitive support on episodic remembering: tracing the process of loss from normal aging to Alzheimer's disease. Psychology and Aging, 13, 267-76.

Backman, L., Small, B. J. \& Fratiglioni, L. (2001). Stability of the preclinical episodic memory deficit in Alzheimer's disease. Brain, 124, 96-102.

Banerjee, S., Samsi, K., Petrie, C. D., Alvir, J., Treglia, M., Schwam, E. M. \& del Valle, M. (2009). What do we know about quality of life in dementia? A review of the emerging evidence on the predictive and explanatory value of disease specific measures of health related quality of life in people with dementia. International Journal of Geriatric Psychiatry, 24, 15-24.

Banerjee, S., Smith, S. C., Lamping, D. L., Harwood, R. H., Foley, B., Smith, P., Murray, J., Prince, M., Levin, E., Mann, A. \& Knapp, M. (2006). Quality of life in dementia: more than just cognition. An analysis of associations with quality of life in dementia. Journal of Neurology, Neurosurgery and Psychiatry, 77, 146-8.

Barnes, D. E. \& Yaffe, K. (2011). The projected effect of risk factor reduction on Alzheimer's disease prevalence. Lancet Neurology, 10, 819-28.

Bellomo, A., De Benedetto, G., Fossati, C., D'Ottavio, E., Formosa, V., Gianturco, V.,Iori, A., Marigliano, B., Lo Iacono, C., Troisi, G. \& Marigliano, V. (2012). Atrial fibrillation (AF) and cognitive impairment in the elderly: a case-control study. Archives of Gerontology and Geriatrics, 55, 247-50.

Chen, P., Ratcliff, G., Belle, S. H., Cauley, J. A., DeKosky, S. T. \& Ganguli, M. (2000). Cognitive tests that best discriminate between presymptomatic AD and those who remain nondemented. Neurology, 55, 1847-53.

Chen, P., Ratcliff, G., Belle, S. H., Cauley, J. A., DeKosky, S. T. \& Ganguli, M. (2001). Patterns of cognitive decline in presymptomatic Alzheimer disease: a prospective community study. Archives of General Psychiatry, 58, 853-8.

Dal Negro, R. W., Bonadiman, L., Tognella, S., Bricolo, F. P. \& Turco, P. (2014). Extent and prevalence of cognitive dysfunction in chronic obstructive pulmonary disease, chronic non-obstructive bronchitis, and in asymptomatic smokers, compared to normal reference values. International Journal of Chronic Obstructive Pulmonary Disease, 9, 675-83.

Didic, M., Felician, O., Barbeau, E. J., Mancini, J., Latger-Florence, C., Tramoni, E. \& Ceccaldi, M. (2013). Impaired visual recognition memory predicts Alzheimer's disease in amnestic mild cognitive impairment. Dementia and Geriatric Cognitive Disorders, 35, 291-9. 
Doraiswamy, P. M., Leon, J., Cummings, J. L., Marin, D. \& Neumann, P. J. (2002). Prevalence and impact of medical comorbidity in Alzheimer's disease. Journals of Gerontology. Series A, Biological Sciences and Medical Sciences, 57, M173-7.

Fabrigoule, C., Rouch, I., Taberly, A., Letenneur, L., Commenges, D., Mazaux, J. M., Orgogozo, J. M. \& Dartigues, J. F. (1998). Cognitive process in preclinical phase of dementia. Brain, 121, 135-41.

Finkel, D., Reynolds, C. A., McArdle, J. J. \& Pedersen, N. L. (2007). Age changes in processing speed as a leading indicator of cognitive aging. Psychology and Aging, 22, 558-68.

Ganguli, M., Du, Y., Dodge, H. H., Ratcliff, G. G. \& Chang, C. C. (2006). Depressive symptoms and cognitive decline in late life: a prospective epidemiological study. Archives of General Psychiatry, 63, 153-60.

Ganguli, M., Snitz, B. E., Saxton, J. A., Chang, C. C., Lee, C. W., Vander Bilt, J., Hughes, T. F., Loewenstein, D. A., Unverzagt, F. W. \& Petersen, R. C. (2011). Outcomes of mild cognitive impairment by definition: a population study. Archives of Neurology, 68, 761-7.

Grober, E., Hall, C. B., Lipton, R. B., Zonderman, A. B., Resnick, S. M. \& Kawas, C. (2008). Memory impairment, executive dysfunction, and intellectual decline in preclinical Alzheimer's disease. Journal of the International Neuropsychological Society, 14, 26678.

Gwyther, L. P. (1997). The perspective of the person with Alzheimer disease: which outcomes matter in early to middle stages of dementia? Alzheimer Disease and Associated Disorders, 11 Suppl 6, 18-24.

Hoogendam, Y. Y., Hofman, A., van der Geest, J. N., van der Lugt, A. \& Ikram, M. A. (2014). Patterns of cognitive function in aging: the Rotterdam Study. European Journal of Epidemiology, 29, 133-40.

Hort, J., Bartos, A., Pirttila, T. \& Scheltens, P. (2010). Use of cerebrospinal fluid biomarkers in diagnosis of dementia across Europe. European Journal of Neurology, 17, 90-6.

Johnson, D. K., Storandt, M., Morris, J. C. \& Galvin, J. E. (2009). Longitudinal study of the transition from healthy aging to Alzheimer disease. Archives of Neurology, 66, 12549.

Joosten-Weyn Banningh, L., Vernooij-Dassen, M., Rikkert, M. O. \& Teunisse, J. P. (2008). Mild cognitive impairment: coping with an uncertain label. International Journal of Geriatric Psychiatry, 23, 148-54.

Klein, M., Gauggel, S., Sachs, G. \& Pohl, W. (2010). Impact of chronic obstructive pulmonary disease (COPD) on attention functions. Respiratory Medicine, 104, 52-60.

Lapid, M. I., Rummans, T. A., Boeve, B. F., McCormick, J. K., Pankratz, V. S., Cha,R. H., Smith, G. E., Ivnik, R. J., Tangalos, E. G. \& Petersen, R. C. (2011). What is the quality of life in the oldest old? International Psychogeriatrics, 23, 1003-10.

Laukka, E. J., Jones, S., Fratiglioni, L. \& Backman, L. (2004). Cognitive functioning in preclinical vascular dementia: a 6-year follow-up. Stroke, 35, 1805-9.

Laukka, E. J., Macdonald, S. W., Fratiglioni, L. \& Backman, L. (2012). Preclinical cognitive trajectories differ for Alzheimer's disease and vascular dementia. Journal of the International Neuropsychological Society, 18, 191-9. 
Linn, R. T., Wolf, P. A., Bachman, D. L., Knoefel, J. E., Cobb, J. L., Belanger, A. J., Kaplan, E. F. \& D'Agostino, R. B. (1995). The 'preclinical phase' of probable Alzheimer's disease. A 13-year prospective study of the Framingham cohort. Archives of Neurology, 52, 485-90.

Logsdon, R. G., Gibbons, L. E., McCurry, S. M. \& Teri, L. (2002). Assessing quality of life in older adults with cognitive impairment. Psychosomatic Medicine, 64, 510-9.

Lyketsos, C. G., Toone, L., Tschanz, J., Rabins, P. V., Steinberg, M., Onyike, C. U., Corcoran, C., Norton, M., Zandi, P., Breitner, J. C., Welsh-Bohmer, K., Anthony, J., Ostbye, T., Bigler, E., Pieper, C., Burke, J., Plassman, B., Green, R. C., Steffens, D. C., Klein, L., Leslie, C., Townsend, J. J., Wyse, B. W., Munger, R. \& Williams, M. (2005).

Population-based study of medical comorbidity in early dementia and "cognitive impairment, no dementia (CIND)": association with functional and cognitive impairment: The Cache County Study. American Journal of Geriatric Psychiatry, 13, 656-64.

Mhaolain, A. M., Gallagher, D., Crosby, L., Ryan, D., Lacey, L., Coen, R. F., Coakley, D., Walsh, J. B., Cunningham, C. \& Lawlor, B. (2012). Frailty and quality of life for people with Alzheimer's dementia and mild cognitive impairment. American Journal of Alzheimer's Disease and Other Dementias, 27, 48-54.

Missotten, P., Squelard, G., Ylieff, M., Di Notte, D., Paquay, L., De Lepeleire, J. \& Fontaine, O. (2008). Quality of life in older Belgian people: comparison between people with dementia, mild cognitive impairment, and controls. International Journal of Geriatric Psychiatry, 23, 1103-9.

Morrow, L. A., Snitz, B. E., Rodriquez, E. G., Huber, K. A. \& Saxton, J. A. (2009). High medical co-morbidity and family history of dementia is associated with lower cognitive function in older patients. Family Practice, 26, 339-43.

Nielsen, H., Lolk, A., Andersen, K., Andersen, J. \& Kragh-Sorensen, P. (1999).

Characteristics of elderly who develop Alzheimer's disease during the next two years-a neuropsychological study using CAMCOG. The Odense Study. International Journal of Geriatric Psychiatry, 14, 957-63.

Oosterveld, S. M., Kessels, R. P., Hamel, R., Ramakers, I. H., Aalten, P., Verhey, F. R., Sistermans, N., Smits, L. L., Pijnenburg, Y. A., van der Flier, W. M., Olde Rikkert, M. G. \& Melis, R. J. (2014). The Influence of Co-Morbidity and Frailty on the Clinical Manifestation of Patients with Alzheimer's Disease. Journal of Alzheimer's Disease.

Patrick, L., Gaskovski, P. \& Rexroth, D. (2002). Cumulative illness and neuropsychological decline in hospitalized geriatric patients. The Clinical Neuropsychologist, 16, 145-56.

Petersen, R. C. \& Morris, J. C. (2005). Mild cognitive impairment as a clinical entity and treatment target. Archives of Neurology, 62, 1160-3; discussion 1167.

Petersen, R. C., Smith, G. E., Waring, S. C., Ivnik, R. J., Tangalos, E. G. \& Kokmen, E. (1999). Mild cognitive impairment: clinical characterization and outcome. Archives of Neurology, 56, 303-8.

Qiu, C., von Strauss, E., Backman, L., Winblad, B. \& Fratiglioni, L. (2013). Twenty-year changes in dementia occurrence suggest decreasing incidence in central Stockholm, Sweden. Neurology, 80, 1888-94.

Rapp, M. A. \& Reischies, F. M. (2005). Attention and executive control predict Alzheimer disease in late life: results from the Berlin Aging Study (BASE). American Journal of Geriatric Psychiatry, 13, 134-41. 
Ready, R. E. \& Ott, B. R. (2003). Quality of Life measures for dementia. Health and Quality of Life Outcomes, 1, 11.

Ready, R. E., Ott, B. R. \& Grace, J. (2004). Patient versus informant perspectives of Quality of Life in Mild Cognitive Impairment and Alzheimer's disease. International Journal of Geriatric Psychiatry, 19, 256-65.

Ridha, B. H., Barnes, J., Bartlett, J. W., Godbolt, A., Pepple, T., Rossor, M. N. \& Fox, N. C. (2006). Tracking atrophy progression in familial Alzheimer's disease: a serial MRI study. Lancet Neurology, 5, 828-34.

Rocca, W. A., Petersen, R. C., Knopman, D. S., Hebert, L. E., Evans, D. A., Hall, K. S., Gao, S., Unverzagt, F. W., Langa, K. M., Larson, E. B. \& White, L. R. (2011). Trends in the incidence and prevalence of Alzheimer's disease, dementia, and cognitive impairment in the United States. Alzheimers \& Dementia, 7, 80-93.

Rubin, E. H., Storandt, M., Miller, J. P., Kinscherf, D. A., Grant, E. A., Morris, J. C. \& Berg, L. (1998). A prospective study of cognitive function and onset of dementia in cognitively healthy elders. Archives of Neurology, 55, 395-401.

Schrijvers, E. M., Verhaaren, B. F., Koudstaal, P. J., Hofman, A., Ikram, M. A. \& Breteler, M. M. (2012). Is dementia incidence declining?: Trends in dementia incidence since 1990 in the Rotterdam Study. Neurology, 78, 1456-63.

Sloane, P. D., Zimmerman, S., Williams, C. S., Reed, P. S., Gill, K. S. \& Preisser, J.S. (2005).

Evaluating the quality of life of long-term care residents with dementia. Gerontologist, 45 Spec No 1, 37-49.

Sluimer, J. D., van der Flier, W. M., Karas, G. B., van Schijndel, R., Barnes, J., Boyes, R. G., Cover, K. S., Olabarriaga, S. D., Fox, N. C., Scheltens, P., Vrenken, H. \& Barkhof, F. (2009). Accelerating regional atrophy rates in the progression from normal aging to Alzheimer's disease. European Radiology, 19, 2826-33.

Steffens, D. C., Otey, E., Alexopoulos, G. S., Butters, M. A., Cuthbert, B., Ganguli, M., Geda, Y. E., Hendrie, H. C., Krishnan, R. R., Kumar, A., Lopez, O. L., Lyketsos, C. G., Mast, B. T., Morris, J. C., Norton, M. C., Peavy, G. M., Petersen, R. C., Reynolds, C. F., Salloway, S., Welsh-Bohmer, K. A. \& Yesavage, J. (2006). Perspectives on depression, mild cognitive impairment, and cognitive decline. Archives of General Psychiatry, 63, 130-8.

Thacker, E. L., McKnight, B., Psaty, B. M., Longstreth, W. T., Jr., Sitlani, C. M., Dublin, S., Arnold, A. M., Fitzpatrick, A. L., Gottesman, R. F. \& Heckbert, S. R. (2013). Atrial fibrillation and cognitive decline: a longitudinal cohort study. Neurology, 81, 119-25.

Twamley, E. W., Ropacki, S. A. \& Bondi, M. W. (2006). Neuropsychological and neuroimaging changes in preclinical Alzheimer's disease. Journal of the International Neuropsychological Society, 12, 707-35.

Uijen, A. A. \& van de Lisdonk, E. H. (2008). Multimorbidity in primary care: prevalence and trend over the last 20 years. European Journal of General Practice, 14 Suppl 1, 28-32.

van den Akker, M., Buntinx, F., Metsemakers, J. F., Roos, S. \& Knottnerus, J. A. (1998). Multimorbidity in general practice: prevalence, incidence, and determinants of cooccurring chronic and recurrent diseases. Journal of Clinical Epidemiology, 51, 367-75.

Visser, P. J., Kester, A., Jolles, J. \& Verhey, F. (2006). Ten-year risk of dementia in subjects with mild cognitive impairment. Neurology, 67, 1201-7.

Walker, M. D., Salek, S. S. \& Bayer, A. J. (1998). A review of quality of life in Alzheimer's disease. Part 1: Issues in assessing disease impact. Pharmacoeconomics, 14, 499-530. 
Whitehouse, P. J. \& Rabins, P. V. (1992). Quality of life and dementia. Alzheimer Disease and Associated Disorders, 6, 135-7.

World Health Organization (2012). Dementia: a public health priority. WHO: Geneva, Switzerland. 


\section{SUMMARY}

The increasing number of people with dementia will have large consequences for society and health care systems. As a result, there is a growing need for early diagnosis of dementia in order to initiate timely care, treatment and support for the patient and his/her family.

The transitional state between normal cognitive functioning and dementia is now usually referred to as Mild Cognitive Impairment (MCI). MCI denominates a heterogeneous group of people with large individual variation in the level and pattern of cognitive impairment, course of decline over time and thus prognosis. This variation is likely due to differences in underlying cause of the impairment, and it is increasingly recognized that multiple factors contribute together to the development of dementia. So, in order to identify and discriminate between individuals that progress to dementia and those that do not, it is of major importance to investigate the profile of impairment and the natural course of cognitive decline in MCI and detect factors that can influence this course. To examine this, the Clinical Course of Cognition and Comorbidity in MCI (4C-MCI) study was initiated. In the first part of this thesis we investigated the profile and course of cognitive decline in MCI. In the second part, we described the influence of the often-overlooked issue of comorbidity on the course of cognitive decline, and also on Health-related Quality of Life (HRQoL) in a memory clinic setting.

In chapter 2, we provided a systematic review and meta-analysis on the rate of domain-specific cognitive decline in global cognition, episodic memory, executive functioning, attention/information processing speed, verbal and visuospatial ability in the pre-dementia phase. In addition, we performed domain wise comparisons with the rates of decline in non-converters. We included 21 studies, representing 2249 pre-dementia subjects and 2439 non-converters. Effect sizes for the extent of decline per year were calculated for each cognitive domain. Results showed that decline in episodic memory and global cognition was almost twofold compared to decline in other domains. In addition, the rate of decline in attention/information processing speed was relatively small and, more importantly, did not differ between converters to dementia and non-converters. Thus, measures for episodic memory and global cognitive functioning seem the most promising tools for early detection of dementia.

In chapter 3, we aimed to further investigate the results from the previous chapter in a multicentre memory-clinic based population of consecutive non-demented patients $(n=819)$. We examined the pattern, magnitude and temporal sequence of decline in various cognitive domains in people who converted to AD dementia and compared this to decline in those who did not convert. We found that the performance of converters and non-converters differed already seven (episodic 
memory) to three (executive functioning and verbal fluency) years prior to $A D$ dementia diagnosis. There was no evidence of decline in attention/information processing speed in both groups and thus no difference in trajectory. So, besides early episodic memory decline, decline in executive functioning may flag future dementia converters and should be given equal weight as memory decline in the diagnostic process.

In chapter 4, we investigated the existence of different cognitive subtypes within a multicentre memory-clinic based population $(n=635)$ and studied their prognostic value for the development of dementia. Using a data-driven approach, we were able to distinguish five different subtypes: patients with high-normal cognition; patients with low-normal cognition; patients with mainly memory impairment in recall; patients with memory impairment in recall and recognition; and patients with non-memory impairments. Lowest dementia risk was found in the highnormal cognition subtype, which likely represents the "worried-well" patients. The highest dementia risk was found in the non-memory impairment subtype, which developed most often non-AD dementia. People with primarily amnestic impairment most often developed AD dementia, regardless of whether they had impaired recognition memory or not. Our findings show that is inefficient to treat patient's data as if coming from a single population, and that failure to take variability into account may dilute associations that exist between subpopulations.

The study design, measurement instruments and relationship between the $4 \mathrm{C}-\mathrm{MCI}$ and the complementary 4C-Dementia study were described in chapter 5 . In the $4 \mathrm{C}$ MCI study 315 consecutive non-demented patients, who presented themselves with cognitive complaints at the memory clinics of three academic centres, were followed for three years. Each year we recorded data on: the course of complaints, medical comorbidities, frailty, medication use and intoxications, quality of life, daily life functioning, neuropsychiatric symptoms and a physical examination and extensive neuropsychological assessment.

In chapter 6, the association between the severity of total comorbidity and cognitive decline and / or conversion to dementia was investigated using data from the 4C-MCI study ( $\mathrm{n}=315$ ). Our results showed that the severity of comorbidity was related to lower performance on speed dependent cognitive tests, already at the time patients presented themselves at the memory clinic. This was found for both the total severity of comorbidity as for specific organ systems (i.e. cardiac, respiratory, neurological and endocrine domain). Further severity of total comorbidity was also related to faster cognitive decline over a three-year period, again on speed dependent tests. However, the severity of total comorbidity was not related to an increased risk of conversion to dementia. Our results show that 
multimorbidity is a significant health problem and underscore the importance of a broad assessment of medical disorders in clinical practice.

The research in chapter 7 focused on determinants of Health-related Quality of Life (HRQoL) in patients who presented themselves with cognitive complaints at a memory clinic $(n=301)$. Our results indicated that most of the variance in HRQoL of memory clinic visitors is explained by emotional functioning and especially by depressive symptoms. In addition, lower HRQoL in MCI was also related to the presence of comorbidities in the eyes/ears/nose and lower gastrointestinal tract domain and to worse performance on a processing speed test. Yet, this was not found for people with subjective cognitive impairment. So, emotional and physical functioning should be taken into account in the memory clinic population and these factors might be promising targets for non-cognitive interventions to improve HRQoL.

Chapter 8 provided a general discussion of the findings described in this thesis. Clinical and research implications of our research were discussed and suggestions for future research were debated. Furthermore, this last chapter included a summary of the findings, a knowledge valorisation, list of author affiliations, list of publications, information about the author, and acknowledgements. 



\section{SAMENVATTING}

Het groeiende aantal mensen met dementie zal grote gevolgen hebben voor onze maatschappij en de gezondheidszorg in het bijzonder. Als gevolg hiervan is er een toenemende behoefte naar vroegdiagnostiek bij dementie om zo tijdig zorg, behandeling en ondersteuning te kunnen bieden aan de patiënt en zijn/haar naasten.

Tegenwoordig spreekt men vaak over het voorstadium van dementie wanneer er sprake is van milde cognitieve problemen (mild cognitive impairment of MCI). De groep mensen met $\mathrm{MCI}$ is een zeer heterogene groep, die grote individuele verschillen laat zien in de mate en het patroon van cognitieve beperkingen, het beloop van achteruitgang over tijd en dus ook in prognose. Deze variatie wordt waarschijnlijk veroorzaakt door verschillen in de onderliggende oorzaak van de cognitieve beperkingen, waarbij het de laatste jaren steeds duidelijker is geworden dat dementie een multifactorieel bepaald ziektebeeld is. Het is dan ook van groot belang om het natuurlijk beloop van cognitieve achteruitgang in MCI te onderzoeken en factoren te ontdekken die het beloop kunnen beïnvloeden, om op deze manier een onderscheid te kunnen maken tussen mensen die dementie gaan ontwikkelen en mensen die dit niet doen. Om dit te onderzoeken werd de Clinical Course of Cognition and Comorbidity in MCI (4C-MCI) studie opgezet.

In het eerste deel van dit proefschrift hebben we het profiel en natuurlijk beloop van cognitieve achteruitgang in MCI onderzocht. In het tweede deel focusten we op de tot nog toe vaak genegeerde factor comorbiditeit. Hierbij onderzochten we de invloed van comorbiditeiten op het beloop van cognitieve achteruitgang. Daarnaast bekeken we de invloed van comorbiditeit op gezondheidsgerelateerde kwaliteit van leven in een geheugenpoli setting.

In hoofdstuk 2 beschreven we de resultaten van een systematische review en meta-analyse naar de mate van domein-specifieke cognitieve achteruitgang in het voorstadium van dementie voor de domeinen: globale cognitieve vermogens, episodisch geheugen, uitvoerende controlefuncties, aandacht/informatieverwerkingssnelheid, verbale en visuospatiële vaardigheden. Daarbij vergeleken we de achteruitgang per domein ook met de achteruitgang in mensen die geen dementie ontwikkelden. Er werden 21 studies geïncludeerd met daarin 2249 mensen in een voorstadium van dementie en 2439 mensen die niet dement werden. Voor de verschillende cognitieve domeinen werden effectgroottes voor de mate van achteruitgang per jaar berekend. Resultaten toonden aan dat achteruitgang in episodisch geheugen en globale cognitieve vermogens bij degenen in het voorstadium van dementie bijna twee keer zo snel verliep als achteruitgang in andere domeinen. Verder viel op dat de mate van achteruitgang in aandacht/snelheid relatief klein was en dat er in dit domein ook geen verschil in achteruitgang bestond tussen mensen die dementie ontwikkelden en zij die geen 
dementie ontwikkelden. Voor alle andere domeinen werd echter een duidelijk verschil in achteruitgang gezien tussen beide groepen. Hieruit kan geconcludeerd worden dat testen voor episodisch geheugen en globale cognitieve vermogens de belangrijkste instrumenten zijn voor een vroege detectie van dementie.

In hoofdstuk 3 werden de bevindingen uit het vorig hoofdstuk nader onderzocht in een multicenter studie waarin 819 niet-demente patiënten, afkomstig van twee geheugenpoli's, zijn geïncludeerd. We onderzochten het patroon, de snelheid en de tijdsvolgorde van achteruitgang in meerdere cognitieve domeinen in patiënten die Alzheimer dementie kregen en patiënten die geen dementie ontwikkelden. We vonden dat de prestaties van deze twee groepen op een geheugentest reeds zeven jaar voor de diagnose dementie werd gesteld van elkaar verschilden. Enkele jaren later vertoonden ook de prestaties op woordvlotheid en uitvoerende controlefuncties een verschil tussen de twee groepen. Daarbij zagen we grote verschillen tussen beide groepen in de snelheid van achteruitgang op met name episodisch geheugen en uitvoerende controlefuncties. In beide groepen werd geen achteruitgang gevonden in aandacht/snelheid en was er dus ook geen verschil in beloop over tijd in dit domein. Hieruit kunnen we concluderen dat naast een vroege achteruitgang in geheugen ook achteruitgang in uitvoerende controlefuncties een indicator is voor het ontwikkelen van Alzheimer dementie en dat beide domeinen van even groot belang zouden moeten zijn in het diagnostisch proces.

In hoofdstuk 4 hebben we het bestaan van verschillende cognitieve subtypes binnen een multicenter geheugenpolipopulatie $(n=635)$ getest en onderzochten we de voorspellende waarde van de verschillende subtypes voor het ontwikkelen van dementie. Met behulp van een vooruitstrevende gegevens-gestuurde aanpak, waren we in staat vijf verschillende cognitieve subtypes te onderscheiden: mensen die presteren op hoognormaal niveau, mensen die presteren op laagnormaal niveau, mensen met geheugenstoornissen in het opdiepen, mensen met geheugenstoornissen in opdiepen en herkennen en mensen met stoornissen in andere functies dan geheugen. De groep die presteerde op hoognormaal niveau had het laagste risico op het ontwikkelen van dementie. Het hoogste risico op het ontwikkelen voor dementie werd gevonden in het subtype met stoornissen in andere functies dan geheugen, deze mensen ontwikkelden het meest frequent dementie van een niet-Alzheimer type. Mensen met voornamelijk geheugenstoornissen ontwikkelden vooral Alzheimer dementie, ongeacht of ze alleen stoornissen hadden in het opdiepen van informatie of stoornissen in zowel opdiepen als herkennen. Onze bevindingen tonen aan dat patiënten niet gezien moeten worden als één grote groep bestaande uit hetzelfde type en dat bestaande associaties tussen subgroepen mogelijk verzwakt worden door geen rekening te houden met deze variabiliteit. 
De studieopzet, gekozen meetinstrumenten en de relatie van de 4C-MCI studie met de complementaire 4C-Dementie studie beschreven we in hoofdstuk 5 van dit proefschrift. In de 4C-MCI studie werden 315 niet-demente patiënten, die zichzelf hadden gemeld met cognitieve klachten op de geheugenpoli van drie academische centra, gevolgd gedurende drie jaar. Ieder jaar werd informatie verzameld over: het beloop van de cognitieve klachten, medische comorbiditeiten, fysieke kwetsbaarheid, medicatiegebruik en intoxicaties, kwaliteit van leven, functioneren in het dagelijks leven en neuropsychiatrische symptomen. Ook werd een lichamelijk onderzoek en een uitgebreid neuropsychologisch onderzoek uitgevoerd.

In hoofdstuk 6 onderzochten we wat de invloed is van de totale ernst van medische comorbiditeiten van een patiënt op cognitieve prestaties, cognitieve achteruitgang en het risico op het krijgen van dementie in de 4C-MCI studie $(n=315)$. Onze bevindingen toonden aan dat de ernst van de comorbiditeiten gerelateerd was aan slechtere prestaties op taken waarbij het tempo van werken van belang was. Dit effect was al zichtbaar op het moment dat mensen zich meldden met klachten. Deze resultaten werden gevonden voor zowel de totale ernst van de comorbiditeiten, als voor de ernst binnen specifieke orgaansystemen (d.w.z. het cardiale, respiratoire, neurologische en endocriene domein). Verder bleek dat de ernst van de comorbiditeiten ook gerelateerd was aan snellere cognitieve achteruitgang over een periode van 3 jaar. Dit effect werd wederom gevonden voor tempo-gerelateerde taken. Ondanks deze resultaten bleek echter dat de ernst van de comorbiditeiten niet geassocieerd was met een verhoogd risico op het krijgen van dementie na 3 jaar. Onze resultaten onderstrepen het belang van een grondig onderzoek naar medische comorbiditeiten in de klinische praktijk, gezien de effecten van multimorbiditeit op cognitie.

In hoofdstuk 7 hebben we onderzocht welke factoren een rol spelen in de kwaliteit van leven van patiënten die zich melden met cognitieve klachten op een geheugenpoli $(n=301)$. Onze resultaten toonden aan dat het grootste deel van de variantie in kwaliteit van leven van geheugenpolipatiënten verklaard wordt door hun emotioneel functioneren en in het bijzonder door de aanwezigheid van depressieve symptomen. Verder bleek dat een lagere kwaliteit van leven in patiënten met MCI geassocieerd was met de aanwezigheid van comorbiditeiten in de domeinen ogen/oren/neus en het maagdarmkanaal en met slechtere prestaties op een snelheidstaak. Deze resultaten werden echter niet gevonden in de groep met alleen subjectieve cognitieve klachten. Concluderend kan worden gesteld dat emotioneel en fysiek functioneren belangrijke factoren zijn om te onderzoeken in een geheugenpolipopulatie en mogelijk zouden deze factoren veelbelovende targets zijn voor niet-cognitieve interventies om kwaliteit van leven in deze groep te verbeteren. 
Hoofdstuk 8 omvat een algemene discussie van onze bevindingen, waarbij ook klinische en wetenschappelijke implicaties worden toegelicht en suggesties voor toekomstig onderzoek worden gegeven. Daarnaast bevat dit hoofdstuk een Engelse en Nederlandstalige samenvatting van de belangrijkste bevindingen, een kennisvalorisatie, een auteurslijst, een publicatielijst, informatie over de auteur en een dankwoord. 


\section{KNOWLEDGE VALORISATION}

The goal of this valorisation paragraph is to describe how the knowledge resulting from the research in this dissertation can be made valuable for clinical and social use. This dissertation focuses on the natural course of cognitive decline in people with Mild Cognitive Impairment (MCI) and the influence of comorbidity on outcomes in this population.

\section{Societal relevance}

Dementia is a growing health problem, since the number of people with dementia is thought to dramatically rise due to the ageing population. This development poses a major challenge for society, health care systems and also has great economical impact. Already in 2011, dementia was the second most expensive medical disease in the Netherlands, with disease-associated costs of almost 5 billion euros. Furthermore, dementia is thought to have the highest disease burden of all medical illnesses for the patient, but has also a tremendous impact on the caregiver.

Currently, the transitional state between normal cognitive functioning and dementia is usually referred to as Mild Cognitive Impairment (MCI). MCI denominates a heterogeneous group of people with large individual variation in the level and pattern of cognitive impairment, course of decline over time and thus prognosis. Therefore, the uncertain MCI label often leads to negative reactions from patients and caregivers and may evoke anxiety, loss of self-confidence, feelings of depression etcetera.

Thus, there are multiple reasons for investigating the course of cognitive decline in MCI as has been done in this thesis. First, for patients and caregivers, a more accurate prognosis on the risk of developing dementia is important to end the uncertainty currently associated with the MCI label and it allows patients and caregivers to make arrangements for the future. In addition, when it is possible to differentiate between individuals who are likely to develop dementia and those who are not, clinicians will be able to initiate timely care, (psychological) treatment and support, which will likely reduce health care costs. Further, if pharmacological treatment becomes available in the future, these drugs are likely to be most effective in the early stages of the disease, which ultimately reduces the total disease burden for society and health care and also diminishes costs.

\section{Target audience}

The results described in this dissertation are relevant to various stakeholders who are involved in dealing with dementia and it's consequences.

First, the results are especially relevant for people with cognitive complaints and their families, since they often want to know the course of their cognitive 
complaints, and whether patients are at increased risk of developing dementia and/or becoming care dependent in the near future.

Clinicians working in memory clinics are also important stakeholders, since they are the ones who have to inform patients with cognitive complaints about their risk of developing dementia in the future. The results of this thesis will aid them improving the accuracy of prognosis by increasing knowledge about which neuropsychological tests are important and early indicators of developing dementia pathology. As a result, they can better inform patients and their families about risks and what specific actions need to be taken. Further, support and education can be given at an early stage and when in the future disease-modifying treatment is available these patients will be an important target group.

Commercial organization concerned with neuropsychological test development could use the results to improve their products and create more dementia-sensitive test batteries. As it appears that especially cognitive decline in episodic memory, executive functioning and global cognitive functioning are important indicators of developing dementia, extra focus should be placed on the development of sensitive, reliable tests that accurately measure small changes in these domains over time.

Decision makers in (government) organizations involved in health care regulations, such as the Dutch Centraal Begeleidingsorgaan (CBO), or similar entities worldwide, could use the results of this thesis to adapt their recommendations about neuropsychological test protocols in dementia diagnostics, placing more emphasis on decline in executive functioning and global cognitive functioning and less on decline in attention/speed.

\section{Products}

The main products of this dissertation are the implications that our results have for routine clinical practice in the assessment of cognitive complaints. In the first place, our results have consequences for the use of optimal neuropsychological test batteries that aim to detect dementia at an early stage. Our results indicate that neuropsychological test protocols should be reshaped, not primarily focussing on episodic memory, but giving equal importance to executive functioning and global cognitive functioning, using sensitive and reliable measures. In addition, the main emphasis should not be on attention/speed, since we showed that decline in this domain did not differ between converters to dementia and non-converters. Besides, we showed that performance and decline on speed-related tests is influenced by the severity of comorbidity. This implicates that a broad assessment of additional medical factors, is important in clinical practice, to take into account other potential causes for cognitive impairment. Further, since (part of) these factors are potentially modifiable, they are also an important target for interventions to ameliorate cognitive performance and in the long-term prevent cognitive decline and conversion to dementia. The importance of the broad 
assessment of additional non-cognitive factors in clinical practice is supported by our findings that Health-related Quality of Life is associated with comorbid disease burden and depressive symptoms. Our general findings thus emphasize the importance of a multidisciplinary approach in the diagnostic and treatment possibilities for people with MCI.

\section{Innovation}

The results in this dissertation are among the first that are based on a large multicentre clinical cohort of people, meaning that patients included in our study presented themselves with cognitive complaints at a memory clinic. This distinguishes them from cognitively normal subjects from the general population who are most often selected for studies into early stage cognitive decline. Further, in contrast to what is often done in MCI studies, we explicitly chose to apply broad inclusion criteria, in which most comorbid disorders were not excluded. By this means, we avoided the elimination of these potentially important contributing factors in advance and maximized generalization to the general elderly population, which is characterized by an increased disease burden and multimorbidity.

\section{Valorisation process}

Before the results of this dissertation are likely to be applied in clinical practice, several additional steps are required. First, other clinical studies into early stage cognitive decline have to be performed to confirm our results. These studies should also include patients with a variety of comorbidities, since they appear to influence both cognitive decline and Health-related Quality of Life in memory clinic visitors. Further, the inclusion of comorbidities live up to the notion that dementia is a multifactorial disease, with diseases and factors not necessarily located in the brain enhancing underlying neurodegenerative pathologies. As far as we are aware, large-scale studies with comparable broad inclusion criteria like ours have not been conducted yet, so new studies have to be set up. On the long term, when our results are validated, neuropsychological test protocols should be reshaped, putting more emphasis on executive functioning and global cognition besides episodic memory and attribute less importance to impairments in attention/speed. Tests for these domains are widely available and used in clinical practice, so practical issues do not hinder implementation in this regard, although new, more reliable and sensitive measures might be developed specifically for the purpose of dementia screening. To assure standardization and allow comparison between assessments at different facilities in the Netherlands, agreements should be made about the exact tests that are recommended to measure the indicated domains. To assure generalisation to all hospital and memory clinics the CBO should include these recommendations about the test protocol in the guidelines for dementia diagnostics and treatment. To make sure 
that members of the advisory committee of the CBO are aware of the current outcomes, it is important to spread the results within the dementia research community by publication in international journals and presentations on dementia related conferences. Ultimately, when results would be implemented in clinical practice, the health care costs associated with dementia could be reduced. First, by offering support and education and an early stage, by means of which patients are likely to be able to live in their home setting longer, thereby avoiding the costs associated with nursing home placement. Second, if disease-modifying medication becomes available in the future, these patients are likely to not develop the fullblown dementia syndrome and so health care costs associated with severe dementia are no longer applicable in these cases. 


\section{AUTHOR AFFILIATIONS}

Pauline Aalten, PhD

Alzheimer Centre Limburg, School for Mental Health and Neuroscience, Maastricht University Medical Centre, Maastricht, the Netherlands

Wiesje M. van der Flier, PhD

Department of Neurology and Neuroscience Campus Amsterdam, VUmc Alzheimer Centre, VUmc Medical Centre, Amsterdam the Netherlands; and Department of Epidemiology \& Biostatistics, VUmc Medical Centre, Amsterdam, the Netherlands

Willemijn J. Jansen, MSc

Alzheimer Centre Limburg, School for Mental Health and Neuroscience, Maastricht University Medical Centre, Maastricht, the Netherlands

Roy P.C. Kessels, PhD

Radboud Alzheimer Centre, Department of Geriatrics, Radboud university medical center, Nijmegen, the Netherlands; and Department of Medical Psychology, Radboud university medical center \& Donders Institute for Brain, Cognition and Behaviour, Radboud University, Nijmegen, the Netherlands

Jos Kleijnen, PhD

Maastricht University, CAPHRI School for Public Healthy and Primary Care, Maastricht, the Netherlands

Sebastian Koehler, PhD

Alzheimer Centre Limburg, School for Mental Health and Neuroscience, Maastricht University Medical Centre, Maastricht, the Netherlands

Ted Koene, MSc

Department of Medical Psychology and Neuroscience Campus Amsterdam, VUmc Alzheimer Centre, VUmc Medical Centre, Amsterdam, the Netherlands

Weiqi Liao, MMed

Radboud Alzheimer Centre, Department of Geriatrics, Radboud university medical center, Nijmegen, the Netherlands

Rene J.F. Melis, MD, PhD

Radboud Alzheimer Centre, Department of Geriatrics, Radboud university medical center, Nijmegen, the Netherlands 
Marcel G.M. Olde Rikkert, MD, PhD

Radboud Alzheimer Centre, Department of Geriatrics, Radboud university medical center, Nijmegen, the Netherlands

Saskia M. Oosterveld, MSc

Radboud Alzheimer Centre, Department of Geriatrics, Radboud university medical center, Nijmegen, the Netherlands

Yolande A.L. Pijnenburg, MD, PhD

Department of Neurology and Neuroscience Campus Amsterdam, VUmc Alzheimer Centre, VUmc Medical Centre, Amsterdam, the Netherlands

Inez H.G.B. Ramakers, PhD

Alzheimer Centre Limburg, School for Mental Health and Neuroscience, Maastricht University Medical Centre, Maastricht, the Netherlands

Philip Scheltens, $M D, P h D$

Department of Neurology and Neuroscience Campus Amsterdam, VUmc Alzheimer Centre, VUmc Medical Centre, Amsterdam, the Netherlands

Nicole Sistermans, MSc

Department of Neurology and Neuroscience Campus Amsterdam, VUmc Alzheimer Centre, VUmc Medical Centre, Amsterdam, the Netherlands

Frans R.J. Verhey, MD, PhD

Alzheimer Centre Limburg, School for Mental Health and Neuroscience, Maastricht University Medical Centre, Maastricht, the Netherlands

Pieter Jelle Visser, $\mathrm{MD}, \mathrm{PhD}$

Alzheimer Centre Limburg, School for Mental Health and Neuroscience, Maastricht University Medical Centre, Maastricht, the Netherlands; and Department of Neurology and Neuroscience Campus Amsterdam, VUmc Alzheimer Centre, VUmc Medical Centre, Amsterdam, the Netherlands

Claire A.G. Wolfs, PhD

Alzheimer Centre Limburg, School for Mental Health and Neuroscience, Maastricht University Medical Centre, Maastricht, the Netherlands 


\section{PUBLICATIONS}

S Koehler, R Hamel, N Sistermans, T Koene, YAL Pijnenburg, WM van der Flier, P Scheltens, PJ Visser, P Aalten, FRJ Verhey, I Ramakers. Progression to dementia in memory clinic visitors without dementia: a latent profile analysis. Neurology 2013; 81; 1342-1349.

SM Oosterveld, RPC Kessels, R Hamel, IHGB Ramakers, P Aalten, FRJ Verhey, N Sistermans, LL Smits, YA Pijnenburg, WM van der Flier, MGM Olde Rikkert, RJF Melis. The influence of co-morbidity and frailty on the clinical manifestation of patients with Alzheimer's Dementia. Journal of Alzheimer's Disease 2014; 42; 501509.

R Hamel, S Koehler, N Sistermans, T Koene, Y Pijnenburg, W van der Flier, P Scheltens, P Aalten, F Verhey, PJ Visser, I Ramakers. The trajectory of cognitive decline in the pre-dementia phase in memory clinic visitors: findings from the $4 \mathrm{C}$ MCI study. Psychological Medicine 2015; 45; 1507-1519.

REG Hamel, IHGB Ramakers, SM Oosterveld, RJF Melis, MGM Olde Rikkert, RPC Kessels, N Sistermans, YAL Pijnenburg, T Koene, WM van der Flier, P Scheltens, P Aalten, CAG Wolfs, FRJ Verhey. Determinants of Health-related Quality of Life in memory clinic visitors without dementia.

REG Hamel, WJ Jansen, PJ Visser, S Koehler, J Kleijnen, FRJ Verhey, IHGB Ramakers. Domain-specific cognitive decline in the pre-dementia phase: as systematic review and meta-analysis.

REG Hamel, IHGB Ramakers, SM Oosterveld, RJF Melis, MGM Olde Rikkert, RPC Kessels, N Sistermans, YAL Pijnenburg, T Koene, WM van der Flier, P Scheltens, PJ Visser, FRJ Verhey. The influence of severity of total comorbidity on cognitive decline and conversion to dementia in memory clinic visitors.

W Liao, REG Hamel, MGM Olde Rikkert, SM Oosterveld, P Aalten, FRJ Verhey, P Scheltens, N Sistermans, YAL Pijnenburg, WM van der Flier, IHGB Ramakers, RJF Melis. Cohort profile: The Clinical Course of Cognition and Comorbidity in Mild Cognitive Impairment and Dementia (The 4C studies): two complementary multicenter longitudinal clinical cohorts in the Netherlands. 



\section{CURRICULUM VITAE}

Renske Hamel werd geboren op 24 september 1987 te Prinsenbeek. In 2005 behaalde ze cum laude haar VWO diploma aan het Mencia Mendoza Lyceum te Breda. Hierna begon zij haar studie Psychologie aan de Universiteit van Tilburg. In 2008 werd haar bachelordiploma, met als hoofdrichting Gezondheidspsychologie cum laude behaald. In datzelfde jaar begon zij aan haar master Medische Psychologie, waarvoor zij een klinische en wetenschapsstage liep op de afdeling Medische Psychologie van het Catharina Ziekenhuis te Eindhoven. In 2010 behaalde ze haar diploma en in 2011 startte ze als promovenda op de afdeling Psychiatrie en Neuropsychologie van de Universiteit Maastricht met het onderzoek dat in dit proefschrift beschreven staat. Renske werkt momenteel als psycholoog bij De Zorggroep in Venlo en als postdoc onderzoeker bij de afdeling Psychiatrie en Neuropsychologie van de Universiteit Maastricht.

Renske Hamel was born on September 241987 in Prinsenbeek. After she graduated cum laude from high school at the Mencia Mendoza Lyceum Breda in 2005, she started to study Psychology at Tilburg University. In 2008 she received her bachelor's degree in Health Psychology cum laude. In the same year, she started her master in Medical Psychology, for which she performed a research and clinical internship at the department of Medical Psychology at the Catharina Hospital Eindhoven. She graduated in 2010 and started working as a PhD candidate at the Department of Psychiatry and Neuropsychology in 2011, where she performed the research described in this thesis. Renske currently works as a psychologist at De Zorggroep in Venlo and as a postdoctoral researcher at the Department of Psychiatry and Neuropsychology of Maastricht University. 



\section{DANKWOORD}

Na vier jaar zwoegen en vele momenten waarop ik dacht dat het allemaal nooit goed zou komen ligt hier dan toch mijn proefschrift. Om een groot onderzoek als de 4C-MCI studie tot een goed einde te brengen is de hulp en ondersteuning van een heleboel mensen van essentieel belang geweest.

Allereerst wil ik natuurlijk alle patiënten en mantelzorgers bedanken die de afgelopen jaren zo trouw hebben deelgenomen aan 4C-MCI. Ik heb jullie al die tijd met plezier gevolgd, veel indrukwekkende verhalen aangehoord en een band op kunnen bouwen met de persoon achter het onderzoeksnummer. Enorm bedankt voor alle tijd die jullie in mijn onderzoek hebben willen steken, de eindeloze NPO's die mensen hebben ondergaan en de bereidheid om toch drie jaar lang mee te blijven doen. Zonder jullie was dit onderzoek nooit mogelijk geweest.

Frans Verhey, mijn promotor. Beste Frans, ik wil je bedanken voor de mogelijkheid die je me geboden hebt om hier klinisch wetenschappelijk onderzoek te verrichten. Ik ben blij dat je me de kans en het vertrouwen hebt gegeven om me als wetenschapper te ontwikkelen. Ik heb je kritische, maar vooral ook klinisch gerichte blik, onschatbare ervaring en betrokkenheid altijd zeer gewaardeerd in de afgelopen jaren.

Inez, mijn co-promotor. Bedankt voor je enthousiasme, begeleiding en vertrouwen in mij. Ondanks je eigen drukke werkzaamheden kon ik altijd bij je binnen lopen met problemen. Je wist me altijd weer de juiste richting op te sturen en snapt als geen ander hoe het is om klem te zitten tussen het wetenschappelijk en klinisch werk. Ik heb veel bewondering voor hoe je alles combineert en hoop in de toekomst je voorbeeld te kunnen volgen.

Pieter Jelle, mijn tweede co-promotor. Zelden heb ik iemand gezien met zoveel kennis en passie voor de wetenschap. Ondanks de vele aio's die je begeleidt en je vele andere taken en verantwoordelijkheden in zowel Amsterdam als Maastricht, was je toch in staat om ook voor mij tijd vrij te maken. Bedankt voor al je tips en suggesties en het verbeteren van de inhoud van mijn artikelen. Ik heb veel van je geleerd.

Sebastian, bedankt voor je kritische blik bij mijn artikelen en al je kennis over statistiek waar ik gebruik van mocht maken. Je had me al snel overtuigd, STATA werkt inderdaad veel gemakkelijker dan SPSS ;)

Pauline, je startte aanvankelijk als mijn begeleider en hoewel je dat stokje hebt overgedragen aan Inez, bleef je als coordinator toch betrokken bij mijn project. 
Bedankt voor het opzetten van de $4 \mathrm{C}$ studies en het aanleveren van een constante stroom aan stagiaires die zo hard nodig waren voor het slagen van dit project.

Alle leden van de beoordelingscommissie: Prof. dr. Ponds, Prof. dr. de Deyn, Prof dr. Schmand, dr. van Boxtel en dr. Leentjens. Bedankt dat jullie de tijd wilden nemen om mijn proefschrift te lezen en te beoordelen.

Alle co-auteurs van mijn artikelen, bedankt voor jullie waardevolle commentaren die de inhoud van mijn stukken telkens verbeterd hebben.

4C-MCI was nooit zo goed verlopen zonder de steun en inzet van diverse mensen. Allereerst en ontzettend belangrijk: Astrid, bedankt voor het inplannen van al die honderden patiënten en de fijne samenwerking. Ik denk dat ik zonder jou na een jaar al gillend was weggelopen.

Tanja \& Carla, jullie bedankt voor de inzet bij de mantelzorggesprekken, ook dat heeft me heel veel werk uit handen genomen. Ook alle stagiaires, Rens, Suzanne, Caroline, Anneloes, Lorraine, Iris, Nele, Eefje, Mijke, Anne, Collin, Laura, Liselot en Angela wil ik bedanken voor het vele werk dat jullie verricht hebben. Als ik al die NPO's zelf had moeten afnemen was mijn proefschrift nu nog niet klaar geweest. Ook Willemijn, Babette, Isabelle, Lies en Stephanie bedankt voor alle ondersteuning bij het zien van patiënten voor de follow-ups. We hebben een hoop bijzondere, maar ook hilarische momenten meegemaakt en het was fijn om te weten dat ik mijn taken altijd met een gerust hart aan jullie kon overlaten. Suzanne Holthuisen, ook jij nog bedankt voor het enthousiasme en de nauwkeurigheid waarmee je me destijds hebt ingewerkt. Je was een gezellige kamergenoot en een geweldige onderzoeksmedewerker. Helaas had je al snel een andere baan gevonden, ik had je nog veel langer willen houden! Claire, jij bedankt voor al je hulp met het scoren van de CIRSen, wat een karwei is dat geweest. Na verloop van tijd werden we bijna medische experts en leverden diagnoses geen enkel probleem meer op, jammer van die plaatjes die we soms op google vonden;). Ondanks het vele werk dat moest gebeuren was het altijd heel gezellig met je.

Manon, bedankt voor het coördineren van het stukje 4C bij de Riagg. Het verloop van het project was niet altijd gemakkelijk, maar uiteindelijk is er toch een mooi resultaat uitgekomen. Ook alle andere medewerkers van Riagg Ouderenzorg bedankt voor jullie inzet bij dit project.

Ik bedank natuurlijk ook alle onderzoekers in Nijmegen en Amsterdam die bij dit project betrokken waren. In het bijzonder wil ik Saskia en Nicole bedanken voor hun inspanningen bij de dataverzameling en voor de goede en snelle communicatie. Ik heb altijd fijn met jullie samen gewerkt en wie weet komen we elkaar in de toekomst nog tegen als psychologen binnen de ouderenzorg. 
Lies \& Stephje, mijn paranimfjes en Belgische Best Friends. Wie had ooit gedacht dat ik hier twee zulke lieve vriendinnetjes zou vinden. Door onze overlappende projecten hadden we veel met elkaar te maken en het was al snel duidelijk dat we een klik hadden. Zonder jullie was mijn aio-periode vast niet zo leuk geweest. Ik dank jullie voor alle mentale support, het aanhoren van mijn klaagzangen, de ondersteuning met dataverzameling, het aanleveren (of opeten) van chocolade en muffins en alle gezellige momenten die we hebben gehad. Natuurlijk wil ik jullie ook bedanken voor het vergroten van mijn vocabulaire, wat er misschien mede voor gezorgd heeft dat ik in mijn eerste jaar in Maastricht al werd aangezien voor Belg!! Maar ook ik draag voortaan golfjes en stel mijn GPS in om te rijden over de autostrade (:). Stephje, de koffie-met-lemoncake-traditie gaan we behouden komend jaar hoor! Liesje, ook al werk je nu niet meer hier er zullen nog genoeg gezellige momenten volgen (met of zonder mannen) met vooral veel lekker eten.

De allerleukste en liefste roomies, Willemijn en Joany, bedankt voor alle wijze adviezen en steun. Maar ook voor alle humor, gezelligheid en het luisterend oor dat jullie altijd boden als ik weer eens niet stil kon zijn. Willemijn, liefste medeBrabo, ik kan zo ontzettend met en om je lachen (remember de kraamvisite met hond en mijn uitroep op het station in Amsterdam) en ben blij dat jij tegenover me zat. Gelukkig hoeven we het komende jaar nog geen afscheid van elkaar te nemen. En ooit wonen we gewoon allebei in Eersel $:$; Lieve Joany (aka zjwaanie) als ik tips wil op welk gebied dan ook: huidverzorging, koken, powerpoint weet ik dat ik bij jou moet zijn. Bedankt voor alle leuke recepten, lieve kleine kadootjes en natuurlijk die geweldige vent van je die mijn omslag zo geweldig heeft gemaakt. Je bent een schatje en we gaan snel op doggy date!

Mijn oud-roomie, Deliane. We hebben helaas niet zolang een kamer kunnen delen, maar dat maakt niet dat je geen plekje in mijn dankwoord verdient. Je kon me met jouw extra jaren ervaring altijd geruststellen als ik me afvroeg hoe promoveren ooit ging lukken en herkende de problemen van patiëntgebonden onderzoek maar al te goed. Ook jou kom ik vast nog wel eens tegen, misschien in de wetenschap en anders gewoon ergens in Brabant!

Sanne, Lizzy, Rosalie \& Isabelle, mijn (ex-)treinmaatjes. Heel hard rennen om die stomme stoptrein of overstap maar te halen, vloeken wanneer de NS weer eens problemen had en wachten op veel te koude stations, het was een stuk leuker samen met jullie. Jullie gezelschap maakte de lange reis telkens toch een stukje korter en aangenamer.

Lizzy, voor jou nog een speciaal bedankje als mijn voormalig medeaiovertegenwoordiger. Het was een interessante, maar ook vooral gezellige en ontspannen tijd samen. Onze samenwerking was zo vanzelfsprekend, heerlijk als 
dat zo goed gaat! Ik mis het soms nog wel een beetje, gelukkig kunnen we nu weer samen verder met Partner in Balans.

Nico, wat had ik zonder jou moeten beginnen! Ik heb regelmatig wanhopig aan je bureau gestaan met allerlei database- en computerproblemen, verdwenen schroefjes en nog erger verdwenen bestanden. Altijd maakte je tijd voor me en wist je me weer op weg te helpen. Zonder jou was dit proefschrift er zeker niet geweest!

Els, ook jij bedankt, met name voor je waardevolle ondersteuning in de laatste fase. Maar daarnaast ook natuurlijk voor het managen van Frans agenda en het altijd weer creëren van een klein gaatje als ik een afspraak wilde verzetten. Ik weet niet hoe je het voor elkaar kreeg, maar ik ben je er wel heel dankbaar voor.

Daarnaast bedank ik natuurlijk al mijn collega's en oud-collega's voor de fijne, open sfeer hier op de afdeling, de gezellige tijd en het aangename gezelschap van sommigen van jullie tijdens congressen en symposia.

Dan was er ook nog een leven buiten deze afdeling:

Lieve Eveline, jij weet als geen ander hoe zwaar het leven als aio kan zijn. Ik vind het superknap van je dat je je hart hebt gevolgd en voor jezelf hebt gekozen.

Daarbij vind ik het zo lief dat je zo mega enthousiast bent over mijn promotie :Fijn dat we zowel de moeilijke als leuke momenten met elkaar kunnen delen en op naar een goed feestje!

Lieve Marleen, altijd fijn om even over de mail of app gezamenlijke frustraties over het aio-bestaan te spuien. Je weet maar al te goed hoe frustrerend de onderzoekswereld soms kan zijn. Enorm geruststellend ook om te weten dat je overal tegen dezelfde problemen aanloopt en dat het dus niet aan mij lag ;) Hierna is het tijd voor jouw promotie, ik heb er al zin in!

Andere vrienden en vriendinnen: Sas, Wouter, Maarten, Eline, Fre, Ilo, Maurice, Mari en Max bedankt ook voor jullie interesse! Waar mijn werk nu precies uit bestond was misschien niet voor iedereen altijd duidelijk, maar bij deze dus het resultaat ;) Naast de interesse wil ik jullie eigenlijk vooral bedanken voor de afleiding en gezelligheid die jullie me boden wanneer ik het eens niet over wetenschap wilde hebben, voor het bieden van een luisterend oor in goede en minder goede tijden, voor de gezellige dagjes weg en etentjes samen en nog veel meer.

Hans en Irene, bedankt voor jullie interesse in mijn werk, de ontspannende vakanties in Duitsland en de geweldig leuke zoon die jullie op de wereld hebben gezet. 
Papa \& mama, van veraf hielden jullie altijd in de gaten waar ik mee bezig was. Jullie waren belangstellend, maar boden me ook alle vrijheid om het vooral niet over m'n werk te hebben als ik er weer eens klaar mee was. Jullie eigenlijke inbreng in dit proefschrift is niet groot, maar jullie inbreng in mijn leven en wie ik geworden ben is des te groter. Heel veel dank daarvoor, ik ben trots op hoe jullie het gedaan hebben, juist ook in het moeilijke afgelopen jaar.

Robin, zo fijn om een zwager te hebben die ook promoveert. Heerlijk om samen te kunnen zeiken over irritante studenten, stomme statistiek, rare treinpassagiers en alles wat verder in een aio-leven niet altijd gemakkelijk gaat. Ik hoop over een paar jaar bij jouw verdediging op de eerste rij te zitten.

Lieve Lotte/Pobie, zo verschillend maar toch ook weer zo gelijk. We hebben het allebei zo druk, maar dat maakt onze band niet minder. Aan 1 woord genoeg als we samen zijn en dat zegt eigenlijk alles. Ik ben heel trots op hoe jij het allemaal doet en ga er stiekem vanuit dat je gewoon ook gaat promoveren ;) Bedankt dat je er altijd voor me bent als ik je nodig heb!

Als laatste en liefste: Alex. We hebben ook de afgelopen vier jaren weer veel meegemaakt; leuke, maar helaas ook veel minder leuke dingen. De laatste maanden toen ik moest afronden waren niet altijd gezellig voor je. Je opluchting toen ik het manuscript eindelijk ingeleverd had was dan ook groot. Sorry, maar je weet dat ik beter presteer onder druk ;). Ook dit hebben we weer samen overleefd en ik ben ervan overtuigd dat we met $z$ 'n tweetjes alles aankunnen.

Je grenzeloze vertrouwen in mij en mijn kunnen zijn de steunpilaar waarop ik kan terugvallen. Bedankt voor alles, de gezelligheid thuis, je humor, je liefde, je vertrouwen en de afleiding die je me bood samen met die twee harige monsters van ons. Op naar een volgend avontuur samen! 